Non-digestible polysaccharides to support the intestinal immune barrier: in vitro models to unravel molecular mechanisms

Yongfu Tang 


\section{Propositions:}

1. To support the immune system by dietary fibers, one should eat whole grain food.

(this thesis)

2. Fibers steer macrophages.

(this thesis)

3. Artificial intelligence is smarter than humans.

4. Plants have an adaptive immune system.

(Spoel et al., Nature Reviews Immunology. 2012. 12(2): 89-100)

5. Amyloid-ß peptide protects the brain.

(Kumar et al., Science Translational Medicine. 2016. 8(340): 340ra72)

6. To be yourself, select food smartly, otherwise you will be controlled by microbiota.

7. A guaranteed result of research is that it leads to new scientific questions.

Propositions belonging to the thesis, entitled:

Non-digestible polysaccharides to support the intestinal immune barrier: in vitro models to unravel molecular mechanisms

Yongfu Tang

Wageningen, 18 December 2017 
Non-digestible polysaccharides to support the intestinal immune barrier: in vitro models to unravel molecular mechanisms

Yongfu Tang 


\section{Thesis committee}

\section{Promotors}

Prof. Dr H.J. Wichers

Special Professor Immune modulation by food

Wageningen University \& Research

\section{Co-promotors}

Dr J.J. Mes

Senior Scientist, Fresh Food \& Chains

Wageningen University \& Research

Dr C.C.F.M. Govers

Scientist, Fresh Food \& Chains

Wageningen University \& Research

\section{Other members}

Prof. Dr R. F. Witkamp, Wageningen University \& Research

Dr F. Liu, The University of Texas Health Science Center at Houston, USA

DrW. Chanput, Kasetsart University, Thailand

Dr C. Soler Rivas, Universidad Autonoma de Madrid, Spain

This research was conducted under the auspices of the Graduate School VLAG (Advanced studies in Food Technology, Agrobiotechnology, Nutrition and Health Sciences). 


\title{
Non-digestible polysaccharides to support the intestinal immune barrier: in vitro models to unravel molecular mechanisms
}

\author{
Yongfu Tang
}

Thesis

submitted in fulfilment of the requirements for the degree of doctor

at Wageningen University

by the authority of the Rector Magnificus,

Prof. Dr A.P.J. Mol,

in the presence of the

Thesis Committee appointed by the Academic Board

to be defended in public

on Monday 18 December 2017

at 11 a.m. in the Aula. 
Yongfu Tang

Non-digestible polysaccharides to support the intestinal immune barrier: in vitro models to unravel molecular mechanisms

168 pages.

PhD thesis, Wageningen University, Wageningen, the Netherlands (2017)

With references, with summary in English

ISBN: 978-94-6343-713-4

DOI: $10.18174 / 425674$ 
For my family 



\section{Table of contents}

Chapter 1 General introduction

Chapter 2 Microarray analysis of Caco-2 exposed to non-digestible polysaccharides reveals differential regulation of immune and cholesterol-related genes

Chapter 3 Non-digestible polysaccharide treated macrophages 57 demonstrate a transcriptionally unique subtype

Chapter 4 Human macrophages stimulated with non-digestible 85 polysaccharides are in function and chemokine production different from inflammatory and tolerant macrophages

Chapter 5 Macrophage plasticity is modulated by non-digestible 109 polysaccharides

Chapter 6 General discussion

Summary

Acknowledgements

About the author 



\section{Chapter 1}

General introduction 


\section{Chapter 1}

\section{Intestinal immune barrier}

The intestine has an intestinal immune barrier which is composed of, firstly, the epithelial barrier that is formed by a single layer of intestinal epithelial cells (IECS) composed of various cell lineages, such as enterocytes, enteroendocrine cells, Paneth cells, goblet cells, and Microfold cells (M cells), all differentiated from a common intestinal epithelial stem cells [1]. IECs provide a physical protective barrier for luminal factors harmful/undesired for the body and are involved in regulation of inflammatory processes [2]. IECs can regulate inflammation in response to antigens by secreting cytokines that attract and/or activate immune cells. IECs not only function as barrier but also absorb nutrients and other compounds from the intestinal lumen. This leads to the passage of an enormous number of antigens into the body. These antigens can be derived from commensal microbiota, pathogens, or ingested foods. To respond to these antigens, there is a large body of immune cells present in the intestines that have a gatekeeper function and form a second part of the intestinal immune barrier (Figure 1). These can be found in the lamina propria of the intestine, but also in Peyers paches (PPs), mesenteric lymph nodes (MLNs), colon patches, and appendix.

The intestinal immune system includes B cells, T cells, monocytes, macrophages, dendritic cells, and recently discovered innate lymphoid cells (ILCS) [3]. The intestinal homeostatic balance between tolerance and inflammation, requires complex interactions between intestinal microbiota, IECs, and intestinal immune cells. Intestinal homeostasis is jeopardized upon imbalance of tolerance and inflammation, and can lead to intestinal dysfunction. As IECS and macrophages are in the first line of immune defense, their response towards food components is pivotal to analyze the immunomodulatory effects of foods.

\section{Intestinal epithelial cells}

The intestinal epithelium is the largest surface of the human body. Often, its surface is described as approximately $300 \mathrm{~m}^{2}$, but recent estimates are more in the order of $30 \mathrm{~m}^{2}$ [4]. The principal function of IECS is that of absorptive enterocytes, to process and absorb nutrients to serve metabolic and digestive functions. Besides that, it also serves as a physical barrier that aids in maintaining intestinal homeostasis. IECs form an essential part of immunity, by maintaining the integrity, and through secretion of mucins by goblet cells, antimicrobial proteins by Paneth cells, and transcytosis of IgA after secretion by plasma cells [5]. IECs also express Toll-like receptors (TLRs) that respond to LPS, LPA, or flagellin which are pathogen-associated molecular patterns (PAMPs) from 
microorganisms [6]. TLR2 and TLR4 are reported to be limitedly expressed by IECs. However, when intestinal damage induces inflammatory stress, TLR2 stimulation effectively preserves tight junction integrity and controls intestinal inflammation [7]. Mucosal inflammation and apoptosis in colitis were suppressed by oral TLR2 ligand treatment which resulted in restoring tight junction-associated barrier [7]. In addition, it was shown that TLR2 could be activated by a dietary fibre (Inulin $\beta 2 \rightarrow 1$-fructans) [8].

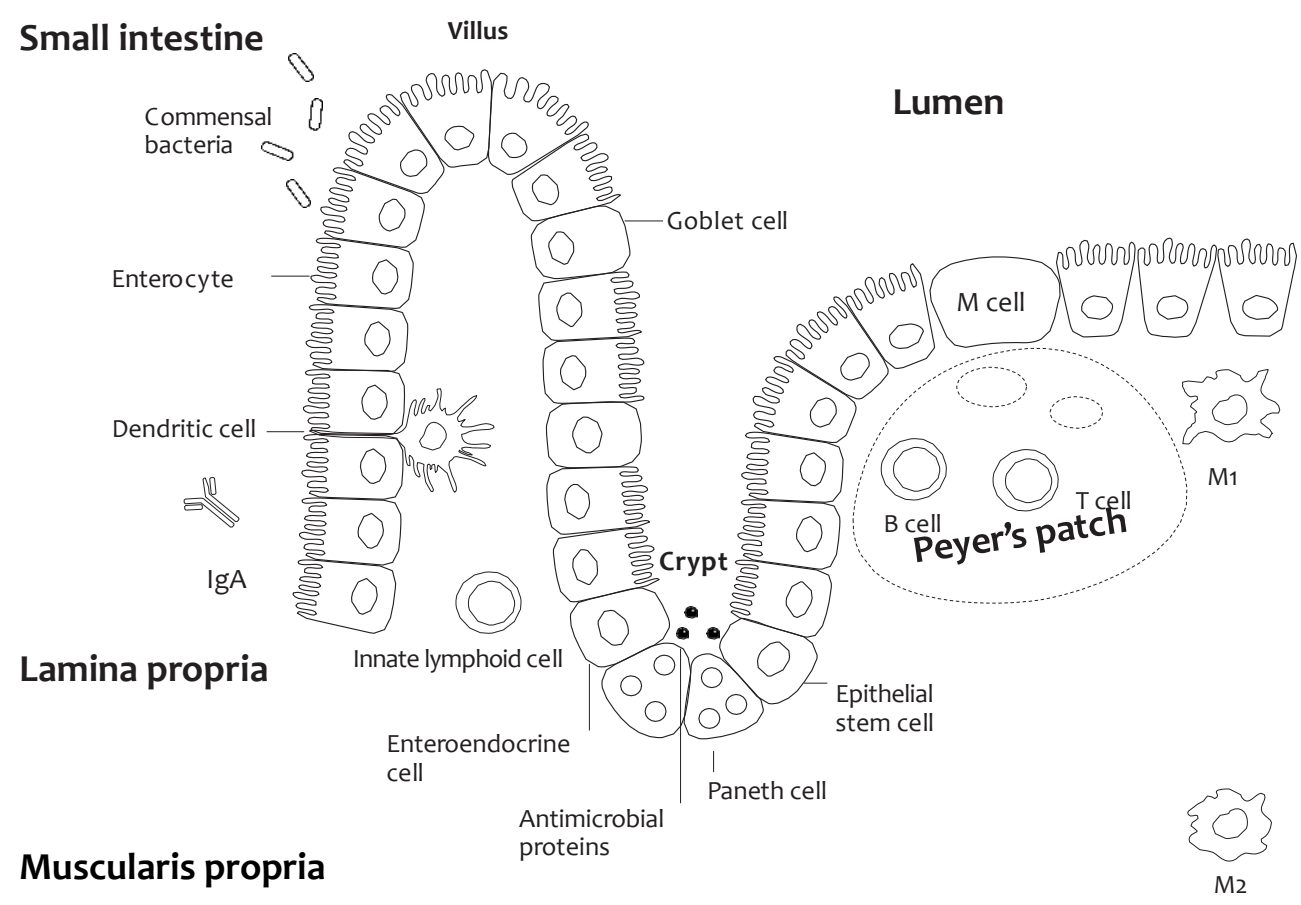

Figure 1. The intestinal immune barrier is composed of an epithelial barrier formed by various cell types with immune cells residing in the lamina propria, Peyer's path, mesenteric lymph nodes, colon patches, and appendix (Adapted and modified from [9]).

$M$ cells as specialized IECs, sample antigens and interact with microbiota to communicate with immune cells. These immune cells are concentrated in Peyer's patches. In addition, IECs recognize and integrate signals from the luminal side to intestinal immune cells [10] by secreting cytokines and chemokines that in turn modulate cytokine production by immune cells $[11,12]$. Cytokines produced by the IECs in a steady-status function as antiinflammatory and include TSLP, TGF $\beta$, IL8, CCL20, CXCL10, IL18, IL33, and IL37. Those anti- 


\section{Chapter 1}

inflammatory cytokines are important to maintain immune tolerance, wound healing and also to recruit monocytes, neutrophils, eosinophils, lymphocytes, T cells, B cells, macrophages, and dendritic cells $[11,13,14]$. Specifically the role of TSLP in maintaining immune homeostasis by IEC that attenuate inflammation status and promote antiinflammation is important, since TSLP secretion could inhibit IL12 production by DCs and activates Th2 polarizing cells [15].

\section{Intestinal macrophages}

Macrophages are described as one of the largest populations of cells which function in maintaining intestinal immune barrier [16]. Macrophages can be differentiated from monocytes in response to antigens presented by IECs or other immune cells [17]. In the steady state, these signals will be anti-inflammatory, produced by the IECs that are in close contact with the macrophages and resident Treg cells. This will lead to tolerant macrophages. In inflammatory status, those anti-inflammatory signals are reduced and inflammatory signals are produced which lead to inflammatory macrophages. Macrophages work as effector cells of the intestinal innate immune system. The contact between macrophages and IECS includes numerous immunoregulatory signals. This contact is in part mediated by the interaction of IECS and microbiota [18]. Through those interactions, macrophages direct the appropriate innate and adaptive immune cell responses and limited intestinal inflammation [19].

Two extreme phenotypes have been described for macrophages, and termed as classical macrophages (inflammatory macrophages or $\mathrm{M}_{1}$ ) [20] or alternative macrophages (tolerant macrophages or $\mathrm{M}_{2}$ ) [21]. Based on the most recent insights, an even larger variation of macrophage phenotypes has been described with an almost infinite continuum between the two most extremes. Therefore, it was suggested to indicate specific conditions that are used to polarize macrophages when describing macrophages subsets [22].

M1 are known to be formed from monocytes by exposure to IFN $\gamma$, LPS, or cytokines as TNFa, and are characterised by high expression of IL12, IL1 $\beta$, TNFa, and IL6. This M1 inflammatory phenotype can be identified by specific markers such as IDO1, CXCL9, CXCL10, and CXCL11 [23]. M2 can be differentiated from monocytes after IL4 or IL13 stimulation and express a characteristic low level of IL12 and high levels of IL10 and scavenger receptors and receptors for mannose and galactose [21].

Beside the $M_{1} / M_{2}$ classification on a linear scale, a colour wheel of macrophages activation was introduced which was based on defined fundamental functions of 
macrophages such as host defence, wound healing, and immune regulation [20]. In example, resolution-phase macrophages were defined as intermediate between $M 1$ and M2, displaying predominantly an M2 phenotype, with weaker antibacterial activity than M1 macrophages, but expressing even higher levels of M1 markers than M1 (i.e., COX-2 and iNOS) [24]. These resolution-phase macrophages are supposed to have a role in mediating ILCs repopulation and restoring tissue homeostasis.

Based on their tissue localisation, intestinal macrophages were grouped as lamina propria macrophages (LPMs) and muscularis propria macrophages (MMs) [25, 26]. Those two types of intestinal macrophages were distinguished by morphological features and cell dynamics in distinct microenvironments in the intestinal tissue. LpMs show M1 features with highly expressed proinflammatory genes, such as IL1B, IL12B, and $C C L 24$, and increased $C D 80$ and increased oxidative burst. MMs typically show $M_{2}$ features, with highly expressed Retnla, MRC1, CD163, and IL10, which are tissue protective and wound healing-related genes.

\section{Non-digestible polysaccharide}

Non-digestible polysaccharides (NDP), represent a class of food fibres composed of polymers of carbohydrates that are resistant to digestion in the stomach and small intestine but often are fermentable by the microbiota in the large intestine (Box 1) [27]. NDPs are typically long chain which can be made up of over a hundred thousand monomeric units but also can be shorter forming oligomers of only 10 sugar units. Beside differences in degree of polymerisation, they can have a complex composition of different types of sugars with variable linkages and different degrees of branching [28, 29]. NDPs have a proven physiological benefit to the intestine and immune related health, which will be discussed in more detail in next paragraphs.

Health effects of NDPs

NDPs initially received interest because for their function to increase stool bulk and improve laxation [30]. Later, also other physiological aspects of NDPs were demonstrated, both in vitro and in vivo. Increased intake of NDPs is associated with reduced incidence of cardiovascular disease [31] and colon cancer [32, 33]. Besides that, human trials have shown biological activity of specific NDPs on cholesterol lowering [34], serum glucose control [35], immunomodulation [36, 37], anticancer activity [38], and towards mitigation of inflammatory bowel disease [39]. 


\section{Chapter 1}

\section{Box 1 Dietary fibres classification}

Dietary fibre has been recognized as having health benefits. However, often information on e.g. source, characterisation, etc. is lacking. Classification of dietary fibre was attempted based on their role in the plant, the type of polysaccharides, the ability to stimulate gastrointestinal activity, site of digestion, or products of digestion; however such classifications are still under debate [40]. The solubility or fermentability in an in vitro system were most commonly used to classify dietary components. Based on such criteria, fibres were classified as non-starch polysaccharide, non-digestible polysaccharides, or fermentable polysaccharides.

Non-starch polysaccharides (NSPs). NSPs include all the plant polysaccharides other than starch. They are the key components of the cell walls of various grains and cover a great variety of biological functions and chemical structures. The major polysaccharides of NSP are cellulose, pectin, $\beta$-glucans, pentosans, heteroxylans, and xyloglucan which cannot be hydrolysed by the endogenous enzymes of humans and monogastric animals [41].

Non-digestible polysaccharides (NDPs). Indigestible polysaccharides (fibre components) are all fibres that are resistant to digestion in the small intestine and that are fermentable in the large intestine. These polysaccharides are typically long polymeric carbohydrate chains containing up to several hundred thousand monomeric units. The polysaccharides differ by the number and type of monomeric units linked together, the order in the chain, the types of linkages between the various monomers, the presence of branch points in the backbone of the molecule, and those having acidic groups present (for example, uronic acids in pectins) [40].

Fermentable polysaccharides. Most fibre types are at least partially fermented, and, generally, well fermented fibres are soluble in water, while partially or poorly fermented fibres are insoluble. They can be fermented by intestinal microbiota into SCFA as major product [42].

These health effects of NDPs might link to the intestinal immune barrier modulation through NDPs consumption. Cytokines that are produced by IECs or immune cells have a crucial role in the pathogenesis of intestinal disease [43] and NDPs appear to have the potency to modulate these [44]. As an example, beneficial effects of NDPs on the treatment and prevention of IBD and direct effects on inflammation have been reported [44]. $\beta$-Glucans from either oat or shiitake inhibited pro-inflammatory factors such as TNFa, IL1 $\beta$, IL6 and iNOS in colonic tissues in DSS-treated colitis mice [45, 46]. NDPs can 
mediate the intestinal immune barrier through multiple ways such as changing fermentation products and microbiota composition, or activation of pattern recognition receptors (PRRs) (Box 2) and inducing cytokines expression and cellular responses.

Direct Interaction between NDP and intestinal immune barrier

The direct interaction of NDP with intestinal immunity was demonstrated by using fluorescent labelled $\beta$-glucans in vivo [47]. Those particles might adhere to and be transported by epithelial cells including $M$ cells [48]. Orally administered $\beta$-glucans can also be taken up by macrophages and transported to other body tissue as spleen, lymph nodes, and bone marrow [47]. Macrophages subsequently can process these glucans and secrete $\beta$-1,3-glucan fragments that activate complement receptor $3\left(C_{3}\right)$ resulting in enhanced granulocyte activity [47].

By direct interaction with IECs, NDPs demonstrated their ability to increase cytokine and chemokine gene expression and protein production in IECs (Caco-2 cells) [49]. This illustrates that NDPs could modulate immune responses via the IECs. Such effects are in some case linked to MW as low MW of cereal $\beta$-glucan (40 kDa) increased IL8 secretion both in a dose and time dependent manner, in contrast to high MW cereal $\beta$-glucan (123$359 \mathrm{kDa}$ ) [50]. Short chain NDPs (a3-sialyllactose and fructooligosaccharides) can reduce the production of proinflammatory cytokines as IL12 and TNFa in IECs (Caco-2 cells) via activation of PPAR $\gamma$ and peptidoglycan recognition protein 3 [51].

NDPs directly activate immune cells by increasing cell numbers and cytokines secretion in the intestine. NDPs have been shown to trigger innate immune responses by activating antigen presenting cells of the intestinal immune system $[52,53]$, increasing the number of lymphocytes and IFN $\gamma$ production [54], and increasing the regulatory T cell population in the intestine $[55,56]$. Oral intake of NDP decreased DSS-induced weight loss and intestinal inflammation in mice. This specific NDP was a multi-fiber mixture including insoluble and soluble polysaccharides [56]. Another well-described NDP are human-milk oligosaccharides (HMO) which are non-digestible and are expected to have an important role in early life. The immune effects of $\mathrm{HMO}$ are related to both changing microbiota composition and direct interaction with immune cells. HMO can skew the Th1/Th2 balance [57] and affect Th2-dominated immune response to peanut allergen in allergic individuals [58]. HMO can be recognized by CD209 which is expressed on macrophages and dendritic cells [59]. 


\section{Chapter 1}

\section{Box 2 Pattern recognition receptors (PRRs)}

PRRs are receptors expressed on a variety of cells, of which mainly immune cells including macrophages and DCs, but also IECs. PRRs include the Toll-like receptors (TLRs), C-type lectin receptors (CLRs), Nod-like receptors (NLRs), and RIG-l-like receptors (RLRs) families. These receptors interact with evolutionary conserved structures on pathogens termed pathogen-associated molecular patterns (PAMPs).

Toll-like receptors (TLRs): The TLR family has 13 members in humans. TLRs can be expressed on the cell surface (TLR1, TLR2, TLR4, and TLR5), or intracellularly in endosomes (TLR3, TLR4, TLR7, TLR8, and TLR9). TLRs on intestinal epithelial cells can be activated by ligation of bacterial-derived structures such as lipopolysaccharides or lipoteichoic acid to induce antimicrobial peptide expression, IgA secretion and cell proliferation by the intestinal immune barrier [9].

C-type lectin receptors (CLRs): CLRs and their signalling pathways are essential for immune activation. Some of these CLRs were already reported respond to NDPs such as dectin-1, dectin-2, dectin-3, Mincle, and DC-SIGN. These CLRs could be activated by carbohydrate structures that are located in cell walls such as $\beta$-glucan and mannan [60-62]. CLR activation modulates both innate and adaptive responses. The response to CLR activation includes phagocytosis, cytokines secretion, and also helper T cells activation.

Nod-like receptor (NLR): NLR proteins are intracellular LRR (leucine-rich repeat)containing proteins that can form an inflammasome upon binding of PAMPs. The formation of inflammasomes can also be induced by non-microbial danger signals such as microbial-derived products and cellular metabolic stress. NLRs can induce the production of pro-inflammatory cytokines such as IL $1 \beta$ and IL18 from pro-IL1 $\beta$ and pro-IL18 [63].

RIG-I-like receptor (RLR): The RLRs include RIG-I, MDA5, and LGP2 which detect a virus infection through viral RNA and initiate innate immune activation and inflammation to control infection. The RLRs cooperate in signalling crosstalk networks with TLRs to modulate both innate and adaptive immune response [64].

The direct activation of immune cells by NDPs might be mediated via PRR activation. For example, $\beta-1,3$-Glucans are well described for their interaction with dectin-1. These glucans are important components of cell walls from nearly all fungi, and are recognized by dectin-1 (CLEC7A), a c-type lectin-like receptor. Interaction between $\beta$-glucans and dectin-1 strongly influences intestinal immune barrier and health. Absence of dectin-1 in 
colitis mice correlated to increased susceptibility to fungi [65]. The activation of dectin-1 by insoluble $\beta$-glucans initiates an innate immune response via phagocytosis and it could be blocked by soluble $\beta$-glucans [66]. Beside $\beta$-glucans from yeast, $\beta$-glucans from the shiitake mushroom also showed to inhibit IL8 gene expression and activate NFKB in DSSinduced colitis [67]. This could also be mediated via dectin-1 activation as a-Mannans, that are found in $\beta$-glucan preparations from shiitake, were shown to activate both dectin-2 and dectin-3 resulting in an inflammatory response [68] and also induced Th17 cell differentiation [69]. Inulin is another NDPs that can activate intestinal immunity through direct interaction with intestinal immune cells. Inulin $\beta 2 \rightarrow 1$-fructans directly activated NF-kB/AP-1 for PBMCs via mainly TLR2 in vitro [70]. These direct effects related to chain length as shorter chain fructans induced a regulatory balance (IL10/IL12 ratio) more towards IL10 compared to longer chain fructans. In addition, $\beta 2 \rightarrow 1$-fructans were also shown to modulate the immune system in conventional mice [71]. The immunomodulatory effects were again shown to be DP-dependent as both short chain and long chain $\beta 2 \rightarrow 1$-fructans increased the number of Th1 cells in PPs, while only shortchain $\beta 2 \rightarrow 1$-fructans increased Treg and CD11bCD103-DCs in MLNs. This effect is likely not mediated by fermentation products and microbiota as no change in microbiota composition and SCFA production were reported. Microbiota-independent effects were also observed in germ-free mice, where $\beta 2 \rightarrow 1$-fructans had no effects on Th1 cells, and only short chain $\beta 2 \rightarrow 1$-fructans induced lower CD80 expression on CD11b ${ }^{-}$CD103 ${ }^{-}$CCs in PPs [71].

Indirect interaction between NDP and intestinal immune barrier

Both via technological advances and because of an enormous increase in the understanding of the role of the microbiota, also the importance of microbial fermentation of NDPs and the formation of short chain fatty acids (SCFAs) from these have drawn attention [72, 73]. Fermentation of NDPs by intestinal microbiota results in changes of microbiota composition and SCFA production in both cecum and colon [74, 75]. Pectin supplementation modulated gut microbiota due to rapid fermentation, which in turn contributes to a shift in fermentation of cereal arabinoxylans [74]. Pectin structure and origin are important for shifting the fermentation site closer to distal parts of the large intestine in pig and for changing the composition of microbiota [75]. These types of responses to NDP could be source and composition independent since various NDPs were found to induce similar mucosa responses through PPARy in mice [76]. The microbiota composition is very relevant for intestinal homeostasis. It has been reported that transplanted microbiota from obese female to germ-free mice increased total body 


\section{Chapter 1}

and fat mass, as well as induced obesity-associated metabolic phenotypes, compared to transplanted microbiota from lean female to germ-free mice [77]. The SCFA are considered as immunomodulatory products that are ligands of FFAR1, FFAR2, and GPR109A. Those GPCRs are broadly expressed on immune cells such as macrophages, dendritic cells, neutrophils, and eosinophils [78-80]. SCFA can target PPARy and stimulate ANGPTL4 synthesis in vitro, and these effects were confirmed by feeding inulin to mice which subsequently showed an activation of PPAR $\gamma$ target genes and pathways in colon tissue [81]. By activating PPAR $\gamma$ and ANGPTL4, NDPs could regulate the lipid metabolism and protect against severe inflammation through SCFA production [82].

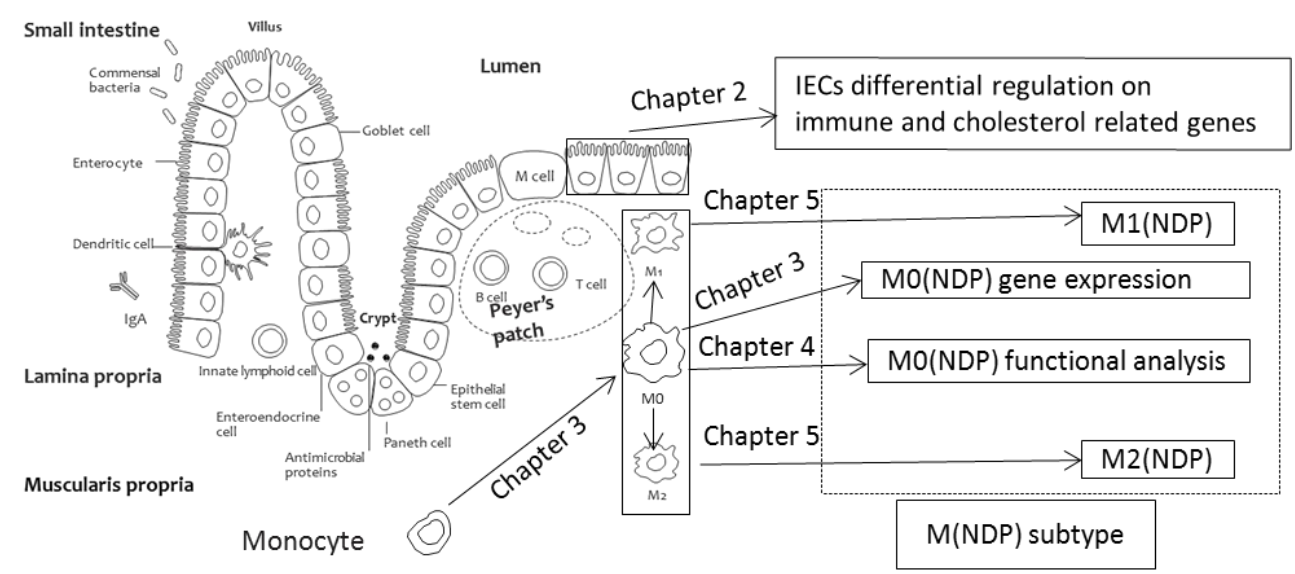

Figure 2. Overview of the structure of this thesis.

\section{Outline of this thesis}

This thesis focuses on the question to what extent and by which mechanisms NDPs directly interact with the intestinal immune barrier, and how the macrophages subsequently respond towards other immune cells (monocytes as an example) which could contribute to the observed intestinal immune support for NDPs. Although some of the NDPs immunomodulatory effects were already reported, this information is still limited regarding their direct interaction with the intestinal immune barrier. To investigate this, we chose five NDPs known to interact with the intestinal immune barrier to link our data to other findings (Figure 2). We selected Caco-2 and macrophages to represent the IEC and immune component of the intestinal immune barrier. Next to investigating the interaction of NDPs with those Caco-2 and macrophages separately, we 
also applied NDPs on a co-culture of Caco-2 and macrophages. Besides this, we wanted to developed analysis strategies that could classify NDPs based on their bioactive activity. In this thesis, research is based on 5 different NDPs with varying structure, monosaccharide composition, branch chain connection, and sources (chapter 2). These NDPs are Wellmune Soluble (a glucan from yeast), RG-I (a pectin from apple), OBG90 (a glucan from oat), LCES (lentinan containing extract from shiitake), and Naxus (rich in arabinoxylan from wheat).

As a first exploration of the potential direct effect of NDPs, research was based on intestinal epithelial cells, Caco-2 cells grown in transwell system for 21-days to resemble small intestine. The Caco-2 were exposed to various NDPs for $6 \mathrm{~h}$. Cell layer integrity, whole-genome gene expression, and chemokine secretion were analysed and compared to characterize the result of the direct exposure (chapter 2).

Macrophages are amongst the most prevalent immune cells in the intestine. Therefore, as a next step we analysed the direct response of macrophages to NDPs (chapter 3 ). To this end we generated human macrophages from primary monocytes in vitro and established polarising cultures to acquire M1-like and M2-like macrophages to mimic inflammatory and tolerant macrophages in intestine, respectively. We did so using gene expression markers described in literature and found through microarray analysis. After stimulation with NDPs for $18 \mathrm{~h}$, gene expression was analysed by qPCR and wholegenome gene expression of macrophages was analysed by microarray. This revealed that NDPs can stimulate macrophages towards an alternative subset macrophages (MNDP). Subsequently the potential function of this MNDP was studied by functional assays like phagocytosis capacity and antigen processing capacity. Specifically, the analysis of secreted cytokines and the effects on migration of immune cells revealed some of its potential function (chapter 4 ). Furthermore, it was studied whether NDPs can also modulate phenotype and function of $\mathrm{M}_{1}$ or $\mathrm{M}_{2}$ polarized cells towards this alternative subset $M_{\text {NDP. }}$ This was to reveal the macrophage plasticity and NDPs immunomodulatory capacity which could be important in vivo as NDPs might encounter both types of macrophages in the intestine and should not over-stimulate in a certain stage (chapter 5).

Finally, in chapter 6, results from this thesis are discussed in relation to each other, to current literature and a general perspective in the research towards revealing immune support of NDPs by current and future models are given. 


\section{Chapter 1}

\section{References}

1. van der Flier, L.G. and H. Clevers, Stem cells, self-renewal, and differentiation in the intestinal epithelium. Annual Review of Physiology, 2009. 71: p. 241-260.

2. Maloy, K.J. and F. Powrie, Intestinal homeostasis and its breakdown in inflammatory bowel disease. Nature, 2011. 474(7351): p. 298-306.

3. Veldhoen, M. and V. Brucklacher-Waldert, Dietary influences on intestinal immunity. Nature Reviews: Immunology, 2012. 12(10): p. 696-708.

4. Helander, H.F. and L. Fandriks, Surface area of the digestive tract - revisited. Scandinavian Journal of Gastroenterology, 2014. 49(6): p. 681-689.

5. Pitman, R.S. and R.S. Blumberg, First line of defense: the role of the intestinal epithelium as an active component of the mucosal immune system. Journal of Gastroenterology, 2000. 35(11): p. 805-814.

6. Wells, J.M., L.M. Loonen, and J.M. Karczewski, The role of innate signaling in the homeostasis of tolerance and immunity in the intestine. International Journal of Medical Microbiology, 2010. 300(1): p. 41-48.

7. Cario, E., G. Gerken, and D.K. Podolsky, Toll-like receptor 2 controls mucosal inflammation by regulating epithelial barrier function. Gastroenterology, 2007. 132(4): p. 1359-1374.

8. Vogt, L.M., D. Meyer, G. Pullens, M.M. Faas, K. Venema, U. Ramasamy, H.A. Schols, and P. de Vos, Toll-Like Receptor 2 Activation by beta 2 -> 1-Fructans Protects Barrier Function of T84 Human Intestinal Epithelial Cells in a Chain Length-Dependent Manner. Journal of Nutrition, 2014. 144(7): p. 1002-1008.

9. Abreu, M.T., Toll-like receptor signalling in the intestinal epithelium: how bacterial recognition shapes intestinal function. Nature Reviews: Immunology, 2010. 10(2): p. 131-144.

10. Goto, Y. and Ivanov, II, Intestinal epithelial cells as mediators of the commensal-host immune crosstalk. Immunology and Cell Biology, 2013. 91(3): p. 204-214.

11. Stadnyk, A.W., Intestinal epithelial cells as a source of inflammatory cytokines and chemokines. Canadian Journal of Gastroenterology, 2002. 16(4): p. 241-246.

12. Peterson, L.W. and D. Artis, Intestinal epithelial cells: regulators of barrier function and immune homeostasis. Nature Reviews: Immunology, 2014. 14(3): p. 141-153.

13. Turner, M.D., B. Nedjai, T. Hurst, and D.J. Pennington, Cytokines and chemokines: At the crossroads of cell signalling and inflammatory disease. Biochimica et Biophysica Acta, 2014. 1843(11): p. 2563-2582.

14. Liu, Y.J., V. Soumelis, N. Watanabe, T. Ito, Y.H. Wang, W. Malefyt Rde, M. Omori, B. Zhou, and S.F. Ziegler, TSLP: an epithelial cell cytokine that regulates $T$ cell differentiation by conditioning dendritic cell maturation. Annual Review of Immunology, 2007. 25: p. 193-219.

15. Rimoldi, M., M. Chieppa, V. Salucci, F. Avogadri, A. Sonzogni, G.M. Sampietro, A. Nespoli, G. Viale, P. Allavena, and M. Rescigno, Intestinal immune homeostasis is regulated by the crosstalk between epithelial cells and dendritic cells. Nature Immunology, 2005. 6(5): p. 507514 .

16. Lee, S.H., P.M. Starkey, and S. Gordon, Quantitative analysis of total macrophage content in adult mouse tissues. Immunochemical studies with monoclonal antibody F4/80. Journal of Experimental Medicine, 1985. 161(3): p. 475-489.

17. Spottl, T., M. Hausmann, M. Kreutz, A. Peuker, D. Vogl, J. Scholmerich, W. Falk, R. Andreesen, T. Andus, H. Herfarth, and G. Rogler, Monocyte differentiation in intestine-like macrophage phenotype induced by epithelial cells. Journal of Leukocyte Biology, 2001. 70(2): p. 241-251.

18. Artis, D., Epithelial-cell recognition of commensal bacteria and maintenance of immune homeostasis in the gut. Nature Reviews: Immunology, 2008. 8(6): p. 411-420. 
19. Grainger, J.R., J.E. Konkel, T. Zangerle-Murray, and T.N. Shaw, Macrophages in gastrointestinal homeostasis and inflammation. Pflügers Archiv. European Journal of Physiology, 2017. 469(3-4): p. 527-539.

20. Mosser, D.M. and J.P. Edwards, Exploring the full spectrum of macrophage activation. Nature Reviews: Immunology, 2008. 8(12): p. 958-969.

21. Gordon, S., Alternative activation of macrophages. Nature Reviews: Immunology, 2003. 3(1): p. 23-35.

22. Murray, P.J., J.E. Allen, S.K. Biswas, E.A. Fisher, D.W. Gilroy, S. Goerdt, S. Gordon, J.A. Hamilton, L.B. Ivashkiv, T. Lawrence, M. Locati, A. Mantovani, F.O. Martinez, J.L. Mege, D.M. Mosser, G. Natoli, J.P. Saeij, J.L. Schultze, K.A. Shirey, A. Sica, J. Suttles, I. Udalova, J.A. van Ginderachter, S.N. Vogel, and T.A. Wynn, Macrophage activation and polarization: nomenclature and experimental guidelines. Immunity, 2014. 41(1): p. 14-20.

23. Martinez, F.O., S. Gordon, M. Locati, and A. Mantovani, Transcriptional profiling of the human monocyte-to-macrophage differentiation and polarization: new molecules and patterns of gene expression. Journal of Immunology, 2006. 177(10): p. 7303-7311.

24. Bystrom, J., I. Evans, J. Newson, M. Stables, I. Toor, N. van Rooijen, M. Crawford, P. ColvilleNash, S. Farrow, and D.W. Gilroy, Resolution-phase macrophages possess a unique inflammatory phenotype that is controlled by CAMP. Blood, 2008. 112(10): p. 4117-4127.

25. Leopold Wager, C.M. and F.L. Wormley, Jr., Classical versus alternative macrophage activation: the Ying and the Yang in host defense against pulmonary fungal infections. Mucosal Immunology, 2014. 7(5): p. 1023-1035.

26. Gabanyi, I., P.A. Muller, L. Feighery, T.Y. Oliveira, F.A. Costa-Pinto, and D. Mucida, Neuroimmune Interactions Drive Tissue Programming in Intestinal Macrophages. Cell, 2016. 164(3): p. 378-391.

27. Jones, J.M., CODEX-aligned dietary fiber definitions help to bridge the 'fiber gap'. Nutrition Journal, 2014. 13: p. 34.

28. Ferreira, S.S., C.P. Passos, P. Madureira, M. Vilanova, and M.A. Coimbra, Structure-function relationships of immunostimulatory polysaccharides: A review. Carbohydr Polym, 2015. 132: p. 378-396.

29. Rieder, A. and A.B. Samuelsen, Do cereal mixed-linked beta-glucans possess immunemodulating activities? Molecular Nutrition \& Food Research, 2012. 56(4): p. 536-547.

30. Schneeman, B.O., Dietary fiber and gastrointestinal function. Nutrition Reviews, 1987. 45(5): p. 129-132.

31. Eshak, E.S., H. Iso, C. Date, S. Kikuchi, Y. Watanabe, Y. Wada, K. Wakai, A. Tamakoshi, and J.S. Group, Dietary fiber intake is associated with reduced risk of mortality from cardiovascular disease among Japanese men and women. J Nutr, 2010. 140(8): p. 1445-1453.

32. Peters, U., R. Sinha, N. Chatterjee, A.F. Subar, R.G. Ziegler, M. Kulldorff, R. Bresalier, J.L. Weissfeld, A. Flood, A. Schatzkin, R.B. Hayes, L.C. Prostate, and T. Ovarian Cancer Screening Trial Project, Dietary fibre and colorectal adenoma in a colorectal cancer early detection programme. Lancet, 2003. 361(9368): p. 1491-1495.

33. Ben, Q., Y. Sun, R. Chai, A. Qian, B. Xu, and Y. Yuan, Dietary fiber intake reduces risk for colorectal adenoma: a meta-analysis. Gastroenterology, 2014.146(3): p. 689-699 e686.

34. Othman, R.A., M.H. Moghadasian, and P.J. Jones, Cholesterol-lowering effects of oat betaglucan. Nutr Rev, 2011. 69(6): p. 299-309.

35. Brockman, D.A., X. Chen, and D.D. Gallaher, Consumption of a high beta-glucan barley flour improves glucose control and fatty liver and increases muscle acylcarnitines in the Zucker diabetic fatty rat. Eur J Nutr, 2013. 52(7): p. 1743-1753.

36. Lehne, G., B. Haneberg, P. Gaustad, P.W. Johansen, H. Preus, and T.G. Abrahamsen, Oral administration of a new soluble branched beta-1,3-D-glucan is well tolerated and can lead to 


\section{Chapter 1}

increased salivary concentrations of immunoglobulin A in healthy volunteers. Clin Exp Immunol, 2006. 143(1): p. 65-69.

37. Kohl, A., O. Gogebakan, M. Mohlig, M. Osterhoff, F. Isken, A.F. Pfeiffer, and M.O. Weickert, Increased interleukin-10 but unchanged insulin sensitivity after 4 weeks of $(1,3)(1,6)$-betaglycan consumption in overweight humans. Nutr Res, 2009. 29(4): p. 248-254.

38. Chen, Y.W., D.J. Hu, K.L. Cheong, J. Li, J. Xie, J. Zhao, and S.P. Li, Quality evaluation of lentinan injection produced in China. J Pharm Biomed Anal, 2013. 78-79: p. 176-182.

39. Ananthakrishnan, A.N., H. Khalili, G.G. Konijeti, L.M. Higuchi, P. de Silva, J.R. Korzenik, C.S. Fuchs, W.C. Willett, J.M. Richter, and A.T. Chan, A prospective study of long-term intake of dietary fiber and risk of Crohn's disease and ulcerative colitis. Gastroenterology, 2013. 145(5): p. 970-977.

40. Tungland, B.C. and D. Meyer Nondigestible Oligo- and Polysaccharides (Dietary Fiber) Their Physiology and Role in Human Health and Food, Comprehensive Reviews in Food Science and Food Safety Volume 1, Issue 3. Comprehensive Reviews in Food Science and Food Safety, 2002. 1, 90-109.

41. Kumar, V., A.K. Sinha, H.P.S. Makkar, G. de Boeck, and K. Becker, Dietary Roles of Non-Starch Polysachharides in Human Nutrition: A Review. Critical Reviews in Food Science and Nutrition, 2012. 52(10): p. 899-935.

42. Blaut, M., Gut microbiota and energy balance: role in obesity. Proceedings of the Nutrition Society, 2015. 74(3): p. 227-234.

43. Neurath, M.F., Cytokines in inflammatory bowel disease. Nature Reviews: Immunology, 2014. 14(5): p. 329-342.

44. Galvez, J., M.E. Rodriguez-Cabezas, and A. Zarzuelo, Effects of dietary fiber on inflammatory bowel disease. Molecular Nutrition \& Food Research, 2005. 49(6): p. 601-608.

45. Liu, B., Q. Lin, T. Yang, L. Zeng, L. Shi, Y. Chen, and F. Luo, Oat beta-glucan ameliorates dextran sulfate sodium (DSS)-induced ulcerative colitis in mice. Food \& Function, 2015. 6(11): p. 34543463.

46. Shi, L., Q. Lin, T. Yang, Y. Nie, X. Li, B. Liu, J. Shen, Y. Liang, Y. Tang, and F. Luo, Oral administration of Lentinus edodes beta-glucans ameliorates DSS-induced ulcerative colitis in mice via MAPK-Elk-1 and MAPK-PPARgamma pathways. Food \& Function, 2016. 7(11): p. 46144627.

47. Hong, F., J. Yan, J.T. Baran, D.J. Allendorf, R.D. Hansen, G.R. Ostroff, P.X. Xing, N.K. Cheung, and G.D. Ross, Mechanism by which orally administered beta-1,3-glucans enhance the tumoricidal activity of antitumor monoclonal antibodies in murine tumor models. Journal of Immunology, 2004. 173(2): p. 797-806.

48. Frey, A., K.T. Giannasca, R. Weltzin, P.J. Giannasca, H. Reggio, W.I. Lencer, and M.R. Neutra, Role of the glycocalyx in regulating access of microparticles to apical plasma membranes of intestinal epithelial cells: implications for microbial attachment and oral vaccine targeting. Journal of Experimental Medicine, 1996. 184(3): p. 1045-1059.

49. Ortega-Gonzalez, M., B. Ocon, I. Romero-Calvo, A. Anzola, E. Guadix, A. Zarzuelo, M.D. Suarez, F. Sanchez de Medina, and O. Martinez-Augustin, Nondigestible oligosaccharides exert nonprebiotic effects on intestinal epithelial cells enhancing the immune response via activation of TLR4-NFkappaB. Molecular Nutrition \& Food Research, 2014. 58(2): p. 384-393.

50. Rieder, A., S. Grimmer, S.O. Kolset, T.E. Michaelsen, and S.H. Knutsen, Cereal beta-glucan preparations of different weight average molecular weights induce variable cytokine secretion in human intestinal epithelial cell lines. Food Chemistry, 2011. 128(4): p. 1037-1043.

51. Zenhom, M., A. Hyder, M. de Vrese, K.J. Heller, T. Roeder, and J. Schrezenmeir, Prebiotic oligosaccharides reduce proinflammatory cytokines in intestinal Caco-2 cells via activation of PPARgamma and peptidoglycan recognition protein 3. Journal of Nutrition, 2011. 141(5): p. 971-977. 
52. Chan, G.C., W.K. Chan, and D.M. Sze, The effects of beta-glucan on human immune and cancer cells. Journal of Hematology \& Oncology, 2009. 2: p. 25.

53. Ganesan, S., V.A. Rathinam, L. Bossaller, K. Army, W.J. Kaiser, E.S. Mocarski, C.P. Dillon, D.R. Green, T.N. Mayadas, S.M. Levitz, A.G. Hise, N. Silverman, and K.A. Fitzgerald, Caspase-8 modulates dectin-1 and complement receptor 3-driven IL-1beta production in response to beta-glucans and the fungal pathogen, Candida albicans. Journal of Immunology, 2014. 193(5): p. 2519-2530.

54. Tsukada, C., H. Yokoyama, C. Miyaji, Y. Ishimoto, H. Kawamura, and T. Abo, Immunopotentiation of intraepithelial lymphocytes in the intestine by oral administrations of beta-glucan. Cellular Immunology, 2003. 221(1): p. 1-5.

55. Kerperien, J., P.V. Jeurink, T. Wehkamp, A. van der Veer, H.J. van de Kant, G.A. Hofman, E.C. van Esch, J. Garssen, L.E. Willemsen, and L.M. Knippels, Non-digestible oligosaccharides modulate intestinal immune activation and suppress cow's milk allergic symptoms. Pediatric Allergy and Immunology, 2014. 25(8): p. 747-754.

56. Hartog, A., F.N. Belle, J. Bastiaans, P. de Graaff, J. Garssen, L.F. Harthoorn, and A.P. Vos, A potential role for regulatory T-cells in the amelioration of DSS induced colitis by dietary nondigestible polysaccharides. The Journal of Nutritional Biochemistry, 2015. 26(3): p. 227-233.

57. Eiwegger, T., B. Stahl, J. Schmitt, G. Boehm, M. Gerstmayr, J. Pichler, E. Dehlink, C. Loibichler, R. Urbanek, and Z. Szepfalusi, Human milk--derived oligosaccharides and plant-derived oligosaccharides stimulate cytokine production of cord blood T-cells in vitro. Pediatric Research, 2004. 56(4): p. 536-540.

58. Eiwegger, T., B. Stahl, P. Haidl, J. Schmitt, G. Boehm, E. Dehlink, R. Urbanek, and Z. Szepfalusi, Prebiotic oligosaccharides: in vitro evidence for gastrointestinal epithelial transfer and immunomodulatory properties. Pediatric Allergy and Immunology, 2010. 21(8): p. 1179-1188.

59. Naarding, M.A., I.S. Ludwig, F. Groot, B. Berkhout, T.B. Geijtenbeek, G. Pollakis, and W.A. Paxton, Lewis X component in human milk binds DC-SIGN and inhibits HIV-1 transfer to CD4+ T lymphocytes. Journal of Clinical Investigation, 2005. 115(11): p. 3256-3264.

60. Yan, H., T. Kamiya, P. Suabjakyong, and N.M. Tsuji, Targeting C-Type Lectin Receptors for Cancer Immunity. Frontiers in Immunology, 2015. 6: p. 408.

61. Geijtenbeek, T.B. and S.I. Gringhuis, Signalling through C-type lectin receptors: shaping immune responses. Nature Reviews: Immunology, 2009. 9(7): p. 465-479.

62. Hardison, S.E. and G.D. Brown, C-type lectin receptors orchestrate antifungal immunity. Nature Immunology, 2012. 13(9): p. 817-822.

63. Martinon, F., A. Mayor, and J. Tschopp, The inflammasomes: guardians of the body. Annual Review of Immunology, 2009. 27: p. 229-265.

64. Loo, Y.M. and M. Gale, Jr., Immune signaling by RIG-I-like receptors. Immunity, 2011. 34(5): p. 680-692.

65. Iliev, I.D., V.A. Funari, K.D. Taylor, Q. Nguyen, C.N. Reyes, S.P. Strom, J. Brown, C.A. Becker, P.R. Fleshner, M. Dubinsky, J.I. Rotter, H.L. Wang, D.P. McGovern, G.D. Brown, and D.M. Underhill, Interactions between commensal fungi and the C-type lectin receptor Dectin-1 influence colitis. Science, 2012. 336(6086): p. 1314-1317.

66. Goodridge, H.S., C.N. Reyes, C.A. Becker, T.R. Katsumoto, J. Ma, A.J. Wolf, N. Bose, A.S.H. Chan, A.S. Magee, M.E. Danielson, A. Weiss, J.P. Vasilakos, and D.M. Underhill, Activation of the innate immune receptor Dectin-1 upon formation of a 'phagocytic synapse'. Nature, 2011. 472(7344): p. 471-U541.

67. Nishitani, Y., L. Zhang, M. Yoshida, T. Azuma, K. Kanazawa, T. Hashimoto, and M. Mizuno, Intestinal anti-inflammatory activity of lentinan: influence on IL-8 and TNFR1 expression in intestinal epithelial cells. PloS One, 2013. 8(4): p. e62441. 


\section{Chapter 1}

68. Zhu, L.L., X.Q. Zhao, C.Y. Jiang, Y. You, X.P. Chen, Y.Y. Jiang, X.M. Jia, and X. Lin, C-Type Lectin Receptors Dectin-3 and Dectin-2 Form a Heterodimeric Pattern-Recognition Receptor for Host Defense against Fungal Infection. Immunity, 2013. 39(2): p. 324-334.

69. Saijo, S., S. Ikeda, K. Yamabe, S. Kakuta, H. Ishigame, A. Akitsu, N. Fujikado, T. Kusaka, S. Kubo, S.H. Chung, R. Komatsu, N. Miura, Y. Adachi, N. Ohno, K. Shibuya, N. Yamamoto, K. Kawakami, S. Yamasaki, T. Saito, S. Akira, and Y. Iwakura, Dectin-2 recognition of alpha-mannans and induction of Th17 cell differentiation is essential for host defense against Candida albicans. Immunity, 2010. 32(5): p. 681-691.

70. Vogt, L., U. Ramasamy, D. Meyer, G. Pullens, K. Venema, M.M. Faas, H.A. Schols, and P. de Vos, Immune Modulation by Different Types of beta $2 \rightarrow$ 1-Fructans Is Toll-Like Receptor Dependent. PloS One, 2013. 8(7).

71. Fransen, F., N.M. Sahasrabudhe, M. Elderman, M. Bosveld, S. El Aidy, F. Hugenholtz, T. Borghuis, B. Kousemaker, S. Winkel, C. van der Gaast-de Jongh, M.I. de Jonge, M.V. Boekschoten, H. Smidt, H.A. Schols, and P. de Vos, $\beta_{2} \rightarrow 1$-Fructans Modulate the Immune System In Vivo in a Microbiota-Dependent and-Independent Fashion. Frontiers in Immunology, 2017. 8(154).

72. Owyang, C. and G.D. Wu, The gut microbiome in health and disease. Gastroenterology, 2014. 146(6): p. 1433-1436.

73. Xu, X., P. Xu, C. Ma, J. Tang, and X. Zhang, Gut microbiota, host health, and polysaccharides. Biotechnol Adv, 2013. 31(2): p. 318-337.

74. Tian, L., J. Scholte, K. Borewicz, B. van den Bogert, H. Smidt, A.J. Scheurink, H. Gruppen, and H.A. Schols, Effects of pectin supplementation on the fermentation patterns of different structural carbohydrates in rats. Molecular Nutrition \& Food Research, 2016. 60(10): p. 22562266.

75. Tian, L., G. Bruggeman, M. van den Berg, K. Borewicz, A.J. Scheurink, E. Bruininx, P. de Vos, H. Smidt, H.A. Schols, and H. Gruppen, Effects of pectin on fermentation characteristics, carbohydrate utilization, and microbial community composition in the gastrointestinal tract of weaning pigs. Molecular Nutrition \& Food Research, 2017. 61(1).

76. Lange, K., F. Hugenholtz, M.C. Jonathan, H.A. Schols, M. Kleerebezem, H. Smidt, M. Muller, and G.J. Hooiveld, Comparison of the effects of five dietary fibers on mucosal transcriptional profiles, and luminal microbiota composition and SCFA concentrations in murine colon. Molecular Nutrition \& Food Research, 2015. 59(8): p. 1590-1602.

77. Ridaura, V.K., J.J. Faith, F.E. Rey, J. Cheng, A.E. Duncan, A.L. Kau, N.W. Griffin, V. Lombard, B. Henrissat, J.R. Bain, M.J. Muehlbauer, O. Ilkayeva, C.F. Semenkovich, K. Funai, D.K. Hayashi, B.J. Lyle, M.C. Martini, L.K. Ursell, J.C. Clemente, W. Van Treuren, W.A. Walters, R. Knight, C.B. Newgard, A.C. Heath, and J.I. Gordon, Gut microbiota from twins discordant for obesity modulate metabolism in mice. Science, 2013. 341(6150): p. 1241214.

78. Macia, L., J. Tan, A.T. Vieira, K. Leach, D. Stanley, S. Luong, M. Maruya, C. Ian McKenzie, A. Hijikata, C. Wong, L. Binge, A.N. Thorburn, N. Chevalier, C. Ang, E. Marino, R. Robert, S. Offermanns, M.M. Teixeira, R.J. Moore, R.A. Flavell, S. Fagarasan, and C.R. Mackay, Metabolite-sensing receptors GPR43 and GPR109A facilitate dietary fibre-induced gut homeostasis through regulation of the inflammasome. Nat Commun, 2015. 6: p. 6734.

79. Smith, P.M., M.R. Howitt, N. Panikov, M. Michaud, C.A. Gallini, Y.M. Bohlooly, J.N. Glickman, and W.S. Garrett, The microbial metabolites, short-chain fatty acids, regulate colonic Treg cell homeostasis. Science, 2013. 341(6145): p. 569-573.

80. Meijer, K., P. de Vos, and M.G. Priebe, Butyrate and other short-chain fatty acids as modulators of immunity: what relevance for health? Current Opinion in Clinical Nutrition and Metabolic Care, 2010. 13(6): p. 715-721.

81. Alex, S., K. Lange, T. Amolo, J.S. Grinstead, A.K. Haakonsson, E. Szalowska, A. Koppen, K. Mudde, D. Haenen, S. Al-Lahham, H. Roelofsen, R. Houtman, B. van der Burg, S. Mandrup, 
A.M. Bonvin, E. Kalkhoven, M. Muller, G.J. Hooiveld, and S. Kersten, Short-chain fatty acids stimulate angiopoietin-like 4 synthesis in human colon adenocarcinoma cells by activating peroxisome proliferator-activated receptor gamma. Molecular and Cellular Biology, 2013. 33(7): p. 1303-1316.

82. Lichtenstein, L., F. Mattijssen, N.J. de Wit, A. Georgiadi, G.J. Hooiveld, R. van der Meer, Y. He, L. Qi, A. Koster, J.T. Tamsma, N.S. Tan, M. Muller, and S. Kersten, Angptl4 protects against severe proinflammatory effects of saturated fat by inhibiting fatty acid uptake into mesenteric lymph node macrophages. Cell Metabolism, 2010. 12(6): p. 580-592. 



\section{Chapter 2}

Gene expression analysis characterizes Caco-2 responses to non-digestible polysaccharides: a first step to a systematic comparison of dietary fibres

Yongfu Tang, Coen Govers, Sophie Le Gall, Luc Saulnier, Anne Rieder, Svein H. Knutsen, Monic M.M. Tomassen, Nicole J.W. de Wit, Harry J. Wichers, Jurriaan J. Mes 


\section{Chapter 2}

\section{Abstract}

Scope: Dietary non-digestible polysaccharides (NDPs) have shown immunomodulatory activity following oral intake. The role of direct interaction with small intestinal epithelial cells, which are the first point of direct contact with NDPs, in this process is unclear. Here the transcriptional changes and cellular responses of small intestinal-like cells in response to different types of NDPs have been studied.

Methods and results: Polarized Caco-2 cells were exposed to NDPs $(500 \mu \mathrm{g} / \mathrm{ml})$ at the luminal side for $6 \mathrm{~h}$. The NDPs reduced translocation of FITC-Dextran of $4 \mathrm{kDa}$ across the epithelial layer, potentially through physical interference. Microarray analysis revealed unique gene expression characteristics in Caco-2 cells upon exposure to different NDPs. An arabinoxylan preparation from wheat and a lentinan containing extract from shiitake mushrooms induced transcriptional upregulation of the NF-kB pathway and production of CXCL10. Besides these immune-related changes by some NDPs, we also observed changes in transcriptional levels of some cell surface receptors (like TLR2, CD14 and GPCRs) and intracellular pathways, amongst which the cholesterol biosynthesis pathway.

Conclusion: NDP preparations are a direct trigger for intestinal epithelial cells to produce chemokines, via the NF-kB pathway. This may support communication towards the innate and adaptive immune cells in gut-associated lymphoid tissue.

Keywords: Arabinoxylan / $\beta$-Glucan / Microarray / NF-kB pathway / Oat

Abbreviations: FID, flame ionization detector; IECs, intestinal epithelial cells; LCES, lentinan containing extracted from shiitake; $\mathbf{M W}$, molecular weight; NDP, non-digestible polysaccharide; PRRs, pathogen recognition receptors; TEER, trans-epithelial electrical resistance 


\section{Introduction}

Polysaccharides are long chains of monosaccharide units bound together by glycosidic linkages. As the units, linkages, chain lengths and branching can vary, an almost infinite variation of polysaccharides can be found in nature, or be engineered [1, 2]. Dietary fibres or non-digestible polysaccharides (NDPs) are not hydrolysed by the endogenous enzymes in the small intestine of humans [3]. NDPs found in common foods, e.g. $\beta$ glucans, arabinoxylans, pectins, cellulose and chitin are, on a quantitative basis, nutritionally important dietary fibres and gained a lot of interest because of health effects as found by epidemiological research. Increased intake of dietary fibres is correlated with reduced incidences of cardiovascular disease [4] and colon cancer [5, 6] among others. Besides that, human trials have shown biological activity of specific NDPs on lowering of cholesterol [7], control of serum glucose [8], immunomodulation [9, 10], anticancer activity [11] and towards mitigation of inflammatory bowel disease [12].

Part of the bioactivity of these orally applied NDPs will result from effects on our gut and immune system. Indeed, receptors have been identified on different human gut and immune cells that detect the presence of NDPs and increase both the innate and adaptive host defence. An example are $\beta$-glucans found in the cell wall of yeast, fungi and bacteria, which can interact with the dectin-1 receptor $[13,14]$ and the complement receptor [15] as studied in immune cells (i.e. dendritic cells, macrophages, monocytes and lymphocytes) both in vitro and in vivo $[16,17]$. Recently we reported that some NPDs can steer the polarisation of macrophages to a subset that can be distinguished from both inflammatory and tolerant macrophage subsets [18]. A less studied field is how $\beta$ glucans and other NDPs interact directly with small intestinal epithelial cells and whether the response of these cells contributes to the biological activity and maintenance of health.

Intestinal epithelial cells (IECs) form a physical barrier in the intestine. The enterocytes are the dominant lineage within the IECs (90\% of total cells) [19] which can be mimicked in vitro by the use of Caco-2 cells. These cells can be differentiated towards polarised small intestinal-like cells [20], and express receptors such as pathogen recognition receptors (PRRs) [21, 22], G-protein coupled receptors, the low density lipid receptor [23], leptin receptor [24], and aryl hydrocarbon receptor [25]. Caco-2 cells have shown to be responsive to many food compounds [26, 27] although direct effects of NDPs have only been studied to a limited degree.

In this study, we exposed transwell-grown Caco-2 cells to five NDP preparations and analysed the effects on cell layer integrity, gene expression and chemokine secretion. This study can be used as a basis to build hypotheses on direct activity of NDPs towards 


\section{Chapter 2}

enterocytes which can be used as part of the classification of NDPs on the basis of their specific bioactivity.

\section{Materials and Methods}

\subsection{Sources, preparation and handling of non-digestible polysaccharides}

A water soluble $\beta$ beta 1,3/1,6 glucan isolated from the yeast Saccharomyces cerevisiae (F3020 lot 12111-016) was provided by BioThera (Eagan, MN, USA). We will refer to this sample as Wellmune Soluble (Wellmune in tables and figures). A preparation of oat water soluble 1,3/1,4 beta-glucan was provided by Swedish Oat Fiber AB (Bua, Sweden) [28]. This sample will be referred to as OBG90. A polysaccharide from wheat flour rich in arabinoxylan (LC-AX 120305), was provided by BioActor (Maastricht, The Netherlands). This sample will be referred to as Naxus.

Shiitake mushrooms were grinded, boiled in water for $8 \mathrm{~h}$, filtered over cheesecloth, and the supernatant ethanol precipitated after which the pellet was freeze dried and powdered. This water soluble, ethanol insoluble fraction contained mainly shiitakederived beta 1,3/1,6 glucans (lentinan) and a minor amount of alfa 1,4/1,6 glucan, identified by susceptibility to hydrolysis by Termamyl (Novozymes). This sample is termed LCES (lentinan containing extract from shiitake).

A concentrate of rhamnogalacturonan I was prepared from apple juice. Apple juice was prepared under inert atmosphere at the INRA (Paris, France) experimental facility in Le Rheu. Apple juice was treated with pectin methyl esterase (30 UI/L, Rapidase SPE, DSM) and polygalacturonase (20 UI/L, PG, Megazyme) at $4{ }^{\circ} \mathrm{C}$ for $12 \mathrm{~h}$ in order to limitedly hydrolyse pectin. Sample was then concentrated by cross flow ultrafiltration using a ceramic membrane ( $0.5 \mathrm{~m}^{2}$, diameter $25 \mathrm{~mm}$, cut-off $8 \mathrm{kDa}$ ). A diafiltration step was further applied (dilution factor 1000), and the sample was finally centrifuged (2800 x g, $30 \mathrm{~min}, 4^{\circ} \mathrm{C}$ ) and freeze dried. This sample will be labelled as RG-I.

To improve solubilisation and to control the concentration in cell culture medium, NDPs were suspended in $\mathrm{MQ}$ (typically $0.5 \mathrm{mg} / \mathrm{mL}$ ), boiled for $30 \mathrm{~min}$, aliquoted, freeze dried and stored at $-20^{\circ} \mathrm{C}$ until use. Boiling did not result in breakdown of the samples as the molecular weight ( $\mathrm{MW}$ ), analysed by SEC-RI before and after the treatment, did not change (data not shown). Before use, the samples were re-suspended in DMEM containing $10 \% \mathrm{FBS}$ at $37^{\circ} \mathrm{C}$. 


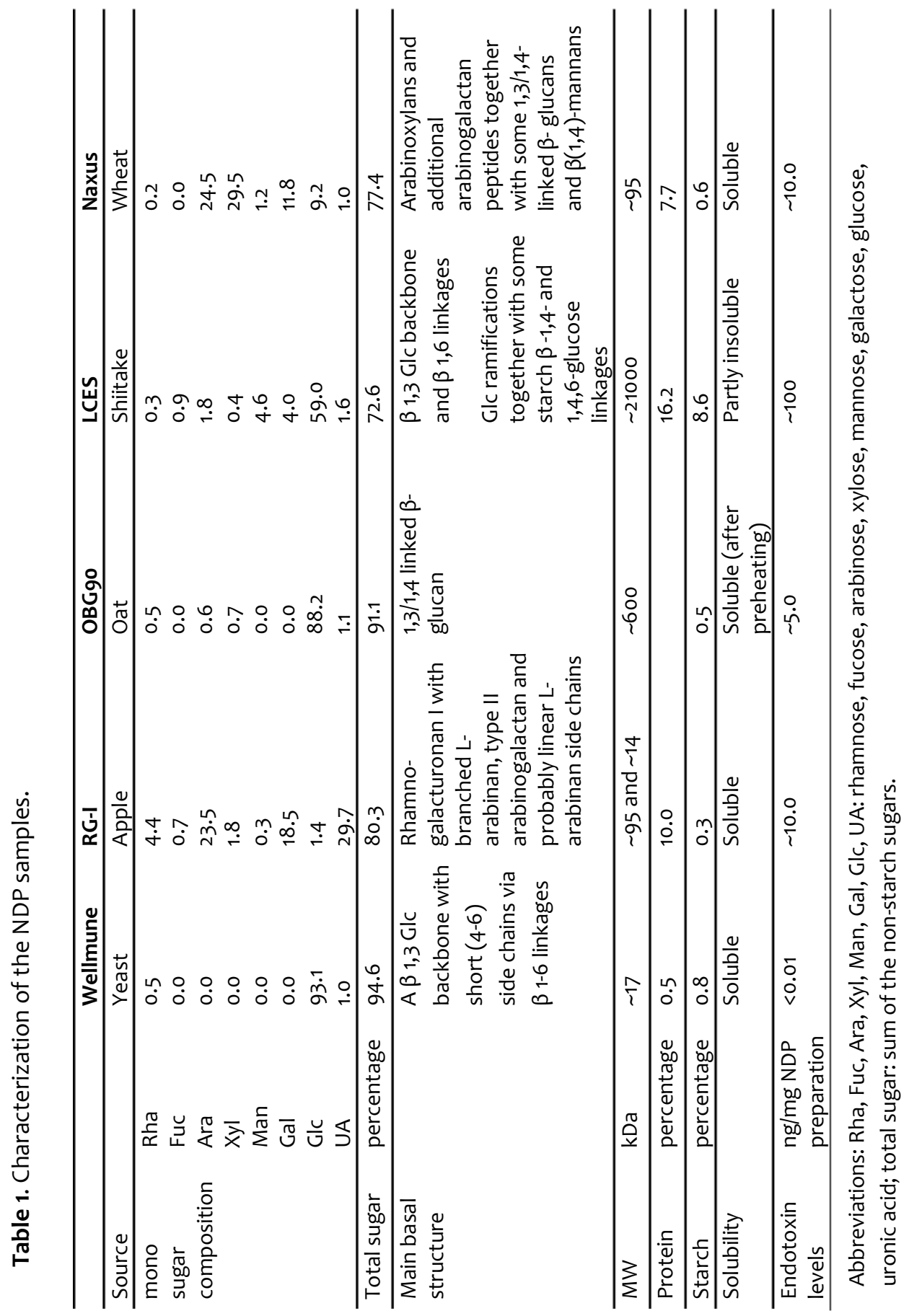




\section{Chapter 2}

\subsection{Chemical analysis}

Constituent neutral sugar analysis was based on acidic hydrolysis, and derivation into alditol acetates and GC as described [29]. In short, acid hydrolysis was performed with 1 $\mathrm{M}$ sulfuric acid $\left(2 \mathrm{~h}, 100^{\circ} \mathrm{C}\right)$ and subsequent derivation was performed as published [30]. Alditolacetates were separated on a DB 225 capillary column (J\&W Scientific, Folsorn, CA, USA; temperature $205^{\circ} \mathrm{C}$, carrier gas $\mathrm{H}_{2}$ ). Standard sugars solution and inositol as internal standard were used for calibration.

Secondly, uronic acids in hydrolysates were quantified using an automated metahydroxydiphenyl colorimetric acid method [31].

Chemical linkages between monomers were determined by permethylation analysis. Polysaccharides were dissolved in DMSO and methylated using the procedure described by Anumula and Taylor [32]. Methylated carbohydrates were hydrolysed with $2 \mathrm{M}$ trifluoroacetic acid and converted to their alditol acetates. The partially methylated alditol acetates were analysed by GC/MS (TRACE-GC-ISQ, Therm, Breda, Netherlands) on a non-polar thermo scientific ${ }^{\text {TM }}$ TraceGOLD $^{\text {TM }}$ TG-1MS GC Column (30 m $\times 0.25$ mm $\times 0.25$ $\mu \mathrm{m})$, carrier gas $\mathrm{H}_{2}$ at $1.5 \mathrm{ml} / \mathrm{min}$. The sample was injected at $240{ }^{\circ} \mathrm{C}$. The oven temperature was maintained for $5 \mathrm{~min}$ at $60{ }^{\circ} \mathrm{C}$ and increased up to $315^{\circ} \mathrm{C}\left(3{ }^{\circ} \mathrm{C} / \mathrm{min}\right)$, where it was maintained for $2 \mathrm{~min}$. The flow rate was set at $1.5 \mathrm{ml} / \mathrm{min}$. The ion source temperature of the electron impact (EI) mass spectrometer was $230{ }^{\circ} \mathrm{C}$. Masses were acquired with a scan range from $\mathrm{m} / \mathrm{z} 100$ to 500 . Identification of partially methylated alditol acetates was based on their retention time and confirmed by mass spectra fragmentation. Quantitative detection was performed at $220^{\circ} \mathrm{C}$ with a flame ionization detector (FID).

Starch quantification was performed according to McCleary et al. [33] using enzymatic digestion by $a$-amylase and amyloglucosidase and measurement of glucose released by HPAEC (CarboPac PA1 column, Thermo, isocratic mode, $\mathrm{NaOH} 100 \mathrm{mM}$ ). Standard glucose solutions and rhamnose as internal standard were used for calibration. MW analysis was carried out on an HPSEC system with on-line laser light scattering detection allowing absolute MW determination, and viscosity detection allowing determination of intrinsic viscosity. Solution at approximately $5 \mathrm{mg} / \mathrm{ml}$ (except for LCES: $0.5 \mathrm{mg} / \mathrm{ml}$ ) were prepared in MilliQ water and filtered through a $0.45 \mu \mathrm{m}$ filter (Millex-HV, PVDF) prior to injection. HPSEC was carried out at room temperature on a system consisting of a Shodex OH SB-G guard column (Shodex, Tokyo, Japan) and two Shodex OH-Pak columns SB-805HQ and SB-804HQ. Injection volume was $50 \mu \mathrm{L}$ and columns were eluted at 0.7 $\mathrm{ml} / \mathrm{min}$ with $50 \mathrm{mM}$ sodium nitrate. A Viscotek tri-SEC model 270 was used for light scattering and differential pressure detection, and a Viscotek VE 3580 RI detector was 


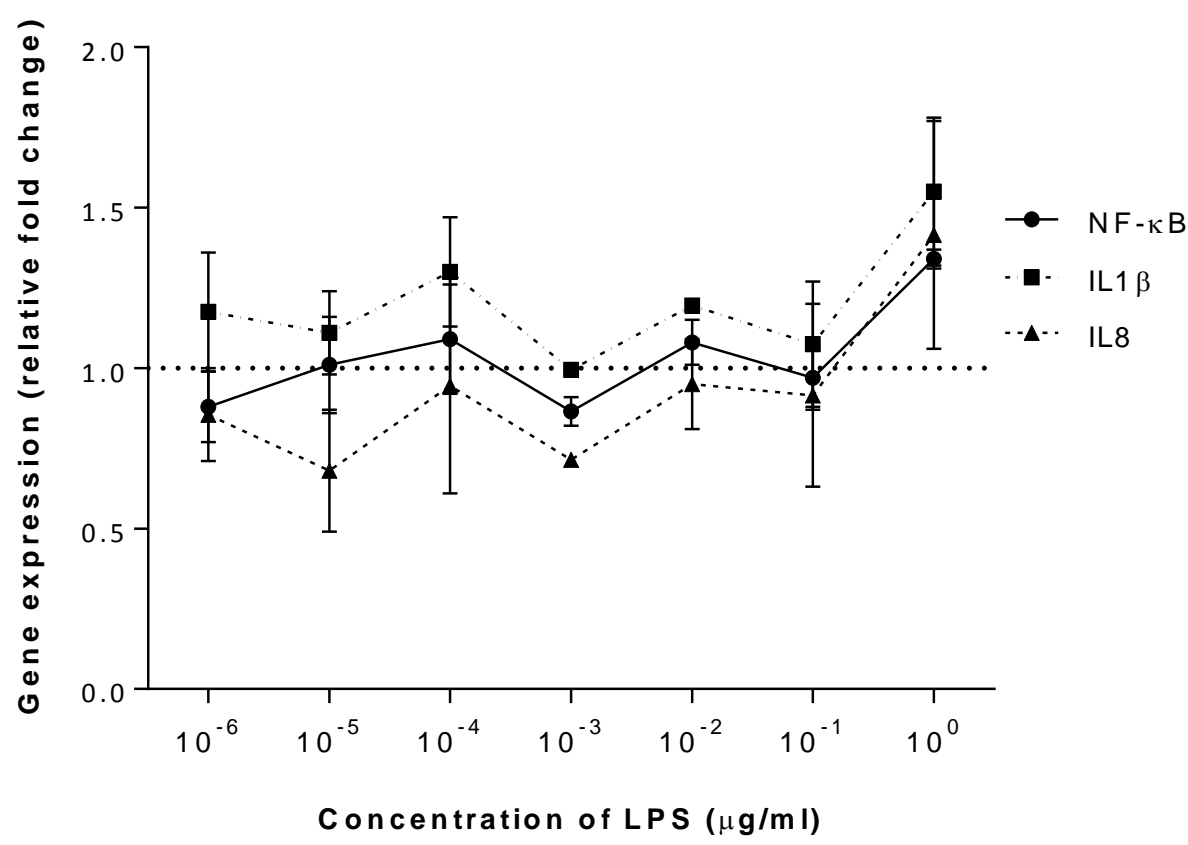

Figure 1. Response of transwell grown Caco-2 to a concentration range of LPS. Transwell grown Caco-2 cells were exposed to LPS ranging from $1 \mathrm{pg} / \mathrm{ml}$ to $1 \mu \mathrm{g} / \mathrm{ml}$ for $6 \mathrm{~h}$. Gene expression of three marker genes (NF-KB, IL1 $\beta$ and IL8) were measured with $\mathrm{qPCR}$ and shown as fold change normalized to the geometric mean of GAPDH and RPLPo and medium control $(\Delta \Delta \mathrm{ct})$. The line chart shows mean values \pm SEM, based on two independent experiments. Statistically significant differences between LPS and medium were calculated with one-way ANOVA by Graphpad Prism 6 and only found significant changes for IL-1 $\beta$ ( $p<0.05$ ) following $0.01 \mu \mathrm{g} / \mathrm{ml}$ LPS exposure.

used for the determination of polymer concentration. A refractive index increment per unit concentration increment $(\mathrm{dn} / \mathrm{dc})$ value of $0.146 \mathrm{ml} / \mathrm{g}$ was used for concentration determination. Data were collected with Omnisec 4.7 software (Viscotek), and all calculations on polymer peaks (concentration, average molecular weights, intrinsic viscosity) were carried out using Omnisec software.

Lipopolysaccharide (LPS) contamination was analysed by ToxinSensor ${ }^{\mathrm{tm}}$ Chromogenic LAL endotoxin Assay Kit (GenScript) and indicated as ng/mg NDP. 


\section{Chapter 2}

\subsection{Cell culture and exposure}

Caco-2 cells (American Type Culture Collection, Rockville, USA) were used between passage number 30 and 40 and grown on transwell inserts (Greiner Bio-one, Monroe, NC, USA) in 24-well plates. (ells were seeded with $3.375 \times 10^{4}$ cells in $150 \mu$ l per insert and grown for 21 days with $5 \% \mathrm{CO}_{2}$ at $37{ }^{\circ} \mathrm{C}$. The medium DMEM (Gibco, Bleiswijk, The Netherlands) supplemented with 10\% FBS (HyClone, Eindhoven, The Netherlands) was used to maintain Caco-2 cells and to replace medium of cells three times a week during differentiation on transwell inserts. One day before exposure to an NDP, we refreshed the apical and basolateral medium. The next day, cells were stimulated for $6 \mathrm{~h}$ in triplicate by replacing apical medium with medium containing an NDP or control treatment. Experiments were performed three times, including a medium control.

\subsection{Cell Integrity and measurement of FD4 translocation}

Trans-Epithelial Electrical Resistance (TEER) was measured using a Millicell-ERS (Millipore) on transwell-grown Caco-2 before adding test samples. In all experiments, only Caco-2 monolayers with TEER values within the range of $280-400 \Omega . \mathrm{cm}^{2}$ were included in the experiment. TEER was measured directly, 1, 3 and $6 \mathrm{~h}$ after exposure of Caco-2 cells and depicted as percentages relative to medium stimulated cells at the same time point [34].

In order to measure permeability, $1 \mathrm{mg} / \mathrm{ml}$ FITC-dextran 4 kDa (FD4, Sigma, St. Louis, MO, USA) was added to the apical compartments with or without NDP [35]. After $8 \mathrm{~h}$ incubation, $100 \mu \mathrm{l}$ medium was taken from the basolateral compartments for FD4 fluorescence intensity assay in multimode microplate readers (Infinite 200 PRO, Tecan, Männedorf, Switzerland) at $544 \mathrm{~nm}$ excitation and $590 \mathrm{~nm}$ emission wavelengths. FD4 concentration was calculated according to FD4 standard curve.

\subsection{RNA extraction and cDNA synthesis}

RNA was extracted and cDNA was prepared as described previously [36]. In brief, RNA extraction with $200 \mu \mathrm{L}$ TRIzol (Invitrogen, Bleiswijk, The Netherlands) was followed by RNeasy (Qiagen, Venlo, The Netherlands) clean-up. RNA concentration and purity were checked using the Nanodrop spectrophotometer system (ND-1000 3.3; Nanodrop Technologies, Wilmington, DE, USA). The integrity of the ribosomal RNA was further checked using agarose (Eurogentec, Liège, Belgium) gel electrophoresis (1\%). Only samples with a ratio (Abs $260 / 280 \mathrm{~nm}$ ) between 1.8 and 2.1 were used for ReverseTranscriptase quantitative Polymerase Chain Reaction (RT-qPCR) and microarray analysis experiments. cDNA was synthesised with iScript (Bio-Rad, Veenendaal, The Netherlands). 


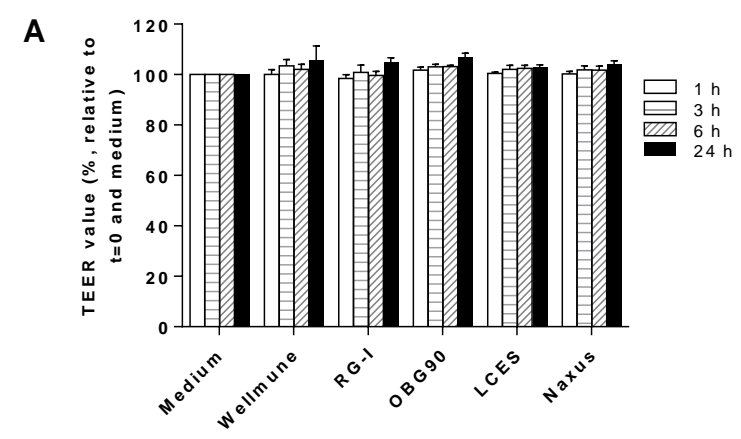

B

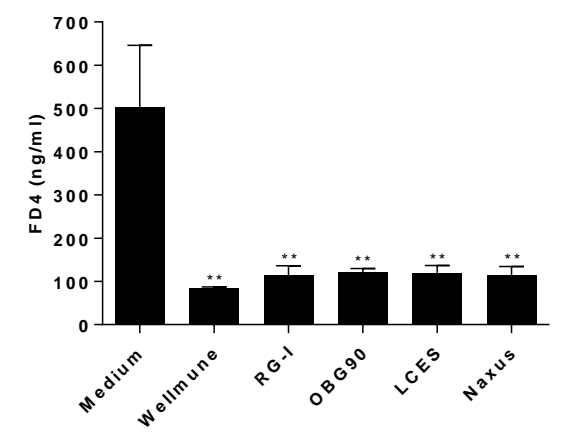

C

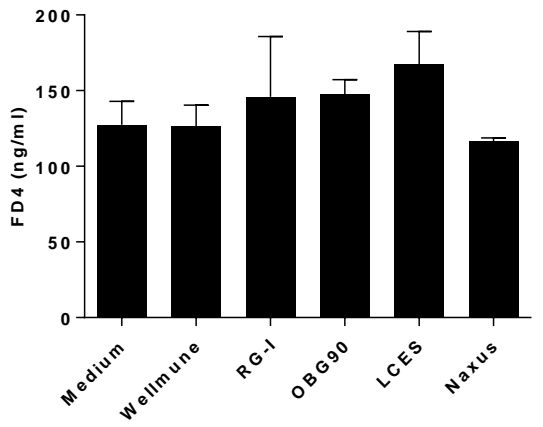

Figure 2. NDPs did not change monolayer integrity or barrier function of transwell grown Caco-2. Transwell grown Caco-2 cells were exposed to Wellmune, RG-I, OBG9o, LCES and Naxus at $500 \mu \mathrm{g} / \mathrm{ml}$. (A) Monolayer integrity was determined by measuring TEER at $T=1,3,6$ and 24 and shown as percentage normalized to levels at $\mathrm{T}=0$ and medium. (B) Barrier function was tested after exposure for $24 \mathrm{~h}$ with NDPs and subsequently $8 \mathrm{~h}$ with FD4 and NDPs. (C) Barrier function was tested after exposure for $24 \mathrm{~h}$ with NDPs and subsequently $8 \mathrm{~h}$ with FD4. Bar charts show mean values + SEM, $\mathrm{n}=3$ independent experiments. Statistically significant differences relative to medium were calculated with one-way ANOVA: **: $p<0.01$.

\subsection{RT-qPCR}

$5 \mu \mathrm{L}$ CDNA were mixed with $10 \mu \mathrm{l} \mathrm{iQ}^{\mathrm{TM}}$ SYBR Green supermix (Bio-Rad), together with forward and revers primers after which $M Q$ was added to total $20 \mu$. Primer concentrations and sequences used for qPCR were chosen based on the sequences available in the GenBank database (www.ncbi.nlm.nih.gov), synthesized by Biolegio (Biolegio, Nijmegen, the Netherlands) and are listed in the supplementary Table 1. GAPDH, RPLPo, IL8, IL1 $\beta$ and NF-kB were designed by Clone manager professional 9. 


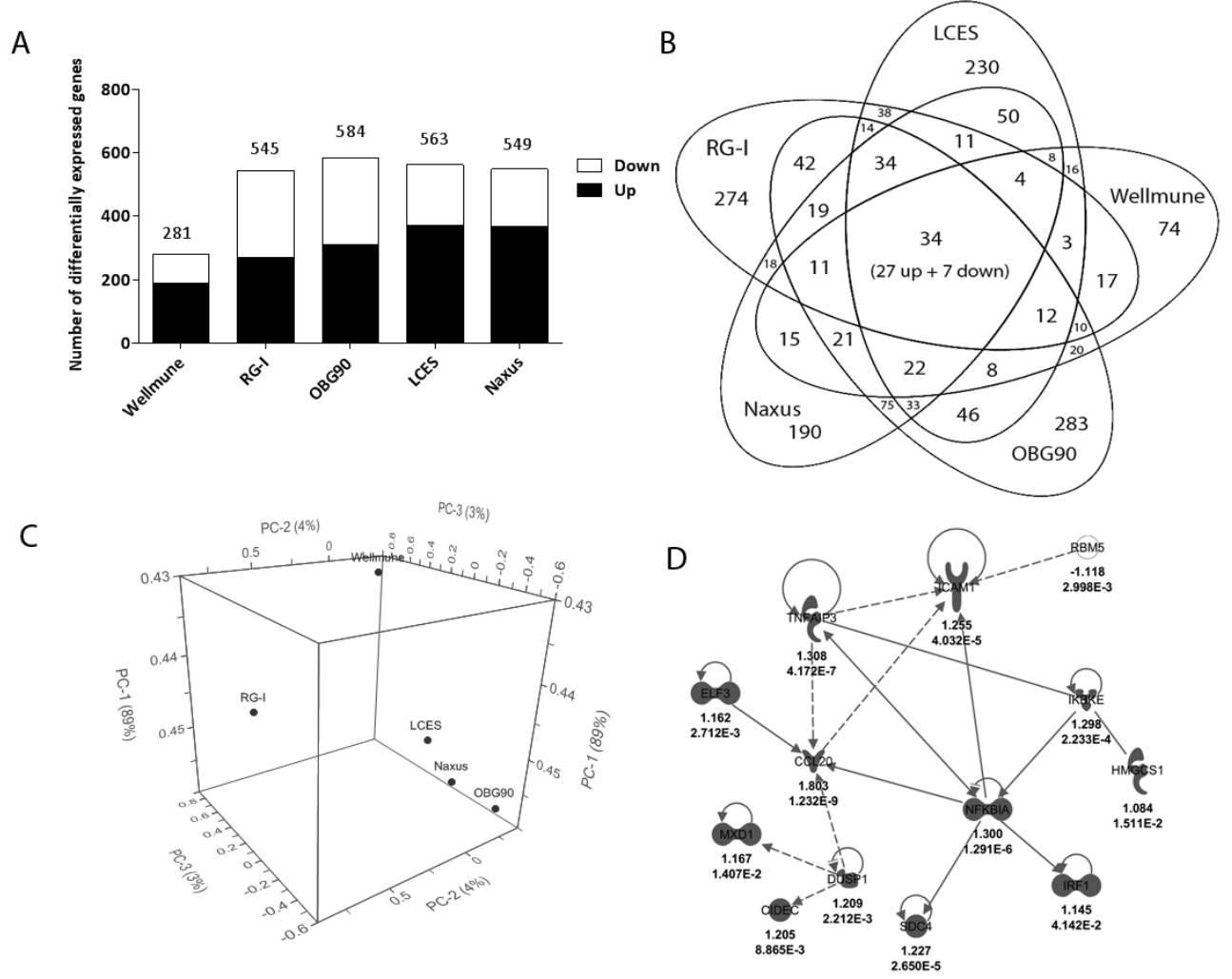

Figure 3. Transwell grown Caco-2 respond with different gene responses to exposure to various NDPs. Transwell grown Caco-2 cells were exposed to Wellmune, RG-I, OBG9o, LCES and Naxus at $500 \mu \mathrm{g} / \mathrm{ml}$ and analysed for their gene expression profile using microarray. Genes that were assigned a UPC value $>0.5$ and a $p$-value $<0.05$ compared to medium control were included in these analysis. (A) Bar chart depicting the number of significantly up- and down-regulated genes for each NDP. (B) Venn diagram displaying NDP unique and shared differential gene expression responses. (C) PCA plot based on signal-log ratio compared to medium with numbers in parentheses indicating relative scaling of the principal variables. (D) IPA protein network based on the 34 genes in figure $3 \mathrm{~B}$ excluded genes without demonstrated functional interaction with at least one other gene. Values represent fold change (upper number) and p-value (lower number) of differential gene expression following Naxus stimulation. Gene symbols in dark grey indicates a significant upregulation of expression and gene symbols in white indicates significant downregulation of expression. Data are expressed as mean values, $\mathrm{n}=3$ independent experiments.

CCL20 and CXCL10 were derived from the Harvard PrimerBank (http://pga.mgh.harvard.edu/primerbank/). The following thermal cycling conditions were used for amplifying the target sequences by $\mathrm{C} 1000$ thermal cycler (Bio-Rad): $90 \mathrm{~s}$ at $95^{\circ} \mathrm{C}$, followed by 40 cycles at $95^{\circ} \mathrm{C}$ for $10 \mathrm{~s}, 58^{\circ} \mathrm{C}$ for $10 \mathrm{~s}$ and $72{ }^{\circ} \mathrm{C}$ for $15 \mathrm{~s}$, and a final elongation step at $72{ }^{\circ} \mathrm{C}$ for $2 \mathrm{~min}$. qPCR were performed in duplicate, and all samples 
were normalised to geometric means of GAPDH (Glyceraldehyde-3-phosphate dehydrogenase) and RPLPo (Ribosomal Protein, Large, Po) expression and medium ( $\Delta \Delta \mathrm{ct}$ ) using the qBase+ software (Biogazelle, Gent, Belgium). The melting curve and agarose gel analysis of amplified qPCR products were checked for amplification of a single product.

\subsection{Microarray analysis}

RNA quality was verified with the RNA 6000 Nano assay on an Agilent 2100 Bioanalyzer and was >8 (Agilent Technologies, Amstelveen, The Netherlands). Hybridization, washing and scanning of the Affymetrix Human Gene 1.1 ST array plate was performed according to standard protocols on an Affymetrix Gene Titan platform. Bioconductor was used to analyse the scans of the arrays [37]. Genes were considered to be expressed if the UPC algorithm valued expression with $p>0.5$ on at least one array [38]. Changes in gene expression were calculated as signal log ratio's or fold changes between NDP exposure and medium control. Genes which significant changed $(p<0.05$ on at least one NDP, IBMT regularised paired t-test) were selected. The functional interpretation of gene signatures was executed using IPA 3.0 (Ingenuity, QIAGEN, Redwood, CA, USA). Microarray data were deposited in the Gene Expression Omnibus database.

\subsection{Cholesterol uptake assay}

The cholesterol uptake assay was performed using the Cholesterol Uptake Cell-Based Assay Kit (Cayman, Ann Arbor, MI, USA) according to the manufacturers' instructions. In brief, transwell grown Caco-2 were washed with medium (phenol red free DMEM without FBS) and exposed to medium (control) or NDPs at $500 \mu \mathrm{g} / \mathrm{ml}$ with or without NBD-cholesterol ( $20 \mu \mathrm{g} / \mathrm{ml}$ ). After $24 \mathrm{~h}$ incubation, cells were trypsinized (Gibco), washed and resuspended in $100 \mu \mathrm{l}$ of assay buffer. Fluorescence of the cells, apical and basolateral medium was analysed with excitation and emission at $485 \mathrm{~nm}$ and $535 \mathrm{~nm}$, respectively. Fluorescent signals of NDP+NBD cholesterol exposed cells were subtracted with the signals of the NDP exposed cells to correct of auto-fluorescent signals. Subsequently the data were expressed as normalized to medium control.

\subsection{ELISA analysis}

Transwell grown Caco-2 were exposed to $500 \mu \mathrm{g} / \mathrm{ml}$ of NDPs for $24 \mathrm{~h}$. Subsequently, Caco-2 spend medium, both apical and basolateral, was collected and chemokines (CCL20 (Sigma); CXCL10 (BioLegend, San Diego, CA, USA) measured by ELISA according to the manufacturer's instructions. The production of CCL20 and CXCL10 was calculated as total amount based on concentration measured and volumes in the transwell system (150 $\mu$ l for apical and $700 \mu \mathrm{l}$ for basolateral compartments). 


\section{Chapter 2}

\subsection{Statistics}

All parameters are presented as means \pm SEM and differences between parameters were assessed for their significance with one-way ANOVA using Prism 6 (Graphpad, La Jolla, CA, USA). Differences with $p<0.05$ were considered significant.

\section{Results}

\subsection{Biochemical analysis of NDP preparations}

The five NDP preparations used in this study were characterized for composition, structure and endotoxin levels (Table 1). Wellmune Soluble, OBG9o and LCES were mainly composed of glucose, but have different backbone structure and side chain branches. OBG90 is a linear 1,3/1,4 linked $\beta$-D-glucan whereas LCES is a high MW, branched 1,3/1,6 linked $\beta$-D-glucan with a 1,3-linked backbone and 1,6-linked glucose side chains. Both preparations did not dissolve fully in regular culture medium. Wellmune Soluble is a low MW branched 1,3/1,6-linked $\beta$-D-glucan typical for yeast $\beta$-glucan. Naxus has a more complex composition with xylose, arabinose and galactose as major constituents with xylose and part of arabinose originating from arabinoxylans while galactose and part of the arabinose originate from arabinogalactan-proteins [39]. Naxus also contained some glucose originating from 1,3/1,4-linked $\beta$-D-glucan. The arabinoxylans, however, represents $62 \%$ of total polysaccharide in Naxus.

RG-I is composed of various neutral sugars (arabinose, galactose and rhamnose) and galacturonic acid. RG-I is primarily a mix of pectin backbone of rhamnogalacturonan I and homogalacturonan.

Besides NDP, the preparations contained proteins and other compounds of unknown origin which have not been examined in further detail. The levels of LPS contamination were determined as it is known that the presence of LPS can hamper certain in vitro analyses. The lowest contamination was found for Wellmune Soluble (<0.01 ng/mg) and the highest level of LPS contamination was found for LCES ( $100 \mathrm{ng} / \mathrm{mg})$. The NDP concentrations of the preparations ranged from $94.6 \%$ (i.e., Wellmune Soluble) to $72.6 \%$ (i.e., LCES). Sample concentrations for experiments were adjusted based on these total carbohydrate values to include equal amounts of NDPs.

3.2 Transwell grown Caco-2 cells are non-responsive to levels of endotoxin contaminations as found in NDP preparations

To investigate whether the observed levels of LPS contamination could lead to nonspecific responses in Caco-2 cells, we exposed the Caco-2 cells for $6 \mathrm{~h}$ to a range of LPS 
concentrations (Figure 1). Cell responses were determined by gene transcription analysis of known early response markers NF-kB, IL1 $\beta$ and IL8. Results indicate that gene expression of these markers are not significantly changed when cells are exposed to LPS concentrations of $1 \mu \mathrm{g} / \mathrm{ml}$ or below.

\subsection{Selected experimental NDP concentration does not change transwell grown Caco-2 monolayer integrity}

The main goal of the study is to investigate effects that NDP preparations can have on enterocytes mimicked by transwell 21-days-grown Caco-2 cells. First, the maximum NDP concentration was determined that did not induce unwanted side effects like apoptosis. Therefore, the cells were exposed to various concentrations of NDPs (ranging from 10 to $1000 \mu \mathrm{g} / \mathrm{ml}$ ) for $6 \mathrm{~h}$ and we analysed cell viability and cell layer integrity. Cell viability was measured using the MTT assay and cell layer integrity was determined by measuring TEER. Both results indicated that Caco-2 cells were not significantly negatively (nor positively) affected by NDP concentrations up to $500 \mu \mathrm{g} / \mathrm{ml}$. At an NDP concentration of $500 \mu \mathrm{g} / \mathrm{ml}$ all samples also contain LPS contamination levels below the threshold level (Table 1).

Time series experiments confirmed that $500 \mu \mathrm{g} / \mathrm{ml}$ NDP did not affect Caco-2 TEER values following $6 \mathrm{~h}$ of incubation. In addition, significant changes were also not observed after a shorter incubation period of 1 or $3 \mathrm{~h}$, or a longer incubation period of $24 \mathrm{~h}$ (Figure $2 \mathrm{~A}$ ). FD4 is a marker for paracellular transport and was added together with the NDP and, following $8 \mathrm{~h}$ of exposure, the basolateral FD4 content was measured. Lowered FD4 levels in the basolateral compartment of NDP-exposed cells compared to control indicated that FD4 translocation was reduced by all NDPs (Figure 2B). However, when the Caco-2 cells were pre-incubated with NDP and subsequently exposed to FD4 in the absence of NDP, then no effect of the NDPs on FD4 translocation was observed (Figure 2C).

\subsection{NDPs induce unique gene expression patterns in transwell grown Caco-2}

To determine gene transcription responses of transwell grown Caco-2 following $6 \mathrm{~h}$ exposure to NDP we performed microarray analysis. NDP-mediated gene expression was compared to medium control and results showed that NDPs significantly affected expression of genes in Caco-2 cells. We observed the lowest number of significant differentially expressed genes for Wellmune Soluble (i.e. 281 genes) and the highest number for OBG90 (i.e. 584 genes) (Figure 3A). A minority of 34 genes were significant differentially expressed by all NDPs (Figure $3 B$ ). This overlap is relatively small as for instance $O B G 90$ induces differential regulation of 283 genes that are not affected by any 


\section{Chapter 2}

Table 2. List of genes significantly affected in expression by all NDP preparations.

\begin{tabular}{|c|c|c|c|c|c|}
\hline Genes & Wellmune & RG-I & OBG90 & LCES & Naxus \\
\hline $\mathrm{ABI} 3 \mathrm{BP}$ & 1.32 & 1.31 & 1.33 & 1.25 & 1.24 \\
\hline APOBEC $3 \mathrm{C}$ & 1.11 & 1.10 & 1.16 & 1.13 & 1.14 \\
\hline C17orf78 & 1.18 & 1.17 & 1.23 & 1.27 & 1.21 \\
\hline CCL2O & 1.21 & 1.18 & 1.35 & 1.56 & 1.80 \\
\hline $\mathrm{CDC}_{42} \mathrm{EP}_{2}$ & 1.13 & 1.14 & 1.12 & 1.11 & 1.13 \\
\hline CIDEC & 1.19 & 1.19 & 1.22 & 1.15 & 1.20 \\
\hline CYP1A1 & 1.41 & 1.26 & 1.64 & 1.74 & 1.47 \\
\hline DUSP1 & 1.15 & 1.19 & 1.25 & 1.22 & 1.21 \\
\hline ELF3 & 1.13 & 1.14 & 1.14 & 1.14 & 1.16 \\
\hline GATAD2A & 1.12 & 1.13 & 1.09 & 1.11 & 1.09 \\
\hline GNA13 & 1.13 & 1.14 & 1.11 & 1.12 & 1.17 \\
\hline HMGCS1 & 1.07 & 1.07 & 1.09 & 1.09 & 1.08 \\
\hline $\mathrm{HNF}_{4} \mathrm{G}$ & 1.16 & 1.22 & 1.20 & 1.18 & 1.23 \\
\hline ICAM1 & 1.12 & 1.12 & 1.15 & 1.23 & 1.25 \\
\hline IKBKE & 1.15 & 1.19 & 1.17 & 1.29 & 1.30 \\
\hline IRF1 & 1.18 & 1.21 & 1.16 & 1.25 & 1.14 \\
\hline MXD1 & 1.16 & 1.16 & 1.17 & 1.21 & 1.17 \\
\hline NFKBIA & 1.15 & 1.11 & 1.20 & 1.22 & 1.30 \\
\hline OCEL1 & 1.13 & 1.10 & 1.11 & 1.16 & 1.12 \\
\hline PELO & 1.13 & 1.17 & 1.13 & 1.10 & 1.10 \\
\hline $\mathrm{SDC}_{4}$ & 1.10 & 1.14 & 1.19 & 1.20 & 1.23 \\
\hline $\mathrm{SLC} 2 \mathrm{OA} 2$ & 1.11 & 1.19 & 1.17 & 1.11 & 1.15 \\
\hline SPRED2 & 1.08 & 1.09 & 1.08 & 1.17 & 1.07 \\
\hline STC1 & 1.31 & 1.26 & 1.27 & 1.39 & 1.26 \\
\hline $\mathrm{TCN} 2$ & 1.18 & 1.21 & 1.24 & 1.15 & 1.17 \\
\hline TNFAIP3 & 1.15 & 1.12 & 1.20 & 1.21 & 1.31 \\
\hline WBP2 & 1.10 & 1.14 & 1.13 & 1.19 & 1.14 \\
\hline B3GALNT2 & -1.17 & -1.15 & -1.18 & -1.22 & -1.19 \\
\hline CLASP2 & -1.12 & -1.10 & -1.19 & -1.12 & -1.12 \\
\hline FAM86EP & -1.17 & -1.19 & -1.22 & -1.17 & -1.15 \\
\hline PLXNC1 & -1.16 & -1.16 & -1.14 & -1.20 & -1.19 \\
\hline RBM5 & -1.08 & -1.08 & -1.09 & -1.08 & -1.12 \\
\hline SNORD52 & -1.22 & -1.41 & -1.22 & -1.33 & -1.29 \\
\hline TAS2R13 & -1.50 & -1.57 & -1.76 & -2.03 & -2.05 \\
\hline
\end{tabular}

Values represent fold changes of gene expression, $n=3$ experiments. Statistically significant differences were calculated with IBMT regularised paired $t$-test: all genes have $p<0.05$. 
other NDP. These strong differences between NDPs are reflected in the PCA plot showing a unique response of Caco-2 cells to each individual NDP (Figure $3 \mathrm{C}$ ).

Interestingly, genes involved in immune-related processes are amongst the genes whose expression shows significant changes in response to all NDPs (Table 2), such as the 13 genes within the network centred around NFKBIA (Figure 3D). Furthermore, two genes related to $G$ protein-coupled receptors (GPCRs) based signalling (GNA13 and TASR13) and two genes within the cholesterol pathway (HMGCS1 and APOBEC3C) showed significant changes for all NDPs.

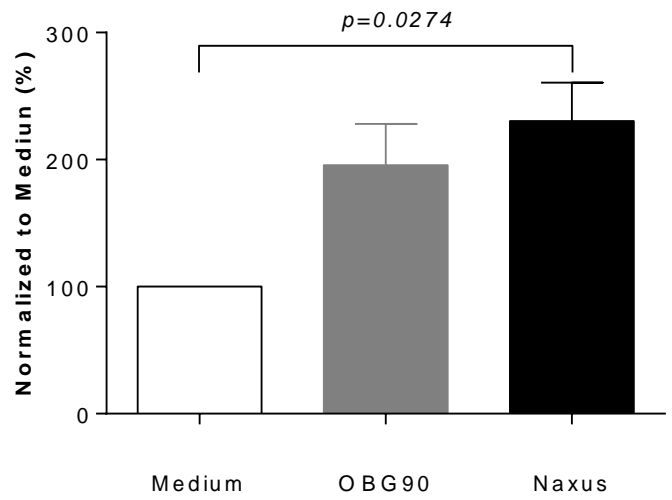

Figure 4. Naxus increases cholesterol uptake but not transport by Caco-2. Transwell grown Caco-2 cells were exposed to OBG9o and Naxus with or without fluorescent labelled cholesterol $(20 \mu \mathrm{g} / \mathrm{ml})$ for $24 \mathrm{~h}$. Cholesterol uptake in cells was normalized to medium control. Bar chart shows mean values + SEM, $\mathrm{n}=$ 3 independent experiments. Statistically significant differences were calculated with one-way ANOVA: *: $p<0.05$.

\subsection{NDPs mediated minor change in expression of cholesterol pathway-related genes in transwell grown Caco-2}

The NDP OBG9o is structurally related to the oat beta-glucan that has demonstrated cholesterol lowering effects in vivo [40]. Based on that knowledge and the observation that two genes related to the cholesterol pathway were identified within the overlap between all NDPs, we set out to detect other differentially regulated genes associated to the cholesterol pathway making use of the IPA software. Significant differentially expressed genes induced by the exposure to at least one NDP, compared to medium control, were listed in table 3. Results indicate that gene expression showed subtle, but significant changes and most differentially regulated genes were found to be upregulated. To analyse how the changes in gene expression induced by the NDPs relate to cholesterol uptake, Caco-2 cells were exposed to OBG9o and Naxus in the presence of fluorescently labelled cholesterol. Both OBG90 and Naxus increased the cholesterol uptake in the enterocytes and following Naxus stimulation we observed a significantly 


\section{Chapter 2}

increased fluorescent signal in the Caco-2 ( $p<0.028$; Figure 4). No significant difference in fluorescent signal was found in the basolateral compartment indicating that the cholesterol was incorporated or utilised by the cells and not excreted, or at least not basolaterally (data not shown).

Table 3. Differential expression of cholesterol-metabolism-related genes.

\begin{tabular}{lllllll}
\hline Gene class & Genes & Wellmu & RG-I & OBG90 & LCES & Naxus \\
\hline Cholesterol & NSDHL & 1.05 & 1.05 & 1.04 & $1.06^{*}$ & $1.08^{*}$ \\
biosynthesis & DHCR24 & $1.06^{*}$ & $1.06^{*}$ & 1.03 & 1.04 & $1.06^{*}$ \\
& EBP & 1.05 & $1.12^{*}$ & $1.11^{*}$ & 1.10 & $1.13^{*}$ \\
& FDFT1 & 1.07 & 1.09 & $1.11^{*}$ & 1.09 & $1.11^{*}$ \\
& GGPS1 & 1.04 & 1.10 & 1.07 & $1.16^{*}$ & 1.08 \\
& HMGCR & $1.10^{*}$ & 1.08 & 1.07 & $1.09^{*}$ & 1.05 \\
& HMGCS1 & $1.07^{*}$ & $1.07^{*}$ & $1.09^{*}$ & $1.09^{*}$ & $1.08^{*}$ \\
& IDI1 & 1.06 & 1.07 & $1.13^{*}$ & 1.08 & $1.15^{*}$ \\
& MSMO1 & $1.16^{*}$ & 1.09 & $1.14^{*}$ & $1.16^{*}$ & $1.17^{*}$ \\
& MVD & 1.07 & $1.13^{*}$ & $1.14^{*}$ & $1.13^{*}$ & $1.12^{*}$ \\
\hline Cholesterol & SC5DL & 1.11 & 1.06 & $1.14^{*}$ & 1.06 & $1.16^{*}$ \\
influx & SQLE & 1.06 & $1.09^{*}$ & 1.05 & $1.09^{*}$ & $1.09^{*}$ \\
\hline HDL related & SCARB1 & $1.08^{*}$ & $1.09^{*}$ & 1.07 & $1.12^{*}$ & $1.08^{*}$ \\
& APOA1 & 1.08 & $1.09^{*}$ & 1.06 & 1.06 & 1.05 \\
\hline Chylomicron & APOD & $1.17^{*}$ & 1.04 & $1.07^{*}$ & 1.03 & 1.05 \\
related & MTTP & $1.12^{*}$ & $1.14^{*}$ & $1.15^{*}$ & 1.07 & $1.18^{*}$ \\
\hline
\end{tabular}

Listed genes are part of the cholesterol biosynthesis pathway as described in IPA and shown significant different expression by at least one NDP exposure compared to medium control. Values represent fold changes of gene expression, $n=3$ experiments. Statistically significant differences were calculated with IBMT regularised paired t-test: *: $p<0.05$.

\subsection{Most strongly differentially regulated genes in response to Naxus and LCES demonstrated a link to immunomodulation}

In order to identify specific effects of NDPs towards transwell-grown Caco-2 cells, the top 10 up and down-regulated genes were studied (Table 4). Besides the genes that demonstrated significant differential expression by all NDPs (among others CYP1A1, CCL20 and ABI3BP; see Table 2), NDPs also show specific changes in gene expression, such as the group of five metallothioneins upregulated specifically by RG-I. From an immunological perspective, the CXCL10, CCL20, BIRC3, CASP1, PTGS2 and CYP1A1 genes 
Table 4. Top 10 up- and down- regulated genes for each NDP.

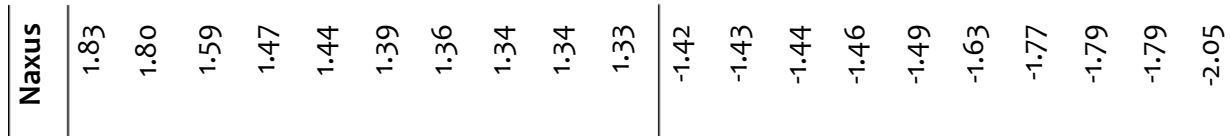

$$
\begin{aligned}
& \text { y }
\end{aligned}
$$

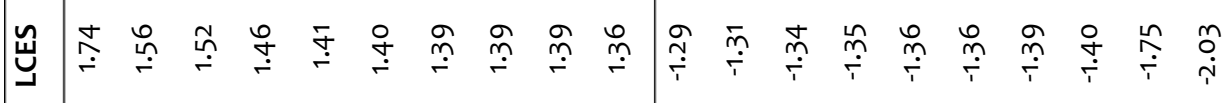

$$
\begin{aligned}
& \text { y } \\
& \text { 悹 }
\end{aligned}
$$

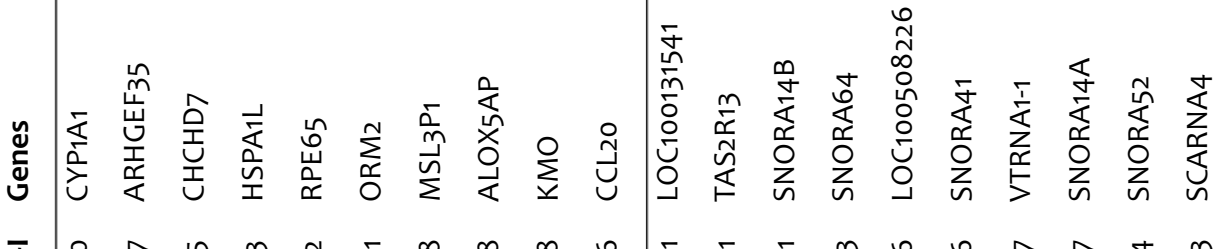

$$
\begin{aligned}
& \text { J }
\end{aligned}
$$

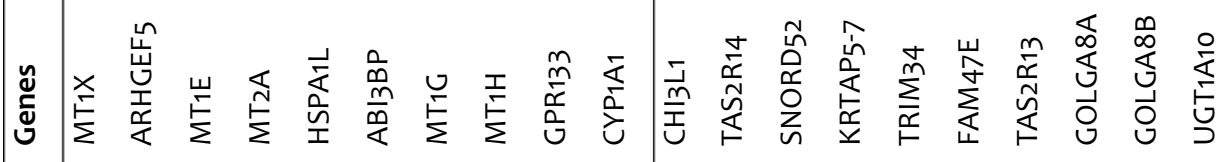

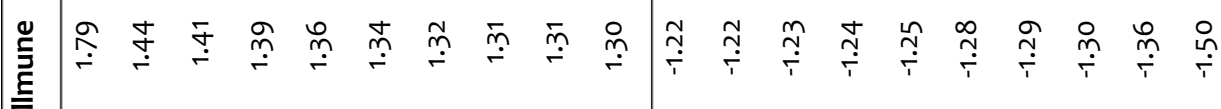

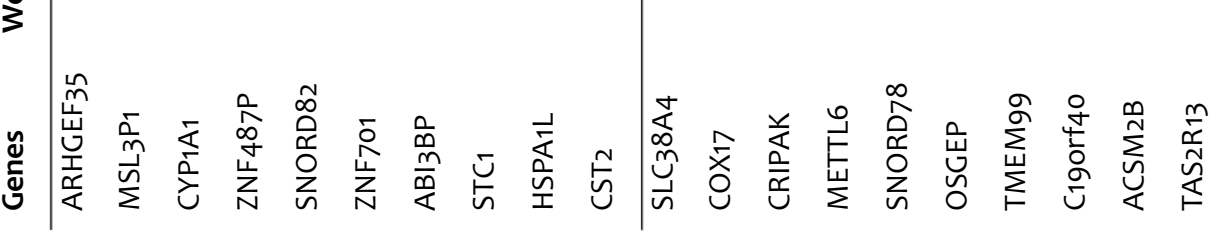

Values represent fold changes of gene expression, $n=3$ experiments. Statistically significant differences were calculated with IBMT regularised paired $t$-test: All genes have $p<0.05$. 


\section{Chapter 2}

are of particular interest. These were all within the top 10 of genes which transcription was significant upregulated by Naxus and transcription of most of them was also significantly upregulated by LCES. These genes are involved in NF-kB signalling (BIRC3 and CASP1), code for chemokines ( $C X C L 10, C C L 20)$, or are involved in the regulation of inflammation processes via prostaglandins (PTGS2 and ALOX5AP).

3.7 NF-kB pathway in transwell-grown Caco-2 is most strongly activated by Naxus and

\section{LCES exposure}

Next, we performed IPA analysis with all significant differentially regulated genes. All NDPs demonstrated to significantly alter gene expression of genes in the NF-kB downstream pathway (Figure 5 and Table 5). LCES (Figure 5D) and Naxus (Figure 5E) again showed the largest number of genes with altered transcription downstream of the NF-kB pathway. In addition, we analysed gene transcription of upstream NF-kB regulators which suggests CD14 and TLR2 might be involved in Naxus or RG-I and OBG90, respectively, mediated NF-kB pathway activation (Table 5 ). The gene transcription of other NF-kB upstream regulators following Naxus stimulation are presented in more detail in figure $5 \mathrm{~F}$. Furthermore, IPA predicted, indicated by $z$-scores above 2 , that NDPs activate the NF-kB complex and REL-associated protein involved in NF-kB heterodimer formation, nuclear translocation and activation (Table 5). G-protein coupled receptors (GPCRs) are suggested to be involved in regulation of NF-kB pathway but are not integrated in the IPA pathways. Since a number of GPCRs were found to be in the top 10 of transcriptionally downregulated genes following Caco-2 exposure to NDPs, we generated an overview including all the GPCRs that revealed significant different expression following at least one NDP exposure (Table 6). This indicated that gene transcription of in particular GPCRs classified as taste receptors were downregulated by the NDPs.

\subsection{Microarray data could partially be confirmed by qPCR and ELISA}

As some of the most relevant changes in gene expression were connected to the NF-kB pathway and downstream effector genes, a validation of these effects was performed. First, transcriptional changes of two chemokine encoding genes, CXCL10 and CCL20, were analysed by $q P C R$. The $\mathrm{qPCR}$ data confirmed that the upregulation of gene expression of CXCL10 and CCL20 by Naxus were both significant (Figure 6A and B). Although both genes were also in the top 10 of LCES, we could only confirm significant increased expression of CCL20 by qPCR.

Subsequently, ELISAs were performed to analyse whether observed changes in gene expression translated to increased protein production and subsequently excreted 


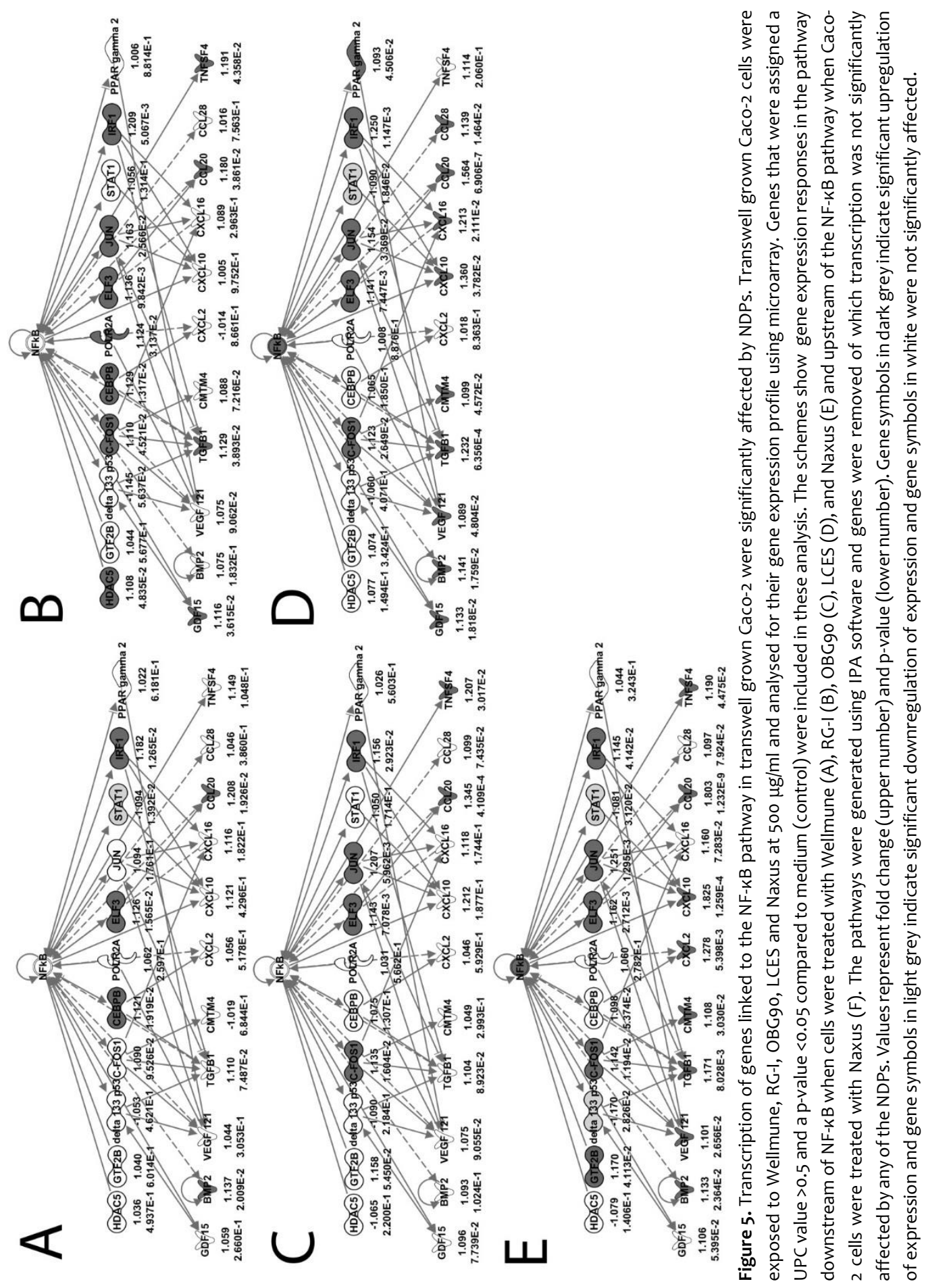




\section{Chapter 2}

Table 5. Differential expression of family members and inhibitor genes related to NF-kB complex following NDP exposure of Caco-2.

\begin{tabular}{|c|c|c|c|c|c|}
\hline Genes & Wellmune & RG-I & OBG90 & LCES & Naxus \\
\hline \multicolumn{6}{|c|}{ Upstream regulators } \\
\hline CD14 & $1.28 *$ & 1.17 & $1.21 *$ & $1.26 *$ & $1.30 *$ \\
\hline ICAM1 & $1.12 *$ & $1.12^{*}$ & $1.15^{*}$ & $1.23^{*}$ & $1.25^{*}$ \\
\hline TLR2 & 1.14 & $1.23^{*}$ & $1.27 *$ & 1.21 & 1.18 \\
\hline EGFR & 1.08 & 1.07 & $1.09 *$ & $1.13^{*}$ & 1.06 \\
\hline ANXA1 & 1.15 & -1.04 & 1.16 & 1.16 & $1.28 *$ \\
\hline CAV1 & 1.17 & $1.22 *$ & $1.21 *$ & $1.46^{*}$ & 1.17 \\
\hline BCAR1 & 1.08 & 1.07 & 1.09 & 1.10 & 1.06 \\
\hline GJA1 & 1.00 & 1.09 & $1.14^{*}$ & -1.01 & 1.02 \\
\hline DLG1 & -1.04 & -1.07 & $-1.10^{*}$ & -1.06 & -1.06 \\
\hline \multicolumn{6}{|c|}{ Transcriptional change } \\
\hline NFKB2 & 1.03 & 1.04 & 1.09 & $1.20 *$ & $1.20 *$ \\
\hline IKBKE & $1.15^{*}$ & $1.19^{*}$ & $1.17^{*}$ & $1.29 *$ & $1.30 *$ \\
\hline IKBIP & 1.11 & $1.24^{*}$ & 1.07 & 1.14 & 1.14 \\
\hline NFKBIA & $1.15^{*}$ & $1.11 *$ & $1.20 *$ & $1.22 *$ & $1.30 *$ \\
\hline NFKBIB & 1.10 & 1.04 & $1.25^{*}$ & 1.13 & $1.17^{*}$ \\
\hline NFKBIE & -1.01 & 1.08 & 1.11 & 1.10 & $1.13^{*}$ \\
\hline \multicolumn{6}{|c|}{ Predicated activation state } \\
\hline EGFR & NA & 1.05 & 1.01 & 1.87 & $2.77 \#$ \\
\hline NFKB complex & $2.61 \#$ & $3.11 \#$ & $2.44 \#$ & $3.09 \#$ & $3.30 \#$ \\
\hline ReLA & $2.22 \#$ & $2.78 \#$ & $2.61 \#$ & $2.79 \#$ & $2.97 \#$ \\
\hline
\end{tabular}

Genes were included when significantly affected in gene expression by one or more NDPs. Values represent fold changes of gene expression, $n=3$ experiments. Statistically significant differences were calculated with IBMT regularised paired $t$-test: *: $p<0.05$. According IPA predication: \#: Z score $>2$, Activated. NA: Not available.

chemokines into the medium. To this end, we analysed CCL20 and CXCL10 protein in medium following exposure of transwell-grown Caco-2 to NDPs for $24 \mathrm{~h}$. Results demonstrated that both LCES and Naxus induced a significant production of CXCL10 when compared to medium stimulated Caco-2 (Figure 6C). However, no significant changes in the medium levels of CCL20 could be observed (Figure 6D). 


\section{Discussion}

Dietary non-digestible polysaccharides have been reported to have many biological effects, including cholesterol lowering and immunomodulatory effects. As these biological effects will partly be exerted through direct interaction with the IEC of the gut, we set out to study direct effects of NDPs towards enterocytes, making up approximately $90 \%$ of all IECS [19] .To this end, five NDP preparations were selected which originated from different sources (yeast, mushroom, oat grain, wheat grain and apple fruit), differed in compositional structure, molecular weight and solubility. The composition of the NDP preparations were in line with commonly reported compositions of such polysaccharide preparations in literature [39, 41-44], except for the MW of Wellmune Soluble which was smaller $(\sim 17 \mathrm{kDa})$ than was previously reported for soluble yeast beta-glucan preparations (i.e. $\sim 150 \mathrm{kDa}$ ) [15]. This is important in comparing results from this research with previous studies as it has been demonstrated that bioactivity of polysaccharides can depend on the structure. For instance, lowering the molecular weight can reduce or abolish bioactivity $[45,46]$.

IEC models like Caco-2 are a promising strategy in the analysis of bioactivity of NDPs as Caco-2 cells can be grown routinely, display many in vivo features of enterocytes and have been shown to respond to different interventions including food compounds. Caco2 cells are used in many labs, resulting in a collection of microarray data that can be systematically exploited to support dedicated enterocyte analysis and the generation of new hypothesis on the relation between food and intestinal function [47]. For research towards the effects of food compounds, such as NPDs, Caco-2 cells have another advantage as they are reasonably tolerant to LPS upon differentiation and polarisation [48]. The sensitivity of Caco-2 cells to LPS, as determined here by studying the threshold for induced expression of major response genes, has been set around $0.1 \mu \mathrm{g} / \mathrm{ml}$. Compared to immune cells such as monocytes and macrophages this makes the Caco-2 cells approximately $1 \times 10^{7}$ times less sensitive [49]. LPS concentrations present in the NDPs used in our exposure experiments most likely do not affect the Caco-2 gene responses directly, although we cannot exclude synergistic effects between LPS and NDPs.

To fully characterize gene transcription responses of Caco-2 to NDPs we performed microarray analysis which provides a broad overview of transcriptional responses. IPAmediated analysis of all significant differentially regulated genes demonstrated a potential role for NF-kB signalling in recognition of NDPs by Caco-2. Our analysis indicated that NDP stimulation of Caco-2 cells significantly upregulated transcription of NF-kB-complex-related genes and upstream regulators and IPA predicted RelA as 

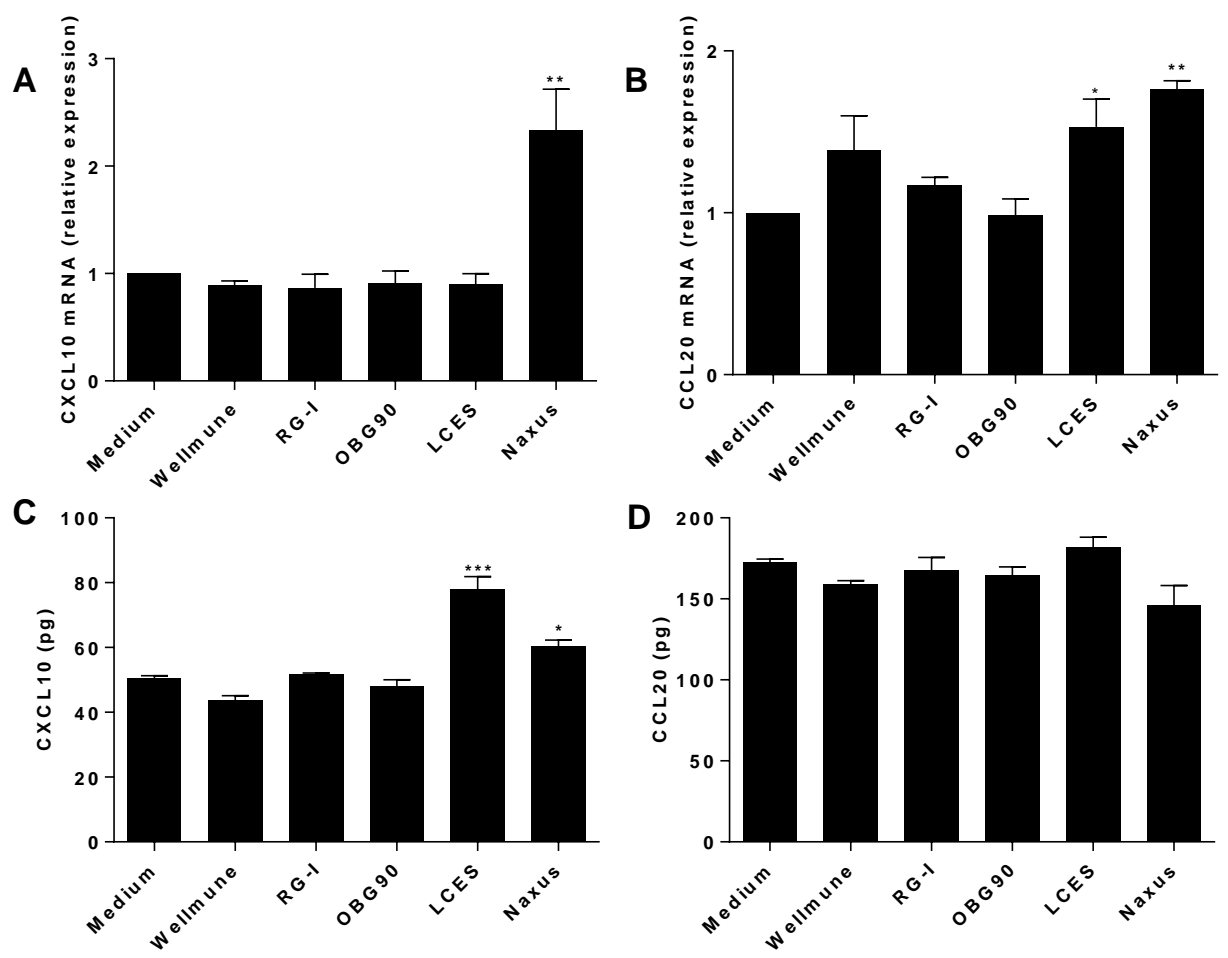

Figure 6. Q-PCR and ELISA validate CXCL10 expression and protein production following Naxus and LCES stimulation of Caco-2. Transwell grown Caco-2 cells were exposed to Wellmune, RG-I, OBG9o, LCES and Naxus at $500 \mu \mathrm{g} / \mathrm{ml}$ for $6 \mathrm{~h}$ and analysed for gene expression by qPCR (A and B) or exposed for $24 \mathrm{~h}$ and analysed for protein level by ELISA ( $C$ and $D$ ). Bar charts represent $(A) C X C L 10$ and $(B) C C L 20$ gene expression are shown as fold change normalized to geometric mean of GAPDH and RPLPo and medium control $(\triangle \Delta C t)$ and (C) CXCL10 and (D) CCL20 protein totals in the medium $24 \mathrm{~h}$ after exposure. Protein analysis was performed on a mixture of apical and basolateral medium and corrected for combined medium volumes to yield a total protein amount. Bar chart shows mean values + SEM, $n=3$ independent experiments. Statistically significant differences were calculated with one-way ANOVA: *: $p<0.05 ; * *$ : $p<0.01 ; * * *$ : $p<0.001$.

activated upstream regulator. This is in line with previous findings for enterocytes [50, 51] and other immune cells [52] including in vivo and in vitro studies [53-55].

We also observed enhanced transcription of TLR2 and CD14, which are known upstream activators of NF-KB [50]. This supports previous studies that identified TLR2 as receptor for other NDPs $[56,57]$. Besides, we also observed upregulation of CYP1A1, a key enzyme in elimination and detoxification of compounds in different cell types, which has been shown to be under control of TLR2 activation [58]. This TLR2 receptor and co-receptor 
CD14 have been found to work together in pathogen recognition and innate defence response against bacterial pathogens like Yersinia spp, Listeria and Rickettsia akari [59] and are important for proper immune function [60]. This would be in line with the hypothesis that some NPSs can activate the innate defence responses similar as pathogens.

The NF-kB complex controls, amongst a number of functions, the production of cytokines and chemokines such as CXCL10 and CCL20. Gene expression of these signalling molecules was upregulated by Naxus and LCES.

Table 6. Differential expression of GPCRs following NDP exposure of Caco-2

\begin{tabular}{llllll}
\hline Genes & Wellmune & RG-I & OBG90 & LCES & Naxus \\
\hline GPR108 & 1.07 & 1.06 & 1.08 & 1.08 & $1.10^{*}$ \\
GPR114 & 1.13 & $1.15^{*}$ & 1.09 & 1.09 & 1.09 \\
GPR133 & 1.18 & $1.28 *$ & $1.21 *$ & 1.13 & 1.14 \\
GPR160 & $1.15^{*}$ & 1.05 & 1.12 & 1.08 & 1.09 \\
TAS2R13 & $-1.50 *$ & $-1.57^{*}$ & $-1.76 *$ & $-2.03 *$ & $-2.05^{*}$ \\
TAS2R14 & -1.25 & $-1.41 *$ & $-1.38 *$ & -1.20 & $-1.39 *$ \\
TAS2R19 & -1.31 & -1.32 & $-1.38 *$ & -1.33 & $-1.46 *$ \\
TAS2R20 & -1.15 & -1.27 & -1.30 & -1.27 & -1.42 \\
TAS2R3 & -1.15 & $-1.35^{*}$ & $-1.42 *$ & -1.30 & -1.27 \\
TAS2R31 & -1.14 & -1.27 & -1.26 & $-1.36 *$ & $-1.40 *$ \\
TAS2R4 & -1.21 & -1.27 & $-1.41^{*}$ & $-1.30 *$ & $-1.42 *$ \\
TAS2R50 & -1.15 & -1.27 & -1.22 & -1.24 & $-1.38 *$ \\
\hline
\end{tabular}

Genes were included when significantly affected in gene expression by one or more NDPs. Values represent fold changes of gene expression, $n=3$ experiments. Statistically significant differences were calculated with IBMT regularised paired $t$-test: *: $p<0.05$.

Further analysis demonstrated that $\mathrm{CXCL} 10$ protein secretion was also increased following Naxus and LCES stimulation of Caco-2, in contrast to CCL20. CXCL10 production by Caco-2 cells was previously reported in response to stimulation with various mixtures of pro-inflammatory cytokines [61]. CXCL10 was demonstrated to control intestinal epithelial cell movement together with IL-13 [62] and, together with $\mathrm{CXCR}_{3}$, held responsible for recruiting $C X C R 3$-positive immune cells in inflammatory bowel disease [63]. It remains to be proven whether observed significant changes in gene transcription of, for instance, ICAM-1 also contributes to attraction of immune cells as these have shown to be involved in adhesion of activated T cells [64]. This potential stimulation of immune cell migration by intestinal enterocytes following exposure to NDPs is 


\section{Chapter 2}

supported by previous results for $1,3 / 1,6-\beta$-glucan from baker's yeast that has been shown to increase the number of intraepithelial lymphocytes in the intestine in $\mathrm{C} 57 \mathrm{BL} / 6$ mice [65].

NDPs are known for their capability to bind compounds like proteins, cholesterol, bile acids, fatty acids, and phytochemicals [66-68]. Interestingly, we found that NDPs reduced FD4 translocation without changing monolayer integrity, but only when NDPs and FD4 were present in the medium simultaneously. Pre-incubation with NDPs had no effect on FD4 translocation suggesting that exposure to NDPs did not change active paracellular transport of Caco-2 but that a direct physical interaction between NDPs and FD4 is preventing translocation. In addition, NDPs increased gene transcription of genes involved in the cholesterol biosynthesis pathway and uptake of cholesterol from medium. Those results indicate that NDPs induce cellular cholesterol levels potentially leading to changed characteristics of cell membranes [69]. The induction of cholesterol related genes was found for all NDPs, but most strongly for LCES, Naxus and OBG90. Oral administration of oat $\beta$-glucan was shown to support maintenance of normal [70] and reduction of blood cholesterol levels [71] by a proposed direct binding of bile acids in the lumen and thereby increased faecal excretion [72]. Arabinoxylans from wheat bran also have been shown to reduce total plasma cholesterol and LDL cholesterol concentrations in hamsters [73]. Our results suggest that a cellular mechanism of intestinal cells might contribute to this cholesterol lowering effects of NDPs in vivo.

In this study, we have attempted to characterize NDPs through their stimulation of enterocytes. We performed gene expression profiling in combination with dedicated functional assays such as analysis of barrier integrity, translocation, cholesterol regulation and chemokine production. The results demonstrated strong differences in Caco-2 responses to the various NDPs, indicating that these analyses discriminate between functional activities of the NDPs. The next step in research to characterize the bioactivity of these NDPs should be human intervention studies to couple our in vitro data to in vivo. Cholesterol lowering effects, which are relatively easy to study and for which trial design and biomarkers are validated, can be expected for some of these NDPs. Besides, the immune modulatory effects could be studied by vaccination efficacy studies and blood cellular parameters.

Y.T., C.G., J.J.M. and H.J.W. conceived and designed the experiments. Y.T., C.G., S.L.G, A.R., S.H.K, M.M.M.T. performed the experiments. Y.T., C.G. N.d.W., S.L.G., L.S., A.R., S.H.K. and J.J.M. analyzed the data. Y.T., C.G., J.J.M. and H.J.W. wrote the manuscript.

The authors have declared no conflicts of interest. 


\section{References}

1. Ferreira, S.S., C.P. Passos, P. Madureira, M. Vilanova, and M.A. Coimbra, Structure-function relationships of immunostimulatory polysaccharides: A review. Carbohydr Polym, 2015. 132: p. 378-396.

2. Xie, J.H., M.L. Jin, G.A. Morris, X.Q. Zha, H.Q. Chen, Y. Yi, J.E. Li, Z.J. Wang, J. Gao, S.P. Nie, P. Shang, and M.Y. Xie, Advances on Bioactive Polysaccharides from Medicinal Plants. Critical Reviews in Food Science and Nutrition, 2015: p. 0.

3. Tungland, B.C. and D. Meyer Nondigestible Oligo- and Polysaccharides (Dietary Fiber) Their Physiology and Role in Human Health and Food, Comprehensive Reviews in Food Science and Food Safety Volume 1, Issue 3. Comprehensive Reviews in Food Science and Food Safety, 2002. 1, 90-109.

4. Eshak, E.S., H. Iso, C. Date, S. Kikuchi, Y. Watanabe, Y. Wada, K. Wakai, A. Tamakoshi, and J.S. Group, Dietary fiber intake is associated with reduced risk of mortality from cardiovascular disease among Japanese men and women. J Nutr, 2010. 140(8): p. 1445-1453.

5. Peters, U., R. Sinha, N. Chatterjee, A.F. Subar, R.G. Ziegler, M. Kulldorff, R. Bresalier, J.L. Weissfeld, A. Flood, A. Schatzkin, R.B. Hayes, L.C. Prostate, and T. Ovarian Cancer Screening Trial Project, Dietary fibre and colorectal adenoma in a colorectal cancer early detection programme. Lancet, 2003. 361(9368): p. 1491-1495.

6. Ben, Q., Y. Sun, R. Chai, A. Qian, B. Xu, and Y. Yuan, Dietary fiber intake reduces risk for colorectal adenoma: a meta-analysis. Gastroenterology, 2014. 146(3): p. 689-699 e686.

7. Othman, R.A., M.H. Moghadasian, and P.J. Jones, Cholesterol-lowering effects of oat betaglucan. Nutr Rev, 2011. 69(6): p. 299-309.

8. Brockman, D.A., X. Chen, and D.D. Gallaher, Consumption of a high beta-glucan barley flour improves glucose control and fatty liver and increases muscle acylcarnitines in the Zucker diabetic fatty rat. Eur J Nutr, 2013. 52(7): p. 1743-1753.

9. Lehne, G., B. Haneberg, P. Gaustad, P.W. Johansen, H. Preus, and T.G. Abrahamsen, Oral administration of a new soluble branched beta-1,3-D-glucan is well tolerated and can lead to increased salivary concentrations of immunoglobulin $A$ in healthy volunteers. Clin Exp Immunol, 2006. 143(1): p. 65-69.

10. Kohl, A., O. Gogebakan, M. Mohlig, M. Osterhoff, F. Isken, A.F. Pfeiffer, and M.O. Weickert, Increased interleukin-10 but unchanged insulin sensitivity after 4 weeks of $(1,3)(1,6)$-betaglycan consumption in overweight humans. Nutr Res, 2009. 29(4): p. 248-254.

11. Chen, Y.W., D.J. Hu, K.L. Cheong, J. Li, J. Xie, J. Zhao, and S.P. Li, Quality evaluation of lentinan injection produced in China. J Pharm Biomed Anal, 2013. 78-79: p. 176-182.

12. Ananthakrishnan, A.N., H. Khalili, G.G. Konijeti, L.M. Higuchi, P. de Silva, J.R. Korzenik, C.S. Fuchs, W.C. Willett, J.M. Richter, and A.T. Chan, A prospective study of long-term intake of dietary fiber and risk of Crohn's disease and ulcerative colitis. Gastroenterology, 2013. 145(5): p. $970-977$.

13. Taylor, P.R., S.V. Tsoni, J.A. Willment, K.M. Dennehy, M. Rosas, H. Findon, K. Haynes, C. Steele, M. Botto, S. Gordon, and G.D. Brown, Dectin-1 is required for beta-glucan recognition and control of fungal infection. Nat Immunol, 2007. 8(1): p. 31-38.

14. Sahasrabudhe, N.M., H.A. Schols, M.M. Faas, and P. de Vos, Arabinoxylan activates Dectin-1 and modulates particulate beta-glucan-induced Dectin-1 activation. Mol Nutr Food Res, 2016. 60(2): p. 458-467.

15. Bose, N., A.S. Chan, F. Guerrero, C.M. Maristany, X. Qiu, R.M. Walsh, K.E. Ertelt, A.B. Jonas, K.B. Gorden, C.M. Dudney, L.R. Wurst, M.E. Danielson, N. Elmasry, A.S. Magee, M.L. Patchen, and J.P. Vasilakos, Binding of Soluble Yeast beta-Glucan to Human Neutrophils and Monocytes is Complement-Dependent. Front Immunol, 2013. 4: p. 230. 


\section{Chapter 2}

16. Goodridge, H.S., A.J. Wolf, and D.M. Underhill, Beta-glucan recognition by the innate immune system. Immunol Rev, 2009. 230(1): p. 38-50.

17. Murphy, E.A., J.M. Davis, and M.D. Carmichael, Immune modulating effects of beta-glucan. Curr Opin Clin Nutr Metab Care, 2010. 13(6): p. 656-661.

18. Tang, Y., C. Govers, H.J. Wichers, and J.J. Mes, Macrophages treated with non-digestible polysaccharides reveal a transcriptionally unique phenotype. Journal of Functional Foods, 2017. 36: p. 280-289.

19. Umar, S., Intestinal stem cells. Curr Gastroenterol Rep, 2010. 12(5): p. 340-348.

20. Engle, M.J., G.S. Goetz, and D.H. Alpers, Caco-2 cells express a combination of colonocyte and enterocyte phenotypes. J Cell Physiol, 1998. 174(3): p. 362-369.

21. Cario, E., G. Gerken, and D.K. Podolsky, Toll-like receptor 2 controls mucosal inflammation by regulating epithelial barrier function. Gastroenterology, 2007. 132(4): p. 1359-1374.

22. Kingma, S.D., N. Li, F. Sun, R.B. Valladares, J. Neu, and G.L. Lorca, Lactobacillus johnsonii N6.2 stimulates the innate immune response through Toll-like receptor 9 in Caco-2 cells and increases intestinal crypt Paneth cell number in biobreeding diabetes-prone rats. J Nutr, 2011. 141(6): p. 1023-1028.

23. Kim, B., Y. Park, C.J. Wegner, B.W. Bolling, and J. Lee, Polyphenol-rich black chokeberry (Aronia melanocarpa) extract regulates the expression of genes critical for intestinal cholesterol flux in Caco-2 cells. J Nutr Biochem, 2013. 24(9): p. 1564-1570.

24. Cammisotto, P.G., M. Bendayan, and E. Levy, Regulation of leptin receptor expression in human polarized Caco-2/15 cells. Endocr Metab Immune Disord Drug Targets, 2012. 12(1): p. 5770.

25. Bothe, H., K. Gassmann, C. Gotz, E. Fritsche, J. Abel, and T. Haarmann-Stemmann, Epigallocatechin-3-gallate does not affect the activity of enzymes involved in metabolic activation and cellular excretion of benzo[a]pyrene in human colon carcinoma cells. Toxicol Lett, 2011. 203(3): p. 258-264.

26. Li, Y., S. Innocentin, D.R. Withers, N.A. Roberts, A.R. Gallagher, E.F. Grigorieva, C. Wilhelm, and $M$. Veldhoen, Exogenous stimuli maintain intraepithelial lymphocytes via aryl hydrocarbon receptor activation. Cell, 2011. 147(3): p. 629-640.

27. Veldhoen, M. and V. Brucklacher-Waldert, Dietary influences on intestinal immunity. Nat Rev Immunol, 2012. 12(10): p. 696-708.

28. Wolever, T.M., S.M. Tosh, A.L. Gibbs, J. Brand-Miller, A.M. Duncan, V. Hart, B. Lamarche, B.A. Thomson, R. Duss, and P.J. Wood, Physicochemical properties of oat beta-glucan influence its ability to reduce serum LDL cholesterol in humans: a randomized clinical trial. Am J Clin Nutr, 2010. 92(4): p. 723-732.

29. Englyst, H.N. and J.H. Cummings, Improved method for measurement of dietary fiber as nonstarch polysaccharides in plant foods. J Assoc Off Anal Chem, 1988. 71(4): p. 808-814.

30. Blakeney, A.B., P.J. Harris, R.J. Henry, and B.A. Stone, A Simple and Rapid Preparation of Alditol Acetates for Monosaccharide Analysis. Carbohydrate Research, 1983. 113(2): p. 291-299.

31. Englyst, H.N., M.E. Quigley, and G.J. Hudson, Determination of Dietary Fiber as Nonstarch Polysaccharides with Gas-Liquid-Chromatographic, High-Performance LiquidChromatographic or Spectrophotometric Measurement of Constituent Sugars. Analyst, 1994. 119(7): p. 1497-1509.

32. Anumula, K.R. and P.B. Taylor, A comprehensive procedure for preparation of partially methylated alditol acetates from glycoprotein carbohydrates. Anal Biochem, 1992. 203(1): p. 101-108.

33. McCleary, B.V., T.S. Gibson, and D.C. Mugford, Measurement of total starch in cereal products by amyloglucosidase-alpha-amylase method: Collaborative study. Journal of AOAC International, 1997. 80(3): p. 571-579. 
34. Bastiaan-Net, S., W. Chanput, A. Hertz, R.D. Zwittink, J.J. Mes, and H.J. Wichers, Biochemical and functional characterization of recombinant fungal immunomodulatory proteins (rFIPs). Int Immunopharmacol, 2013. 15(1): p. 167-175.

35. Mee, C.J., J. Grove, H.J. Harris, K. Hu, P. Balfe, and J.A. McKeating, Effect of cell polarization on hepatitis C virus entry. Journal of Virology, 2008. 82(1): p. 461-470.

36. Vreeburg, R.A., S. Bastiaan-Net, and J.J. Mes, Normalization genes for quantitative RT-PCR in differentiated Caco-2 cells used for food exposure studies. Food Funct, 2011. 2(2): p. 124-129.

37. Gentleman, R.C., V.J. Carey, D.M. Bates, B. Bolstad, M. Dettling, S. Dudoit, B. Ellis, L. Gautier, Y. Ge, J. Gentry, K. Hornik, T. Hothorn, W. Huber, S. lacus, R. Irizarry, F. Leisch, C. Li, M. Maechler, A.J. Rossini, G. Sawitzki, C. Smith, G. Smyth, L. Tierney, J.Y. Yang, and J. Zhang, Bioconductor: open software development for computational biology and bioinformatics. Genome Biol, 2004. 5(10): p. R80.

38. Piccolo, S.R., M.R. Withers, O.E. Francis, A.H. Bild, and W.E. Johnson, Multiplatform singlesample estimates of transcriptional activation. Proc Natl Acad Sci U S A, 2013. 110(44): p. 1777817783.

39. Saulnier, L., F. Guillon, and A.L. Chateigner-Boutin, Cell wall deposition and metabolism in wheat grain. J Cereal Sci, 2012. 56(1): p. 91-108.

40. Efsa Panel on Dietetic Products, N. and Allergies, Scientific Opinion on the substantiation of a health claim related to oat beta glucan and lowering blood cholesterol and reduced risk of (coronary) heart disease pursuant to Article 14 of Regulation (EC) No 1924/2006. EFSA Journal, 2010. 8(12): p. 1885-1900.

41. Wood, P.J., Cereal beta-glucans in diet and health. J Cereal Sci, 2007. 46(3): p. 230-238.

42. Maji, P.K., I.K. Sen, B. Behera, T.K. Maiti, P. Mallick, S.R. Sikdar, and S.S. Islam, Structural characterization and study of immunoenhancing properties of a glucan isolated from a hybrid mushroom of Pleurotus florida and Lentinula edodes. Carbohydr Res, 2012. 358: p. 110115.

43. Schols, H.A., M.A. Posthumus, and A.G.J. Voragen, Structural Features of Hairy Regions of Pectins Isolated from Apple Juice Produced by the Liquefaction Process. Carbohydrate Research, 1990. 206(1): p. 117-129.

44. Renard, C.M.G.C., H.A. Schols, A.G.J. Voragen, J.F. Thibault, and W. Pilnik, Studies on Apple Protopectin .3. Characterization of the Material Extracted by Pure Polysaccharidases from Apple Cell-Walls. Carbohydr Polym, 1991. 15(1): p. 13-32.

45. Kojima, T., K. Tabata, W. Itoh, and T. Yanaki, Molecular-Weight Dependence of the AntitumorActivity of Schizophyllan. Agricultural and Biological Chemistry, 1986. 50(1): p. 231-232.

46. Blaschek, W., J. Kasbauer, J. Kraus, and G. Franz, Pythium aphanidermatum: culture, cell-wall composition, and isolation and structure of antitumour storage and solubilised cell-wall (1--3),(1---6)-beta-D-glucans. Carbohydr Res, 1992. 231: p. 293-307.

47. Venkatasubramanian, P.B., G. Toydemir, N. de Wit, E. Saccenti, V.A.P. Martins Dos Santos, P. van Baarlen, J.M. Wells, M. Suarez-Diez, and J.J. Mes, Use of Microarray Datasets to generate Caco-2-dedicated Networks and to identify Reporter Genes of Specific Pathway Activity. Scientific Reports, 2017. 7(1): p. 6778.

48. Savidge, T.C., P.G. Newman, W.H. Pan, M.Q. Weng, H.N. Shi, B.A. McCormick, A. Quaroni, and W.A. Walker, Lipopolysaccharide-induced human enterocyte tolerance to cytokine-mediated interleukin-8 production may occur independently of TLR-4/MD-2 signaling. Pediatr Res, 2006. 59(1): p. 89-95.

49. Teodorowicz, M., O. Perdijk, I. Verhoek, C. Govers, H.F. Savelkoul, Y. Tang, H. Wichers, and K. Broersen, Optimized Triton X-114 assisted lipopolysaccharide (LPS) removal method reveals the immunomodulatory effect of food proteins. PloS One, 2017. 12(3): p. e0173778. 


\section{Chapter 2}

50. Lee, B.C., M.S. Kim, S.H. Choi, and T.S. Kim, Involvement of capsular polysaccharide via a TLR2/NF-kappaB pathway in Vibrio vulnificus-induced IL-8 secretion of human intestinal epithelial cells. International Journal of Molecular Medicine, 2010. 25(4): p. 581-591.

51. Ortega-Gonzalez, M., B. Ocon, I. Romero-Calvo, A. Anzola, E. Guadix, A. Zarzuelo, M.D. Suarez, F. Sanchez de Medina, and O. Martinez-Augustin, Nondigestible oligosaccharides exert nonprebiotic effects on intestinal epithelial cells enhancing the immune response via activation of TLR4-NFkappaB. Mol Nutr Food Res, 2014. 58(2): p. 384-393.

52. Choi, H., R.H. Lee, N. Bazhanov, J.Y. Oh, and D.J. Prockop, Anti-inflammatory protein TSG-6 secreted by activated MSCs attenuates zymosan-induced mouse peritonitis by decreasing TLR2/NF-kappaB signaling in resident macrophages. Blood, 2011. 118(2): p. 330-338.

53. Balachandran, P., N.D. Pugh, G. Ma, and D.S. Pasco, Toll-like receptor 2-dependent activation of monocytes by Spirulina polysaccharide and its immune enhancing action in mice. Int Immunopharmacol, 2006. 6(12): p. 1808-1814.

54. Won, D.P., J.S. Lee, D.S. Kwon, K.E. Lee, W.C. Shin, and E.K. Hong, Immunostimulating activity by polysaccharides isolated from fruiting body of Inonotus obliquus. Mol Cells, 2011. 31(2): p. 165-173.

55. Zhang, X., R. Ding, Y. Zhou, R. Zhu, W. Liu, L. Jin, W. Yao, and X. Gao, Toll-like receptor 2 and Toll-like receptor 4-dependent activation of $B$ cells by a polysaccharide from marine fungus Phoma herbarum YS4108. PLoS One, 2013. 8(3): p. e60781.

56. Vogt, L., U. Ramasamy, D. Meyer, G. Pullens, K. Venema, M.M. Faas, H.A. Schols, and P. de Vos, Immune Modulation by Different Types of beta $2 \rightarrow$ 1-Fructans Is Toll-Like Receptor Dependent. PLoS One, 2013. 8(7).

57. Vogt, L.M., D. Meyer, G. Pullens, M.M. Faas, K. Venema, U. Ramasamy, H.A. Schols, and P. de Vos, Toll-Like Receptor 2 Activation by beta 2 -> 1-Fructans Protects Barrier Function of T84 Human Intestinal Epithelial Cells in a Chain Length-Dependent Manner. Journal of Nutrition, 2014. 144(7): p. 1002-1008.

58. Do, K.N., L.N. Fink, T.E. Jensen, L. Gautier, and A. Parlesak, TLR2 controls intestinal carcinogen detoxication by CYP1A1. PLoS One, 2012. 7(3): p. e32309.

59. Sing, A., D. Rost, N. Tvardovskaia, A. Roggenkamp, A. Wiedemann, C.J. Kirschning, M. Aepfelbacher, and J. Heesemann, Yersinia V-antigen exploits toll-like receptor 2 and CD14 for interleukin 10-mediated immunosuppression. Journal of Experimental Medicine, 2002. 196(8): p. 1017-1024.

60. Zhang, Z.Y., Z. Zhang, and H.J. Schluesener, Toll-like receptor-2, CD14 and heat-shock protein 70 in inflammatory lesions of rat experimental autoimmune neuritis. Neuroscience, 2009. 159(1): p. 136-142.

61. Zingg, U., D. Miskovic, I. Pasternak, P. Meyer, C.T. Hamel, and U. Metzger, Effect of bisacodyl on postoperative bowel motility in elective colorectal surgery: a prospective, randomized trial. International Journal of Colorectal Disease, 2008. 23(12): p. 1175-1183.

62. Cliffe, L.J., N.E. Humphreys, T.E. Lane, C.S. Potten, C. Booth, and R.K. Grencis, Accelerated intestinal epithelial cell turnover: a new mechanism of parasite expulsion. Science, 2005. 308(5727): p. 1463-1465.

63. Nishimura, M., Y. Kuboi, K. Muramoto, T. Kawano, and T. Imai, Chemokines as novel therapeutic targets for inflammatory bowel disease. Ann N Y Acad Sci, 2009. 1173: p. 350-356.

64. Kaiserlian, D., D. Rigal, J. Abello, and J.P. Revillard, Expression, function and regulation of the intercellular adhesion molecule-1 (ICAM-1) on human intestinal epithelial cell lines. Eur $J$ Immunol, 1991. 21(10): p. 2415-2421.

65. Tsukada, C., H. Yokoyama, C. Miyaji, Y. Ishimoto, H. Kawamura, and T. Abo, Immunopotentiation of intraepithelial lymphocytes in the intestine by oral administrations of beta-glucan. Cellular Immunology, 2003. 221(1): p. 1-5. 
66. Ebihara, K. and B.O. Schneeman, Interaction of bile acids, phospholipids, cholesterol and triglyceride with dietary fibers in the small intestine of rats. J Nutr, 1989. 119(8): p. 1100-1106.

67. Camire, M.E. and M.P. Dougherty, Raisin dietary fiber composition and in vitro bile acid binding. J Agric Food Chem, 2003. 51(3): p. 834-837.

68. Palafox-Carlos, H., J.F. Ayala-Zavala, and G.A. Gonzalez-Aguilar, The role of dietary fiber in the bioaccessibility and bioavailability of fruit and vegetable antioxidants. J Food Sci, 2011. 76(1): p. R6-R15.

69. Yang, S.T., A.J. Kreutzberger, J. Lee, V. Kiessling, and L.K. Tamm, The role of cholesterol in membrane fusion. Chemistry and Physics of Lipids, 2016. 199: p. 136-143.

70. Efsa Panel on Dietetic Products, N. and Allergies, Scientific Opinion on the substantiation of health claims related to beta-glucans from oats and barley and maintenance of normal blood LDL-cholesterol concentrations (ID 1236, 1299), increase in satiety leading to a reduction in energy intake (ID 851, 852), reduction of post-prandial glycaemic responses (ID 821, 824), and "digestive function" (ID 850) pursuant to Article 13(1) of Regulation (EC) No 1924/2006. EFSA Journal, 2011. 9(6): p. 2207-2228.

71. Efsa Panel on Dietetic Products, N. and Allergies, Scientific Opinion on the substantiation of a health claim related to barley beta-glucans and lowering of blood cholesterol and reduced risk of (coronary) heart disease pursuant to Article 14 of Regulation (EC) No 1924/2006. EFSA Journal, 2011. 9(12): p. 2470-2484.

72. Drzikova, B., G. Dongowski, E. Gebhardt, and A. Habel, The composition of dietary fibre-rich extrudates from oat affects bile acid binding and fermentation in vitro. Food Chemistry, 2005. 90(1-2): p. 181-192.

73. Tong, L.T., K. Zhong, L. Liu, J. Qiu, L. Guo, X. Zhou, L. Cao, and S. Zhou, Effects of dietary wheat bran arabinoxylans on cholesterol metabolism of hypercholesterolemic hamsters. Carbohydr Polym, 2014. 112: p. 1-5. 


\section{Chapter 2}

Supplementary Table 1. Primer details

\begin{tabular}{llll}
\hline Genes & Forward (5'-3') & Reverse (5'-3') & Accession \\
\hline GAPDH & TGCACCACCAACTGCTTAGC & GGCATGGACTGTGGTCATGAG & NM_002046 \\
RPLPo & GCAATGTTGCCAGTGTCTG & GCCTTGACCTTTTCAGCAA & NM_001002.3 \\
IL8 & CTGATTTCTGCAGCTCTGTG & GGGTGGAAAGGTTTGGAGTATG & NM_000584.2 \\
IL1 $\beta$ & GTGGCAATGAGGATGACTTGTTC & TAGTGGTGGTCGGAGATTCGTA & NM_000576.2 \\
NFKB & TGAGTCCTGCTCCTTCCA & GCTTCGGTGTAGCCCATT & NM_003998.2 \\
CCL20 & TGCTGTACCAAGAGTTTGCTC & CGCACACAGACAACTTTTTCTTT & NM_004591 \\
CXCL10 & GTGGCATTCAAGGAGTACCTC & TGATGGCCTTCGATTCTGGATT & NM_001565 \\
\hline
\end{tabular}

a Gene accession number refer to the sequence on which the primer design was based. 


\section{Chapter 3}

\section{Macrophages treated with non-digestible polysaccharides reveal a transcriptionally unique phenotype}

Yongfu Tang*, Coen Govers ${ }^{*}$, Harry J. Wichers, Jurriaan J. Mes

*These authors contributed equally to this work. Journal of functional foods, 2017 (36): 280-289 


\section{Chapter 3}

\section{Abstract}

Dietary non-digestible polysaccharides (NDPs) might promote intestinal health via immuno-modulation. Immunomodulatory effects of NDP are most likely brought about by antigen processing cells such as macrophages that populate the intestine, although the mechanisms are still poorly understood. We validated the in vitro model of M1 and M2 macrophages to mimic the intestinal inflammatory and tolerant macrophages using literature and microarray-derived gene markers. All these markers were used to characterise the macrophage phenotype following NDP stimulation. This identified an alternative subset, termed MNDP, which commonly modulated a set of 126 genes, involved in migration, metabolic processes, cell cycle, and inflammatory immune function. This gene-based analysis for macrophage subsets provides an additional tool to characterise NDP bioactivity for their in vivo potential.

Keywords: Arabinoxylan; $\beta$-Glucans; Intestinal immunity; Macrophage polarisation; Gene expression markers

Abbreviations: CLRs, C-type lectin receptors; GO-BP, gene ontology - biological process; IECs, intestinal epithelial cells; LCES, lentinan containing extracted from shiitake; $\mathbf{M}_{\mathrm{NDP}}$, NDP specific macrophage subset; NDP, non-digestible polysaccharide; PCA, principal component analysis; PRRs, pattern recognition receptors; TLRs, toll-like receptors;

\section{Graphical abstract:}
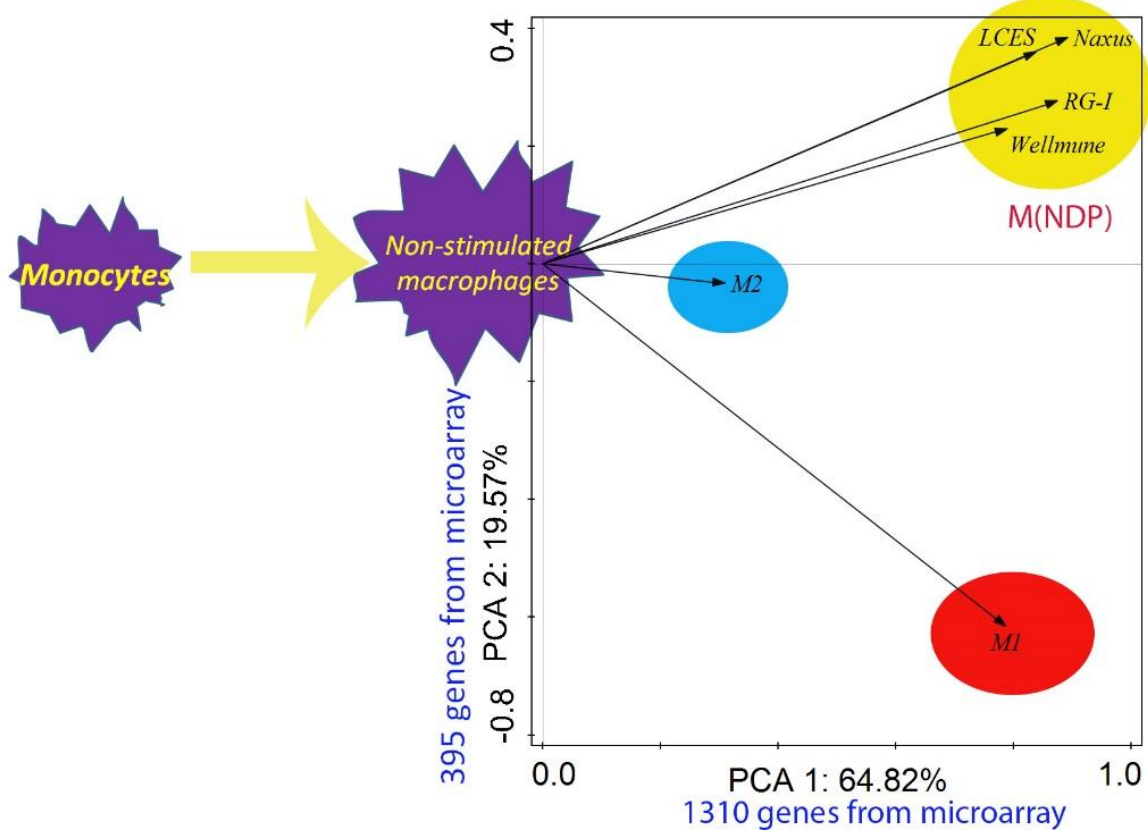


\section{Introduction}

Dietary non-digestible polysaccharides (NDPs), amongst which glucans [1], pectin [2], arabinoxylan [3], inulin [4], and resistant starch [5] are described to possess immune modulatory activity. NDPs have been shown to trigger innate immune responses by activating antigen processing cells of the intestinal immune system [6] and to increase the regulatory $\mathrm{T}$ cell population in the intestine and tip the balance towards an antiinflammatory phenotype [7]. The mechanism behind this is of great interest and only partially understood. Also, NDPs have demonstrated to directly interact with the microbiota and gut epithelium. Fermentation of NDPs by intestinal microbiota results in changes of microbiota composition and short chain fatty acid production in both the cecum [8] and the colon [9]. We and others found that NDPs were also able to directly interact with intestinal epithelial cells. NDPs have been demonstrated to increase cytokine and chemokine gene expression and protein production in Caco-2 cells [10], illustrating that NDPs might modulate immune responses via the intestinal epithelial cells.

Since a large amount of macrophages are to be found in the intestine [11], these cells likely are important in maintaining homeostasis. Within these intestinal macrophage population tolerant and inflammatory subsets have been described [12]. Tolerant macrophages are the main subset found in homeostasis. They have a low turnover and are located underneath the submucosal region in close proximity to $C_{4} \mathrm{~T}$ cell populations [13] and are sustained by stromal cues [14]. These cells lack expression of CD14, TLR2, CCR2 and MHC class II and production of TNFa [15], but demonstrate phagocytic and bactericidal activity [14], produce IL-10 and balance T cell differentiation away from Th17 cells towards a regulatory $T$ cell phenotype [13]. Inflammatory macrophages appear to be absent under homeostatic conditions but are rapidly recruited in large numbers upon infection following CCR2-dependent monocyte migration and differentiation [16]. These macrophages have a high rate of turnover and express various pattern recognition receptors and produce TNFa and multiple other proinflammatory cytokines $[17,18]$. Both subsets were found to be able to directly sample the luminal content by extending protrusions between epithelial cells in a $C_{3} \mathrm{CR}_{1}$ dependent manner [19, 20].

We are interested in these direct interactions of NDP with intestinal macrophages and used in vitro cultures and conditions to generate non-polarised macrophages (i.e. Mo), inflammatory or classically activated macrophages (i.e. M1), or tolerant or alternatively activated macrophages (i.e. M2). Besides markers that have been described in the literature additional markers were selected and subsequently used to characterise the macrophage subset after exposure to four different NDPs. This revealed that NDPs 


\section{Chapter 3}

induce a distinct phenotype characterised by putative epigenetic modification resulting in differential transcription of genes related to migration, metabolic processes, cell cycle progression and inflammatory responses and which combined may prove a practical resource for studying the effects of NDPs in vitro and potentially in vivo.

\section{Materials and Methods}

\subsection{NDP characterisation}

We used four NDPs being: Wellmune Soluble (referred to as 'Wellmune' in table and figures), RG-I, LCES and Naxus. Wellmune Soluble is a 94\% pure preparation of water soluble $\beta-1,3 / 1,6$-glucan of approximately $17 \mathrm{kDa}$ isolated from the yeast Saccharomyces cerevisiae and provided by BioThera (Eagan, MN, USA). RG-I is a $80 \%$ pure preparation of rhamno-galacturonan-I with branced L-arabinan, type II arabinogalactan and probably linear L-arabinan side chains with a molecular weight (MW) of approximately 95 and 14 $\mathrm{kDa}$ isolated from apple and provided by INRA (Paris, France). The isolation procedure including pectin methyl esterase (30 U/L, Rapidase SPE, DSM) and polygalacturonase (20 UI/L, PG, Megazyme, IL, USA) treatment at $4^{\circ} \mathrm{C}$ for $12 \mathrm{~h}$ after which the extract was concentrated by cross flow ultrafiltration using a ceramic membrane $\left(0.5 \mathrm{~m}^{2}\right.$, diameter $25 \mathrm{~mm}$, cut-off $8 \mathrm{kDa}$ ). Next, a diafiltration step was applied (dilution factor 1000), and the sample was centrifuged $\left(2800 \times \mathrm{g}, 30 \mathrm{~min}, 4{ }^{\circ} \mathrm{C}\right.$ ) and lyophilized. LCES (lentinan containing extract from shiitake) is a $73 \%$ pure preparation of $\beta-1,3 / 1,6$-glucan, with a minor amount of $\alpha-1,4 / 1,6$ glucan and mannose and galactose units, of approximately $21000 \mathrm{kDa}$ isolated from shiitake mushrooms. For isolation of LCES the mushrooms were minced and boiled for $8 \mathrm{~h}$ in water, filtered over cheesecloth, and LCES was precipitated with ethanol and finally lyophilized. Naxus is $77 \%$ pure preparation of arabinoxylans with additional arabinogalactan peptides together with some 1,3/1,4-linked $\beta$ - glucans and $\beta(1,4)$-mannans with an average MW of $\sim 95 \mathrm{kDa}$ isolated from wheat and provided by BioActor (Maastricht, The Netherlands).

To remove LPS contamination, NDPs were treated as previously described [21]. In brief, RG-I was treated with alkaline-ethanol at $4{ }^{\circ} \mathrm{C}$ for $5 \mathrm{~h}$, while LCES and Naxus were treated with alkaline-ethanol at $56^{\circ} \mathrm{C}$ for $5 \mathrm{~h}$. NDPs were lyophilized following neutralization with $\mathrm{HCl}$. For Wellmune Soluble, low in LPS contamination, no LPS removal treatment was applied. For all NDPs, LPS levels were below those that would result in immune stimulations [21]. 


\subsection{Primary macrophage differentiation and polarization}

Human monocytes were obtained from buffy coats from healthy donors (Sanquin, Nijmegen, The Netherlands) using the quadroMACS system and CD14 microbeads according to the manufacturer's protocol (Miltenyi Biotec, Leiden, The Netherlands). A written informed consent was obtained before sample collection. Monocytes were differentiated into macrophages following 7 days culturing in RPMI 1640 - Glutamax medium (Gibco, Bleiswijk, The Netherlands) supplemented with $10 \%$ fetal bovine serum (FBS, Hyclone, Eindhoven, The Netherlands), 1\% MEM non-essential amino acids (Gibco), 1\% Na-pyruvate (Lonza, Breda, The Netherlands), $1 \%$ Pen/strep (Sigma, St. Louis, MO, USA) and $50 \mathrm{ng} / \mathrm{ml}$ MCSF (R\&D systems, Minneapolis, MN, USA) at $1 \times 10^{6}$ cells $/ 2 \mathrm{ml} /$ well in a 24-well plate. Half of the medium was replaced after 3 and 5 days of culture with medium containing $100 \mathrm{ng} / \mathrm{ml}$ MCSF. On day 7, macrophages were polarized by replacing all the culture medium with medium containing no additions (Mo), $20 \mathrm{ng} / \mathrm{ml}$ TNF- $\alpha$ (R\&D systems) and $20 \mathrm{ng} / \mathrm{ml} \mathrm{IFN-} \gamma$ (R\&D systems) (M1), $20 \mathrm{ng} / \mathrm{ml} \mathrm{IL-4} \mathrm{(R \& D} \mathrm{systems)} \mathrm{(M2)} \mathrm{or}$ $500 \mu \mathrm{g} / \mathrm{ml}$ NDPs without MCSF and incubated for $18 \mathrm{~h}$.

\subsection{RNA extraction and cDNA synthesis}

RNA was extracted by lysing cells with $200 \mu \mathrm{L}$ TRIzol (Invitrogen, Bleiswijk, The Netherlands) for each well in the 24-well plates. This was followed by RNeasy (Qiagen, Venlo, The Netherlands) clean-up according to manufacturer's protocol. The integrity of the ribosomal RNA was analysed using agarose (Eurogentec, Liège, Belgium) gel electrophoresis (1\%). RNA concentration and purity were checked using the Nanodrop spectrophotometer system (Nanodrop Technologies, Wilmington, DE, USA) and only samples with a ratio (Abs $260 / 280 \mathrm{~nm}$ ) between 1.8 and 2.1 were used for qPCR and microarray analysis. Subsequently, cDNA was synthesised with iScript (Bio-Rad, Veenendaal, The Netherlands) according to manufacturer's protocol.

\section{4 qPCR}

qPCR was performed as described elsewhere [22]. In brief, $5 \mu$ l CDNA was mixed with 10 $\mu \mathrm{IQ} \mathrm{iQ}^{\mathrm{TM}}$ SYBR Green supermix (Bio-Rad), forward and reverse primers, and milliQ to a total volume of $20 \mu \mathrm{l}$. Primers were derived from the Harvard Primerbank (http://pga.mgh.harvard.edu/primerbank/) or designed using Clone Manager Professional 9 and synthesized by Biolegio (Nijmegen, The Netherlands). Primers and their final used concentrations are listed in supplementary Table 1. The following thermal cycling conditions were used for amplifying the target sequences: $90 \mathrm{~s}$ at $95^{\circ} \mathrm{C}$, followed by 40 cycles at $95^{\circ} \mathrm{C}$ for $10 \mathrm{~s}, 58^{\circ} \mathrm{C}$ for $10 \mathrm{~s}$ and $72{ }^{\circ} \mathrm{C}$ for $15 \mathrm{~s}$, and a final elongation step 


\section{Chapter 3}

at $72{ }^{\circ} \mathrm{C}$ for 2 min and performed on the CFX96 Touch Real-Time PCR Detection System (Bio-Rad). qPCR was performed in technical duplicate, and all samples were normalised to geometric means of PUM1 and RPLPo expression and medium-stimulated macrophages using the $\mathrm{qBase}^{+}$software (Biogazelle, Gent, Belgium). To allow comparison in terms of fold change, transcript levels below detection thresholds in Mo were set at 40 cycles.

Table 1. Most differentially expressed genes in $M_{1}$ and $M_{2}$ macrophages as determined by microarray

\begin{tabular}{|c|c|c|c|}
\hline Subsets & Genes & Mean & Description \\
\hline \multirow{25}{*}{ M1 } & IDO1 & 122.00 & indoleamine 2,3-dioxygenase 1 \\
\hline & IRG1 & 121.95 & immunoresponsive 1 homolog (mouse) \\
\hline & ANKRD22 & 105.57 & ankyrin repeat domain 22 \\
\hline & GBP5 & 91.66 & guanylate binding protein 5 \\
\hline & GBP4 & 89.87 & guanylate binding protein 4 \\
\hline & RARRES3 & 59.52 & retinoic acid receptor responder (tazarotene \\
\hline & IFITM1 & 50.21 & interferon induced transmembrane protein 1 \\
\hline & $\mathrm{GCH} 1$ & 48.16 & GTP cyclohydrolase 1 \\
\hline & $\mathrm{HAPLN}_{3}$ & 46.59 & hyaluronan and proteoglycan link protein 3 \\
\hline & VCAM1 & $43 \cdot 32$ & vascular cell adhesion molecule 1 \\
\hline & CLEC6A & 42.85 & C-type lectin domain family 6 , member $A$ \\
\hline & UBD & 40.35 & ubiquitin D \\
\hline & SCIN & 39.03 & scinderin \\
\hline & RSAD2 & 36.36 & radical S-adenosyl methionine domain containing 2 \\
\hline & $\mathrm{IDO}_{2}$ & 35.93 & indoleamine 2,3-dioxygenase 2 \\
\hline & PLA1A & 35.15 & phospholipase A1 member A \\
\hline & LAMP3 & $34 \cdot 38$ & lysosomal-associated membrane protein 3 \\
\hline & IL31RA & 32.74 & interleukin 31 receptor $A$ \\
\hline & $\mathrm{IFI} 27$ & 32.71 & interferon, alpha-inducible protein 27 \\
\hline & CXCL11 & 32.48 & chemokine (C-X-C motif) ligand 11 \\
\hline & $\mathrm{FAM} 26 \mathrm{~F}$ & 32.20 & family with sequence similarity 26 , member $F$ \\
\hline & CCL15 & 31.92 & chemokine (C-C motif) ligand 15 \\
\hline & CLEC4E & 30.64 & C-type lectin domain family 4 , member $\mathrm{E}$ \\
\hline & $\mathrm{C}_{1} \mathrm{~S}$ & 29.65 & complement component $1, \mathrm{~s}$ subcomponent \\
\hline & ETV7 & 27.78 & ets variant 7 \\
\hline
\end{tabular}




\begin{tabular}{|c|c|c|c|}
\hline & IL17RB & 59.72 & interleukin 17 receptor $\mathrm{B}$ \\
\hline & ALOX15 & 42.4 & arachidonate 15 -lipoxygenase \\
\hline & CD180 & 31.9 & CD180 molecule \\
\hline & ST8SIA6 & 30.81 & ST8 alpha-N-acetyl-neuraminide \\
\hline & $\mathrm{CHDH}$ & 24.61 & choline dehydrogenase \\
\hline & GPR34 & $24 \cdot 54$ & G protein-coupled receptor 34 \\
\hline & CCL13 & 20.16 & chemokine (C-C motif) ligand 13 \\
\hline & FCER2 & 19.13 & Fc fragment of IgE, low affinity II, receptor for \\
\hline & MAOA & 18.49 & monoamine oxidase $A$ \\
\hline & CCL26 & 18.08 & chemokine (C-C motif) ligand 26 \\
\hline & PTGFRN & 18.01 & prostaglandin F2 receptor inhibitor \\
\hline & TSPAN15 & 17.8 & tetraspanin 15 \\
\hline M2 & THBD & 17.65 & thrombomodulin \\
\hline & PPM1L & 17.26 & protein phosphatase, $\mathrm{Mg} 2+/ \mathrm{Mn} 2+$ dependent, $1 \mathrm{~L}$ \\
\hline & TMEM37 & 17.02 & transmembrane protein 37 \\
\hline & CD200R1 & 15.65 & CD200 receptor 1 \\
\hline & DNASE1L3 & $15 \cdot 59$ & deoxyribonuclease I-like 3 \\
\hline & KLHL13 & 15.1 & kelch-like family member 13 \\
\hline & FAXDC2 & 14.69 & fatty acid hydroxylase domain containing 2 \\
\hline & CTNNAL1 & $14 \cdot 38$ & catenin (cadherin-associated protein), alpha-like 1 \\
\hline & TMEM71 & $14 \cdot 35$ & transmembrane protein 71 \\
\hline & GNG2 & 13.81 & guanine nucleotide binding protein ( $G$ protein), \\
\hline & METTL7A & 13.63 & methyltransferase like $7 \mathrm{~A}$ \\
\hline & GSDMA & 13.22 & gasdermin A \\
\hline & IL1R1 & 13.1 & interleukin 1 receptor, type I \\
\hline
\end{tabular}

Values represent fold changes of gene expression of $M_{1}$ over $M_{2}$, or $M_{2}$ over $M_{1}, n=3$ different donors.

\subsection{Microarray analysis}

Microarray analysis was performed as described previously [23]. Briefly, RNA quality was verified with the RNA 6000 Nano assay on an Agilent 2100 Bioanalyzer (Agilent Technologies, Amstelveen, The Netherlands). Hybridization, washing and scanning of the Affymetrix Human Gene 1.1 ST array plate was performed on an Affymetrix Gene Titan platform according to standard protocols. Scans of arrays were analysed using package from Bioconductor project. Raw signal intensities were obtained by Robust Multi-array Average method. Probe sets were defined using remapped chip definition file (CDF) based on Entrez gene database. Individual Genes were considered to be 


\section{Chapter 3}

expressed if UPC algorithm values are above 0.5 on at least one array [24]. Genes were selected that meet the cut-off of absolute fold change $>1.8$ and false discovery rate corrected $\mathrm{p}<0.05$ (IBMT regularised paired $t$-test) on at least one treatment. The functional interpretation of gene signatures was executed using IPA 3.0 (Ingenuity, QIAGEN, Redwood, CA, USA). Microarray data were deposited in the Gene Expression Omnibus (GEO) database.

\subsection{Statistics}

All parameters are presented as means \pm SEM and differences between parameters were assessed for their significance with one-way ANOVA using Prism 6 (Graphpad, La Jolla, (A, USA). Differences with $\mathrm{p}<0.05$ were considered significant. To relate changes in groups and genes, principal component analysis [25] was used as implemented in the CANOCO 5 software package [26].

A

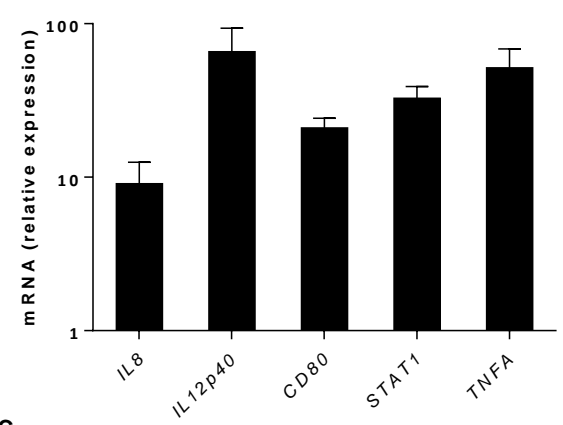

C

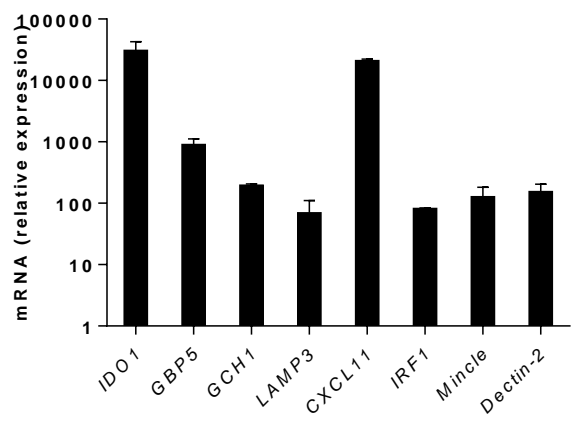

B

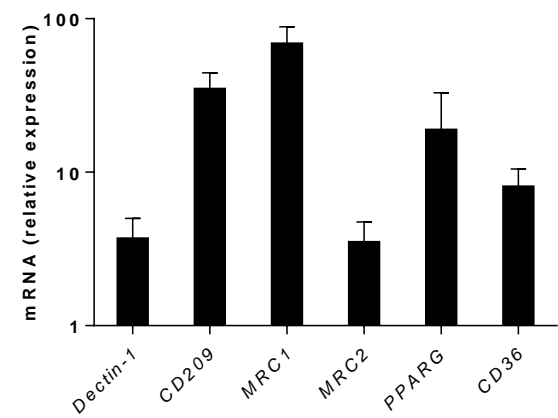

D

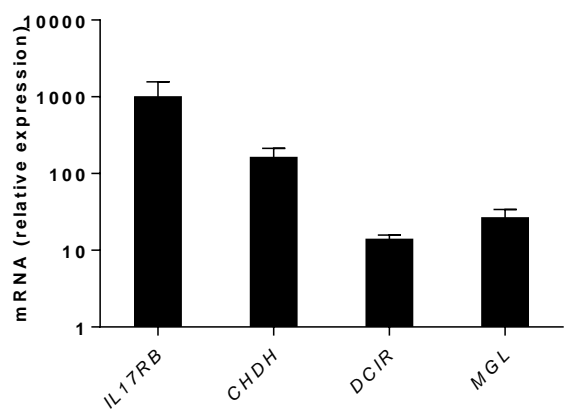

Figure 1. Literature marker list substantiates macrophage polarization and is expanded using microarray. Primary monocytes were differentiated for 7 days to macrophages and were subsequently polarised to $M_{1}$ or $M_{2}$. Markers identified in literature for $M_{1}(A)$ and $M_{2}(B)$ and by 
microarray for $M_{1}(C)$ and $M_{2}(D)$ were tested for gene expression in polarised macrophages by qPCR. Results are shown as fold change between $M 1$ and $M 2$ macrophages with bars representing mean values $\pm \mathrm{SEM}, \mathrm{n}=3$ or 6 different donors.

\section{Results}

3.1 Polarised primary macrophages can be characterized by specific gene transcription markers

Inflammatory and tolerant macrophages were generated according to established protocols [27]. Stimulation with TNFa and IFN $\gamma$ yielded inflammatory macrophages (M1) and stimulation with IL-4 yielded tolerant macrophages (M2). To verify polarization a qPCR-based approach was used to analyse the gene expression of reported M1 markers (i.e. IL8, IL12p40, CD80, TNFA, and STAT1) and M2 markers (i.e. Dectin-1, CD209, MRC1, $M R C 2, C D 36$ and PPARG). Fold change expression ratios of $M_{1}$ markers and $M 2$ markers indicated that the polarisation protocol applied indeed yielded $M 1$ and $M 2$ macrophages (Figure $1 \mathrm{~A}$ and $1 \mathrm{~B}$ ).

Considering the lack of standards in macrophage culture and polarization, we decided to further characterize our M1 and M2 macrophages by microarray analysis. Interestingly, when ranking the differential expressed genes, some genes revealed to be more discriminative than most genes reported in literature. The top 25 most differentially expressed genes between $M_{1}$ and $M_{2}$ macrophages are listed in Table 1. From this table, we selected genes to serve as $M_{1}$ and $M_{2}$ markers based on their expression level or potential function in macrophage reactivity towards NDPs (supplementary Table 2). qPCR analysis to validate these genes, similar to the markers reported in literature, verified the high expression levels and discrimination between $M 1$ and $M 2$ macrophages (Figure $1 C$ and $1 D$ ). In fact, differential fold changes were between 1.1 and 657 times higher when compared to microarray analysis.

\subsection{Based on M1 and M2 markers, NDPs induce an alternative macrophage phenotype}

We used the newly identified gene marker set as means to identify macrophage responses following exposure to NDPs in comparison to M1 or M2 macrophage polarisation. We treated macrophages with a yeast- (Wellmune Soluble), a shiitakederived (LCES) $\beta$-glucan, an apple rhamnogalacturonan I-derived from pectin (RG-I) and a wheat-derived arabinoxylan (Naxus). Gene transcription responses for $\mathrm{M}_{1}$ and $\mathrm{M}_{2}$ polarisation were similar as before, whereas the NDPs demonstrated a variety of changes to the transcriptional response (Figure 2). We did not observe any significant alteration in gene transcription following macrophage exposure to Wellmune Soluble. 


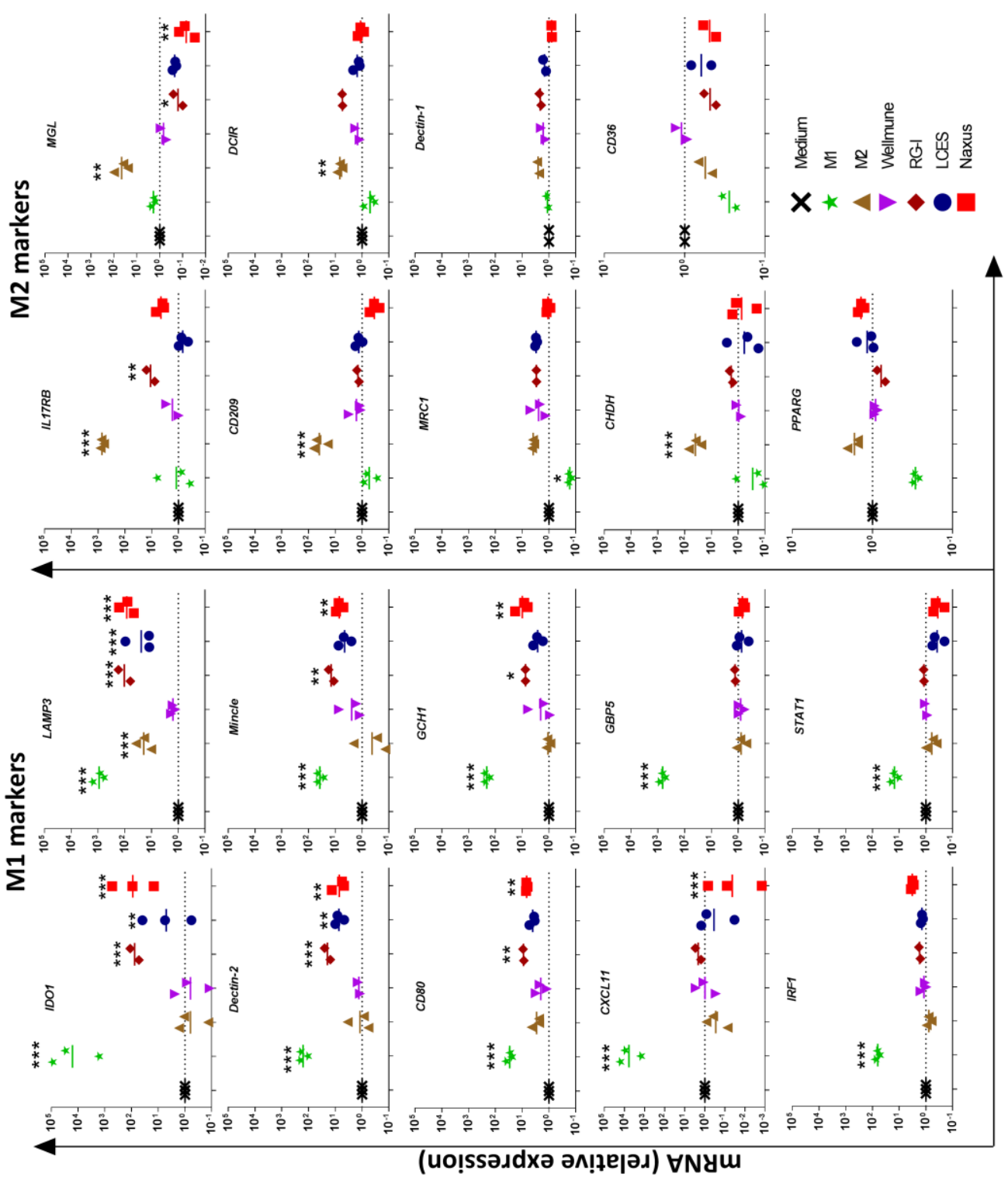

Figure 2. NDPs induce a $M 1$ and $M 2$ independent macrophage phenotype. Primary monocytes were differentiated for 7 days to macrophages and were subsequently polarised to $M_{1}$ or $M_{2}$ or exposed to Wellmune, RG-I, LCES, or Naxus. Macrophages were analysed for gene expression of M1 and $M_{2}$ markers by $\mathrm{QPCR}$ and results are shown in mean values as fold change compared to non-treated macrophages, $\mathrm{n}=2$ or 3 different donors. Statistically significant differences were analysed by oneway ANOVA: * $p<0.05, * * p<0.01, * * * p<0.001$. 


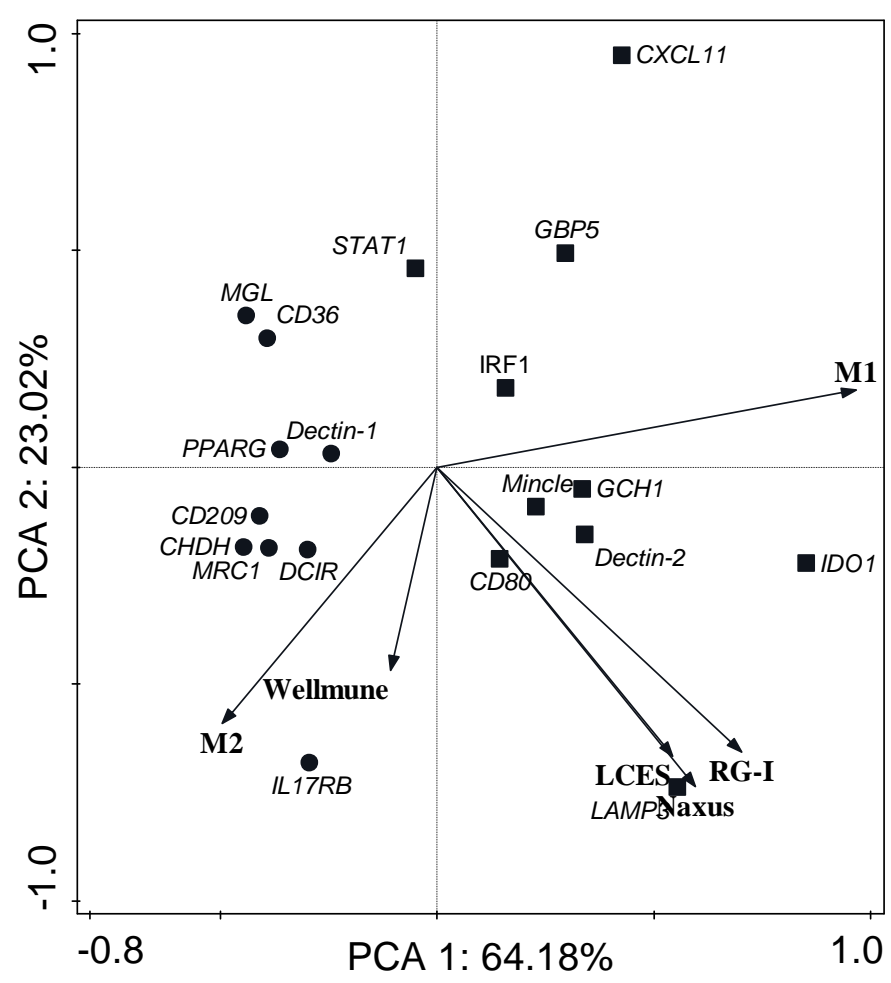

Figure 3. NDPs induce a transcriptionally unique macrophage subset. Primary monocytes were differentiated for 7 days to macrophages and were subsequently polarised to $M_{1}$ or $M_{2}$ or exposed to Wellmune, RG-I, LCES, or Naxus. Gene expression of $M_{1}(\boldsymbol{\square})$ and $M_{2}(\bullet)$ markers as analysed by $\mathrm{qPCR}$ and shown in Figure 2 were log-2 manipulated and shown in a PCA plot with relative scaling of the principal variables indicated, $\mathrm{n}=3$ different donors.

LCES only significantly enhanced expression of three M1 markers. In contrast, RG-I and Naxus comparably enhanced transcription of most of the M1 markers and at the same time significantly downregulated expression of the $M 2$ marker gene MGL. Of interest are also the gene markers of which expression is not altered by the NDPs. The M1 specific markers GBP5, IRF1, and STAT1 were not significantly increased in expression indicating NDPs do not induce a full M1 phenotype. PCA analysis clearly indicates that NDP exposure induced a macrophage phenotype that differs from M1 and M2 macrophages (Figure 3). Naxus, RG-I, and LCES appeared to induce a comparable specific macrophage subset which we coined MNDP. The PCA analysis also suggested that IDO1 and LAMP3, in addition to being M1 markers, might also function as $M_{N D P}$ markers. 


\section{Chapter 3}

\subsection{NDPs affect expression of a specific subset of genes in macrophages}

Following our finding that Naxus, RG-I, and LCES induced a transcriptional unique NDPmacrophage subset, we aimed to identify MNDP specific markers. To this end, we performed microarray analysis of the NDP-treated macrophage transcriptome. When analysing the metadata of these microarrays, we observed the most significantly altered gene transcription compared to medium following Naxus treatment ( 945 genes) and the least following Wellmune Soluble treatment (4 genes; Figure 4A). Furthermore, using PCA the NDP-treated macrophages could clearly be distinguished from $M_{1}$ and $M_{2}$ macrophages (Figure 4B). As could be expected, Wellmune Soluble appeared to be most similar to medium-treated macrophages while Naxus demonstrated the strongest changes over especially PC-1. The NDPs that strongly affected macrophage gene transcription (i.e. RG-I, LCES, and Naxus) demonstrated similar effects for 126 genes (Figure $4 C$ ), of which expression was upregulated for 59 genes and downregulated for 67 genes (Figure 5). These genes therefore appear most related to the MNDP macrophage subset.

We investigated this list of 126 genes for functional relationships using gene ontology biological process (GO-BP) descriptions (Figure 5). GO-BP terms describing migration were observed for 6 transcriptionally downregulated genes and 12 upregulated genes and included a number of $\mathrm{C}-\mathrm{C}$ motif chemokine ligands. We also found a subset of genes involved in cell cycle. Expression was downregulated for 17 genes and upregulated for 9 genes, which in fact negatively influenced cell cycle. Within the group of 17 downregulated genes, 3 were part of the replication-dependent HIST1-family, of which another 4 were downregulated but lack a GO-BP description. GO-BP terms describing metabolic processes were observed for 9 transcriptionally downregulated and 10 transcriptionally upregulated genes. Not to our surprise, within the cluster of inflammatory immune function, genes of which expression was upregulated included IDO1 and LAMP3. These genes were clustered together based on GO-BP terms demonstrating inflammatory responses and were already linked to the $M_{\text {NDP }}$ phenotype in the PCA plot (Figure 3).

\subsection{NDPs demonstrate varying transcriptional profiles of CLRs}

Many C-type lectin receptors (CLRs) have been described to be important in NDP recognition. We observed 2 CLRs, CLEC5A and CLEC6A, to be similar transcriptionally regulated following macrophage exposure to RG-I, LCES or Naxus (Figure 5). Further analysis revealed that each macrophage subset affects transcription of a number of CLRs. Strikingly, M1 polarisation strongly affected transcription of CLEC4E (Mincle) and CLEC6A (Dectin-2) and M2 polarisation strongly affected transcription of CLEC4A, 

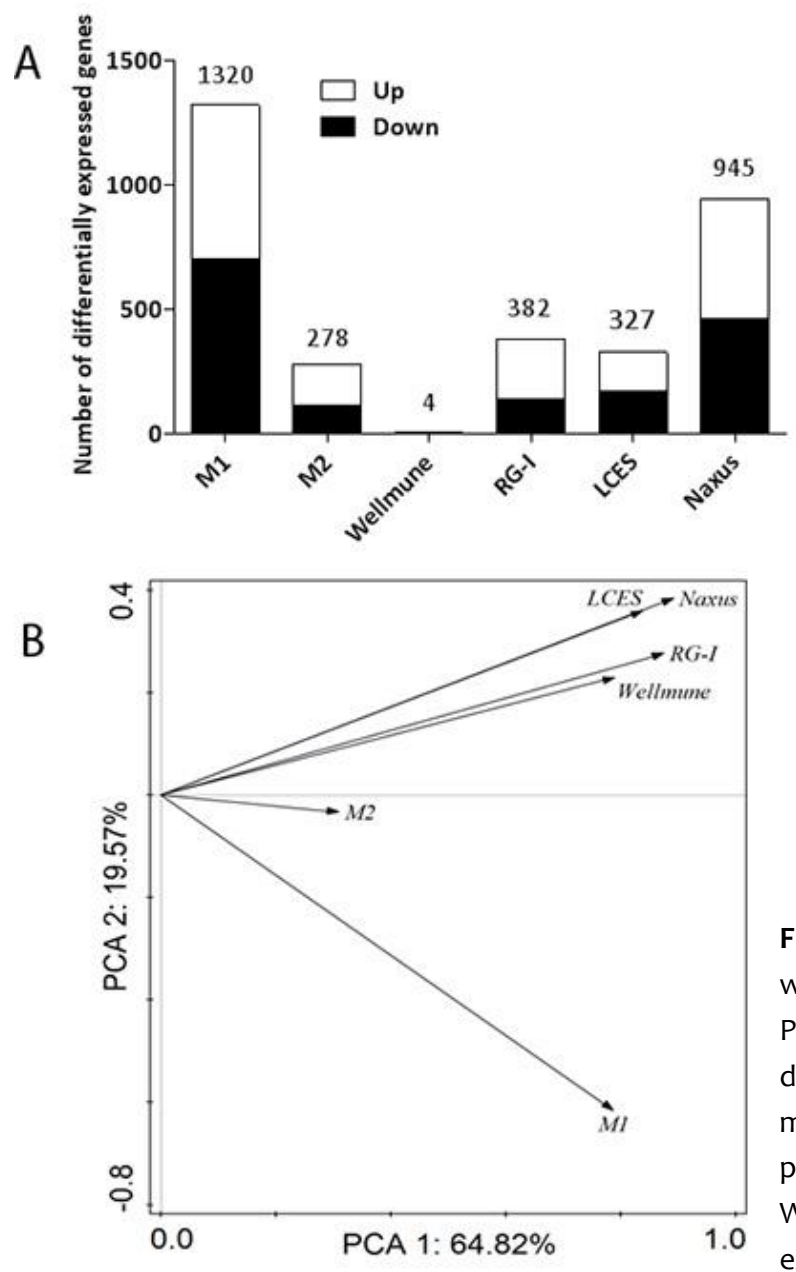

Figure 4. NDPs vary in their genomewide differential gene expression. Primary monocytes were differentiated for 7 days to macrophages and were subsequently polarised to $\mathrm{M}_{1}$ or $\mathrm{M}_{2}$ or exposed to Wellmune, RG-I, LCES, or Naxus. Gene expression was analysed using C

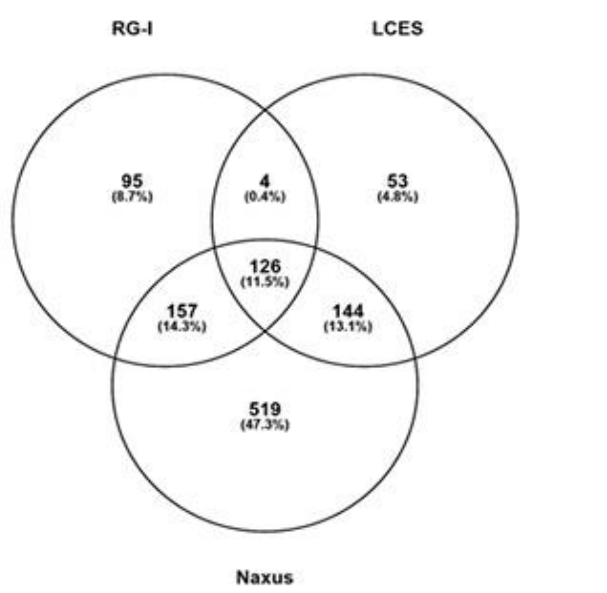
microarray and compared to nontreated macrophages. The number of up- and down-regulated genes for each treatment is depicted in a bar chart (A). Relative gene expression is shown as PCA plot, based on a signallog ratio, with relative scaling of the principal variables indicated (B). Number of NDP unique and shared differentially regulated genes is shown in a Venn diagram (C). Data are expressed as mean values, $n=3$ different donors. 


\section{Chapter 3}

Table 2. C-type lectin expression profiles as determined by microarray

\begin{tabular}{|c|c|c|c|c|c|c|c|}
\hline Genes & Aliases & M1 & M2 & Wellmune & RG-I & LCES & Naxus \\
\hline CLEC6A & Dectin-2 & $24.53^{* * *}$ & 1.04 & 4.28 & $8.59 *$ & $5 \cdot 71 *$ & $5.34^{*}$ \\
\hline $\mathrm{CLEC}_{4} \mathrm{E}$ & Mincle & $12.52^{* * *}$ & -2.99 & 3.77 & $8.99 * *$ & 3.94 & $6.36 * *$ \\
\hline $\mathrm{CLEC}_{4} \mathrm{D}$ & Dectin-3/MCL & $6.74 * *$ & -1.08 & 2.45 & $5.77^{*}$ & 1.99 & $4.86 * *$ \\
\hline $\mathrm{CLEC}_{2} \mathrm{C}$ & CD69 & $2.32 * * *$ & -1.1 & -1.08 & 1.01 & 1.00 & -1.05 \\
\hline CLEC4J & FCER2/CD23 & 1.21 & $23.73^{* * *}$ & 1.82 & 1.58 & 2.52 & 2.60 \\
\hline CLEC10A & MGL & 1.04 & $19.81 * * *$ & 2.01 & -1.11 & -1.39 & -1.93 \\
\hline CLEC4L & $\begin{array}{l}\text { DC- } \\
\text { SIGN/CD209 }\end{array}$ & $-2.40^{*}$ & $13.08 * * *$ & 1.93 & 1.59 & -1.17 & -1.55 \\
\hline $\mathrm{CLEC}_{4} \mathrm{~A}$ & $\mathrm{DCIR}$ & $-3.11 * *$ & $4.28 * * *$ & 2.12 & $3.16 * *$ & 1.22 & 1.47 \\
\hline CLEC13D & $\mathrm{MRC} 1$ & $-4.69 * * *$ & $2.73^{*}$ & 2.12 & 1.67 & 1.68 & 1.10 \\
\hline CLEC8A & LOX-1/OLR1 & $-4.60 *$ & -1.61 & 1.89 & 3.11 & $6.99 * *$ & $9.88 * * *$ \\
\hline CLEC13A & DCL-1/CD302 & $-3.35^{* * *}$ & 1.01 & -1.52 & $-2.60 *$ & $-2.84 * *$ & $-4.92 * * *$ \\
\hline CLEC13E & $\mathrm{MRC2}$ & $-1.95 * *$ & -1.19 & -1.61 & $-2.14^{*}$ & -1.63 & $-2.56 * * *$ \\
\hline CLEC $7 \mathrm{~A}$ & Dectin-1 & -1.44 & $1.87^{* *}$ & 1.34 & $1.32 *$ & -1.03 & $-1.65 *$ \\
\hline CLEC5A & MDL1 & -1.50 & -1.96 & 3.39 & $3.33^{* *}$ & $3.52 * *$ & $2.06^{*}$ \\
\hline CLEC4G & LSECtin & 1.05 & $2.40 * *$ & 1.21 & 1.17 & 1.05 & -1.03 \\
\hline CLEC1A & - & -1.10 & $2.60 * *$ & 1.71 & $2.07^{*}$ & 1.26 & 1.13 \\
\hline
\end{tabular}

Values represent fold changes of gene expression, $n=3$ experiments. Statistically significant differences were calculated with IBMT regularised paired $t$-test: * FDR $p<0.05$, ** FDR $p<0.01$; *** FDR $p<0.001$.

CLEC4L, CLEC10A (MGL), and CLEC13D (Figure $1 C$ and D). In total, we found significant transcriptional upregulation of 4 CLRs in $\mathrm{M}_{1}$ and 8 CLRs in M2 macrophages, and downregulation of 6 CLRs in M1 and none in M2 macrophages (Table 2).

There are clear differences in CLR gene expression profiles between $M_{1}, M_{2}$ and NDPtreated macrophages. Gene expression of CLEC5A and CLEC8A (LOX-1) was found 


\section{Unique phenotype for NDP treated macrophages subsets}

\begin{tabular}{|c|c|c|c|c|c|c|c|}
\hline \multicolumn{4}{|c|}{ Cell migration } & \multicolumn{4}{|l|}{ Cell cycle } \\
\hline Gene & RG-I & LCES & Naxus & Gene & RG-I & LCES & Naxus \\
\hline CCL1 & 4.6 & 5.8 & 7.9 & INHBA & 3.4 & 6.0 & 7.5 \\
\hline CCL24 & 4.2 & 6.9 & 7.2 & IL7R & 5.4 & 4.2 & 5.2 \\
\hline CXCL8 & 5.1 & 4.1 & 5.7 & MMP12 & 3.9 & 4.3 & 4.7 \\
\hline IL1B & 4.3 & 3.4 & 5.0 & SLAMF1 & 3.2 & 2.2 & 4.9 \\
\hline SLC7A11 & 4.5 & 3.9 & 4.5 & SOCS3 & 2.8 & 2.3 & 4.0 \\
\hline CCL4 & 2.1 & 3.3 & 3.6 & KDM6B & 0.9 & 1.5 & 2.2 \\
\hline SERPINE1 & 2.3 & 2.6 & 3.3 & LRP12 & 1.6 & 1.2 & 2.1 \\
\hline CCL3L3 & 1.4 & 2.0 & 2.8 & DCUN1D3 & 1.4 & 0.9 & 1.4 \\
\hline PDPN & 3.1 & 2.0 & 2.7 & VDR & 1.2 & 0.9 & 1.1 \\
\hline CCL3 & 1.4 & 2.2 & 2.7 & HIST1H2BF & -1.1 & -1.3 & -1.0 \\
\hline ICAM1 & 1.7 & 1.2 & 2.1 & HIST1H2AI & -0.9 & -1.0 & -1.3 \\
\hline MMP14 & 1.6 & 1.1 & 1.7 & HIST1H3B & -1.9 & -1.3 & -2.0 \\
\hline ITGA4 & -1.0 & -1.0 & -1.8 & HIST1H2BM & -2.0 & -1.6 & -2.4 \\
\hline PRR5L & -1.7 & -1.2 & -2.0 & HIST1H3G & -2.2 & -1.5 & -2.6 \\
\hline SORL1 & -2.5 & -1.8 & -2.3 & HIST1H3F & -1.5 & -1.3 & -2.0 \\
\hline HGF & -2.5 & -2.3 & -2.4 & HIST1H1B & -1.1 & -1.1 & -1.6 \\
\hline IGF1 & -2.1 & -2.3 & -2.7 & ANLN & -1.3 & -1.0 & -1.5 \\
\hline ADORA3 & -2.8 & -3.3 & -4.1 & MYBL2 & -1.1 & -0.9 & -1.5 \\
\hline \multicolumn{4}{|c|}{ Inflammatory immune function } & PLK1 & -1.3 & -1.0 & -1.3 \\
\hline Gene & RG-I & LCES & Naxus & APPL2 & -0.9 & -1.2 & -1.2 \\
\hline IDO1 & 4.0 & 2.0 & 5.8 & $\mathrm{FANCl}$ & -1.0 & -1.0 & -1.2 \\
\hline IL3RA & 4.5 & 4.3 & 5.8 & PRLR & -1.3 & -1.3 & -1.3 \\
\hline TNIP3 & 5.4 & 2.4 & 5.5 & REPS2 & -1.3 & -1.1 & -1.4 \\
\hline TNFAIP6 & 3.7 & 1.9 & 5.3 & ESCO2 & -1.0 & -1.1 & -1.9 \\
\hline LAMP3 & 3.6 & 1.5 & 4.0 & TOP2A & -1.4 & -1.1 & -2.0 \\
\hline TRAF1 & 2.4 & 2.7 & 4.0 & RRM2 & -1.8 & -1.0 & -2.0 \\
\hline BIRC3 & 1.7 & 1.6 & 3.3 & \multicolumn{4}{|c|}{ Metabolic process } \\
\hline IRAK2 & 1.3 & 1.7 & 3.0 & Gene & RG-I & LCES & Naxus \\
\hline CD274 & 2.0 & 1.3 & 2.6 & HS3ST3B1 & 2.9 & 1.7 & 4.1 \\
\hline CLEC6A & 3.1 & 2.5 & 2.4 & GOS2 & 3.3 & 1.9 & 2.9 \\
\hline TNFAIP3 & 1.3 & 1.6 & 2.4 & SH3PXD2B & 2.9 & 1.8 & 2.7 \\
\hline TNIP1 & 1.8 & 1.3 & 2.4 & ABCG1 & 1.2 & 1.2 & 2.6 \\
\hline CD40 & 1.2 & 1.1 & 1.6 & CYP27B1 & 1.7 & 1.6 & 2.5 \\
\hline KCNN4 & 0.9 & 1.3 & 1.3 & STK17A & 1.4 & 0.9 & 1.8 \\
\hline CLEC5A & 1.7 & 1.8 & 1.0 & MAOA & 2.0 & 1.0 & 1.6 \\
\hline PIK3IP1 & -1.2 & -1.1 & -1.0 & SOD2 & 1.7 & 0.9 & 1.6 \\
\hline АРОВЕСЗВ & -1.0 & -1.1 & -1.3 & ST3GAL2 & 0.9 & 1.0 & 1.5 \\
\hline CD28 & -1.4 & -1.4 & -1.7 & ABCA1 & 1.0 & 0.9 & 1.2 \\
\hline SIGLEC16 & -1.4 & -2.0 & -1.8 & DPEP2 & -1.3 & -1.1 & -1.2 \\
\hline CD200R1 & -1.4 & -1.0 & -1.9 & AMDHD1 & -1.1 & -0.9 & -1.2 \\
\hline TLR5 & -1.3 & -1.3 & -2.1 & CD101 & -1.6 & -1.1 & -1.4 \\
\hline DEPTOR & -1.6 & -1.8 & -2.1 & CMBL & -1.1 & -1.5 & -1.9 \\
\hline CD302 & -1.4 & -1.5 & -2.3 & GATM & -1.5 & -1.4 & -2.1 \\
\hline FFAR4 & -1.8 & -1.0 & -2.3 & GCNT1 & -1.4 & -1.6 & -2.6 \\
\hline MEF2C & -1.7 & -1.6 & -2.3 & SLC46A1 & -1.8 & -2.1 & -2.8 \\
\hline LILRB5 & -1.4 & -2.3 & -2.7 & GAL3ST4 & -1.9 & -3.2 & -3.3 \\
\hline GAPT & -3.1 & -3.6 & -3.3 & SEPP1 & -3.0 & -3.7 & -4.1 \\
\hline TLR7 & -3.0 & -3.0 & -3.5 & & & & \\
\hline
\end{tabular}

\begin{tabular}{|c|c|c|c|}
\hline \multicolumn{4}{|c|}{ Other functions } \\
\hline Gene & RG-I & LCES & Naxu \\
\hline IVEP2 & 1.1 & 1.6 & 3.2 \\
\hline SC & .0 & 1.8 & 2.4 \\
\hline 17orf96 & 2.0 & 1.8 & 2.2 \\
\hline & 1.3 & 1.0 & 2.1 \\
\hline & 1.9 & 1.3 & 2.1 \\
\hline AM20A & 2.0 & 1.0 & 1.9 \\
\hline ОВ3В & & 1.2 & 1.8 \\
\hline $\operatorname{rf} 48$ & 1.2 & 1.0 & 1.7 \\
\hline XN1 & 1.9 & 1.2 & 1.6 \\
\hline r & 2.2 & 1.6 & 1.5 \\
\hline ZSW & 1.3 & 0.9 & 1.3 \\
\hline$A 2$ & 1.4 & & 1.8 \\
\hline $\mathrm{RHB}$ & 0.9 & & 1.3 \\
\hline ZNF836 & & -1.0 & -1.1 \\
\hline P3 & -1.3 & -1.3 & -1.1 \\
\hline & & & -1.2 \\
\hline LPAR5 & & & -1.2 \\
\hline GPB & & & -1.3 \\
\hline RHOBTB1 & -1.3 & -1.1 & -1.3 \\
\hline MAML3 & -1.0 & -1.1 & -1.3 \\
\hline ASRGL1 & -1.0 & -0.9 & -1.4 \\
\hline FXYD6 & -1.3 & & -1.5 \\
\hline DBP & -1.2 & & -1.7 \\
\hline FAXDC2 & & & -1.7 \\
\hline PTGFRN & & & -1.7 \\
\hline RAD51AP1 & & & -1.9 \\
\hline SLC46A3 & -0.9 & & -1.9 \\
\hline CRYBB1 & -1.3 & -1.6 & -2.1 \\
\hline RGS18 & -1.6 & -1.5 & -2.2 \\
\hline GPR155 & -1.3 & -1.5 & -2.3 \\
\hline SLC40A1 & -2.9 & -3.2 & -2.8 \\
\hline MRO & -2.2 & -2.5 & -2.9 \\
\hline P2RY8 & -2.5 & -2.6 & -3.1 \\
\hline TMEMЗ7 & -2.1 & -3.5 & -4.3 \\
\hline MS4A6A & -2.1 & -4.0 & -4.6 \\
\hline
\end{tabular}

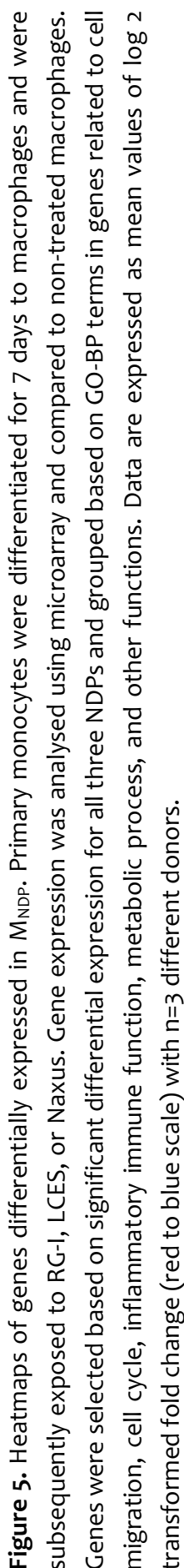




\section{Chapter 3}

decreased and CLEC10A increased in both $M_{1}$ and $M_{2}$ macrophages, albeit not all significant, but oppositely regulated in $\mathrm{M}_{\mathrm{NDP}}$. Furthermore, gene expression of CLEC4L and CLEC13D were decreased in $\mathrm{M}_{1}$ and increased in $\mathrm{M}_{2}$ but not affected by NDPs. NDPs also affected transcription of some CLRs similarly to M1 or M2 macrophages. Differential CLR gene expression as in M1 macrophages was observed in LCES-treated macrophages in case of 2 CLRs and in Naxus-treated and RG-I-treated macrophages in case of 5 CLRs, which include CLEC6A. However, only RG-I also significantly affected gene expression of CLRs (CLEC1A, CLEC4A and CLEC7A) similar as in $M_{2}$ macrophages. The CLR transcriptional profile therefore appears representative for the alternative $M_{N D P}$ subset when compared to $\mathrm{M} 1$ and $\mathrm{M} 2$.

\subsection{Naxus and RG-I differ in the kinetics of induction of IDO1 and LAMP3 gene expression}

The $18 \mathrm{~h}$ exposure time point used in the previous analyses was based on pilot experiments when setting up the polarisation towards $\mathrm{M}_{1}$ and $\mathrm{M}_{2}$ macrophages characterised by the markers from literature. In order to better understand the expression kinetics related to MNDP, we analysed gene transcription levels of IDO1 and LAMP3, being markers for M1 (Figure 1) and MNDP (Figure 6). Analysis of a time series of M1 polarisation or macrophage exposure to RG-I or Naxus demonstrated that IDO1 and LAMP3 expression was already significant upregulated in M1 polarised and RG-I-treated macrophages after $4 \mathrm{~h}$, with an expression that peaked at $18 \mathrm{~h}$ for $\mathrm{M} 1$ and $8 \mathrm{~h}$ for RG-I.

Differential IDO1 and LAMP3 gene expression following Naxus treatment reached significance only after $8 \mathrm{~h}$ and also peaked at $18 \mathrm{~h}$ after which the expression remained stable until the $48 \mathrm{~h}$ time point. In contrast, IDO1 expression in response to RG-I declined after peaking at $8 \mathrm{~h}$.

\section{Discussion}

Macrophages that can sample antigens in the lumen can, in particular, be expected to have a central role in responding to luminal stimuli and maintaining homeostasis in the intestine [20,28]. Non-digestible polysaccharides are not or to a limited extent degraded in the upper gastric tract and can therefore act as luminal stimuli to these sampling macrophages. Indeed, macrophages express receptors such as dectin-1 to respond to treatment with $\beta$-glucan preparations with cytokine release [29].

To investigate the effects of NDPs on macrophages in more detail, we used a monocytederived macrophage culture system as a follow-up to previous work on THP-1 macrophages [30]. Upon differentiation, the macrophages were treated with NDPs or polarised towards inflammatory or tolerant subsets. The latter two subsets can be 

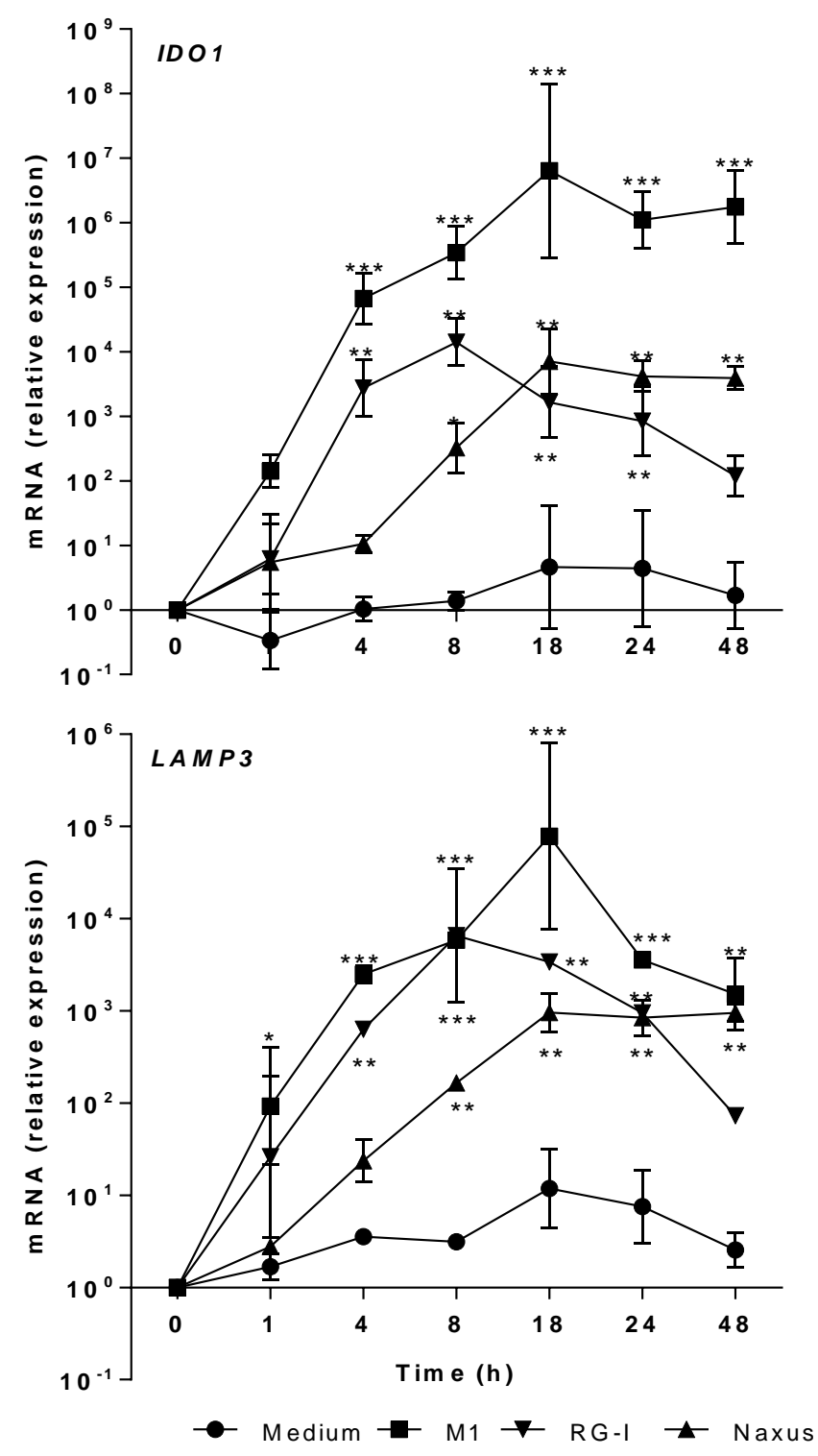

Figure 6. Naxus and RG-I demonstrate an opposite gene expression kinetics for IDO1 and LAMP3. Primary monocytes were differentiated for 7 days to macrophages and were subsequently polarised to M1 or exposed to RG-I or Naxus. IDO1 and LAMP3 gene expression was analysed by qPCR at $1 \mathrm{~h}, 4 \mathrm{~h}, 8 \mathrm{~h}, 18 \mathrm{~h}, 24 \mathrm{~h}, 48 \mathrm{~h}$ and results shown as fold change compared to non-treated macrophages by mean values \pm SEM, $n=2$ different donors. Statistically significant differences were analysed by one-way ANOVA: * $p<0.05,{ }^{* *} P<0.01, * * *$ 


\section{Chapter 3}

considered extremes to be found in the intestine depending on whether there is a homeostatic or inflammatory environment [12]. Polarisation of macrophages to a tolerant $\left(M_{2}\right)$ or inflammatory (M1) phenotype can be determined by gene markers reported in the literature [31-33], which were confirmed in our study. For IL12p40 it was shown that this gene was also specifically upregulated in inflammatory macrophages in the intestine of mice as it was in M1 macrophages in our system [19]. Similarly, MRC1 was upregulated in tolerant $\mathrm{M}_{2}$ type macrophages. Our microarray analysis, supported by qPCR validation, revealed gene markers that are even more strongly differentiating between $\mathrm{M}_{1}$ and $\mathrm{M}_{2}$ macrophages in our culture system. Among those genes are IDO1, LAMP3, CXCL11, Dectin-2, and Mincle that can be used as M1 markers and IL17RB, CD209, and $M R C 1$ to identify $M 2$ macrophages. This resulted in a final marker gene list as shown in Figure 2 which can be used for improved characterisation of inflammatory and tolerant macrophages in vitro and potentially also in vivo. This list mainly contains markers related to microbial carbohydrate recognition ( $M_{1}$ or $\left.M_{2}\right)$, inflammatory responses (M1), immunoregulation and energy supply (all M2; supplementary Table 2). For both M1 and M2 macrophages we observed a strong transcriptional regulation of CLRs, which are receptors specific for carbohydrate recognition [34] enabling recognition of microbial structures [35].

When using the marker gene set to characterise macrophage phenotypes following NDP exposure, we observed a transcriptionally unique macrophage subset that we termed $M_{\text {NDP. }}$ Remarkably, PCA analysis based on all differential expressed genes demonstrated that NDPs induced a similar macrophage subset but with different intensity, although only limited effects on gene expression were observed for Wellmune Soluble. Wellmune Soluble was described to interact with the $C_{3} 3$ receptor to prime this for binding to antibodies [36]. In contrast, Wellmune Soluble does not cluster cell surface receptors and fails in initiating intracellular signalling [29]. Therefore, it is likely that Wellmune Soluble does not induce gene transcription in our model. The other NDPs induced macrophage gene transcription to various extents, with Naxus being the most potent. This likely occurred via interactions with carbohydrate binding receptors [35]. For example, it has been shown that dectin- 1 binds $\beta$-glucans, the major polysaccharide in LCES, and arabinoxylan, the major constituent of Naxus [37, 38]. Furthermore, Mincle was demonstrated to recognize a-mannose, which can be found in the Naxus and LCES preparations, and both Dectin-2 and Dectin-3 were shown to bind a-mannans [39-41], which are also present in Naxus. As a result of NDP recognition, macrophages mainly increased expression of CLRs, which might constitute a positive feedback mechanism to enhance vigilance towards microbes or fungi. 
Gene markers that related to the MNDP phenotype are LAMP3 and IDO1. LAMP3 was reported to associate with dendritic cell differentiation and maturation by performing a key role in processing of exogenous antigens [42]. IDO1 is an enzyme that catalyses the first and rate-limiting step in tryptophan catabolism to $\mathrm{N}$-formyl-kynurenine [43], and thereby modulates innate and adaptive immune responses [44] and potentially represents an important feedback mechanism for macrophage activity. Both genes therefore have an important role in macrophage functionality which prompted us to analyse the expression pattern in more depth following NDP exposure that showed a strong upregulated $\mathrm{LAMP}_{3}$ and IDO1 gene expression (i.e. Naxus and RG-I). M1 macrophages and macrophages treated with RG-I or Naxus all demonstrated a different kinetic profile of gene transcription of both IDO1 and LAMP3. A striking difference between M1 and RG-I on the one hand and Naxus-treated macrophages on the other hand is the rapid increase versus the lag time in transcription, respectively. IDO1 transcription has been described to be regulated by STAT1, which can directly bind to the gene promotor, or indirectly regulated by STAT3, via activation of the non-canonical NFkB pathway which could lead to alternative kinetics in IDO1 gene transcription [45, 46]. Activity of transcription factors can be inferred from gene transcription profiles using IPA Upstream Regulator Analysis resulting in Z-scores. In concordance with observed IDO1 transcription and anticipated kinetic difference in STAT transcriptional activity, STAT1 was predicted to be active in M1 with a Z-score above 2 (i.e. 3.4). For RG-I-treated macrophages, demonstrating a minor lag time compared to M1 macrophages, STAT1 but also STAT3 were predicted to be active with a Z-score of 2.0 and 2.2, respectively. Finally, for Naxus-treated macrophages STAT1 was not predicted to be active (Z-score of 0.1), but STAT3 activation was predicted with a Z-score of 1.6 suggesting a mainly STAT3 driven IDO1 transcription. Differences in carbohydrate recognition receptor ligation might result in variable STAT1 and STAT3 activation which likely can result in alternative kinetics of IDO1 gene transcription. So, although these genes represent suitable $M_{N D P}$ markers between 8 and $48 \mathrm{~h}$ of treatment, their expression kinetics might enable further discrimination between NDP bioactivity.

A continuous concern for in vitro immune analysis of for instance NDPs, is lipopolysaccharide [47] contamination. LPS is often found in food-derived preparations and can be a cause of false positive results [48]. To be able to identify LPS-mediated macrophage responses we opted to induce M1 polarisation with TNFa and IFN $\gamma$ instead of the frequently used combination of LPS and IFN $\gamma$. LPS also demonstrated the potency to induce IDO1 and LAMP3 expression in macrophages (supplementary Figure $1 A$ and $B$ ). CXCL11, which serves in our panel as M1 marker, has also been shown to be a strong response marker for LPS recognition by primary monocytes [49]. Indeed, CXCL11 


\section{Chapter 3}

expression is significantly enhanced in our macrophages when exposing these to as low as $100 \mathrm{fg} / \mathrm{ml}$ of LPS (supplementary Figure $1 \mathrm{C}$ ). In a previous study we demonstrated that LPS was efficiently removed from NDPs using a $\mathrm{NaOH}$-based treatment [21]. Exposing macrophages to treated NDPs confirms the absence of LPS in our samples as no significant differential CXCL11 transcription was observed (supplementary Figure 1D).

Extended analysis of macrophage transcriptional responses to NDP treatment revealed the downregulation of HIST1 family genes. These replication-dependent histones are actively transcribed during mitosis and reach a peak during the S-phase of the cell cycle $[50,51]$. Not only via alternative HIST1 gene regulation, but also by expression of lysinespecific demethylase 6B (KDM6B/Jmjd3; Figure 5), that can demethylate both trimethylated and dimethylated $\mathrm{H}_{3} \mathrm{~K}_{2} 7$ histones [52], NDP appear to affect macrophage phenotype via epigenetic regulation. This demethylation increases transcription of inflammatory genes via activation of various signalling pathways, including NFkB, STAT, SMAD, and T-bet transcription factors [53]. This is in line with candida-derived NDP, from the sub-group of glucans which includes lentinan, which demonstrated to use epigenetic regulation to induce so-called 'trained immunity' [54]. Epigenetic changes upon $\beta$-glucaninduced trained immunity results in transcriptional profiles most similar to classical macrophages [55]. In contrast, putatively induced HIST1-dependent proliferation linked to the $\mathrm{M} 2$ phenotype.

Taken together, we describe a qPCR marker set to characterise inflammatory (M1) or tolerant $\left(\mathrm{M}_{2}\right)$ phenotypes and identified a distinct macrophage subset following exposure to NDPs. It will be of interest to analyse whether this transcriptionally unique MNDP subset can also be distinguished in vivo and how this depends on the NDPs in our diet or other luminal triggers such as microbiota composition or metabolites. The unique and overlapping set of gene markers to identify $M_{1}, M_{2}$, and $M_{N D P}$ can likely contribute to those analyses.

Y.T., C.G., and J.J.M. conceived and designed the experiments. Y.T. performed the experiments. Y.T., C.G., and J.J.M. analysed the data. Y.T., C.G., J.J.M., and H.J.W. wrote the manuscript.

The authors have declared no conflicts of interest. 


\section{References:}

1. Skau-Mikkelsen, M., B.M. Jespersen, A. Mehlsen, S.B. Engelsen, and H. Frokiaer, Cereal betaglucan immune modulating activity depends on the polymer fine structure. Food Research International, 2014. 62: p. 829-836.

2. Bernard, H., J.L. Desseyn, N. Bartke, L. Kleinjans, B. Stahl, C. Belzer, J. Knol, F. Gottrand, and M.O. Husson, Dietary pectin-derived acidic oligosaccharides improve the pulmonary bacterial clearance of Pseudomonas aeruginosa lung infection in mice by modulating intestinal microbiota and immunity. Journal of Infectious Diseases, 2015. 211(1): p. 156-165.

3. Chen, H., W. Wang, J. Degroote, S. Possemiers, D. Chen, S. De Smet, and J. Michiels, Arabinoxylan in wheat is more responsible than cellulose for promoting intestinal barrier function in weaned male piglets. Journal of Nutrition, 2015. 145(1): p. 51-58.

4. Ito, H., N. Takemura, K. Sonoyama, H. Kawagishi, D.L. Topping, M.A. Conlon, and T. Morita, Degree of polymerization of inulin-type fructans differentially affects number of lactic acid bacteria, intestinal immune functions, and immunoglobulin A secretion in the rat cecum. Journal of Agricultural and Food Chemistry, 2011. 59(10): p. 5771-5778.

5. Haenen, D., C. Souza da Silva, J. Zhang, S.J. Koopmans, G. Bosch, J. Vervoort, W.J. Gerrits, B. Kemp, H. Smidt, M. Muller, and G.J. Hooiveld, Resistant starch induces catabolic but suppresses immune and cell division pathways and changes the microbiome in the proximal colon of male pigs. Journal of Nutrition, 2013.143(12): p. 1889-1898.

6. Chan, G.C., W.K. Chan, and D.M. Sze, The effects of beta-glucan on human immune and cancer cells. Journal of Hematology \& Oncology, 2009. 2: p. 25.

7. Hartog, A., F.N. Belle, J. Bastiaans, P. de Graaff, J. Garssen, L.F. Harthoorn, and A.P. Vos, A potential role for regulatory T-cells in the amelioration of DSS induced colitis by dietary nondigestible polysaccharides. The Journal of Nutritional Biochemistry, 2015. 26(3): p. 227-233.

8. Tian, L., J. Scholte, K. Borewicz, B. van den Bogert, H. Smidt, A.J. Scheurink, H. Gruppen, and H.A. Schols, Effects of pectin supplementation on the fermentation patterns of different structural carbohydrates in rats. Molecular Nutrition \& Food Research, 2016. 60(10): p. 22562266.

9. Tian, L., G. Bruggeman, M. van den Berg, K. Borewicz, A.J. Scheurink, E. Bruininx, P. de Vos, H. Smidt, H.A. Schols, and H. Gruppen, Effects of pectin on fermentation characteristics, carbohydrate utilization, and microbial community composition in the gastrointestinal tract of weaning pigs. Molecular Nutrition \& Food Research, 2017. 61(1).

10. Ortega-Gonzalez, M., B. Ocon, I. Romero-Calvo, A. Anzola, E. Guadix, A. Zarzuelo, M.D. Suarez, F. Sanchez de Medina, and O. Martinez-Augustin, Nondigestible oligosaccharides exert nonprebiotic effects on intestinal epithelial cells enhancing the immune response via activation of TLR4-NFkappaB. Molecular Nutrition \& Food Research, 2014. 58(2): p. 384-393.

11. Lee, S.H., P.M. Starkey, and S. Gordon, Quantitative analysis of total macrophage content in adult mouse tissues. Immunochemical studies with monoclonal antibody F4/80. Journal of Experimental Medicine, 1985.161(3): p. 475-489.

12. Flannigan, K.L., D. Geem, A. Harusato, and T.L. Denning, Intestinal Antigen-Presenting Cells: Key Regulators of Immune Homeostasis and Inflammation. American Journal of Pathology, 2015. 185(7): p. 1809-1819.

13. Denning, T.L., Y.C. Wang, S.R. Patel, I.R. Williams, and B. Pulendran, Lamina propria macrophages and dendritic cells differentially induce regulatory and interleukin 17-producing T cell responses. Nature Immunology, 2007. 8(10): p. 1086-1094.

14. Smythies, L.E., M. Sellers, R.H. Clements, M. Mosteller-Barnum, G. Meng, W.H. Benjamin, J.M. Orenstein, and P.D. Smith, Human intestinal macrophages display profound inflammatory anergy despite avid phagocytic and bacteriocidal activity. Journal of Clinical Investigation, 2005. 115(1): p. 66-75. 


\section{Chapter 3}

15. Platt, A.M., C.C. Bain, Y. Bordon, D.P. Sester, and A.M. Mowat, An independent subset of TLR expressing CCR2-dependent macrophages promotes colonic inflammation. Journal of Immunology, 2010.184(12): p. 6843-6854.

16. Tsou, C.L., W. Peters, Y. Si, S. Slaymaker, A.M. Aslanian, S.P. Weisberg, M. Mack, and I.F. Charo, Critical roles for $\mathrm{CCR}_{2}$ and $\mathrm{MCP}-3$ in monocyte mobilization from bone marrow and recruitment to inflammatory sites. Journal of Clinical Investigation, 2007. 117(4): p. 902-909.

17. Zigmond, E., C. Varol, J. Farache, E. Elmaliah, A.T. Satpathy, G. Friedlander, M. Mack, N. Shpigel, I.G. Boneca, K.M. Murphy, G. Shakhar, Z. Halpern, and S. Jung, Ly6C hi monocytes in the inflamed colon give rise to proinflammatory effector cells and migratory antigenpresenting cells. Immunity, 2012. 37(6): p. 1076-1090.

18. Seo, S.U., P. Kuffa, S. Kitamoto, H. Nagao-Kitamoto, J. Rousseau, Y.G. Kim, G. Nunez, and N. Kamada, Intestinal macrophages arising from $\mathrm{CCR}_{2}(+)$ monocytes control pathogen infection by activating innate lymphoid cells. Natture Communications, 2015. 6: p. 8010.

19. Gabanyi, I., P.A. Muller, L. Feighery, T.Y. Oliveira, F.A. Costa-Pinto, and D. Mucida, Neuroimmune Interactions Drive Tissue Programming in Intestinal Macrophages. Cell, 2016. 164(3): p. 378-391.

20. Mazzini, E., L. Massimiliano, G. Penna, and M. Rescigno, Oral Tolerance Can Be Established via Gap Junction Transfer of Fed Antigens from CX3CR1(+) Macrophages to CD103(+) Dendritic Cells. Immunity, 2014. 40(2): p. 248-261.

21. Govers, C., M.M.M. Tomassen, A. Rieder, S. Ballance, S.H. Knutsen, and J.J. Mes, Lipopolysaccharide quantification and alkali-based inactivation in polysaccharide preparations to enable in vitro immune modulatory studies. Bioactive Carbohydrates and Dietary Fibre, 2016. 8(1): p. 15-25.

22. Chanput, W., M. Reitsma, L. Kleinjans, J.J. Mes, H.F. Savelkoul, and H.J. Wichers, beta-Clucans are involved in immune-modulation of THP-1 macrophages. Molecular Nutrition \& Food Research, 2012. 56(5): p. 822-833.

23. de Wit, N.J., M. Hulst, C. Govers, J. van der Meulen, A. van Hoef, G. Stoopen, A. Hamers, A. Hoekman, R. de Vos, T.F. Bovee, M. Smits, J.J. Mes, and P.J. Hendriksen, Effects of Digested Onion Extracts on Intestinal Gene Expression: An Interspecies Comparison Using Different Intestine Models. PloS One, 2016. 11(9): p. e0160719.

24. Piccolo, S.R., M.R. Withers, O.E. Francis, A.H. Bild, and W.E. Johnson, Multiplatform singlesample estimates of transcriptional activation. Proceedings of the National Academy of Sciences of the United States of America, 2013. 110(44): p. 17778-17783.

25. Cordes, T., M. Wallace, A. Michelucci, A.S. Divakaruni, S.C. Sapcariu, C. Sousa, H. Koseki, P. Cabrales, A.N. Murphy, K. Hiller, and C.M. Metallo, Immunoresponsive Gene 1 and Itaconate Inhibit Succinate Dehydrogenase to Modulate Intracellular Succinate Levels. Journal of Biological Chemistry, 2016. 291(27): p. 14274-14284.

26. Cajo, J.F.T.B., Canonical Correspondence Analysis: A New Eigenvector Technique for Multivariate Direct Gradient Analysis. Ecology, 1986. 67(5): p. 1167-1179.

27. Martinez, F.O. and S. Gordon, The M1 and M2 paradigm of macrophage activation: time for reassessment. F100oPrime Rep, 2014. 6: p. 13.

28. Rescigno, M., M. Urbano, B. Valzasina, M. Francolini, G. Rotta, R. Bonasio, F. Granucci, J.P. Kraehenbuhl, and P. Ricciardi-Castagnoli, Dendritic cells express tight junction proteins and penetrate gut epithelial monolayers to sample bacteria. Nature Immunology, 2001. 2(4): p. 361-367.

29. Goodridge, H.S., C.N. Reyes, C.A. Becker, T.R. Katsumoto, J. Ma, A.J. Wolf, N. Bose, A.S.H. Chan, A.S. Magee, M.E. Danielson, A. Weiss, J.P. Vasilakos, and D.M. Underhill, Activation of the innate immune receptor Dectin-1 upon formation of a 'phagocytic synapse'. Nature, 2011. 472(7344): p. 471-U541. 
30. Chanput, W., J.J. Mes, H.F.J. Savelkoul, and H.J. Wichers, Characterization of polarized THP-1 macrophages and polarizing ability of LPS and food compounds. Food \& Function, 2013. 4(2): p. 266-276.

31. Krausgruber, T., K. Blazek, T. Smallie, S. Alzabin, H. Lockstone, N. Sahgal, T. Hussell, M. Feldmann, and I.A. Udalova, IRF5 promotes inflammatory macrophage polarization and TH1TH17 responses. Nature Immunology, 2011. 12(3): p. 231-238.

32. Murray, P.J., J.E. Allen, S.K. Biswas, E.A. Fisher, D.W. Gilroy, S. Goerdt, S. Gordon, J.A. Hamilton, L.B. Ivashkiv, T. Lawrence, M. Locati, A. Mantovani, F.O. Martinez, J.L. Mege, D.M. Mosser, G. Natoli, J.P. Saeij, J.L. Schultze, K.A. Shirey, A. Sica, J. Suttles, I. Udalova, J.A. van Ginderachter, S.N. Vogel, and T.A. Wynn, Macrophage activation and polarization: nomenclature and experimental guidelines. Immunity, 2014. 41(1): p. 14-20.

33. Martinez, F.O., S. Gordon, M. Locati, and A. Mantovani, Transcriptional profiling of the human monocyte-to-macrophage differentiation and polarization: new molecules and patterns of gene expression. Journal of Immunology, 2006. 177(10): p. 7303-7311.

34. Geijtenbeek, T.B. and S.I. Gringhuis, Signalling through C-type lectin receptors: shaping immune responses. Nature Reviews: Immunology, 2009. 9(7): p. 465-479.

35. Buzas, E.I., B. Gyorgy, M. Pasztoi, I. Jelinek, A. Falus, and H.J. Gabius, Carbohydrate recognition systems in autoimmunity. Autoimmunity, 2006. 39(8): p. 691-704.

36. Bose, N., A.S. Chan, F. Guerrero, C.M. Maristany, X. Qiu, R.M. Walsh, K.E. Ertelt, A.B. Jonas, K.B. Gorden, C.M. Dudney, L.R. Wurst, M.E. Danielson, N. Elmasry, A.S. Magee, M.L. Patchen, and J.P. Vasilakos, Binding of Soluble Yeast beta-Glucan to Human Neutrophils and Monocytes is Complement-Dependent. Frontiers in Immunology, 2013. 4: p. 230.

37. Brown, G.D., J. Herre, D.L. Williams, J.A. Willment, A.S. Marshall, and S. Gordon, Dectin-1 mediates the biological effects of beta-glucans. Journal of Experimental Medicine, 2003. 197(9): p. 1119-1124.

38. Sahasrabudhe, N.M., H.A. Schols, M.M. Faas, and P. de Vos, Arabinoxylan activates Dectin-1 and modulates particulate beta-glucan-induced Dectin-1 activation. Molecular Nutrition \& Food Research, 2016. 60(2): p. 458-467.

39. Yamasaki, S., M. Matsumoto, O. Takeuchi, T. Matsuzawa, E. Ishikawa, M. Sakuma, H. Tateno, J. Uno, J. Hirabayashi, Y. Mikami, K. Takeda, S. Akira, and T. Saito, C-type lectin Mincle is an activating receptor for pathogenic fungus, Malassezia. Proceedings of the National Academy of Sciences of the United States of America, 2009. 106(6): p. 1897-1902.

40. Saijo, S., S. Ikeda, K. Yamabe, S. Kakuta, H. Ishigame, A. Akitsu, N. Fujikado, T. Kusaka, S. Kubo, S.H. Chung, R. Komatsu, N. Miura, Y. Adachi, N. Ohno, K. Shibuya, N. Yamamoto, K. Kawakami, S. Yamasaki, T. Saito, S. Akira, and Y. Iwakura, Dectin-2 recognition of alpha-mannans and induction of Th17 cell differentiation is essential for host defense against Candida albicans. Immunity, 2010. 32(5): p. 681-691.

41. Zhu, L.L., X.Q. Zhao, C.Y. Jiang, Y. You, X.P. Chen, Y.Y. Jiang, X.M. Jia, and X. Lin, C-Type Lectin Receptors Dectin-3 and Dectin-2 Form a Heterodimeric Pattern-Recognition Receptor for Host Defense against Fungal Infection. Immunity, 2013. 39(2): p. 324-334.

42. de Saint-Vis, B., J. Vincent, S. Vandenabeele, B. Vanbervliet, J.J. Pin, S. Ait-Yahia, S. Patel, M.G. Mattei, J. Banchereau, S. Zurawski, J. Davoust, C. Caux, and S. Lebecque, A novel lysosomeassociated membrane glycoprotein, DC-LAMP, induced upon DC maturation, is transiently expressed in MHC class II compartment. Immunity, 1998. 9(3): p. 325-336.

43. Mellor, A.L. and D.H. Munn, IDO expression by dendritic cells: tolerance and tryptophan catabolism. Nature Reviews: Immunology, 2004. 4(10): p. 762-774.

44. Pallotta, M.T., C. Orabona, C. Volpi, C. Vacca, M.L. Belladonna, R. Bianchi, G. Servillo, C. Brunacci, M. Calvitti, S. Bicciato, E.M. Mazza, L. Boon, F. Grassi, M.C. Fioretti, F. Fallarino, P. Puccetti, and $U$. Grohmann, Indoleamine 2,3-dioxygenase is a signaling protein in long-term tolerance by dendritic cells. Nature Immunology, 2011. 12(9): p. 870-878. 


\section{Chapter 3}

45. Wang, Y., B.H. Yang, H. Li, S. Cao, X.B. Ren, and J.P. Yu, IDO(+) DCs and signalling pathways. Current Cancer Drug Targets, 2013. 13(3): p. 278-288.

46. Yu, J.P., Y. Wang, F. Yan, P. Zhang, H. Li, H. Zhao, C.H. Yan, F. Yan, and X.B. Ren, Noncanonical NF-kappa B Activation Mediates STAT3-Stimulated IDO Upregulation in Myeloid-Derived Suppressor Cells in Breast Cancer. Journal of Immunology, 2014. 193(5): p. 2574-2586.

47. Sato, K., X.L. Yang, T. Yudate, J.S. Chung, J.M. Wu, K. Luby-Phelps, R.P. Kimberly, D. Underhill, P.D. Cruz, and K. Ariizumi, Dectin-2 is a pattern recognition receptor for fungi that couples with the Fc receptor gamma chain to induce innate immune responses. Journal of Biological Chemistry, 2006. 281(50): p. 38854-38866.

48. Rieder, A., S. Grimmer, F.L. Aachmann, B. Westereng, S.O. Kolset, and S.H. Knutsen, Generic tools to assess genuine carbohydrate specific effects on in vitro immune modulation exemplified by beta-glucans. Carbohydrate Polymers, 2013. 92(2): p. 2075-2083.

49. Ovstebo, R., O.K. Olstad, B. Brusletto, A.S. Moller, A. Aase, K.B. Haug, P. Brandtzaeg, and P. Kierulf, Identification of genes particularly sensitive to lipopolysaccharide (LPS) in human monocytes induced by wild-type versus LPS-deficient Neisseria meningitidis strains. Infection and Immunity, 2008. 76(6): p. 2685-2695.

50. Harris, M.E., R. Bohni, M.H. Schneiderman, L. Ramamurthy, D. Schumperli, and W.F. Marzluff, Regulation of histone mRNA in the unperturbed cell cycle: evidence suggesting control at two posttranscriptional steps. Molecular and Cellular Biology, 1991. 11(5): p. 2416-2424.

51. Heintz, N., H.L. Sive, and R.G. Roeder, Regulation of human histone gene expression: kinetics of accumulation and changes in the rate of synthesis and in the half-lives of individual histone mRNAs during the HeLa cell cycle. Molecular and Cellular Biology, 1983. 3(4): p. 539-550.

52. Agger, K., P.A. Cloos, J. Christensen, D. Pasini, S. Rose, J. Rappsilber, I. Issaeva, E. Canaani, A.E. Salcini, and K. Helin, UTX and JMJD3 are histone $\mathrm{H}_{3} \mathrm{~K}_{2} 7$ demethylases involved in HOX gene regulation and development. Nature, 2007. 449(7163): p. 731-734.

53. Salminen, A., K. Kaarniranta, M. Hiltunen, and A. Kauppinen, Histone demethylase Jumonji D3 (JMJD3/KDM6B) at the nexus of epigenetic regulation of inflammation and the aging process. Journal of Molecular Medicine (Berlin, Germany), 2014. 92(10): p. 1035-1043.

54. Ifrim, D.C., J. Quintin, L.A. Joosten, C. Jacobs, T. Jansen, L. Jacobs, N.A. Gow, D.L. Williams, J.W. van der Meer, and M.G. Netea, Trained immunity or tolerance: opposing functional programs induced in human monocytes after engagement of various pattern recognition receptors. Clinical and vaccine immunology: CVI, 2014. 21(4): p. 534-545.

55. Saeed, S., J. Quintin, H.H. Kerstens, N.A. Rao, A. Aghajanirefah, F. Matarese, S.C. Cheng, J. Ratter, K. Berentsen, M.A. van der Ent, N. Sharifi, E.M. Janssen-Megens, M. Ter Huurne, A. Mandoli, T. van Schaik, A. Ng, F. Burden, K. Downes, M. Frontini, V. Kumar, E.J. GiamarellosBourboulis, W.H. Ouwehand, J.W. van der Meer, L.A. Joosten, C. Wijmenga, J.H. Martens, R.J. Xavier, C. Logie, M.G. Netea, and H.G. Stunnenberg, Epigenetic programming of monocyteto-macrophage differentiation and trained innate immunity. Science, 2014. 345(6204): p. 1251086. 
Supplementary Table 1. Primer details

\begin{tabular}{|c|c|c|}
\hline Genes & Forward (5'-3') & Reverse (5'-3') \\
\hline PUM1 & TGAGGTGTGCACCATGAAC & CAGAATGTGCTTGCCATAGG \\
\hline RPLPo & GCAATGTTGCCAGTGTCTG & GCCTTGACCTTTTCAGCAA \\
\hline IL8 & СTGATTTCTGCAGCTCTGTG & GGGTGGAAAGGTTTGGAGTATG \\
\hline IL12p40 & СTCTGGCAAAACCCTGACC & GCTTAGAACCTCGCCTCCTT \\
\hline CD80 & ACCATCCAAGTGTCCATACC & CACGTGGATAACACCTGAAC \\
\hline STAT1 & CTGGCACCAGAACGAATG & GCTGACGTTGGAGATCAC \\
\hline TNFA & GGCGTGGAGCTGAGAGATAA & GATGGCAGAGAGGAGGTTGA \\
\hline CD209 & AGGAGCAGAACTTCCTAC & GCTCTCCTCTGTTCCAATAC \\
\hline MRC1 & CAGCGCTTGTGATCTTCATT & TACCCCTGCTCCTGGTTTTT \\
\hline MRC2 & GGAAACTCCCACGGAAAG & GTCTCGCAGTCGTTACTC \\
\hline PPARG & TCTAAAGAGCCTGCGAAAGC & GCGGTCTCCACTGAGAATAATG \\
\hline CD36 & GCCAAGGAAAATGTAACCCAGG & GCCTCTGTTCCAACTGATAGTGA \\
\hline IDO1 & GCCAGCTTCGAGAAAGAGTTG & ATCCCAGAACTAGACGTGCAA \\
\hline GBP5 & ACATTAGTTCTGCTTGACACCG & GCTGCTCAGTAAGAGTGCCAG \\
\hline $\mathrm{GCH} 1$ & ACGAGCTGAACCTCCCTAAC & GAACCAAGTGATGCTCACACA \\
\hline LAMP3 & ACTACCCCAGCGACTACAAAA & CTAGGGCCGACTGTAACTTCA \\
\hline CXCL11 & GACGCTGTCTTTGCATAGGC & GGATTTAGGCATCGTTGTCCTTT \\
\hline IRF1 & GCAGCTACACAGTTCCAGG & GTCCTCAGGTAATTTCCCTTCCT \\
\hline Mincle & CTGAAACACAATGCACAGAGAGA & AAAGATGCGAAATGTCACAACAC \\
\hline Dectin-1 & AACCACAGCTACCCAAGAAAAC & GGGCACACTACACAGTTGGTC \\
\hline Dectin-2 & GCTTTCAGACCCACAAGGTAAT & GCAGAATGATTGGGCTCACCTA \\
\hline IL17RB & GGCTGCCTAGACCACATAATG & GCTGTGTTGGATAAGAGCCAT \\
\hline $\mathrm{CHDH}$ & TATCACCCTCCATTCAGCACA & GAACCCACCTGTTTCCAGATG \\
\hline DCIR & GACTGTGCTAGAATGGAGGCT & GTCGCTGACCTTCTGGATCTC \\
\hline MGL & AGCAACTTCACCTCAAACACTG & AGATGCTATCGTTTCTTCCAAGC \\
\hline
\end{tabular}




\section{Chapter 3}

Supplementary Table 2: Function of gene markers for $\mathrm{M}_{1}$ and $\mathrm{M}_{2}$

\begin{tabular}{|c|c|c|c|c|c|}
\hline Subset & General function ${ }^{a}$ & Gene & Microarrayb & $q P^{\prime} R^{b}$ & Notes \\
\hline \multirow{10}{*}{ M1 } & \multirow{2}{*}{$\begin{array}{l}\text { Carbohydrate } \\
\text { recognition }\end{array}$} & $\begin{array}{l}\text { Dectin- } \\
2\end{array}$ & 23 & 154 & $\begin{array}{l}\text { Binds high-mannose } \\
\text { carbohydrates }\end{array}$ \\
\hline & & Mincle & 16 & 128 & $\begin{array}{l}\text { Binds damaged cells, } \\
\text { fungi and mycobacteria }\end{array}$ \\
\hline & \multirow{2}{*}{$\begin{array}{l}\text { Interferon related } \\
\text { transcription factor }\end{array}$} & STAT1 & 5 & 27 & $\begin{array}{l}\text { Mediates cellular } \\
\text { responses to interferons }\end{array}$ \\
\hline & & IRF1 & 23 & 82 & $\begin{array}{l}\text { Activator of interferon- } \alpha \\
\text { and- } \beta \text { transcription }\end{array}$ \\
\hline & \multirow{6}{*}{$\begin{array}{l}\text { Functional } \\
\text { inflammatory } \\
\text { responses to } \\
\text { pathogens }\end{array}$} & CD80 & 10 & 11 & $\begin{array}{l}\text { Provides co-stimulatory } \\
\text { signals essential for } T\end{array}$ \\
\hline & & LAMP3 & 81 & 70 & $\begin{array}{l}\text { Involved in antigen } \\
\text { processing }\end{array}$ \\
\hline & & GBP5 & 74 & 904 & $\begin{array}{l}\text { Activator of NLRP3 } \\
\text { inflammasome }\end{array}$ \\
\hline & & $\mathrm{GCH} 1$ & 32 & 196 & $\begin{array}{l}\text { Positively regulates } \\
\text { nitric oxide synthesis }\end{array}$ \\
\hline & & IDO1 & 799 & 30780 & $\begin{array}{l}\text { Catalyzes rate-limiting } \\
\text { step in tryptophan }\end{array}$ \\
\hline & & CXCL11 & 32 & 21017 & $\begin{array}{l}\text { Induces chemotactic } \\
\text { responses in activated } \mathrm{T}\end{array}$ \\
\hline \multirow{9}{*}{ M2 } & \multirow{3}{*}{ Energy supply } & CD36 & 1 & 8 & $\begin{array}{l}\text { Binds long-chain fatty } \\
\text { acids and facilitates }\end{array}$ \\
\hline & & PPARG & 2 & 6 & $\begin{array}{l}\text { Controls the } \\
\text { peroxisomal beta- } \\
\text { oxidation pathway of }\end{array}$ \\
\hline & & $\mathrm{CHDH}$ & 25 & 162 & $\begin{array}{l}\text { Mitochondrial } \\
\text { oxidoreductase activity }\end{array}$ \\
\hline & \multirow{5}{*}{$\begin{array}{l}\text { Carbohydrate } \\
\text { recognition }\end{array}$} & $\mathrm{MRC} 1$ & 7 & 20 & $\begin{array}{l}\text { Mediates the } \\
\text { endocytosis of }\end{array}$ \\
\hline & & $\begin{array}{l}\text { Dectin- } \\
1\end{array}$ & 3 & 4 & $\begin{array}{l}\text { Specifically binds } \beta-1,3- \\
\text { linked and } \beta-1,6 \text {-linked }\end{array}$ \\
\hline & & CD209 & 15 & 70 & $\begin{array}{l}\text { Mediates the } \\
\text { endocytosis of }\end{array}$ \\
\hline & & $\mathrm{DCIR}$ & 7 & 14 & $\begin{array}{l}\text { Putative role in } \\
\text { regulating immune }\end{array}$ \\
\hline & & MGL & 19 & 26 & Binds to glycoproteins \\
\hline & $\begin{array}{l}\text { Intestinal } \\
\text { immunoregulatory } \\
\text { activity }\end{array}$ & IL17RB & 12 & 995 & $\begin{array}{l}\text { Receptor that can } \\
\text { activate NF-kB and } \\
\text { induce IL- } 8 \text { production }\end{array}$ \\
\hline
\end{tabular}

a Function was extracted from description in www.genecards.org. ${ }^{b}$ Fold-change of $\mathrm{M}_{1} / \mathrm{M}_{2}$ (for M1 cells) or M2/M1 (for $M_{2}$ cells). 


\section{Supplementary Figure 1}

A

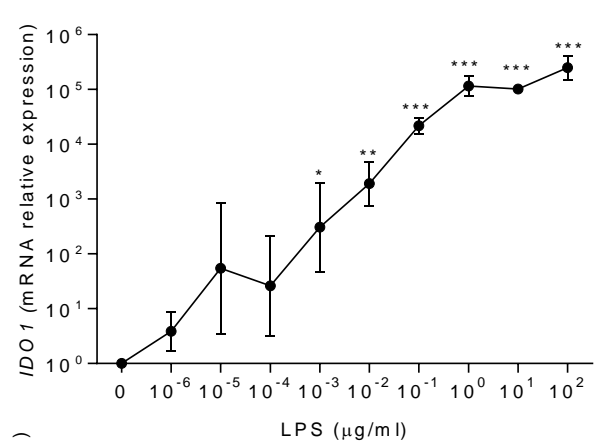

C

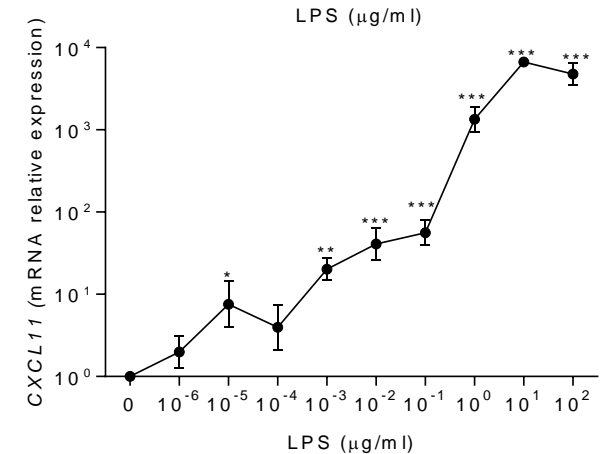

B

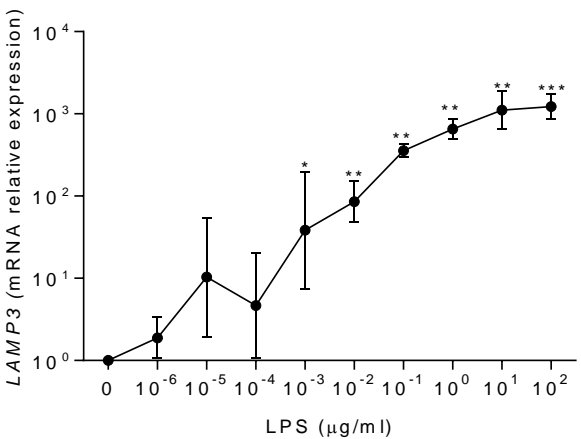

D

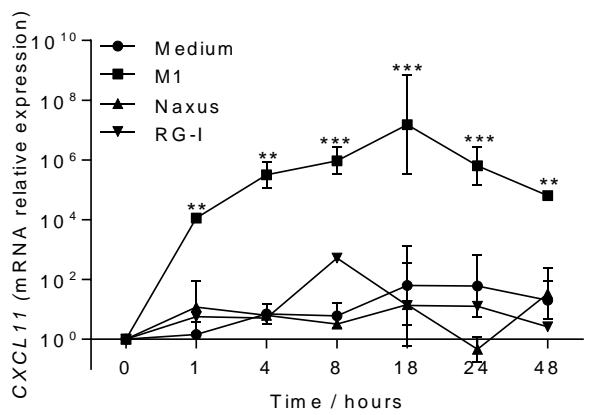

Supplementary Figure 1. LPS induces IDO1, LAMP3 and CXCL11 expression in macrophages, of which the latter is not observed in RG-I- and Naxus-stimulated macrophages. Primary monocytes were differentiated for 7 days to macrophages which were subsequently stimulated with various concentrations of LPS or NDPs. Gene expression of (A) IDO1, (B) LAMP3, and (C) CXCL11 was analysed by $\mathrm{qPCR}$ following Mo stimulation with various concentrations of LPS, $n=3$ different donors. (D) CXCL11 gene expression was analysed by $\mathrm{qPCR}$ in more details following 1, 4, 8, 18, 24, and $48 \mathrm{~h}$ of M1 polarisation or RG-I or Naxus stimulation. Results are shown as fold change compared to non-stimulated macrophages by mean values \pm SEM. Statistically significant differences were analysed by one-way ANOVA: * $\mathrm{p}<0.05,{ }^{* *} \mathrm{P}<0.01, * * * \mathrm{p}<0.001$. 



\section{Chapter 4}

Human macrophages stimulated with nondigestible polysaccharides are in function and chemokine production different from inflammatory and tolerant macrophages

Yongfu Tang, Coen Govers, Ellen H. Stolte, Harry J. Wichers, Jurriaan J. Mes

Manuscript in preparation 


\section{Chapter 4}

\section{Abstract}

Scope: The immunomodulatory properties of non-digestible polysaccharides (NDPs) have been recognized in in vitro and in vivo studies. Macrophages represent an important cell type for mediating immune signaling following NDP consumption. In a previous study we analyzed macrophage gene transcription following NDP treatment with four different NDPs which revealed a transcriptionally unique phenotype when compared to $\mathrm{M}_{1}$ or $\mathrm{M}_{2}$ macrophages. The aim of this study was to functionally characterize $\mathrm{M}_{\mathrm{NDP}}$ in comparison to $\mathrm{M}_{1}$ and $\mathrm{M}_{2}$ macrophages.

Methods and results: We assessed $M_{1}$ and $M_{2}$ and NDP-treated macrophages for IDO activity, characteristic of M1 macrophages, and antigen uptake and processing capacity, characteristic of M2 macrophages, and for phagocytotic capacity. Surprisingly, NDPtreated macrophages showed no IDO activity and inhibited antigen uptake and processing. Their phagocytotic capacity was reduced compared to $M_{1}$ or $M_{2}$ macrophages. Furthermore, microarray analysis revealed an alternative expression pattern for NDP-treated macrophages which was confirmed by protein measurements. The signature mix of $C_{C L} 1, C C L 5, C C L 20, C C L 24, C X C L 8$, and IL1 $\beta$ secreted by $M_{N D P}$, and in particular when macrophages were treated with Naxus, was shown to induce migration of monocytes.

Conclusion: We have shown that NDP-treatments results in a macrophage phenotype that is transcriptionally and functionally different from $M_{1}$ and $M_{2}$ macrophages. This $M_{N D P}$ might represent an intermediate phenotype that contributes to the maintenance of intestinal homeostasis.

Keywords: Arabinoxylan; Cytokines; $\beta$-Glucans; Migration; Phagocytosis; Wheat

Abbreviations: LCES, lentinan containing extracted from shiitake; MFI, Mean fluorescence intensity; $\mathbf{M}_{\mathrm{NDP}}$, NDP specific macrophage subset; NDP, non-digestible polysaccharide; 


\section{Introduction}

Non-digestible polysaccharides (NDPs) are known for their immune-modulating properties $[1,2]$. These properties were not only demonstrated in vitro but also reported in clinical studies. NDP intake by obese people resulted in a reduction of proinflammatory cytokines (i.e. IL6 and TNFa) and an increase in the anti-inflammatory IL10 levels in peripheral blood [3]. These changes in cytokine balance were accompanied by a reduced waist circumference and blood pressure which are considered risk factors. Furthermore, NDPs demonstrated to increase NK cell activity and peripheral blood levels of myeloid dendritic cells and $\mathrm{T}_{\mathrm{H} 1}$ related cytokines in multiple myeloma patients, however without reported beneficial effects on disease progress [4]. Other examples in which NDPs demonstrated effects in clinical trials include an increase in NK cell activity linked to a reduction in metastasis in lung and breast cancer patients [5]; an increase in blood leukocytes, neutrophils, IgG and IgM accompanied by a delayed progression of non-small cell lung cancer [6]; and transiently increased blood levels of IgG and IgM and NK cell counts linked to a reduction in flu and flu-like symptoms and respiratory tract infections in children [7].

To benefit health through immunomodulation, NDPs need to be recognized and/or sampled to induce cellular responses. NDPs can come into contact with intestinal immune cells located in the Peyer's patches by transcytosis across the intestinal epithelium by microfold cells [8]. Peyer's patches consist of a wide array of immune cells including T cells, B cells, dendritic cells and macrophages. Alternatively, NDPs have been shown to directly interact with the intestinal immune system [9]. Especially $C_{3} C_{3} \mathrm{C}_{1}$ positive antigen presenting cells can directly sample the lumen and were shown to consist for $75-80 \%$ of macrophages [10]. These CX3CR1-macrophages were demonstrated to be of an immune suppressive subset (often referred to as $M_{2}$ ) [11]. In case of intestinal inflammation the influx of an inflammatory macrophage subset can be observed (often referred to as M1) $[12,13]$. Both macrophages subsets have an important role in maintaining homeostasis [14]. $\beta$-Glucans can potentially influence the polarisation of macrophages through interaction with expressed pattern recognition receptors (PRRs) such as dectin-1. This was the first receptor proven to bind $\beta$-glucans to initiate functional responses in macrophages [15]. More and more PRRs are being identified through which NDPs can modulate immune responses including dectin-2 [16], mannose receptor [17], complement receptor 3 [18] and scavenger receptors [19]. We previous showed that NDPs increased gene expression of dectin-2, dectin-3, Mincle, and LOX1, and decreased CD302, MRC2, and MDL1 on [20], which might suggest a positive-feedback signal. 


\section{Chapter 4}

In a previous study we demonstrated that NDPs from different sources induced a transcriptionally unique macrophage subset, termed $M_{N D P}$, compared to inflammatory and tolerant macrophages [20]. Here, we analysed the functionality of $M_{N D P}$ in comparison to $\mathrm{M}_{1}$ and $\mathrm{M}_{2}$ macrophages to gain insight into the potential implications of interactions between NDP and macrophages in the intestine.

\section{Materials and Methods}

\subsection{NDP characteristics}

Macrophages were treated with Wellmune Soluble, RG-I, LCES, or Naxus as described previously [20]. In brief, Wellmune Soluble (referred as Wellmune in tables and figures) is a water soluble $\beta-1,3 / 1,6$-glucan from the yeast Saccharomyces cerevisiae provided by BioThera (Eagan, MN, USA). RG-I is a concentrate of rhamnogalacturonan I from apple juice provided by INRA (Paris, France). LCES (lentinan containing extract from shiitake) is a $\beta-1,3 / 1,6$-glucan extract from shiitake. Naxus is a polysaccharide from wheat, rich in arabinoxylan, provided by BioActor (Maastricht, The Netherlands). Before exposure to macrophages, RG-I was treated with alkaline-ethanol at $4{ }^{\circ} \mathrm{C}$ for $5 \mathrm{~h}$, and LCES and Naxus were treated with alkaline-ethanol at $56^{\circ} \mathrm{C}$ for $5 \mathrm{~h}$, followed by neutralization with $\mathrm{HCl}$ and freeze-drying to inactivate lipopolysaccharide (LPS) [21]. Resulting functional LPS contaminations of all NDPs samples was demonstrated to be below $0.01 \mathrm{EU} / \mathrm{mg}$ [21].

\subsection{Primary macrophage differentiation and polarization}

Primary macrophages were differentiated as previously described [20]. In brief, human monocytes were obtained from buffy coats from healthy donors (Sanquin, Nijmegen, The Netherlands) using the QuadroMACS system and CD14 microbeads according to manufacturer's protocol (Miltenyi Biotec, Leiden, The Netherlands). A written informed consent was obtained before sample collection. Monocytes were differentiated into macrophages following 7 days culturing in presence of $50 \mathrm{ng} / \mathrm{ml}$ MCSF (R\&D systems, Minneapolis, USA). MCSF was replenished after 3 and 5 days of culture. On day 7 macrophages were polarized by addition of medium containing $20 \mathrm{ng} / \mathrm{ml}$ TNFa and 20 $\mathrm{ng} / \mathrm{ml} \mathrm{IFN \gamma}$ (for M1), $20 \mathrm{ng} / \mathrm{ml} \mathrm{IL4} \mathrm{(for} \mathrm{M2)} \mathrm{or} 500 \mu \mathrm{g} / \mathrm{ml}$ NDPs (for MNDP generation) for $18 \mathrm{~h}$ (unless stated otherwise).

\subsection{RNA extraction and microarray analysis}

RNA extraction and microarray analysis was performed as described previously [20]. Briefly, RNA was extracted with TRIzol (Invitrogen, Bleiswijk, The Netherlands) and RNeasy kits (Qiagen, Venlo, The Netherlands). RNA quality was verified with the RNA 
6000 Nano assay on the Agilent 2100 Bioanalyzer (Agilent Technologies, Amstelveen, The Netherlands) and microarray analysis was performed using Affymetrix Human Gene 1.1 ST array plates and an Affymetrix Geen Titan platform. Data was processed using the Bioconductor project package, the Robust Multi-array Average method to acquire signal intensities, remapped chip definition file (CDF) to define probe sets, and the UPC algorithm to identify expressed genes. Next, cut-off values of absolute fold change compared to non-stimulated macrophages $>1.8$ and a false discovery rate of $p<0.05$ (IBMT regularised paired t-test) for at least one treatment were used to select genes for functional interpretation with Ingenuity Pathway Analysis (IPA) 3.0 (Ingenuity, Qiagen, Redwood, CA, USA). Microarray data were deposited in the Gene Expression Omnibus (GEO) database.

\subsection{Kynurenine assay}

Polarised, NDP-treated or medium stimulated macrophages were washed with PBS and incubated with $0.5 \mathrm{mM}$ tryptophan (Sigma, St. Louis, MO, USA) for $24 \mathrm{~h}$. Supernatant of macrophage cultures $(100 \mu \mathrm{l})$ was mixed with $20 \mu \mathrm{L}$ of $30 \%$ trichloroacetic acid and incubated at $50{ }^{\circ} \mathrm{C}$ for 30 minutes followed by centrifugation at $2500 \mathrm{~g}$ for 15 minutes. Subsequently, $75 \mu \mathrm{l}$ of supernatant was added to $75 \mu \mathrm{l}$ of Ehrlich reagent (100 mg Pdimethylbenzaldehyde (Sigma) in $5 \mathrm{~mL}$ glacial acetic acid) in 96-well plate wells and measured at $475 \mathrm{~nm}$ with a microplate reader (Tecan, Männedorf, Switzerland). A calibration range of kynurenine concentration (0-200 $\mu \mathrm{M})$ was included in each plate. All assays were performed in biological triplicates and each sample analysed by technical duplicates.

\subsection{Flow cytometry}

IDO protein level was analysed by intracellular staining and analysed by flow cytometry. Polarised, NDP-treated or medium stimulated macrophages were washed with PBS without calcium and magnesium and detached by 10 minutes incubation with $0.25 \%$ Trypsin/EDTA (Gibco, Bleiswijk, The Netherlands) at $37^{\circ} \mathrm{C}$. Following two washes with PBS (450g centrifugation), macrophages were permeabilized using the FIX\&PERM cell permeabilization kit (Invitrogen) according to the manufacturer's instructions. Cells were subsequently stained with $2 \mu$ of IDO-APC (R\&D systems) or an isotype control (BD Biosciences, Breda, The Netherlands) for 30 minutes in the dark at RT. Finally, cells were washed with PBS and analysed using flow cytometry (excitation at $635 \mathrm{~nm}$, emission at $670 \mathrm{~nm}$ ) (Accuri ${ }^{\mathrm{TM}}$ C6, BD Biosciences) with Accuri C6 software. 


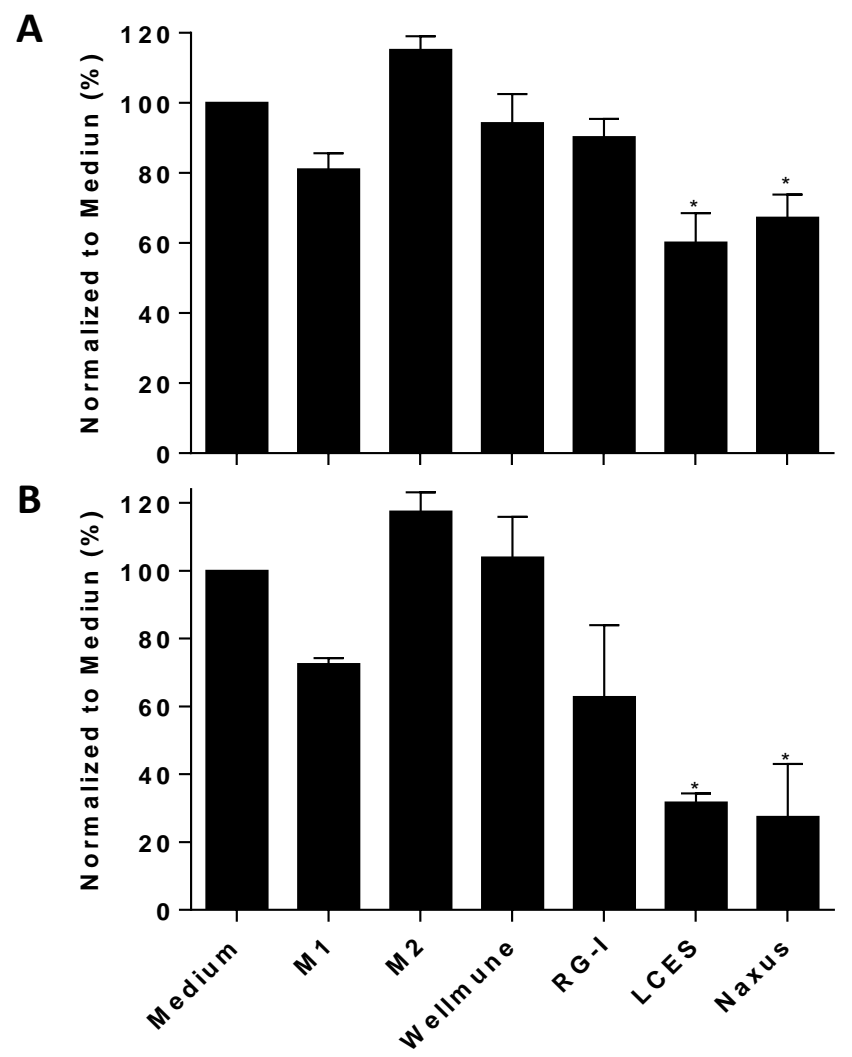

Figure 1. NDP-treated macrophages demonstrated decreased phagocytosis of E.coli particles. Macrophages were polarised towards $M_{1}$ or $M_{2}$ or treated with $500 \mu \mathrm{g} / \mathrm{ml}$ Wellmune Soluble, RGI, LCES, or Naxus for 18 (A) or $48 \mathrm{~h}$ (B) and subsequently incubated for $1 \mathrm{~h}$ with fluorescent E.colibioparticles. Phagocytosis of E.coli-bioparticles was analysed by measuring MFI using flow cytometry. Bar charts show mean values normalised to medium stimulation (100\%) \pm SEM of $n=5$ (A) or 2 (B) different donors. Statistically significant differences were analysed compared to medium by one-way ANOVA: * $\mathrm{p}<0.05$

\subsection{Phagocytosis assay and antigen processing analysis}

To analyse phagocytic activity and antigen processing, polarised, NDP-treated or medium stimulated macrophages were washed with PBS and incubated for $1 \mathrm{~h}$ in $0.5 \mathrm{ml}$ culture medium containing $2 \mu \mathrm{g} / \mathrm{ml}$ E.coli bioparticles (Molecular Probes, Leiden, The Netherlands) or $10 \mathrm{ng} / \mathrm{ml}$ DQ-OVA (D12053, Molecular Probes), respectively. Before 
addition, E.coli bioparticles were re-suspended in non-heat-inactivated human serum (2 $\mathrm{mg} / 100 \mu \mathrm{l}$ ) and incubated for 60 minutes at $37^{\circ} \mathrm{C}$. Macrophages were detached as described above and diluted three times with PBS with $2 \%$ FBS. Cells were re-suspended in $200 \mu \mathrm{l}$ PBS and analysed using flow cytometry (bioparticles: excitation at $495 \mathrm{~nm}$, emission at $519 \mathrm{~nm}$; DQ-OVA: excitation at $505 \mathrm{~nm}$, emission at $515 \mathrm{~nm}$ ) with Accuri C6 software.

\subsection{Multiplex cytokine analysis}

Secretion of cytokines and chemokines by macrophages following stimulation with medium, polarisation or treatment with NDP was measured using Bio-Plex Pro Reagent Kit (BioRad, Veenendaal, The Netherlands) according to the manufacturer's instructions. In brief, $50 \mu \mathrm{L}$ magnetic beads were dispersed in a plate together with $50 \mu$ l of undiluted sample or standard and incubated for $1 \mathrm{~h}$ at RT. Subsequently, the beads were incubated with $25 \mu$ l detection antibodies for $30 \mathrm{~min}$ and with $50 \mu \mathrm{l}$ streptavidin-PE for $10 \mathrm{~min}$ at RT. The beads were re-suspended in $125 \mu$ lassay buffer and read by Bio-Plex ${ }^{\circledR}$ MAGPIX ${ }^{\mathrm{TM}}$ Multiplex Reader (BioRad). Data processing was performed by using Bio-Plex Manager 5.0 , and concentrations (in $\mathrm{pg} / \mathrm{ml}$ ) were interpolated from standard curves. To identify relations and to display our results most effectively, we used lower or upper limit of the standard curve for data points that were below or above the standard curve, respectively.

\subsection{Migration assay}

Migration assays were performed using an xCELLigence RTCA DP system (xCELLigence, ACEA Biosciences, San Diego, USA) and CIM-16 well plates, according to the manufacturer's instructions. In brief, $160 \mu \mathrm{l}$ of macrophage-conditioned medium following polarisation, NDP-treatment or medium stimulation were added to the lower chamber of CIM-16 well plates. Fresh macrophage culture medium was used as negative control and CCL5 $(400 \mathrm{ng} / \mathrm{ml})$ as positive control. Following upper chamber attachment to the lower chamber, the upper chamber wells were filled with $50 \mu \mathrm{l} \mathrm{THP-1}$ cell culture medium and equilibrated at $37^{\circ} \mathrm{C}$ for $1 \mathrm{~h}$ which was recorded as background cell index. Next, $50 \mu \mathrm{l}$ THP-1 cell suspension ( $8 \times 10^{6}$ cells $/ \mathrm{ml}$ ) was added to the upper chamber after which cells were allowed to settle for 5 minutes at RT. The cell index is a unit-less parameter used to indicate the impedance of electron flow caused by adherent cells and defined as (impedance at time point impedance - impedance in the absence of cells) / nominal impedance value. The cell index was measured every 5 min over the course of $22 \mathrm{~h}$. Monocyte migration was subsequently calculated as area under the curve using Prism 6 software (Graphpad, La Jolla, USA). 


\section{Chapter 4}

\subsection{Statistics}

All parameters are presented as means \pm SEM and differences between parameters were assessed for their significance with one-way ANOVA using Prism 6 software. Differences with $\mathrm{p}<0.05$ were considered significant.

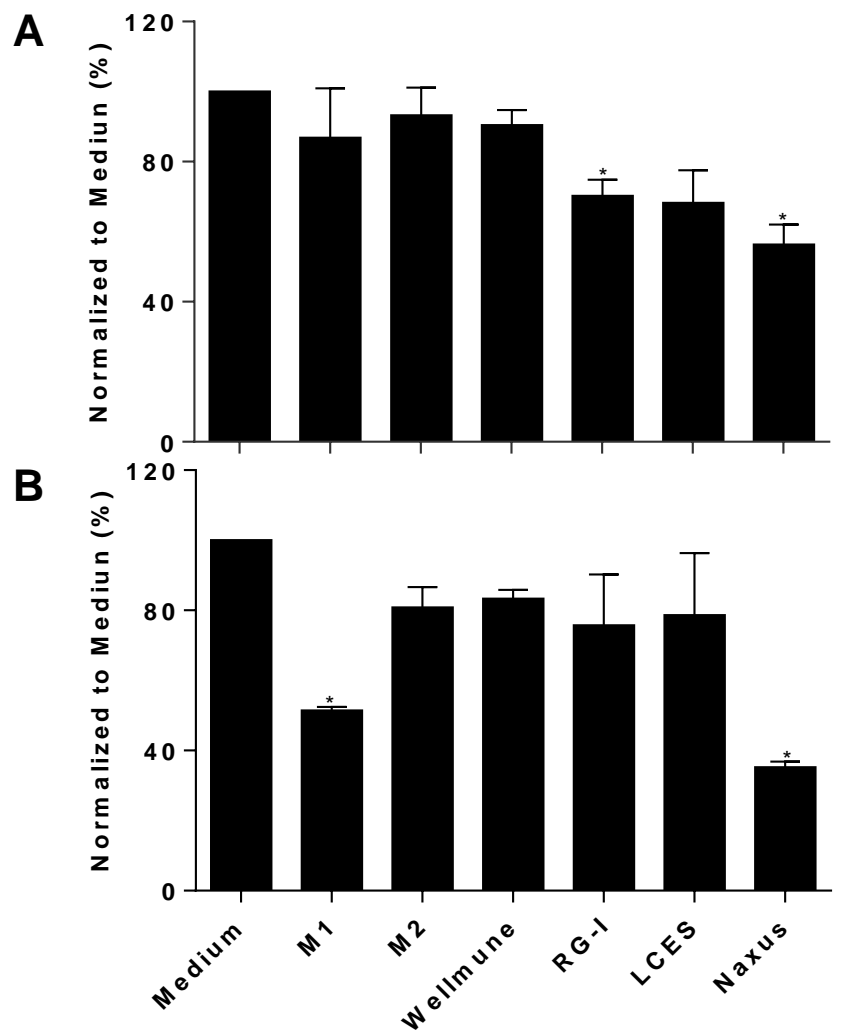

Figure 2. NDP-treatment of macrophages decreases their antigen processing capacity. Macrophages were polarised towards $\mathrm{M}_{1}$ or $\mathrm{M} 2$ or treated with $500 \mu \mathrm{g} / \mathrm{ml}$ Wellmune Soluble, RGI, LCES, or Naxus for 18 (A) or $48 \mathrm{~h}$ (B) and subsequently incubated for $1 \mathrm{~h}$ with DQ-OVA. Processing of DQ-OVA was analysed by measuring MFI using flow cytometry. Bar charts show mean values normalised to medium stimulation (100\%) \pm SEM of $n=4$ (A) or 2 (B) different donors. Statistically significant differences were compared to medium by one-way ANOVA: * $p<0.05$. 


\section{Results}

\subsection{NDPs LCES and Naxus reduce macrophage phagocytic capacity}

Phagocytosis constitutes an important function and characteristic of macrophages [22]. In our previous study, where we investigated gene transcriptional responses of macrophages, analysis with Ingenuity Pathway analysis (IPA) revealed that genes coding for proteins involved in the pathway of phagosome formation were strongly affected by the NDPs (Supplementary Table 1) [20]. Those genes included receptors for NDP recognition (Dectin-1, MRC1, MRC2, CD302, MTERTK, TLR3, TLR4, and TLR7) and adaptors for modulating signalling pathways (SYK, PKC, PI3K, Rho-GTPase). To evaluate phagocytosis capacity of macrophages stimulated with various NDPs, we analysed uptake of E. coli bioparticles by flow cytometry (Figure 1). Following 18 and $48 \mathrm{~h}$ of incubation, $\mathrm{M}_{2}$ macrophages demonstrated an enhanced uptake of E.coli-bioparticles and M1 macrophages showed a reduced uptake. Interestingly, LCES and Naxus significantly reduced E.coli-bioparticle uptake following $18 \mathrm{~h}$ and, even more pronounced, following $48 \mathrm{~h}$ of incubation. In addition, RG-I demonstrated a reduced, albeit not significant, phagocytosis after $48 \mathrm{~h}$ of incubation.

\subsection{NDP-treated macrophages demonstrated reduced antigen processing capacity}

As phagocytosis of pathogens can lead to antigen presentation [23], we investigated whether LCES and Naxus also reduce antigen processing in macrophages. To study this, polarized or NDP-treated macrophages were incubated with DQ-OVA, a self-quenching conjugate of ovalbumin that fluoresces upon proteolytic degradation (Figure 2). Following $18 \mathrm{~h}$ of macrophage treatment, M1 and M2 macrophages demonstrated no change in antigen processing. However, NDPs RG-I and Naxus significantly, and LCES non-significantly, reduced antigen processing of macrophages. Of note, M1 macrophages and also Naxus-treated macrophages, but not RG-I-treated macrophages, showed significantly reduced antigen processing following $48 \mathrm{~h}$ of incubation.

\subsection{NDPs did not induce IDO translation and activity}

IDO activity is considered a key characteristic of M1 [24] and IDO1 was identified as MNDP gene transcription marker [20]. To investigate IDO activity we analysed kynurenine levels in macrophage-conditioned medium following polarisation towards $M_{1}, M_{2}$, or treatment with NDPs (Figure 3A). As expected, we found high concentrations of kynurenine in M1-conditioned medium and could not detect kynurenine in $\mathrm{M}_{2}$ conditioned medium. Surprisingly, kynurenine levels in $\mathrm{M}_{\mathrm{NDP}}$-conditioned medium was also non detectable. To investigate the discrepancy between IDO gene transcription and activity in macrophages treated with NDPs, we analysed IDO protein expression 


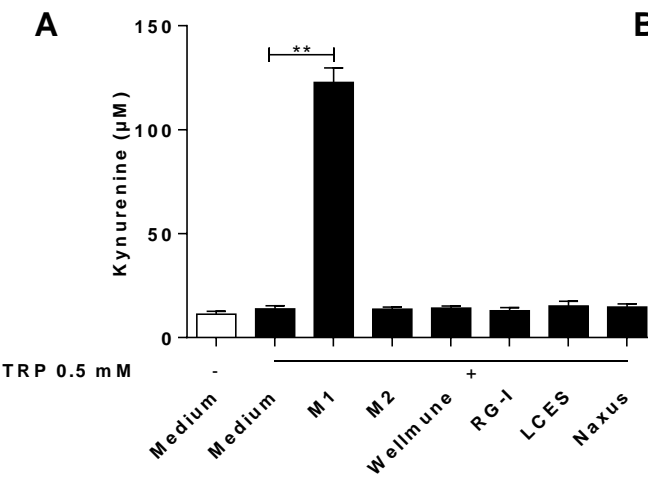

Figure 3. Naxus-treated macrophages do not induce IDO activity nor protein production. (A) Macrophages were polarised to $\mathrm{M}_{1}$ or $\mathrm{M}_{2}$ macrophages or treated with $500 \mu \mathrm{g} / \mathrm{ml}$ Wellmune Soluble, RG-I, LCES, or Naxus for $18 \mathrm{~h}$. Macrophages were subsequently incubated with tryptophan for $24 \mathrm{~h}$ after which kynurenine secretion was analysed by colorimetric assay. (B-D) Macrophages were analysed for IDO protein production by flow cytometry during polarisation towards $\mathrm{M}_{1}$ or treatment with Naxus following 1, 4, 8, 18, 24, and $48 \mathrm{~h}$. Bar charts show mean values + SEM of $n=3$ different donors. Statistically significant differences were analysed compared to medium by one-way ANOVA: * $p<0.05$.
B

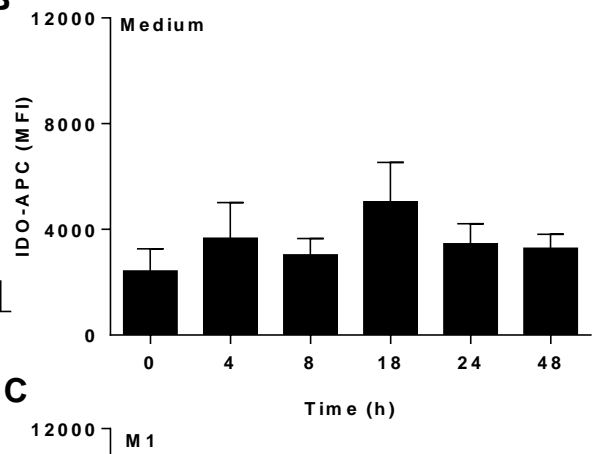

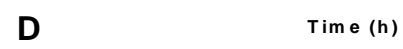

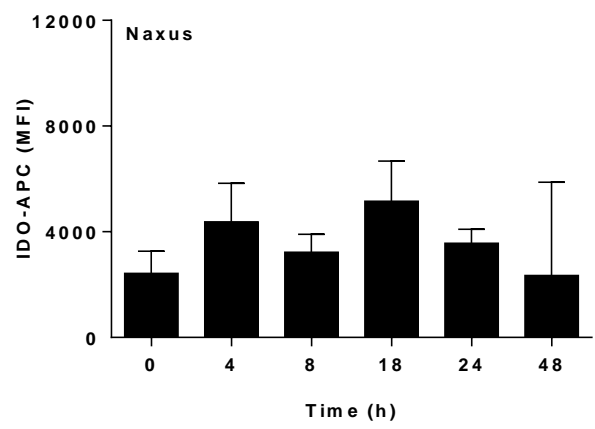

following 4, 8, 18, 24, and 48 h of incubation in M1- and Naxus-treated macrophages, which induced the strongest increase in IDO1 transcription among the NDPs. We used flow cytometry and analysed relative intracellular IDO protein concentrations by detecting mean fluorescence intensity (Figure 3B-D). This revealed that $M 1$ macrophages contain significantly increased levels of IDO protein compared to medium-stimulated macrophages following $24 \mathrm{~h}$ of incubation. Naxus-treated macrophages, however, demonstrated no apparent increase in IDO protein level compared to medium control at any time point. 


\subsection{NDPs promote macrophage secretion of a unique set of signalling molecules}

Analysis of gene transcriptional responses of macrophages to NDPs revealed a distinct signature profile of cytokine and chemokine gene expression when compared to M1 and M2 macrophages (Table 1). To analyse how these high levels of transcripts related to protein production, we quantified cytokines and chemokines in macrophageconditioned medium following 18 and $48 \mathrm{~h}$ of incubation by multiplex cytokine analysis (Figure 4 and Supplementary Figure 1, respectively). CXCL9, CXCL10, CXCL11, and TNFa were chosen for analysis based on M1 macrophage gene expression levels, CCL24 was chosen based on $\mathrm{M} 2$ macrophage gene expression levels, and CCL1, CCL5, CCL20, CXCL8, IL1 $\beta$, and MMP-1 were chosen based on NDP-treated macrophage gene expression levels. Most of the significant differences in gene transcription between medium stimulated and NDP-treated or polarised macrophages could not be confirmed with protein secretion. However, the multiplex results did even more strongly than gene transcription analysis demonstrate the unique profile of cytokine and chemokine production of NDPtreated macrophages when compared to medium, or $M_{1}$ and $M_{2}$ macrophages. $M_{1}$ macrophages demonstrated a significant increase in secretion of TNFa, CXCL9, CXCL10, and CXCL11 following $18 \mathrm{~h}$ of polarisation and also of CCL5 following $48 \mathrm{~h}$ of incubation. In contrast, $\mathrm{M}_{2}$ macrophages did not show a significant change in cytokine and chemokine secretion compared to medium following either 18 or $48 \mathrm{~h}$ of incubation, including $\mathrm{CCL}_{24}$ which was identified as M2 macrophage marker. Naxus-treated macrophages demonstrated a significant increase in $C_{C L 1}, C_{C L}, C C L 20, C X C L 8$, and IL1 $\beta$ secretion following $18 \mathrm{~h}$ of incubation and also of CCL24 following $48 \mathrm{~h}$ of incubation. Macrophages treated with LCES significantly increased secretion of CCL1, CCL24, and CXCL8 following $18 \mathrm{~h}$ of incubation whereas RG-I-treated macrophages only significantly increased CXCL8 production. Finally, none of the cytokines or chemokines of which Wellmune Soluble significantly increase gene transcription revealed an increased secretion level compared to medium-stimulated macrophages.

Figure 4. Macrophages treated with NDPs secrete a unique mixture of cytokines and chemokines. Macrophages were polarised towards $M_{1}$ or $M_{2}$ or treated with $500 \mu \mathrm{g} / \mathrm{ml}$ Wellmune Soluble, RG-I, LCES, or Naxus for 18 h. Cytokine and chemokine secretion was analysed with Bio-Plex multiplex analysis. Bar charts show mean values $\pm S E M$ of $n=3$ different donors. Statistically significant differences were analysed compared to medium by one-way ANOVA: * $\mathrm{p}<0.05, * * \mathrm{p}<0.01, * * * \mathrm{P}<0.001$. (See next page) 

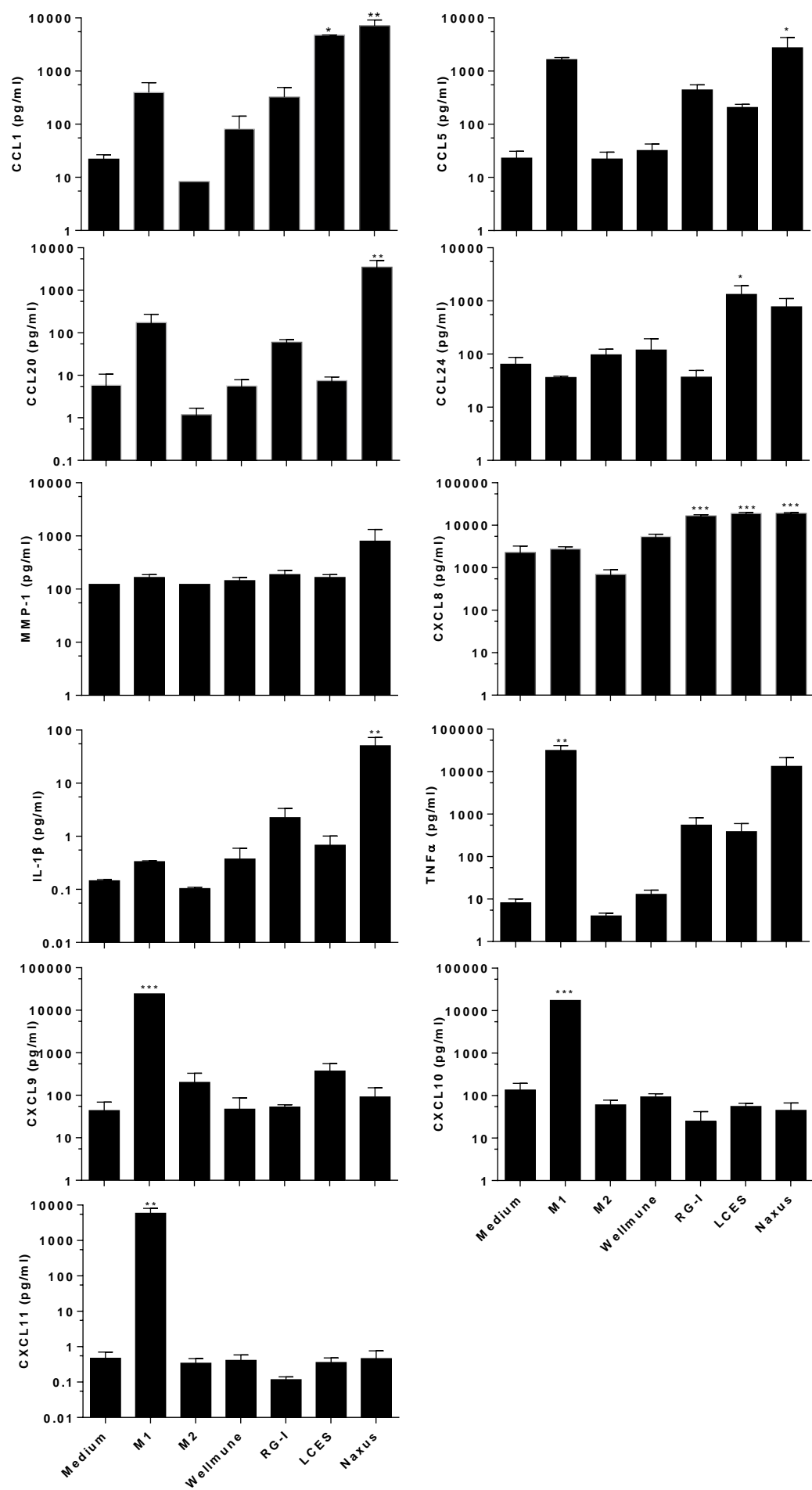


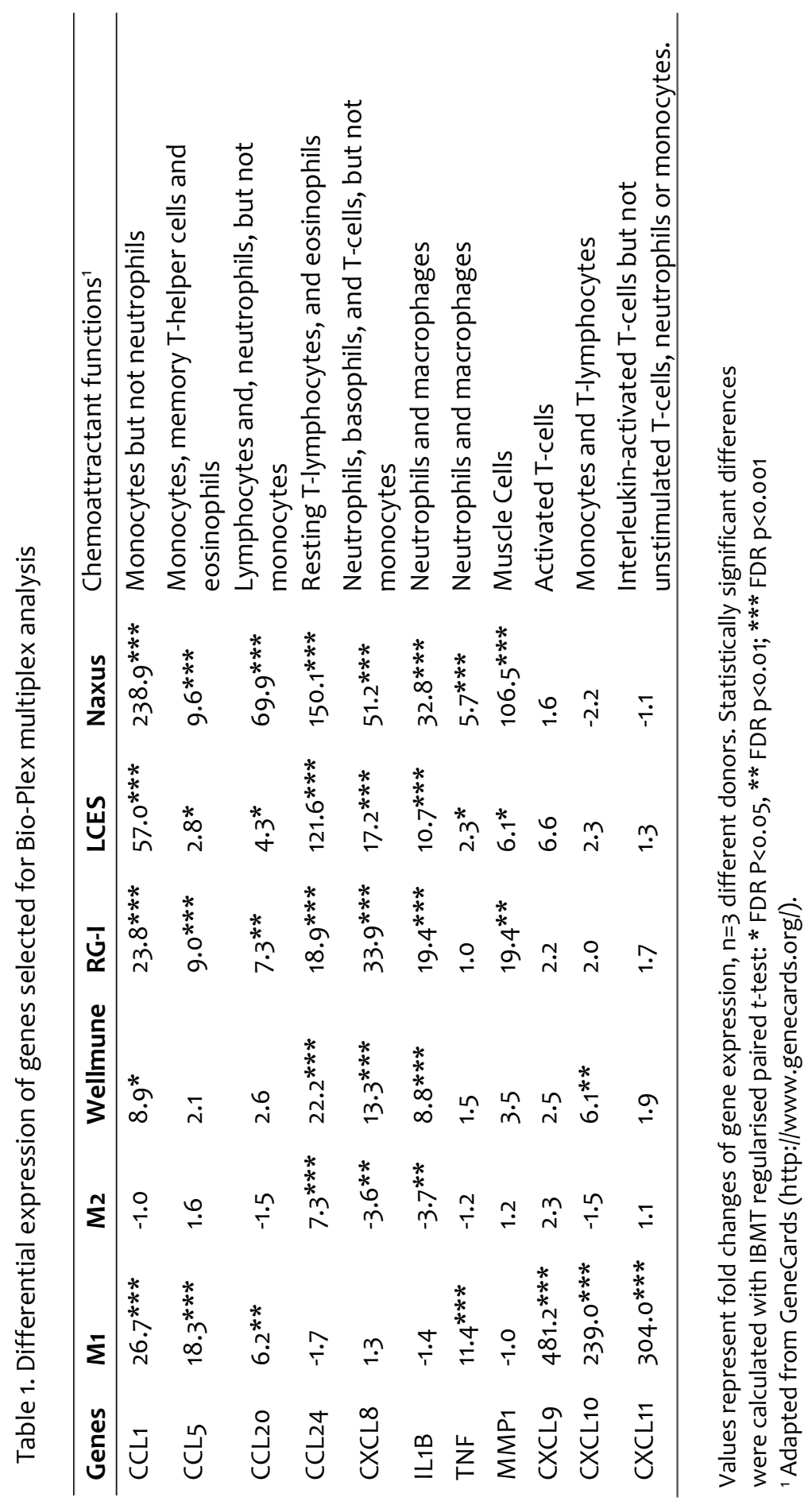




\section{Chapter 4}

\subsection{Naxus promotes macrophages recruitment of monocytes}

M1 macrophages and NDP-treated macrophages, in particular after treatment with Naxus, demonstrated production of varying combinations of cytokines and chemokines. Based on the described activities of the signalling molecules (Table 1), we anticipated that the different combinations mainly lead to migration of monocytes and T cells. In addition, Naxus-treated macrophages might also induce migration of various granulocytes. To test whether the secreted signalling molecules of M1 and Naxus-treated macrophages indeed induce migration of monocytes and T cells, we performed a cell migration assay. To this end we used a transwell system in which the impedance of electron flow through the permeable membrane indicates cellular migration. We added monocytes or T cells to the upper compartment and CCL5 or macrophage-conditioned medium to the lower compartment. Unfortunately, the $T$ cells were not able to impede the electric current, possible due to too small cell size, as no signal was detected whilst $T$ cells could be detected by microscope in the lower compartment (data not shown). In contrast, monocyte migration was detected and variable depending on the medium added to the lower compartment (Figure 5). Monocytes did not spontaneously migrate as no signal was detected when fresh macrophage medium was added to the lower compartment. The presence of CCL5 or signalling molecules released by non-stimulated macrophages induced significant monocyte migration compared to fresh medium. In turn, signalling molecules released by $\mathrm{M}_{1}$ or Naxus-treated macrophages induced a significant increase in migration compared to non-stimulated macrophages.

\section{Discussion}

NDPs are considered immunomodulatory food components but the mechanism of action is not well understood yet. Besides that, different NDPs are expected to have different bioactive properties but there is no consensus on strategies how to properly analyse the bioactivity of NDPs [25]. Based on a large body of evidence it can be hypothesised that macrophages, as one of the key resident cell types in intestinal tissue, including Peyer's Patches, are involved in sensing NDPs in or from the lumen [26]. Based on the interaction with luminal ligands, macrophages will signal to other immune cells and hence may activate a multitude of complex downstream events. Here, we analysed four different NDPs with different biochemical characteristics for their effects on macrophage functionality in comparison to $M_{1}$ and $M_{2}$ macrophages. We demonstrated that an NDP such as Naxus can modulate macrophage function by decreasing phagocytosis and antigen processing capacity, which are essential innate immune 


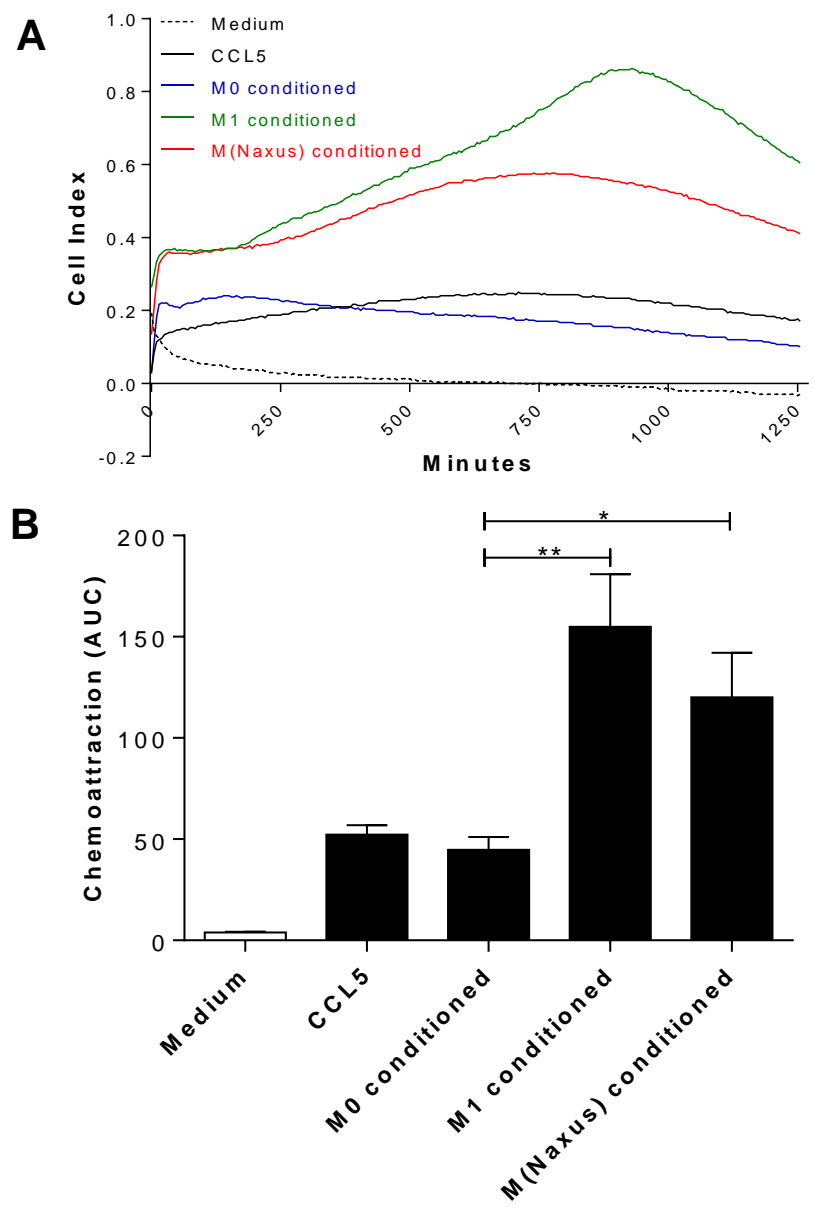

Figure 5. Naxus-treated macrophages promotes migration of monocytes. Macrophages were nontreated, polarised towards $\mathrm{M}_{1}$ or treated with $500 \mu \mathrm{g} / \mathrm{ml}$ Naxus for $18 \mathrm{~h}$. The macrophageconditioned medium, CCL5 or fresh medium was placed in the bottom compartment of the xCeLLigence RTCA DP system and THP-1 monocytes in the upper compartment. Migration of monocytes was determined by measuring every 5 minutes the electrical current resulting from the connection of electrodes by monocyte passage which is shown as the cell index. (A) Migration curves are shown as cell index that was recorded every $5 \mathrm{~min}$. (B) Monocyte migration was compared by analysing area under curve. Bar charts show mean values \pm SEM of $n=3$ different donors. Statistically significant differences were analysed compared to Mo-conditioned medium by one-way ANOVA: * $\mathrm{p}<0.05,{ }^{* *} \mathrm{p}<0.01$. 


\section{Chapter 4}

functions and part of the first line of defence. At the same time, Naxus increases chemokine production and enhances monocyte recruitment by macrophages and possibly other immune cells towards the place of exposure.

A characteristic function of $M 1$ macrophages is their IDO activity [27]. As IDO gene transcription was also strongly induced in NDP-stimulated macrophages [20], we analysed IDO protein expression and activity. M1 macrophages indeed demonstrated a strong IDO protein expression and activity, but, surprisingly, NDP-stimulated macrophages did not increase IDO protein content nor demonstrated IDO activity and kynurenine production (Figure 3). This suggests an inadequate translation of IDO mRNA or a selective inhibition of IDO protein production. Short-hairpin RNA (shRNA) was used to reduce IDO activity in tumour models which abrogated immune suppression [28]. It would therefore be of interest to analyse whether NDP-treatment of macrophages results in increases anti-IDO shRNA production as this might benefit colon cancer treatments.

M2 macrophages demonstrate increased particle uptake and processing capabilities when compared to M1 macrophages [29]. Interestingly, NDP-treated macrophages, in particular those treated with Naxus and LCES, strongly decreased phagocytosis compared to $\mathrm{M}_{2}$ and $\mathrm{M} 1$ macrophages. This decrease might be linked to the previously described reduction in gene expression of certain lectins such as CD302, MERTK and dectin-1. All are known to be involved in formation of the phagocytic synapse and uptake of particles [20, 30, 31].

When particle uptake is reduced one might anticipate to also observe a reduced particle processing. However, we used DQ-OVA to test particle processing and ovalbumin uptake was linked to mannose receptor (Aliases: MRC-1, CLEC13D, CD206) activity [32] which expression was not affected by NDPs [20]. Without evidence that the uptake of DQ-OVA might be impeded it appears that NDP-stimulated macrophages have a reduced capacity to process particles as well as a reduced capacity to take up particles. Indeed, the NDPs significantly downregulate gene expression of HLA-DM and HLA-DO (Supplementary Table 2) which are critically involved in loading of lysosomal antigens on HLA-class II molecules [33].

NDP-treated macrophages are equally dissimilar from $M_{1}$ and $M_{2}$ macrophages regarding cytokine/chemokine production as for the above described characteristics. NDP-treated macrophages, in particular Naxus, secreted a signature mix of CCL1, CCL5, CCL20, CCL24, CXCL8 and IL1 $\beta$ in the absence of CXCL9, 10 and 11 (Figure 4). Notably, the absence of CXCL11 as well as functional IDO protein production by NDP-treated macrophages again confirms that our NDP-preparations were devoid of functional LPS- 
contaminations. We observed that chemokines produced by M1 macrophages strongly attract monocytes (Figure 5). This is in line with literature which indicates that an influx of bone-marrow-derived monocytes replenishes intestinal macrophage populations and in particular M1-like macrophages [13]. Similarly, Naxus-treated macrophages also induced migration of monocytes. The combination of chemokines produced by Naxustreated macrophages might also attract eosinophils, neutrophils, basophils and resting T cells (Table 1). More directly, IL1 $\beta$ production was shown to be important for intestinal ILC3 activation [34], CCL5 mediates recruitment of CCR5-positive regulatory T cells into the intestine [35] and CCL2O is essential for migration of CCR6-positive $\mathrm{TH} 17$ cells towards the intestine [36]. As all these cells have demonstrated to prevent exacerbation of inflammation in the intestine, NDP-treated macrophages might strongly contribute to maintenance of intestinal homeostasis.

This broad effect on immune interaction and activity is in line with various studies describing beneficial health effects of orally administered NDPs [3, 5, 7]. The recruitment of a variety of immune cells by macrophages may be pivotal in orchestrating a full blown innate response, resulting in signalling to and, possibly, activation of the adaptive immune functions.

In conclusion, following a transcriptional analysis we here characterized MNDP from a functional perspective. NDPs and especially Naxus were shown to induce an alternative functionality in macrophages compared to inflammatory or tolerant macrophages. NDPtreated macrophages were also characterized by a unique cytokine and chemokine secretion profile and prompted macrophages recruitment on monocytes. This specific NDP-induced phenotype may be relevant in regulating the physiological consequences of NDP-intake. Ex vivo analysis of macrophage phenotypes following oral intake of NDPs coupled to intestinal health and homeostasis measurement could clarify such possible relevance.

Y.T., C.G., and J.J.M. conceived and designed the experiments. Y.T. performed the experiments. Y.T., C.G., and J.J.M. analysed the data. E. H. S. contributed Multiplex cytokine analysis. Y.T., C.G., J.J.M., and H.J.W. wrote the manuscript.

The authors have declared no conflicts of interest. 


\section{Chapter 4}

\section{References:}

1. Novakovic, B., E. Habibi, S.Y. Wang, R.J. Arts, R. Davar, W. Megchelenbrink, B. Kim, T. Kuznetsova, M. Kox, J. Zwaag, F. Matarese, S.J. van Heeringen, E.M. Janssen-Megens, N. Sharifi, C. Wang, F. Keramati, V. Schoonenberg, P. Flicek, L. Clarke, P. Pickkers, S. Heath, I. Gut, M.G. Netea, J.H. Martens, C. Logie, and H.G. Stunnenberg, beta-Glucan Reverses the Epigenetic State of LPS-Induced Immunological Tolerance. Cell, 2016. 167(5): p. 1354-1368 e1314.

2. Noss, I., G. Doekes, P.S. Thorne, D.J. Heederik, and I.M. Wouters, Comparison of the potency of a variety of beta-glucans to induce cytokine production in human whole blood. Innate Immunity, 2013. 19(1): p. 10-19.

3. Mosikanon, K., D. Arthan, A. Kettawan, R. Tungtrongchitr, and P. Prangthip, Yeast betaGlucan Modulates Inflammation and Waist Circumference in Overweight and Obese Subjects. Journal of Dietary Supplements, 2017. 14(2): p. 173-185.

4. Cholujova, D., J. Jakubikova, B. Czako, M. Martisova, L. Hunakova, J. Duraj, M. Mistrik, and J. Sedlak, MGN-3 arabinoxylan rice bran modulates innate immunity in multiple myeloma patients. Cancer Immunology, Immunotherapy, 2013. 62(3): p. 437-445.

5. Kodama, N., K. Komuta, and H. Nanba, Effect of Maitake (Grifola frondosa) D-Fraction on the activation of NK cells in cancer patients. Journal of Medicinal Food, 2003. 6(4): p. 371-377.

6. Tsang, K.W., C.L. Lam, C. Yan, J.C. Mak, G.C. Ooi, J.C. Ho, B. Lam, R. Man, J.S. Sham, and W.K. Lam, Coriolus versicolor polysaccharide peptide slows progression of advanced non-small cell lung cancer. Respiratory Medicine, 2003. 97(6): p. 618-624.

7. Jesenak, M., J. Majtan, Z. Rennerova, J. Kyselovic, P. Banovcin, and M. Hrubisko, Immunomodulatory effect of pleuran (beta-glucan from Pleurotus ostreatus) in children with recurrent respiratory tract infections. International Immunopharmacology, 2013. 15(2): p. 395399.

8. Mabbott, N.A., D.S. Donaldson, H. Ohno, I.R. Williams, and A. Mahajan, Microfold (M) cells: important immunosurveillance posts in the intestinal epithelium. Mucosal Immunology, 2013. 6(4): p. 666-677.

9. Chan, G.C., W.K. Chan, and D.M. Sze, The effects of beta-glucan on human immune and cancer cells. Journal of Hematology \& Oncology, 2009. 2: p. 25.

10. Marelli, G., C. Belgiovine, A. Mantovani, M. Erreni, and P. Allavena, Non-redundant role of the chemokine receptor $\mathrm{CX}_{3} \mathrm{CR}_{1}$ in the anti-inflammatory function of gut macrophages. Immunobiology, 2017. 222(2): p. 463-472.

11. Flannigan, K.L., D. Geem, A. Harusato, and T.L. Denning, Intestinal Antigen-Presenting Cells: Key Regulators of Immune Homeostasis and Inflammation. American Journal of Pathology, 2015. 185(7): p. 1809-1819.

12. Gabanyi, I., P.A. Muller, L. Feighery, T.Y. Oliveira, F.A. Costa-Pinto, and D. Mucida, Neuroimmune Interactions Drive Tissue Programming in Intestinal Macrophages. Cell, 2016. 164(3): p. 378-391.

13. Zigmond, E., C. Varol, J. Farache, E. Elmaliah, A.T. Satpathy, G. Friedlander, M. Mack, N. Shpigel, I.G. Boneca, K.M. Murphy, G. Shakhar, Z. Halpern, and S. Jung, Ly6C hi monocytes in the inflamed colon give rise to proinflammatory effector cells and migratory antigenpresenting cells. Immunity, 2012. 37(6): p. 1076-1090.

14. Lee, S.H., P.M. Starkey, and S. Gordon, Quantitative analysis of total macrophage content in adult mouse tissues. Immunochemical studies with monoclonal antibody F4/80. Journal of Experimental Medicine, 1985.161(3): p. 475-489.

15. Brown, G.D., J. Herre, D.L. Williams, J.A. Willment, A.S. Marshall, and S. Gordon, Dectin-1 mediates the biological effects of beta-glucans. Journal of Experimental Medicine, 2003. 197(9): p. 1119-1124. 
16. Saijo, S., S. Ikeda, K. Yamabe, S. Kakuta, H. Ishigame, A. Akitsu, N. Fujikado, T. Kusaka, S. Kubo, S.H. Chung, R. Komatsu, N. Miura, Y. Adachi, N. Ohno, K. Shibuya, N. Yamamoto, K. Kawakami, S. Yamasaki, T. Saito, S. Akira, and Y. Iwakura, Dectin-2 recognition of alpha-mannans and induction of Th17 cell differentiation is essential for host defense against Candida albicans. Immunity, 2010. 32(5): p. 681-691.

17. van de Veerdonk, F.L., R.J. Marijnissen, B.J. Kullberg, H.J. Koenen, S.C. Cheng, I. Joosten, W.B. van den Berg, D.L. Williams, J.W. van der Meer, L.A. Joosten, and M.G. Netea, The macrophage mannose receptor induces IL-17 in response to Candida albicans. Cell Host Microbe, 2009. 5(4): p. 329-340.

18. Vetvicka, V., B.P. Thornton, and G.D. Ross, Soluble beta-glucan polysaccharide binding to the lectin site of neutrophil or natural killer cell complement receptor type 3 (CD11b/CD18) generates a primed state of the receptor capable of mediating cytotoxicity of $\mathrm{iC} 3 \mathrm{~b}$-opsonized target cells. Journal of Clinical Investigation, 1996. 98(1): p. 50-61.

19. Rice, P.J., J.L. Kelley, G. Kogan, H.E. Ensley, J.H. Kalbfleisch, I.W. Browder, and D.L. Williams, Human monocyte scavenger receptors are pattern recognition receptors for (1-->3)-beta-Dglucans. Journal of Leukocyte Biology, 2002. 72(1): p. 140-146.

20. Tang, Y., C. Govers, H.J. Wichers, and J.J. Mes, Macrophages treated with non-digestible polysaccharides reveal a transcriptionally unique phenotype. Journal of Functional Foods, 2017. 36: p. 280-289.

21. Govers, C., M.M.M. Tomassen, A. Rieder, S. Ballance, S.H. Knutsen, and J.J. Mes, Lipopolysaccharide quantification and alkali-based inactivation in polysaccharide preparations to enable in vitro immune modulatory studies. Bioactive Carbohydrates and Dietary Fibre, 2016. 8(1): p. 15-25.

22. Cannon, G.J. and J.A. Swanson, The macrophage capacity for phagocytosis. Journal of Cell Science, 1992. 101 ( Pt 4): p. 907-913.

23. Mantegazza, A.R., J.G. Magalhaes, S. Amigorena, and M.S. Marks, Presentation of phagocytosed antigens by MHC class I and II. Traffic, 2013. 14(2): p. 135-152.

24. Jaguin, M., N. Houlbert, O. Fardel, and V. Lecureur, Polarization profiles of human M-CSFgenerated macrophages and comparison of M1-markers in classically activated macrophages from GM-CSF and M-CSF origin. Cellular Immunology, 2013. 281(1): p. 51-61.

25. Rieder, A. and A.B. Samuelsen, Do cereal mixed-linked beta-glucans possess immunemodulating activities? Molecular Nutrition \& Food Research, 2012. 56(4): p. 536-547.

26. Baumgart, D.C. and W.J. Sandborn, Crohn's disease. Lancet, 2012. 380(9853): p. 1590-1605.

27. Rani, R., M.B. Jordan, S. Divanovic, and D.R. Herbert, IFN-gamma-driven IDO production from macrophages protects IL-4Ralpha-deficient mice against lethality during Schistosoma mansoni infection. American Journal of Pathology, 2012. 180(5): p. 2001-2008.

28. Liu, K.T., Y.H. Liu, H.L. Liu, I.W. Chong, M.C. Yen, and P.L. Kuo, Neutrophils are Essential in Short Hairpin RNA of Indoleamine 2,3- Dioxygenase Mediated-antitumor Efficiency. Mol Ther Nucleic Acids, 2016. 5(12): p. e397.

29. Kapellos, T.S., L. Taylor, H. Lee, S.A. Cowley, W.S. James, A.J. Iqbal, and D.R. Greaves, A novel real time imaging platform to quantify macrophage phagocytosis. Biochemical Pharmacology, 2016. 116: p. 107-119.

30. Kato, M., S. Khan, E. d'Aniello, K.J. McDonald, and D.N. Hart, The novel endocytic and phagocytic C-Type lectin receptor DCL-1/CD302 on macrophages is colocalized with F-actin, suggesting a role in cell adhesion and migration. Journal of Immunology, 2007. 179(9): p. 60526063 .

31. Goodridge, H.S., A.J. Wolf, and D.M. Underhill, Beta-glucan recognition by the innate immune system. Immunological Reviews, 2009. 230(1): p. 38-50. 


\section{Chapter 4}

32. Autenrieth, S.E. and I.B. Autenrieth, Variable antigen uptake due to different expression of the macrophage mannose receptor by dendritic cells in various inbred mouse strains. Immunology, 2009. 127(4): p. 523-529.

33. Kropshofer, H., A.B. Vogt, C. Thery, E.A. Armandola, B.C. Li, G. Moldenhauer, S. Amigorena, and G.J. Hammerling, A role for HLA-DO as a co-chaperone of HLA-DM in peptide loading of MHC class II molecules. EMBO Journal, 1998. 17(11): p. 2971-2981.

34. Mortha, A., A. Chudnovskiy, D. Hashimoto, M. Bogunovic, S.P. Spencer, Y. Belkaid, and M. Merad, Microbiota-dependent crosstalk between macrophages and ILC3 promotes intestinal homeostasis. Science, 2014. 343(6178): p. 1249288.

35. Kang, S.G., R.J. Piniecki, H. Hogenesch, H.W. Lim, E. Wiebke, S.E. Braun, S. Matsumoto, and C.H. Kim, Identification of a chemokine network that recruits $\mathrm{FoxP}_{3}(+)$ regulatory $\mathrm{T}$ cells into chronically inflamed intestine. Gastroenterology, 2007.132(3): p. 966-981.

36. Esplugues, E., S. Huber, N. Gagliani, A.E. Hauser, T. Town, Y.Y. Wan, W. O'Connor, Jr., A. Rongvaux, N. Van Rooijen, A.M. Haberman, Y. Iwakura, V.K. Kuchroo, J.K. Kolls, J.A. Bluestone, K.C. Herold, and R.A. Flavell, Control of TH17 cells occurs in the small intestine. Nature, 2011. 475(7357): p. 514-518. 
Supplementary Table 1 Differential expression of genes in phagosome formation pathway

\begin{tabular}{|c|c|c|c|c|c|c|}
\hline Gene & M1 & $\mathrm{M} 2$ & Wellmune & RG-I & LCES & Naxus \\
\hline ITGA2 & 1.3 & 1.07 & 1.14 & 2.2 & 1.6 & $6.7^{* *}$ \\
\hline FCAR & -1.7 & -1.71 & $2.23^{*}$ & $3.7^{* * *}$ & 1.6 & $3.1 * * *$ \\
\hline RND3 & 1.4 & -1.54 & $2.06 *$ & $2.5^{* *}$ & $2.3^{* * *}$ & $3.1 * *$ \\
\hline ITGA5 & 1.1 & 1.14 & $1.50 * *$ & $1.7 * * *$ & $2.1 * * *$ & $2.9^{* * *}$ \\
\hline $\mathrm{RHOH}$ & 1.3 & -1.01 & 1.11 & 2.0 & 1.1 & $2.9 * *$ \\
\hline FCER2 & 1.2 & $23.73 * * *$ & 1.82 & 1.6 & $2.5^{*}$ & $2.6^{*}$ \\
\hline PRKCH & $-2.5 * * *$ & $-1.6^{*}$ & 1.1 & 1.2 & $1.7^{*}$ & $2.1^{* *}$ \\
\hline PLCB1 & -1.1 & $2.7^{* * *}$ & 1.1 & 1.1 & $1.7^{*}$ & $2.0^{* *}$ \\
\hline TLR2 & -1.5 & $-1.6^{*}$ & $2.0^{* *}$ & $2.8^{* * *}$ & -1.2 & 1.5 \\
\hline PIK3R6 & $1.5^{*}$ & $2.1 * * *$ & 1.3 & 1.4 & 1.3 & 1.3 \\
\hline RHOQ & $2.1 * * *$ & 1.2 & 1.0 & $1.3^{*}$ & $1.4^{* *}$ & 1.2 \\
\hline RHOF & $-2.0 * * *$ & $1.5^{*}$ & -1.1 & -1.1 & 1.1 & 1.2 \\
\hline RHOU & $2.0 * * *$ & -1.0 & 1.3 & $1.7^{* *}$ & $-1.4^{*}$ & 1.2 \\
\hline FCGR2A & $-3.6 * * *$ & 1.0 & 1.0 & 1.3 & $-1.6^{*}$ & 1.1 \\
\hline MRC1 & $-4.7^{* * *}$ & $2.7^{* * *}$ & $2.1 * *$ & $1.7^{*}$ & $1.7^{*}$ & 1.1 \\
\hline FCGR2B & $-4.8^{* *}$ & 1.8 & 1.7 & 1.6 & -1.4 & -1.0 \\
\hline PRKCA & $-2.1 * * *$ & 1.0 & -1.1 & $-1.4^{*}$ & 1.1 & -1.2 \\
\hline $\mathrm{FN} 1$ & $-2.2 *$ & 2.0 & -1.5 & -1.2 & -1.0 & -1.4 \\
\hline MARCKS & 1.4 & 1.4 & -1.2 & 1.1 & $-2.8 * * *$ & -1.5 \\
\hline Dectin-1 & $-1.4^{*}$ & $1.9^{* * *}$ & 1.3 & $1.3^{*}$ & -1.0 & $-1.7^{* *}$ \\
\hline $\mathrm{PIK}_{3} \mathrm{C}_{2} \mathrm{~B}$ & $-2.1 * * *$ & 1.3 & $-1.7^{*}$ & $-1.9^{* *}$ & -1.4 & $-1.7^{*}$ \\
\hline TLR8 & $2.9^{* *}$ & -1.4 & -1.2 & -1.0 & $-1.8^{*}$ & -1.8 \\
\hline MSR1 & -1.4 & -1.3 & -1.3 & $-1.7^{*}$ & -1.2 & $-1.8^{*}$ \\
\hline $\mathrm{PIK}_{3} C \mathrm{CD}$ & -1.3 & 1.2 & -1.4 & -1.3 & $-1.5^{*}$ & $-1.9^{* * *}$ \\
\hline $\mathrm{PIK}_{3} \mathrm{R}_{3}$ & 1.6 & -1.1 & -1.3 & $-1.9^{*}$ & -1.7 & $-1.9^{*}$ \\
\hline PLCL2 & -1.2 & -1.2 & $-1.3^{*}$ & $-1.5 * * *$ & $-1.8 * * *$ & $-2.0 * * *$ \\
\hline $\mathrm{TLR}_{3}$ & 1.4 & -1.1 & -1.5 & -1.5 & $-2.3^{* *}$ & $-2.1 * *$ \\
\hline TLR4 & 1.2 & -1.3 & -1.2 & -1.4 & $-2.1 * * *$ & $-2.2^{* * *}$ \\
\hline$I_{T G A}$ & $-2.9^{* * *}$ & 1.0 & -1.4 & $-2.0 * * *$ & -1.3 & $-2.2^{* * *}$ \\
\hline $\mathrm{MRC2}$ & $-2.0 * * *$ & -1.2 & $-1.6^{*}$ & $-2.1 * * *$ & $-1.6 * *$ & $-2.6 * * *$ \\
\hline INPP5D & 1.1 & 1.2 & -1.2 & $-1.6 *$ & $-1.6 *$ & $-2.7^{* * *}$ \\
\hline FCGR3A & $-2.9^{* * *}$ & -1.1 & 1.1 & -1.0 & $-2.2^{* *}$ & $-3.4 * * *$ \\
\hline ITGA4 & $-2.0 * * *$ & -1.1 & -1.4 & $-2.0 * * *$ & $-1.9 * * *$ & $-3.6 * * *$ \\
\hline MERTK & $-5.1 * * *$ & -1.8 & -1.1 & -1.3 & $-2.1^{*}$ & $-3.7^{* * *}$ \\
\hline TLR5 & $-4.7^{* * *}$ & -1.1 & -1.2 & $-2.4^{* * *}$ & $-2.5^{* * *}$ & $-4 \cdot 3^{* * *}$ \\
\hline $\mathrm{CD}_{3} \mathrm{O}_{2}$ & $-3.4^{* * *}$ & 1.0 & -1.5 & $-2.6^{*}$ & $-2.8 * *$ & $-4.9^{* * *}$ \\
\hline TLR7 & -1.0 & $-3.4 * *$ & $-4.2 * *$ & $-8.2 * * *$ & $-7.9 * * *$ & $-11.2 * * *$ \\
\hline
\end{tabular}




\section{Chapter 4}

Values represent fold changes of gene expression of M1 or M2 macrophages or Wellmune Soluble, RG-I, LCES or Naxus-treated macrophages compared to non-stimulated macrophages of $n=3$ different donors. Statistically significant differences were calculated with IBMT regularised paired t-test: * FDR P<0.05, ** FDR p<0.01; *** FDR p<0.001.

Supplementary Table 2 Differential expression of antigen processing related genes

\begin{tabular}{lllllll}
\hline Genes & M1 & M2 & Wellmune & RG-I & LCES & Naxus \\
\hline CD80 & $11.7^{* * *}$ & $1.7^{*}$ & $2.4^{* *}$ & $4.7^{* * *}$ & $2.2^{* *}$ & $4.9 * * *$ \\
CD83 & $2.9 * * *$ & $1.4^{* *}$ & 1.1 & 1.1 & $1.7^{* * *}$ & $2.0 * * *$ \\
CD274 & $12.8^{* * *}$ & $3.0^{* * *}$ & $2.2^{* *}$ & $4.0^{* * *}$ & $2.5^{* * *}$ & $5.9 * * *$ \\
\hline HLA-DMA & $1.3^{*}$ & 1.2 & 1.0 & $-1.5^{* *}$ & $-1.5^{* *}$ & $-1.9^{* * *}$ \\
HLA-DMB & 1.3 & -1.0 & -1.2 & $-2.2 * * *$ & $-1.7^{* *}$ & $-3.1 * * *$ \\
HLA-DOA & $3.6^{* * *}$ & $1.7^{* * *}$ & -1.2 & $-1.8 * * *$ & $-1.7^{* * *}$ & $-3.5^{* * *}$ \\
HLA-DOB & $5.6^{* * *}$ & 1.3 & 1.1 & 1.1 & 1.1 & 1.1 \\
HLA-DQA2 & $11.4^{* * *}$ & 1.1 & 2.2 & 2.2 & 1.5 & 2.2 \\
HLA-DQB2 & $3.0^{* * *}$ & 1.1 & 1.2 & 1.3 & 1.0 & -1.1 \\
\hline HLA-F & $2.8^{* * *}$ & -1.0 & 1.1 & 1.2 & -1.0 & 1.0 \\
HLA-L & $3.3^{* * *}$ & 1.1 & -1.3 & -1.0 & -1.1 & -1.0 \\
\hline
\end{tabular}

Values represent fold changes of gene expression of M1 or M2 macrophages or Wellmune Soluble, RG-I, LCES or Naxus-treated macrophages compared to non-stimulated macrophages of $n=3$ different donors. Statistically significant differences were calculated with IBMT regularised paired t-test: *FDR P<0.05, ** FDR $p<0.01 ; * * *$ FDR $p<0.001$.

Supplementary Figure 1. Macrophages treated with NDPs produce a unique cytokine and chemokine profile following $48 \mathrm{~h}$ of incubation. Macrophages were polarised towards $\mathrm{M} 1$ or M2 or treated with $500 \mu \mathrm{g} / \mathrm{ml}$ Wellmune Soluble, RG-I, LCES, or Naxus for 48 h. Cytokine and chemokine secretion was analysed with Bio-Plex multiplex analysis. Bar charts show mean values $\pm S E M$ of $n=2$ different donors. Statistically significant differences compare to medium were analysed by one-way ANOVA: ${ }^{*} p<0.05,{ }^{* *} p<0.01,{ }^{* * *} P<0.001$. (See next page) 

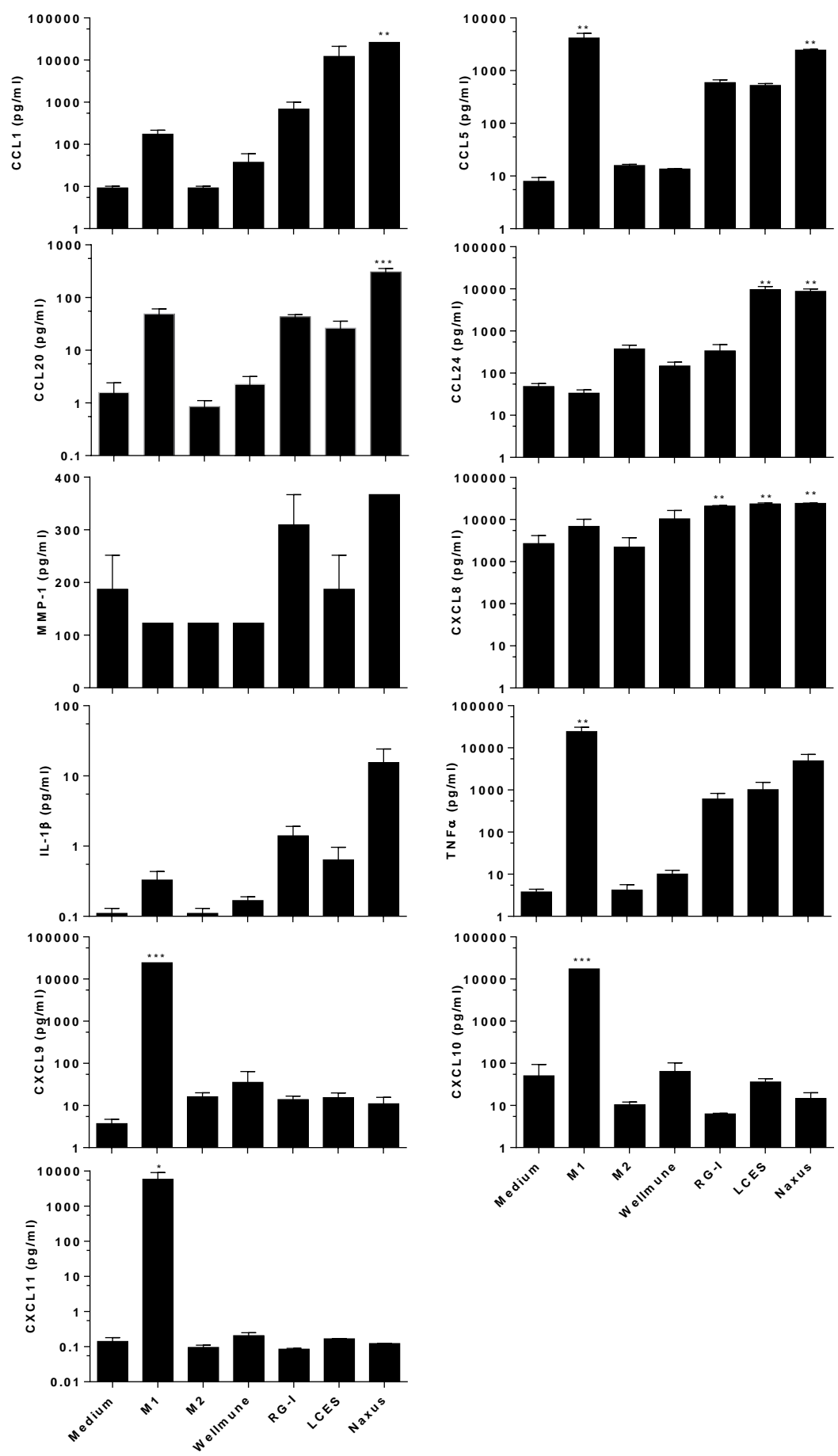



\section{Chapter 5}

\section{Macrophage plasticity can be modulated by non-digestible polysaccharides}

Yongfu Tang, Coen Govers, Ellen H. Stolte, Harry J. Wichers, Jurriaan J. Mes

Manuscript in preparation 


\section{Chapter 5}

\section{Abstract}

Macrophage plasticity is essential for intestinal immune homeostasis. We previously reported that non-digestible polysaccharides (NDPs) skewed macrophages to an alternative subset $M_{N D P}$ compared to inflammatory macrophages (M1) as induced by TNFa and IFN $\gamma$ or tolerant macrophages $\left(M_{2}\right)$ as induced by IL4. Here, we analysed plasticity of $M_{1}$ and $M_{2}$ macrophages in response to NDPs treatment to evaluate whether phenotype and function of $M_{1}$ and $M_{2}$ can be further modulated. Subset specific gene expression markers were analysed together with functional properties including phagocytosis capacity, antigen processing capacity, cytokine secretion, and monocytes recruiting. Macrophage plasticity was demonstrated as $M_{1}$ and $M_{2}$ macrophages could be skewed to an alternative subset indicated by gene expression markers. In addition, phagocytosis and antigen processing capacity of both $\mathrm{M}_{1}$ and $\mathrm{M}_{2}$ were decreased by the NDP Naxus. Besides, cytokine secretion by both $M_{1}$ and $M_{2}$ macrophages were induced by Naxus. In addition, Naxus induced $\mathrm{M}_{2}$ macrophages recruiting ability, but not M1. In conclusion, we observed that NDP Naxus modulated M1 and $M_{2}$ macrophage towards phenotype and function of $M_{N D P}$, which implies the NDP Naxus might be used for modulating intestinal immune balance.

Keywords: Arabinoxylan; Inflammatory macrophages; Macrophages function; Tolerant macrophages; Wheat 


\section{Introduction}

Macrophages play a critical role in intestinal immunity as the largest amount of immune cells in intestine [1]. Intestinal macrophages are constantly replenished from circulating CD14+ monocytes by CCR2-dependent influx in the intestine [2]. They play a role in maintaining intestinal homeostasis by remodelling tissue [3] and clearing dying cells [4]. These functions are initiated upon activation of pattern recognition receptors (PRRs) through ligand binding [5] or as response to environmental ques in the form of cytokines or other signalling molecules [6, 7].

Macrophages respond with modulating their phenotype (also termed plasticity) upon these stimulations exemplified by skewing of tolerant (M2) macrophages to inflammatory (M1) macrophages by LPS stimulation [8]. The process of subset skewing is accompanied by metabolic reprogramming [9]. For instance, M1 macrophages polarised by LPS were modulated by IL10 and underwent metabolic reprogramming from glucose uptake and glycolysis to oxidative phosphorylation [9].

There are two main subsets of intestinal macrophages termed lamina propria macrophages (LPM) and muscularis propria macrophages (MMs), which function as M1 and $M_{2}$ macrophages, respectively [10]. Those two subsets balance intestinal immunity by sensing the danger signals from the local environment and are important for wound healing and tissue repair [5]. Research has shown that microbiota and dietary components are able to direct macrophage subtypes [11]. $\omega-3$ fatty acid exhibited antiinflammatory effects by decreasing both gene expression and protein secretion of LPSinduced M1 markers TNFa and IL6 through PPAR4 activation [12]. In addition, yeastderived $\beta$-glucan converted $M_{1}$ to $M_{2}$ as shown by an enhanced glycolysis, Krebs cycle, and glutamine utilization [13].

Non-digestible polysaccharides (NDPs) potentially simulate cell wall fragments of natural pathogens which can be recognized by receptors on the surface of macrophages. $\beta$ Glucan, as component in fungal cell walls, was proven to activate dectin-1 and trigger NFAT activation in macrophages and dendritic cells to secrete cytokines [14]. This activation initiated an innate immune response via dectin-1 activation and was accompanied with the formation of a phagocytic synapse [15]. Like the fungus-derived $\beta$-glucans, also the yeast-derived $\beta$-glucans could skew $M_{2}$ to $M_{1}$ through dectin- 1 and subsequently the Syk-Card9-ERK pathway [13]. Also other dietary $\beta$-glucans were reported to be taken up and transported by intestinal macrophages [16]. Lentinan, the $\beta$-glucan from shiitake, upregulated pro-inflammatory cytokines (IL1a, TNFa, and IL6) through TLR4 signalling in murine macrophages in vitro. However, it also inhibits IL1 $\beta$ production through inhibiting AIM2 inflammasome activation [17]. In addition, a 


\section{Chapter 5}

randomized dietary intervention in healthy young adults demonstrated that shiitake mushrooms affected immunity by increasing IL4, IL10, TNFa and IL1a levels and decreased MIP1a/CCL3 level [18]. Oral intake of oat $\beta$-glucans activated NF-kB transactivation and increased IL12 in intestinal leukocytes in mice [19]. Immune activation by cereal glucans might also proceed through the dectin-1 pathway. For example, barley $\beta$-glucans induced IL6 secretion in murine macrophages, and this activation is mediated by the dectin-1 pathway and accompanied by phosphorylation of Syk [20]. Furthermore, we previously showed that NDPs derived from wheat, apple and shiitake skewed macrophages to an alternative subset $\left(M_{N D P}\right)$. These $M_{N D P}$ were characterised by increasing gene expression of IDO1, LAMP3, dectin-2, Mincle, CD80, GCH1, and decreasing gene expression of CXCL11 and MGL compared to medium control (Mo) [21]. In addition, $\mathrm{M}_{\mathrm{NDP}}$ showed decreased phagocytosis and antigen processing capacity (Chapter 4) but an increased production of chemokines and recruiting ability towards monocytes compared to Mo (Chapter 4).

M1 and M2 subset macrophages do play distinct roles in intestinal immunity. It is hence interesting to investigate whether NDPs can induce plasticity in these subsets and repolarize these macrophage subsets towards the newly identified $M_{\text {NDP. }}$ In this study, we confirmed the effects of NDPs on the phenotype and functional capacity of M1 and M2. As a result, the effects of NDPs on $M_{1}$ and $M_{2}$ showed a similar trend in the gene expression as primary non-polarised macrophages exposed to NDP; Naxus significantly decreased phagocytosis and antigen processing capacity of both $M_{1}$ and $M_{2}$ while increasing the secretion of CCL1 and other cytokines. This enhanced recruiting ability capacity of $M_{2}$ but not of $M_{1}$. However, these effects on $M_{1}$ and $M_{2}$ were blocked by a Caco-2 monolayer of small intestinal cells in a coculture system indicating that a physical interaction of NDPs and macrophages is required.

\section{Materials and Methods}

\subsection{NDPs information}

Macrophages were treated with Wellmune Soluble, RG-I, LCES, or Naxus as described previously [21]. In brief, Wellmune Soluble (referred as Wellmune in tables and figures) is a water soluble $\beta-1,3 / 1,6$-glucan from the yeast Saccharomyces cerevisiae provided by BioThera (Eagan, MN, USA). RG-I is a concentrate of rhamnogalacturonan I from apple juice provided by INRA (Paris, France). LCES (lentinan containing extract from shiitake) is a $\beta-1,3 / 1,6$-glucan extract from shiitake. Naxus is a polysaccharide from wheat, rich in arabinoxylan, provided by BioActor (Maastricht, The Netherlands). Before exposure to 
macrophages, RG-I was treated with alkaline-ethanol at $4{ }^{\circ} \mathrm{C}$ for $5 \mathrm{~h}$, and LCES and Naxus were treated with alkaline-ethanol at $56^{\circ} \mathrm{C}$ for $5 \mathrm{~h}$, followed by neutralization with $\mathrm{HCl}$ and freeze-drying to inactivate lipopolysaccharide (LPS) [22]. Resulting functional LPS contaminations of all NDPs samples was demonstrated to be below $0.01 \mathrm{EU} / \mathrm{mg}$ [22].

\subsection{Primary macrophage differentiation and polarization}

Primary macrophages were differentiated as previously described [21]. In brief, human monocytes were obtained from buffy coats from healthy donors (Sanquin, Nijmegen, The Netherlands) using the QuadroMACS system and CD14 microbeads according to manufacturer's protocol (Miltenyi Biotec, Leiden, The Netherlands). A written informed consent was obtained before sample collection. Monocytes were differentiated into macrophages following 7 days culturing in presence of $50 \mathrm{ng} / \mathrm{ml}$ MCSF (R\&D systems, Minneapolis, USA). MCSF was replenished after 3 and 5 days of culture. On day 7 , macrophages were polarised by $20 \mathrm{ng} / \mathrm{ml} \mathrm{TNFa}$ and $20 \mathrm{ng} / \mathrm{ml}$ IFN $\gamma$ (for M1 polarization), or $20 \mathrm{ng} / \mathrm{ml} \mathrm{IL4} \mathrm{(for} \mathrm{M2} \mathrm{polarization)} \mathrm{without} \mathrm{MCSF} \mathrm{for} 18 \mathrm{~h}$. To analyse plasticity, these $\mathrm{M} 1$ and $\mathrm{M}_{2}$ macrophages subsets at day 8 were then exposed to $500 \mu \mathrm{g} / \mathrm{ml}$ NDPs in medium without and appropriate controls for $24 \mathrm{~h}$.

\subsection{RNA extraction and CDNA synthesis}

RNA was extracted by lysing cells with $200 \mu \mathrm{L}$ TRIzol (Invitrogen, Bleiswijk, The Netherlands) for each well in the 24-well plates. This was followed by RNeasy (Qiagen, Venlo, The Netherlands) clean-up according to manufacturer's protocol. The integrity of the ribosomal RNA was analysed using agarose (Eurogentec, Liège, Belgium) gel electrophoresis (1\%). RNA concentration and purity were checked using the Nanodrop spectrophotometer system (Nanodrop Technologies, Wilmington, DE, USA) and only samples with a ratio (Abs $260 / 280 \mathrm{~nm}$ ) between 1.8 and 2.1 were used for qPCR and microarray analysis. Subsequently, cDNA was synthesised with iScript (Bio-Rad, Veenendaal, The Netherlands) according to manufacturer's protocol.

\section{4 qPCR}

qPCR was performed as described elsewhere [23]. In brief, $5 \mu$ l CDNA was mixed with 10 $\mu \mathrm{IQ} \mathrm{iQ}^{\mathrm{TM}}$ SYBR Green supermix (Bio-Rad), forward and reverse primers, and milliQ water to total $20 \mu \mathrm{l}$. Primers were derived from the Harvard Primerbank (http://pga.mgh.harvard.edu/primerbank/) or designed using Clone Manager Professional 9 and synthesized by Biolegio (Nijmegen, The Netherlands). Primers are listed in Supplementary Table 2. The following thermal cycling conditions were used for amplifying the target sequences: $90 \mathrm{~s}$ at $95^{\circ} \mathrm{C}$, followed by 40 cycles at $95^{\circ} \mathrm{C}$ for $10 \mathrm{~s}, 58$ ${ }^{\circ} \mathrm{C}$ for $10 \mathrm{~s}$ and $72{ }^{\circ} \mathrm{C}$ for $15 \mathrm{~s}$, and a final elongation step at $72{ }^{\circ} \mathrm{C}$ for 2 min and performed 


\section{Chapter 5}

on the CFX96 Touch Real-Time PCR Detection System (Bio-Rad). qPCR was performed in technical duplicate, and all samples were normalised to geometric means of PUM1 and RPLPo expression [24] and medium-stimulated macrophages using the qBase ${ }^{+}$software (Biogazelle, Gent, Belgium).

\subsection{Microarray analysis}

Microarray analysis was performed as described previously [25]. Briefly, RNA quality was verified with the RNA 6000 Nano assay on an Agilent 2100 Bioanalyzer (Agilent Technologies, Amstelveen, The Netherlands). Hybridization, washing and scanning of the Affymetrix Human Gene 1.1 ST array plate was performed on an Affymetrix Gene Titan platform according to standard protocols. Scans of arrays were analysed using package from Bioconductor project. Raw signal intensities were obtained by Robust Multi-array Average method. Probe sets were defined using remapped chip definition file (CDF) based on Entrez gene database. Individual Genes were considered to be expressed if UPC algorithm values are above 0.5 on at least one array [26]. Genes were selected that meet the cut-off of absolute fold change $>1.8$ and false discovery rate corrected $\mathrm{p}<0.05$ (IBMT regularised paired $t$-test) on at least one treatment. The functional interpretation of gene signatures was executed using IPA 3.0 (Ingenuity, QIAGEN, Redwood, CA, USA). Microarray data were deposited in the Gene Expression Omnibus (GEO) database.

\subsection{Phagocytosis assay and antigen processing analysis}

To analyse phagocytic activity and antigen processing, $M_{1}$ and $M_{2}$ macrophages with or without NDP treatment were washed with PBS and incubated for $1 \mathrm{~h}$ in $0.5 \mathrm{ml}$ culture medium containing $2 \mu \mathrm{g} / \mathrm{ml}$ E.coli bioparticles (Molecular Probes, Leiden, The Netherlands) or $10 \mathrm{ng} / \mathrm{ml}$ DQ-OVA (Molecular Probes), respectively. Before addition, E.coli bioparticles were re-suspended in non-heat-inactivated human serum ( $2 \mathrm{mg} / 100$ $\mu \mathrm{l})$ and incubated for 60 minutes at $37{ }^{\circ} \mathrm{C}$. Macrophages were detached as described above and diluted three times with PBS with $2 \%$ FBS. Cells were re-suspended in $200 \mu \mathrm{l}$ PBS and analysed using flow cytometry (bioparticles: excitation at $495 \mathrm{~nm}$, emission at $519 \mathrm{~nm}$; DQ-OVA: excitation at $505 \mathrm{~nm}$, emission at $515 \mathrm{~nm}$ ) with Accuri (6 software.

\subsection{Multiplex cytokine analysis}

Secretion of cytokines and chemokines by $\mathrm{M}_{1}$ and $\mathrm{M}_{2}$ macrophages with or without NDP stimulation were measured using Bio-Plex Pro Reagent Kit (BioRad, Veenendaal, The Netherlands) according to the manufacturer's instructions. In brief, $50 \mu \mathrm{L}$ magnetic beads were dispersed in a plate together with $50 \mu$ of undiluted sample or standard and incubated for $1 \mathrm{~h}$ at RT. Subsequently, the beads were incubated with $25 \mu$ letection 
antibodies for 30 min and with $50 \mu$ streptavidin-PE for 10 min at RT. The beads were resuspended in $125 \mu$ l assay buffer and read by Bio-Plex ${ }^{\circledR}$ MAGPIX ${ }^{\mathrm{TM}}$ Multiplex Reader (BioRad). Data processing was performed by using Bio-Plex Manager 5.0, and concentrations (in $\mathrm{pg} / \mathrm{ml}$ ) were interpolated from standard curves. To identify relations and to display our results most effectively, we used lower or upper limit of the standard curve for data points that were below or above the standard curve, respectively.

\subsection{Migration assay}

Migration assays were performed using an xCELLigence RTCA DP system (xCELLigence, ACEA Biosciences, San Diego, USA) and CIM-16 well plates, according to the manufacturer's instructions. In brief, $160 \mu \mathrm{l}$ of macrophage-conditioned medium were

\section{Figure 1A}
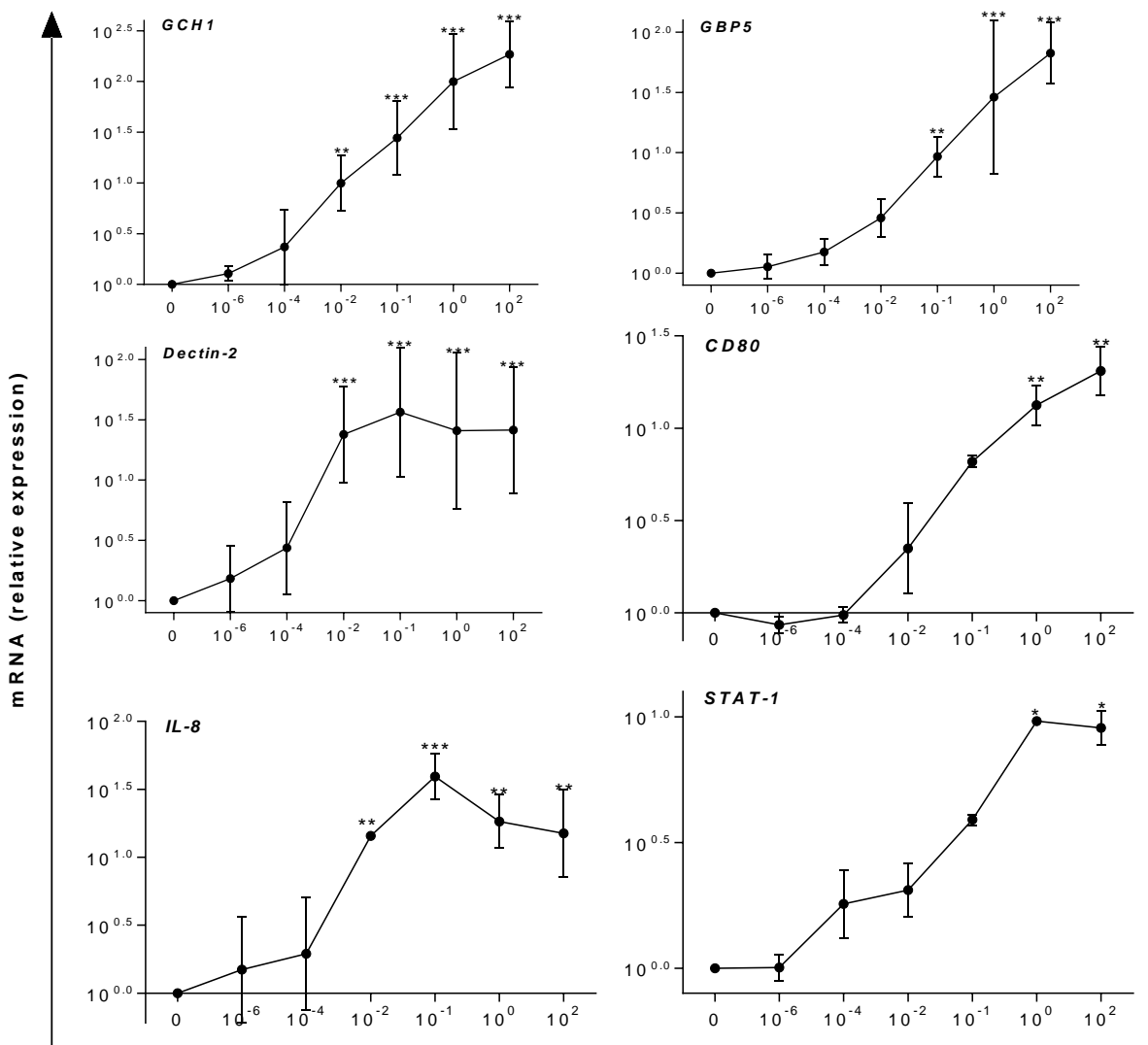

Concentration of LPS $(\mathrm{ng} / \mathrm{ml})$ 


\section{Chapter 5}

added to the lower chamber of CIM-16 well plates. Fresh macrophage culture medium was used as negative control and $\mathrm{CCL}_{5}(400 \mathrm{ng} / \mathrm{ml})$ as positive control. Following upper chamber attachment to the lower chamber, the upper chamber wells were filled with 50 $\mu \mathrm{l}$ THP-1 cell culture medium and equilibrated at $37{ }^{\circ} \mathrm{C}$ for $1 \mathrm{~h}$ which was recorded as background cell index. Next, $50 \mu \mathrm{l} \mathrm{THP-1}$ cell suspension $\left(8 \times 10^{6}\right.$ cells $\left./ \mathrm{ml}\right)$ was added to the upper chamber after which cells were allowed to settle for 5 minutes at RT. The cell index is a unit-less parameter used to indicate the impedance of electron flow caused by adherent cells and defined as (impedance at time point impedance - impedance in the absence of cells) / nominal impedance value. The cell index was measured every 5 min over the course of $22 \mathrm{~h}$. Monocyte migration was subsequently calculated as area under the curve using Prism 6 software (Graphpad, La Jolla, USA).

\section{Figure 1B}
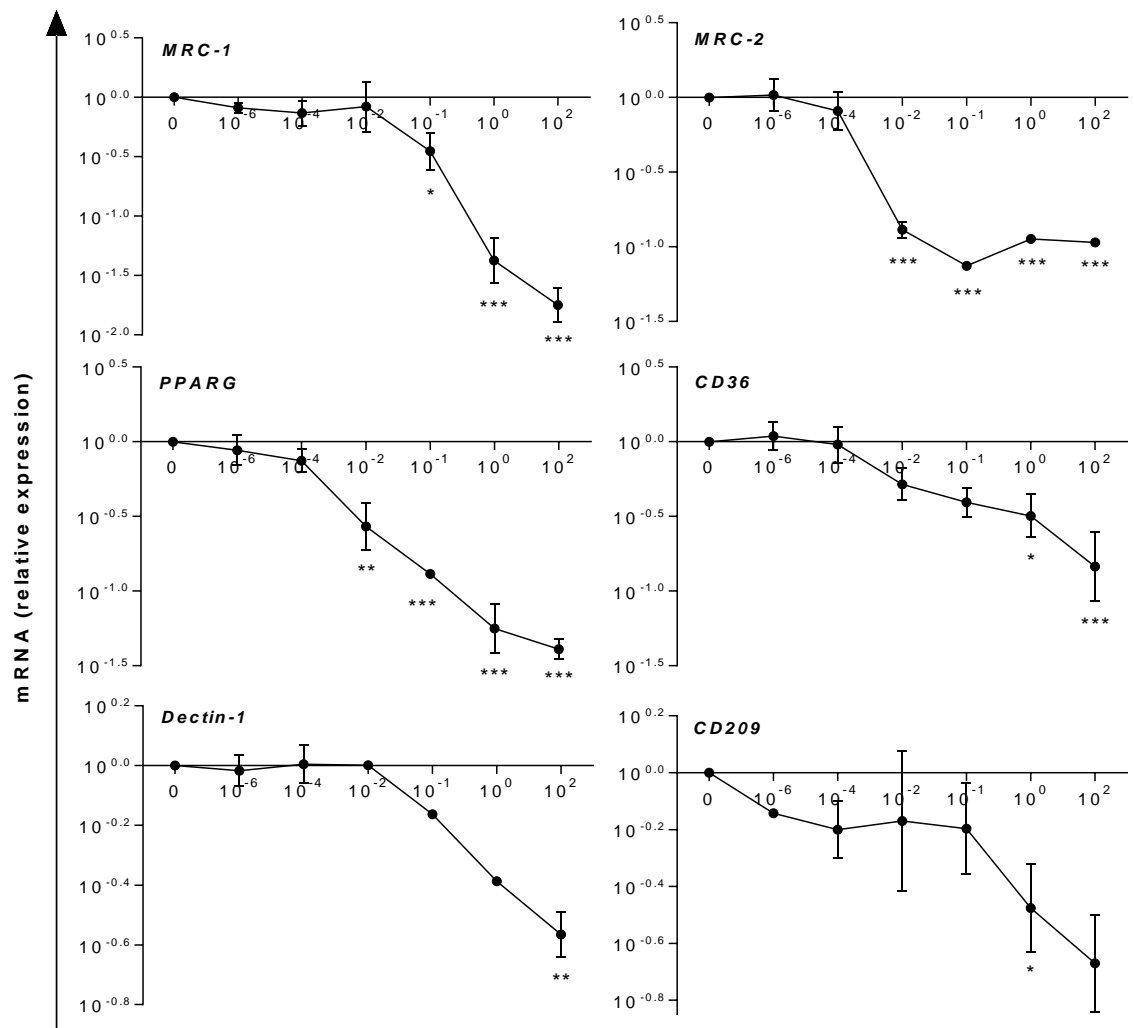

Concentration of LPS ( $\mathrm{ng} / \mathrm{mI})$

(Legend on page 117) 


\subsection{Caco-2-macrophages coculture}

Macrophages were differentiated on $250 \mu$ hydrogel (Cellendes, Reutingen, Germany) coated 24-well plate for 7 days with MCSF and differentiated to either Mo, M1 or M2 for $18 \mathrm{~h}$. This was followed with coculturing with 21-day transwell grown Caco-2 (Chapter 1) which were stimulated with either medium control, LCES $(500 \mu \mathrm{g} / \mathrm{ml})$ or Naxus $(500$ $\mu \mathrm{g} / \mathrm{ml}$ ). Macrophage-conditioned medium was collected for migration analysis, and macrophages were collected by TRizel for qPCR.

\subsection{Statistics}

All parameters are presented as means \pm SEM and differences between parameters were assessed for their significance with one-way ANOVA using Prism 6. Differences with $\mathrm{p}<0.05$ were considered significant.

\section{Figure $1 \mathrm{C}$}

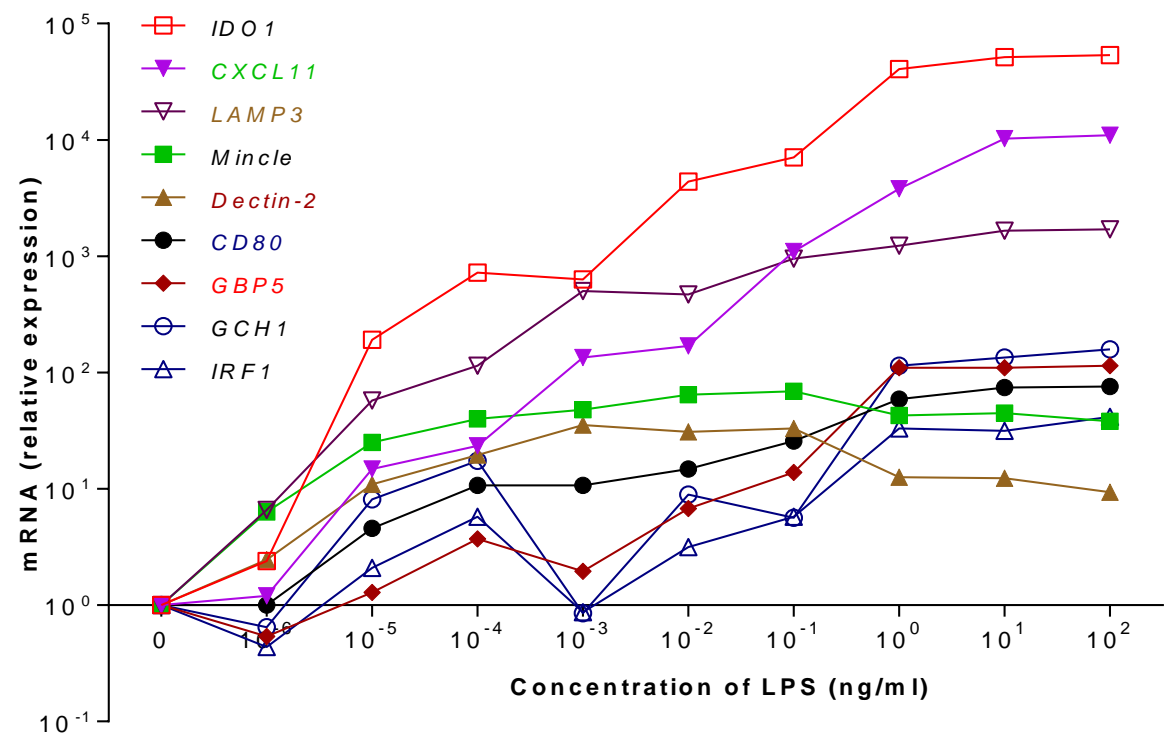

Figure 1. Gene expression pattern of macrophages following exposure to titrated amounts of LPS. Mo macrophages were stimulated with various concentrations of LPS $(\mathrm{ng} / \mathrm{ml})$ for $18 \mathrm{~h}$ and analysed for gene expression of $M_{1}(A)$ and $M_{2}(B)$ markers using qPCR. Results are shown as fold change compared to non-stimulated macrophages by mean values $\pm S E M, n=2$ different donors. Statistically significant differences were analysed by one-way ANOVA: * $p<0.05, * * p<0.01, * * *$ $\mathrm{P}<0.001$. C. M2 macrophages were stimulated with various concentrations of LPS ( $\mathrm{ng} / \mathrm{ml})$ for $24 \mathrm{~h}$ and analysed gene expression of M1 markers using QPCR. Results are shown as fold change compared to non-stimulated macrophages, $n=1$ donors. 


\section{Chapter 5}

\section{Results}

\subsection{Macrophages plasticity characterised by responding to LPS}

To study the plasticity of macrophages, first the response to a strong immune potent agent was analysed by exposure to different concentrations of LPS. M1 ( $\mathrm{CCH}_{1}, \mathrm{GBP} 5$, dectin-2, CD80, IL8, and STAT1) and M2 (MRC1, MRC2, PPARG, CD36, dectin-1, and CD209) specific gene expression markers were subsequently analysed by qPCR. Results clearly showed that gene expression of $M_{1}$ markers on Mo were increased in an LPS concentration dependent manner (Figure $1 \mathrm{~A}$ ). Expression of $\mathrm{GCH} 1$, dectin-2, and IL-8 showed more sensitivity than other $\mathrm{M}_{1}$ makers and already significant changes in expression were found at $0.01 \mathrm{ng} / \mathrm{ml}$ LPS. On the other hand, gene expression of $\mathrm{M}_{2}$ markers on Mo were decreased in an LPS concentration dependent manner (Figure 1B). $M R C_{1}, M R C_{2}$, and PPAR $\gamma$ were more sensitive than other $M_{2}$ markers, and $M R C_{1}$ responded stronger to the highest experimental concentration $(100 \mathrm{ng} / \mathrm{ml})$ than other markers.

To investigate plasticity of our macrophages, we analysed gene expression of some $\mathrm{M}_{1}$ markers in $\mathrm{M} 2$ cells exposed to LPS (Figure $1 \mathrm{C}$ ). The expression of all of the genes in the list was increased and showed to be concentration dependent. IDO1, CXCL11, and LAMP3 showed more sensitively in responding to LPS than other genes. This gene expression trend of $M_{1}$ markers shows the inherent ability of $M_{2}$ macrophages to alter their phenotype in our culturing and polarization method.

\subsection{NDPs can re-polarise both $M_{1}$ and $M_{2}$ macrophages towards an $M_{\text {NDP }}$ subset based on gene expression analysis}

Our previous research showed that NDPs can also polarise Mo towards a phenotype alternative to pro-inflammatory and tolerant macrophages which was termed $M_{N D P}$. This could be demonstrated most clearly based on gene expression of IDO1, LAMP3, CD80, Mincle, dectin-2, CXCL11, MGL, and IRF1 [21]. Through microarray analysis, the marker panel is expanded with CCL20, IL1ß, IL8, LOX1, TNF, CCL13, and TLR7 (Supplementary Table 1) which all specifically responded to NDP-stimulations. To investigate whether NDPs can also re-polarise $M 1$ and $M 2$ polarised macrophages, we stimulated M1 with four different NDPs (i.e. Wellmune soluble, RG-I, LCES, and Naxus) and analysed gene expression (Figure 2). Naxus treatment increased gene expression of IL1B, IL8, TNF, CD80, dectin-2, Mincle, LOX1, CCL20, and LAMP3, while it decreased gene expression of MGL, TLR7, and CXCL11. Similarly, RG-I increased gene expression for IL1B, IL8, CD80, dectin-2, Mincle, LOX1, CCL20, and LAMP3, while it decreased gene expression for MGL, TLR7, and CXCL11. LCES increased IL1B, IL8, and CCL20 gene expression, while it 


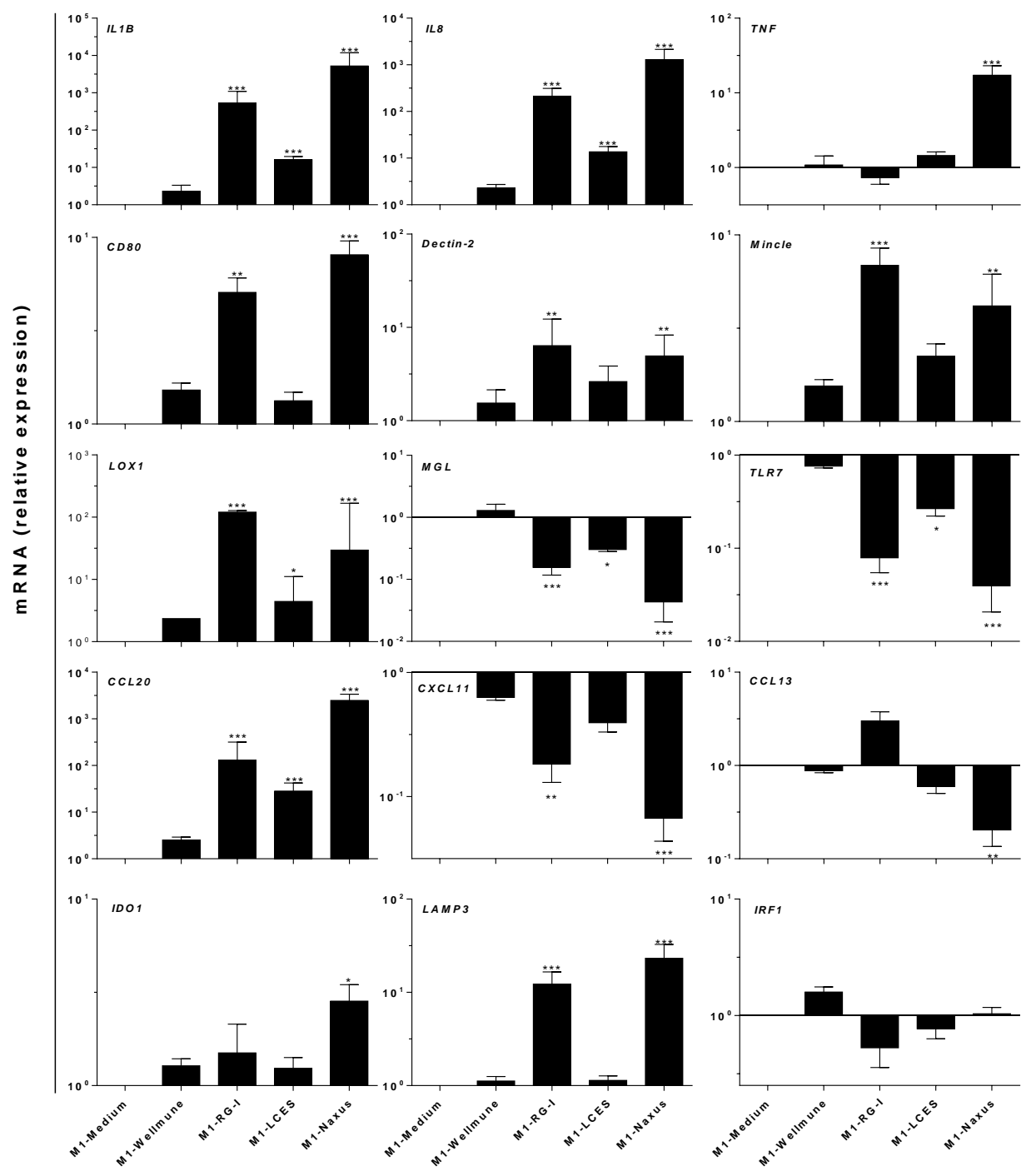

Figure 2. NDPs promote re-polarisation of $M 1$ to an $M_{N D P}$ phenotype. $M 1$ polarised macrophages were stimulated with Wellmune, RG-I, LCES, and Naxus at $500 \mu \mathrm{g} / \mathrm{ml}$ for $24 \mathrm{~h}$ and analysed for gene expression using qPCR. Results are shown as fold change by mean values \pm SEM in a bar chart, $n=3$ 4 different donors. Statistically significant differences compared to medium control were analysed by two-way ANOVA: * $p<0.05, * * p<0.01, * * * p<0.001$. 


\section{Chapter 5}

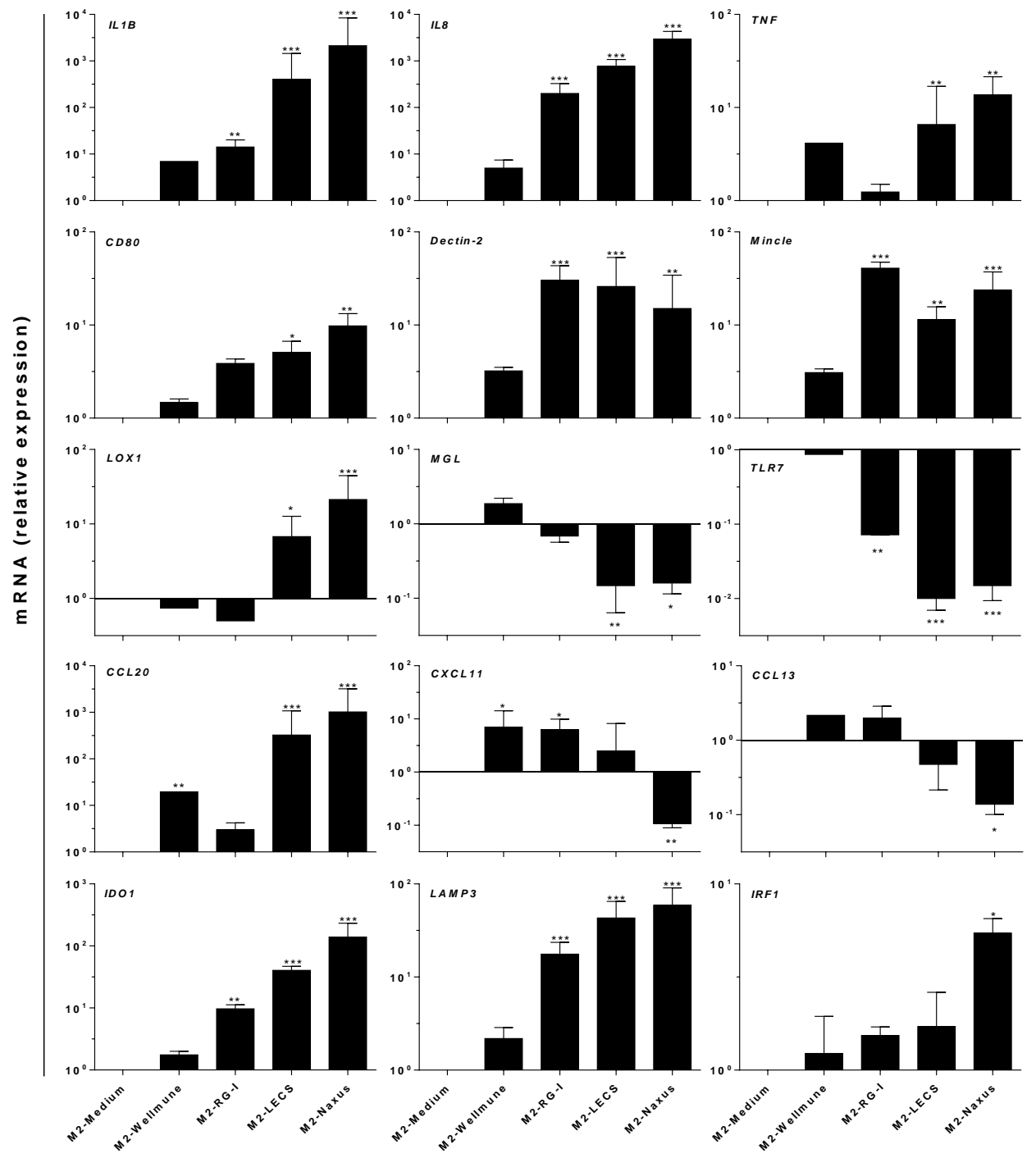

Figure 3. NDPs promote re-polarisation of $M 2$ polarised macrophages towards a $M_{\text {NDP }}$ phenotype. M2 polarised macrophages were stimulated with Wellmune, RG-I, LCES, and Naxus at $500 \mu \mathrm{g} / \mathrm{ml}$ for $24 \mathrm{~h}$ and analysed for gene expression using $\mathrm{qPCR}$. Results are shown as fold change by mean values \pm SEM in a bar chart, $n=2-3$ different donors. Statistically significant differences compared to medium control were analysed by two-way ANOVA: * $p<0.05,{ }^{* *} p<0.01, * * * p<0.001$. 
decreased gene expression of MGL. Wellmune Soluble did not modulate gene expression of these genes, similar as we had seen when Mo were exposed to Wellmune Soluble [21].

Similar as for the plasticity of M1 macrophages we also studied the plasticity of $\mathrm{M}_{2}$ macrophage subsets when exposed to the four NDPs and analysed gene expression (Figure 3). Interestingly, NDPs triggered a similar gene expression trend in $M_{2}$ macrophages as they did in M1 (Figure 9). Naxus increased gene expression of IL-1B, IL8, TNF, CD80, dectin-2, Mincle, LOX1, CCL20, IDO1, LAMP3, and IRF1, while it decreased gene expression of MGL, TLR7, CXCL11, and CCL13. Again, also LCES increased gene expression for IL-1B, IL-8, TNF, CD80, dectin-2, Mincle, LOX1, CCL20, IDO1, and LAMP3, while it decreased gene expression for MGL, TLR7, and CXCL11. RG-I increased gene expression for IL-1B, IL-8, dectin-2, Mincle, IDO1, and LAMP3, while it decreased gene expression for TLR7. Wellmune Soluble only increased gene expression of CCL2O.

These profiles following stimulation of $M_{1}$ or $M_{2}$ polarised macrophages indicate that NDPs have the capacity to change the macrophage phenotype and skew them towards an $M_{\text {NDP }}$ subset (Figure 9 and Supplementary Table 1).

A

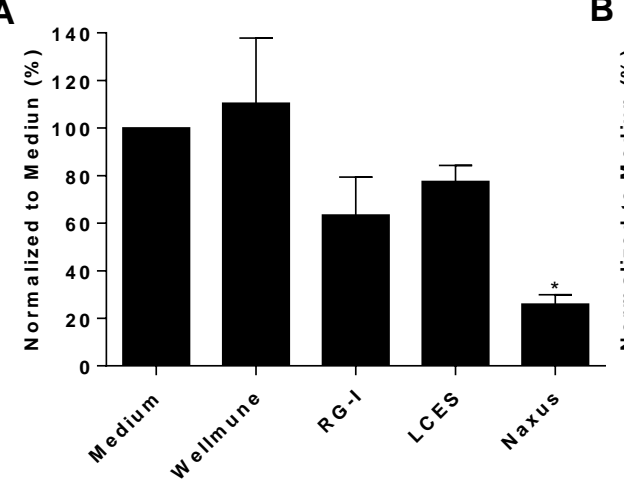

B

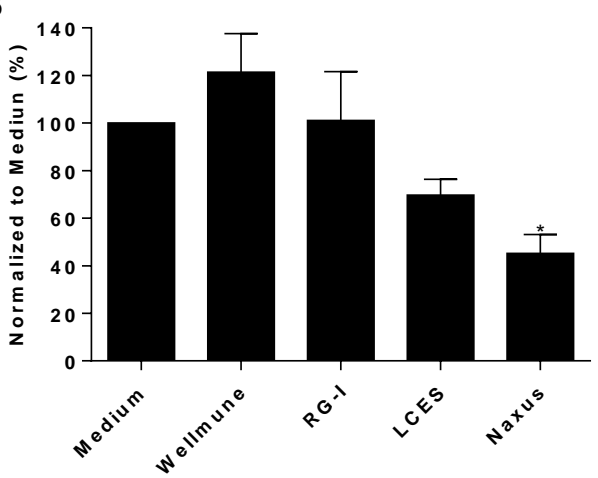

Figure 4. NDP decreased phagocytosis function of $M_{1}$ and $M_{2}$. $M_{1}(A)$ and $M_{2}$ (B) were stimulated with Wellmune, RG-I, LCES, and Naxus at $500 \mu \mathrm{g} / \mathrm{ml}$ for $24 \mathrm{~h}$ followed by $1 \mathrm{~h}$ incubation with E.coli bioparticles and analysis with flow cytometry. The bar chart shows mean fluorescence intensity $(\mathrm{MFI})$ values $\pm \mathrm{SEM}, \mathrm{n}=3$ different donors. Data was normalized to medium control. Statistically significant differences compared to medium control were analysed by one-way ANOVA: * $p<0.05$. 


\section{Chapter 5}

\subsection{NDPs decrease phagocytosis capacity of both M1 and M2 polarised macrophages}

We previously showed that LCES and Naxus decreased the phagocytosis capacity of Mo macrophages both after $18 \mathrm{~h}$ and $48 \mathrm{~h}$ stimulation (Chapter 4). Similarly, Naxus significantly decreased the uptake of $E$. coli bioparticles for M1 polarised macrophages (Figure 4A) and at the same time it also deceased phagocytosis capacity of M2 polarised macrophages, although this was not significant (Figure 4B). LCES showed a lowering, but insignificant trend in phagocytosis capacity for both $M_{1}$ and $M_{2}$ polarised macrophages. The other NDPs did not modulate uptake of $E$. coli bioparticles by neither M1 nor M2 polarised macrophages. This was also found for Mo macrophages exposed to these same NDPs.

\subsection{NDPs decrease antigen processing capacity of both $\mathrm{M}_{1}$ and $\mathrm{M}_{2}$ polarised macrophages}

Our previous research proved that both RG-I and Naxus decreased antigen processing capacity of Mo (Chapter 4). To analyse whether NDPs modulate antigen processing capacity of inflammatory or tolerant macrophages, $M_{1}$ and $M_{2}$ were stimulated by NDPs and antigen processing was analysed by using DQ-OVA. Naxus significantly decreased processing of DQ-OVA for M1 polarised macrophages but other NDPs did not show any effect on this activity (Figure $5 \mathrm{~A}$ ). Again, only Naxus changed antigen processing capacity of $\mathrm{M}_{2}$ polarised macrophages (Figure $5 \mathrm{~B}$ ).

A

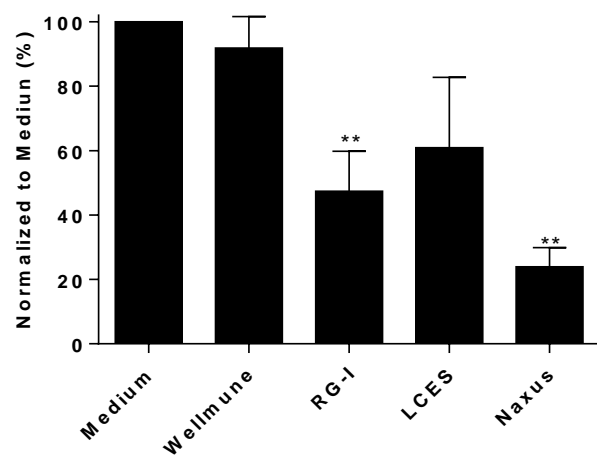

B

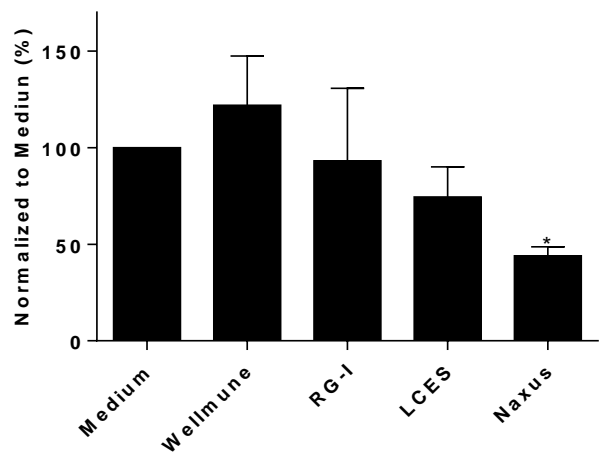

Figure 5. NDP decreased antigen procession function of $M 1$ and $M 2$ polarised macrophages. $M 1$ (A) and $M_{2}$ (B) polarised macrophages were stimulated with Wellmune, RG-I, LCES, and Naxus at 500 $\mu \mathrm{g} / \mathrm{ml}$ for $24 \mathrm{~h}$ followed by $1 \mathrm{~h}$ incubation with DQ-OVA and analysed by flow cytometry. The bar chart shows MFI values $\pm \mathrm{SEM}, \mathrm{n}=3$ different donors. Data was normalized to medium control. Statistically significant differences compared to medium control were analysed by one-way ANOVA: * $\mathrm{p}<0.05, * * \mathrm{p}<0.01$. 


\subsection{NDPs activated $M 1$ and $M 2$ to produce $C_{C L 1}$}

A significantly increased CCL1 production was previously found when Mo cells were exposed to Naxus and LCES, while $M_{1}$ or $M_{2}$ polarised macrophages showed no significant CCL1 production. Here, we analysed whether NDPs are capable of modulating CCL1 production in $\mathrm{M}_{1}$ and $\mathrm{M}_{2}$ polarised macrophages. Indeed, Naxus increased production of CCL1 in both $\mathrm{M}_{1}$ and $\mathrm{M}_{2}$ polarised macrophages, albeit only significant for M1 polarised macrophages (Figure 6). In addition, we analysed other cytokines and chemokines (Table 1). M1 polarised macrophages were stimulated with Naxus which resulted in increased IL8, CCL5, CCL20, CCL24, IL1 $\beta$, and TNFa production, while stimulation with RG-I increased IL8, CCL5, CCL20, CCL24, and TNFa production and LCES stimulation increased IL8 production. M2 polarised macrophages stimulated with Naxus or LCES increased IL8, CCL5, CCL20, CCL24, IL1 $\beta$, and TNFa production, while stimulation with RG-I increased IL8, CCL5, CCL20, and TNFa production. All tested NDPs had no effects on secretion of MMP-1, CXCL9, CXCL10, and CXCL11 by M1 or M2 polarised macrophages.

Table 1. NDPs modulate cytokines M1 and M2 macrophage cytokine secretion.

\begin{tabular}{|c|c|c|c|c|c|c|c|c|c|c|}
\hline & IL8 & CCL5 & CCL2O & CCL24 & IL1 $\beta$ & TNFa & $\begin{array}{l}\text { MMP- } \\
1\end{array}$ & CXCL9 & CXCL10 & CXCL11 \\
\hline $\begin{array}{l}\text { M1- } \\
\text { Medium }\end{array}$ & 921.0 & 916.3 & 17.8 & 14.9 & 0.2 & 203.4 & 122.7 & 24198.6 & 224944.3 & 1188.0 \\
\hline M1-RG-I & 15864.9 & 1897.8 & 110.3 & 54.1 & 0.3 & 3035.3 & 251.9 & 24198.6 & 2603.3 & 36.6 \\
\hline $\begin{array}{l}\text { M1- } \\
\text { LCES }\end{array}$ & 4335.5 & 704.9 & 13.2 & 16.4 & 0.2 & 284.0 & 122.7 & 24198.6 & 699198.1 & 409.5 \\
\hline $\begin{array}{l}\text { M1- } \\
\text { Naxus }\end{array}$ & 19590.0 & 4961.2 & 1783.8 & 647.7 & 3.1 & 30330.8 & 122.7 & 24198.6 & 17327.2 & 698.2 \\
\hline $\begin{array}{l}\text { M2- } \\
\text { Medium }\end{array}$ & 298.4 & 9.9 & 0.8 & 352.1 & 0.1 & 2.3 & 122.7 & 25.2 & 13.5 & 0.1 \\
\hline M2-RG-I & 21968.3 & 375.4 & 18.3 & 271.5 & 0.2 & 549.0 & 251.9 & 37.7 & 18.7 & 0.1 \\
\hline $\begin{array}{l}\text { M2- } \\
\text { LCES }\end{array}$ & 23591.8 & 889.6 & 223.4 & 1969.8 & 1.3 & 10011.8 & 251.9 & 37.7 & 28.8 & 0.2 \\
\hline $\begin{array}{l}\text { M2- } \\
\text { Naxus }\end{array}$ & 23213.1 & 1928.8 & 858.7 & 1784.3 & 4.1 & 23877.0 & 367.0 & 126.2 & 64.8 & 0.4 \\
\hline
\end{tabular}

Values represent concentration of cytokines/chemokines $(\mathrm{pg} / \mathrm{ml})$ analysed by Bio-Plex multiplex, $\mathrm{n}=1$ donor. 
A

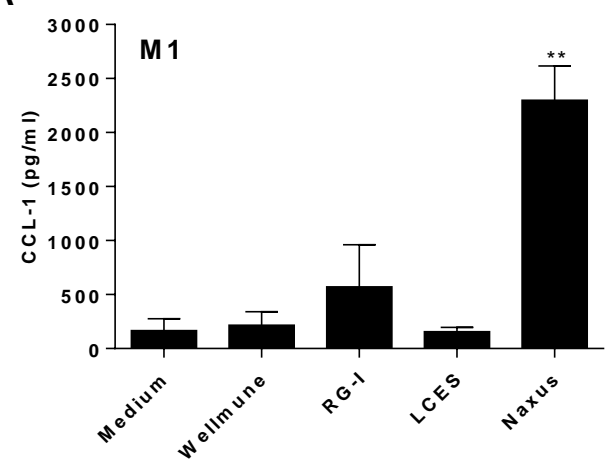

B

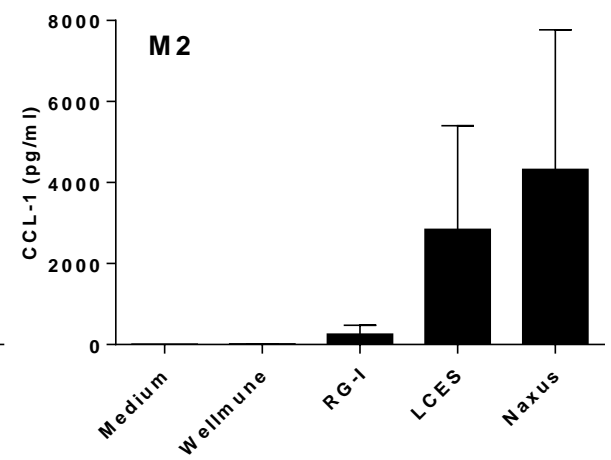

Figure 6. Naxus induced $C C L 1$ production in $M_{1}$ and $M 2$ polarised macrophages. $M 1(A)$ and $M_{2}(B)$ polarised macrophages were stimulated with Wellmune, RG-I, LCES, and Naxus at $500 \mu \mathrm{g} / \mathrm{ml}$ for 24 h. CCL1 secretion was analysed by Bio-Plex multiplex analysis. The bar chart shows mean values \pm $\mathrm{SEM}, \mathrm{n}=2$ different donors. Statistically significant differences compared to medium control were analysed by one-way ANOVA: ** $p<0.01$.

A

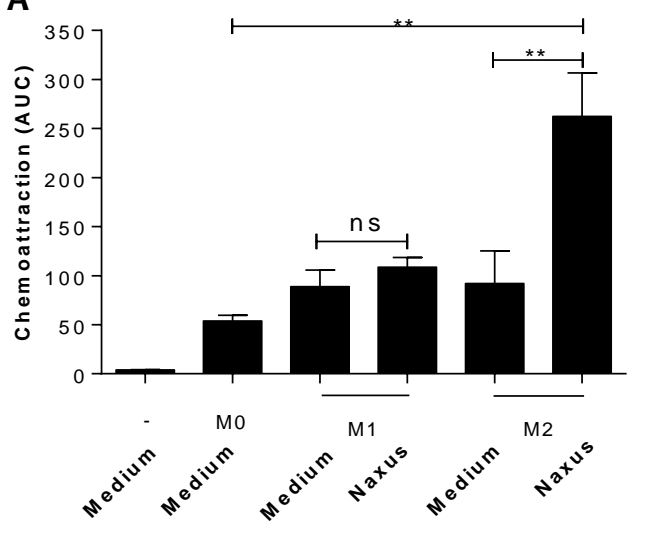

B

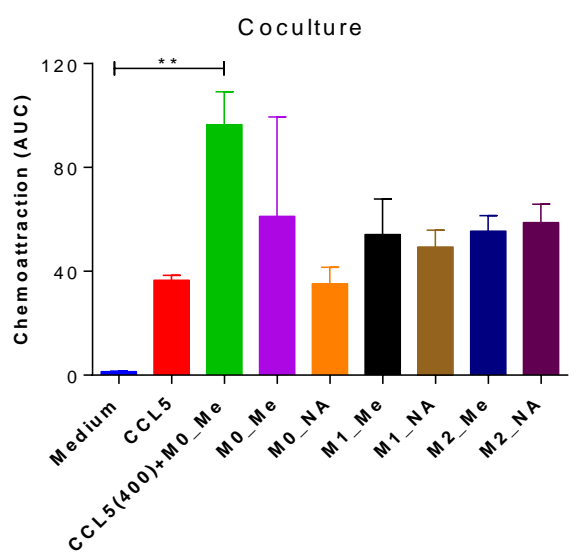

Figure 7. Naxus enhanced $M 2$ macrophages recruiting ability which can abolished by Caco-2 barrier in coculture. Mo, M1, and M2 macrophages were stimulated with Naxus (NA) at $500 \mu \mathrm{g} / \mathrm{ml}$ or medium control $(\mathrm{Me})$ for $24 \mathrm{~h}$ either direct interact with macrophages by single culture (A) or indirect interact by adding to Caco-2 in coculture (B). Chemoattraction were analysed by THP-1 monocytes cell migration induced by macrophages conditioned medium. The bar chart shows mean values $\pm S E M, n=3$ different experiments (A) or $n=2$ technique replicates (B). Statistically significant differences were analysed by one-way ANOVA: ** $p<0.01$. 


\subsection{NDPs promote recruiting ability for $M_{2}$ polarised macrophages but not for $M_{1}$}

In comparison to $\mathrm{M}_{1}$ and $\mathrm{M}_{2}$ polarised macrophages, $\mathrm{M}_{\mathrm{NDP}}$ had shown increased chemokine secretion. Therefore, we analysed migration of THP-1 monocytes by conditioned medium from $\mathrm{M}_{1}$ or $\mathrm{M}_{2}$ macrophages that had been exposed to Naxus (Figure $7 \mathrm{~A}$ ). Mo conditioned medium showed increased recruiting ability compared to fresh medium (background control) and CCL5 (the positive control). M1 and M2 polarised macrophage conditioned medium demonstrated a slight increase in monocyte recruitment compared to Mo conditioned medium. Naxus exposure did not change THP1 monocyte recruiting ability by M1 polarised macrophages. However, Naxus exposure did significantly increase recruiting ability by $\mathrm{M}_{2}$ polarised macrophages.

\subsection{Intestinal immune system in vitro model}

To mimic the intestinal immune barrier in vitro, an intestinal epithelial cells-macrophages coculture system was used. As a first test, it was studied whether cocultivation of 21 days differentiated small intestinal-like Caco-2 grown on the transwell with $\mathrm{M}_{1}$ or $\mathrm{M} 2$ polarised macrophages in the basolateral compartment affected specific gene expression markers of the polarised macrophages. Neither expression of the M1 gene markers (CXCL11, IDO1, dectin-2, and CXCL9), the M2 markers (CCL13, MGL, CCL18, and IL17RB) nor the MNDP gene marker (CCL-1, IL8, CCL24, and CXCL5) were significantly changed in $\mathrm{M}_{1}$ or $\mathrm{M}_{2}$ polarised macrophages following coculture (Figure 8). Subsequently, we analysed whether the NDPs Naxus or LCES could directly or indirectly influence macrophage polarization when applied in the apical compartment. Therefore, we analysed changes in macrophage polarisation again using the gene expression markers (Figure 8). M1 markers CXCL11, IDO1, dectin-2, and CXCL9 were similarly high expressed in M1 polarised macrophages in coculture, following apical exposure to both LCES and Naxus, as in single cultures. The same was found for the M2 specific gene markers CCL13, MGL, CCL1B, and IL17RB which were also not changed in the coculture compared to the single cultured cells. CCL1, IL8, CCL24, and CXCL5 gene expression, indicators for NDPs recognition and responses by macrophages in single cultures, neither changed. In addition, we analysed recruiting ability of THP-1 monocytes by basolateral medium from the Mo, M1, and $M_{2}$ coculture system with and without apical exposure of Naxus (Figure $7 \mathrm{~B}$ ). The results indicate that the apical exposure of Naxus did not influence the recruitment capability of the Mo, M1, or M2 polarised macrophages. 


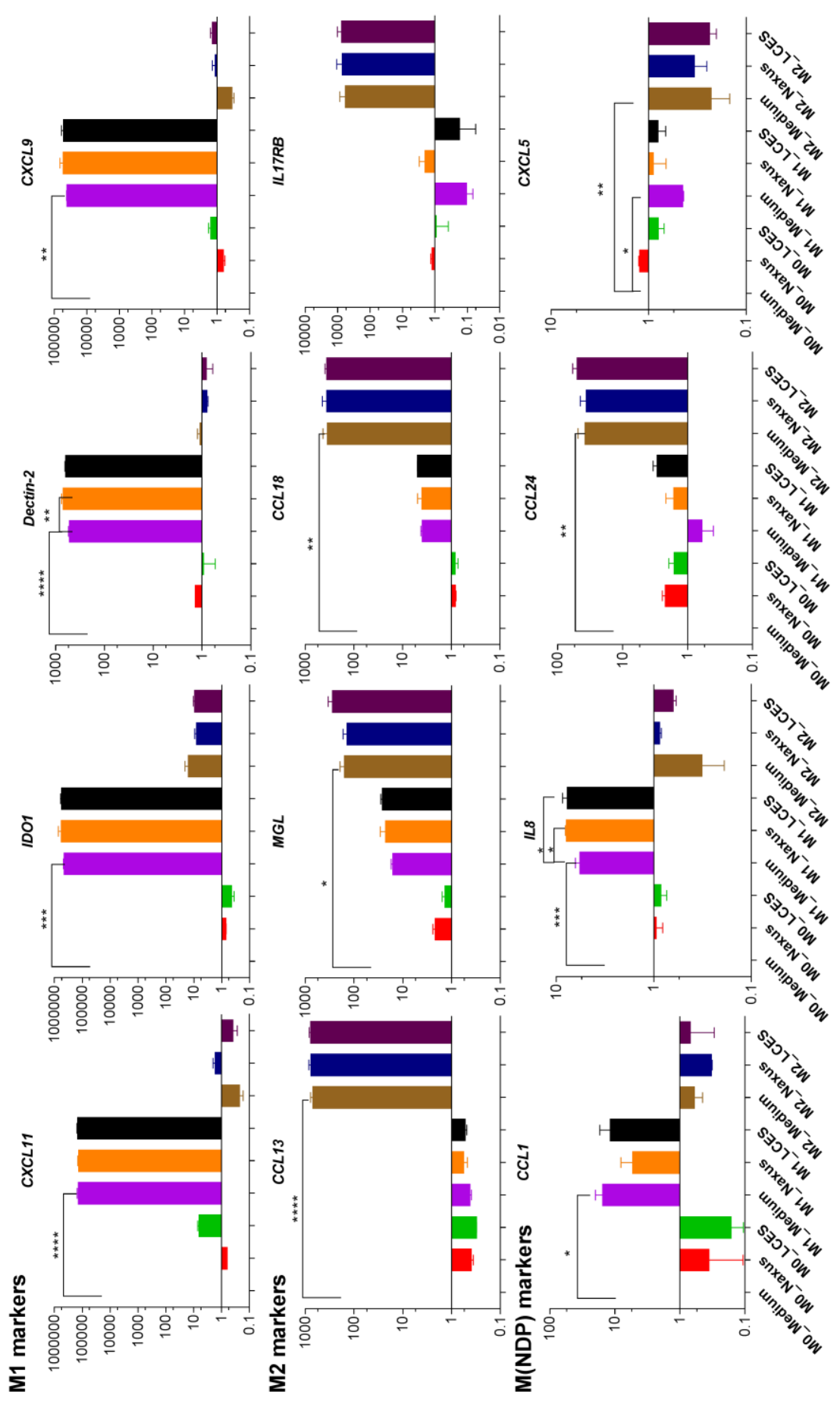




\section{Discussion}

The intestine contains the largest macrophage population in the body [1]. Within this population, a continuous spectrum of subsets exists, with inflammatory (M1) and tolerant macrophages $\left(M_{2}\right)$ as extremes [10]. Plasticity of macrophages is one of the functional properties to balance the intestinal immune status. Macrophages are polarised towards the M1 subset upon inflammatory stimulation such as the sensing of danger signals resulting in macrophages capacity to kill microorganisms and increase cytokine secretion in the host [27]. The M2 subset is formed after IL-4, and IL13 stimulation, and functions in wound healing, tissue repair and remodeling [6]. Food components that impact the macrophage phenotype may lead to the formation of inflammatory or tolerant macrophages or to an alternative status. We previously found that NDPs skewed macrophages to an alternative subset compared to $M_{1}$ and $M 2$, based on gene expression markers [21].

In this study, we analysed the immunomodulatory effects of NDPs on M1 and M2 by analysing phenotype and functionality after NDP-stimulation. We used cocultures of intestinal epithelial cells and macrophages in vitro to mimic the intestinal immune barrier and to evaluate the effects of NDPs on this model. Previous studies revealed that Caco2 spent medium enhanced cytokine production by dendritic cells which was attenuated by dietary fibers [28]. However, the direct effects of NDPs on macrophages were blocked by the Caco-2 layers, for both gene expression and monocyte recruitment. This might be due to the lack of direct physical interaction of NDPs with immune cells, since the Caco2 layer can block passage and signals from the apical side. This might be supported by our previous finding that NDPs reduced FD4 translocation by Caco-2 (Chapter 2). To investigate the importance of direct contact between Caco-2 and macrophages, the upside-down culture model might be applied [29]. In the coculture system, macrophage phenotype and recruiting ability were not influenced by Caco-2. Also, $M$ cells might be interesting to be included in such studies, since $M$ cells might sample NDPs to macrophages.

Figure 8. Naxus and LCES do not affect macrophages gene transcription in coculture with Caco-2. Transwell grown 21 days differentiated Caco-2 were placed in wells with Mo, M1 or M2 polarised macrophages for $24 \mathrm{~h}$. On the apical side, Caco-2 were stimulated with either medium control, 500 $\mu \mathrm{g} / \mathrm{ml}$ LCES or Naxus. Mo, M1, and M2 polarised macrophages located at the basolateral side were analysed for gene expression using qPCR. The bar chart shows fold change by mean values \pm SEM, $\mathrm{n}=2$ different donors. Statistically significant differences were analysed by one-way ANOVA: * $\mathrm{p}<0.05$, $* * \mathrm{p}<0.01, * * * \mathrm{p}<0.001, * * * * \mathrm{p}<0.005$. (Legend for page 126) 


\section{Chapter 5}

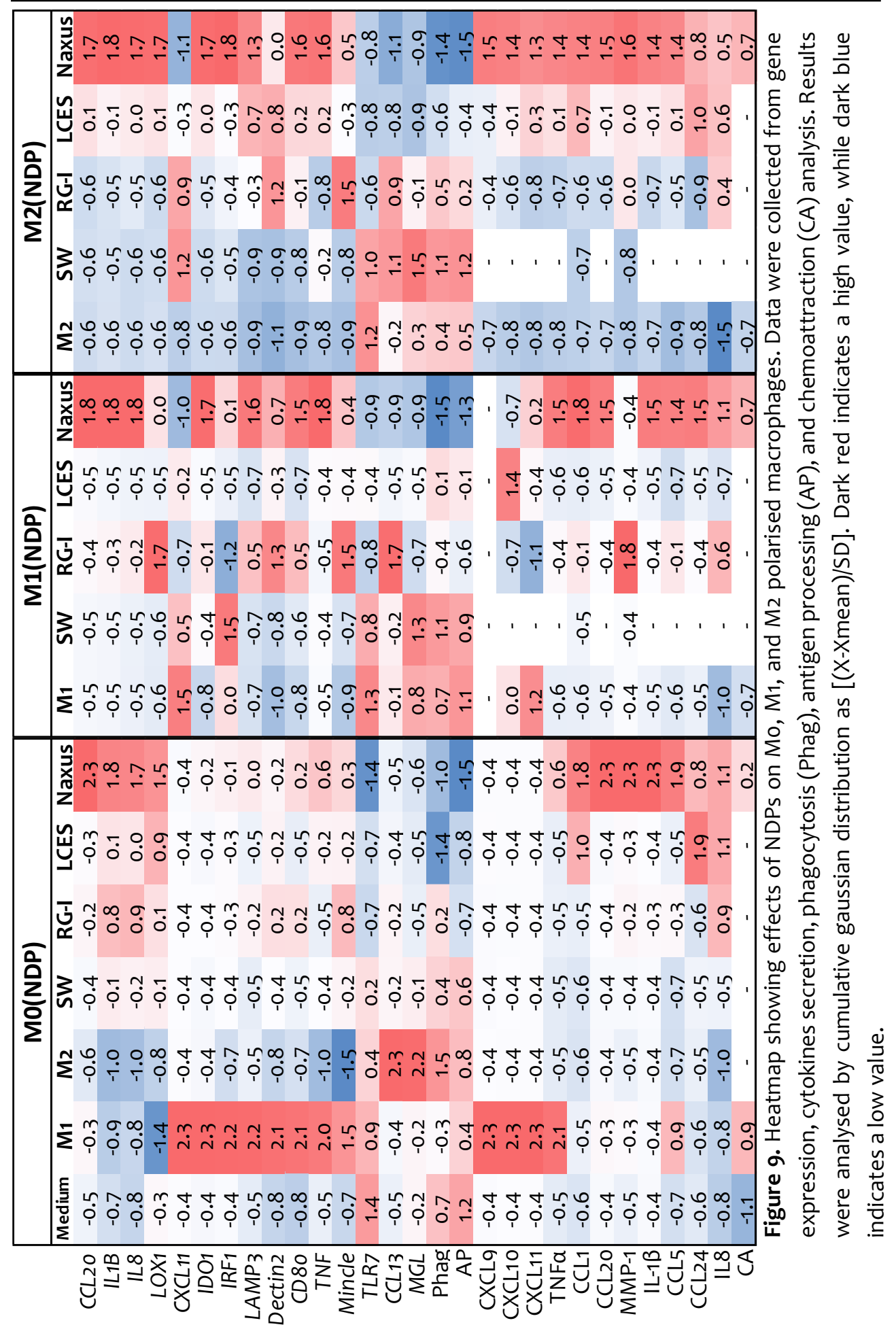


Upon direct exposure of $\mathrm{M}_{1}$ and $\mathrm{M}_{2}$ polarised macrophages to Naxus we observed a skewing to a subset similar as found for Mo exposed to the same NDP. This intermediate $M_{N P D}$ could be hypothesised to be an intermediate and resolving type of macrophage that in case of inflammation can prohibit overstimulation and damage of tissue. Similar conclusions on anti-inflammatory activity have been drawn previously for several polysaccharides based on inhibiting LPS-induced nitric oxide production in macrophages, including arabinoxylans and lentinan containing extracts [30, 31]. Some studies hypothesized that this effect could be caused by blocking of the TLR4 receptor as some of the molecular structures of polysaccharides show similar structures with LPS [32]. Our experimental setup, however, is free of LPS as we used TNF $\alpha$ and IFN $\gamma$, instead of LPS, to induce M1 polarisation and our polysaccharides were devoid of functional levels of LPS contaminations [22]. Instead of blocking the TLR4 receptor, the NDPs might signal via other receptors to exert their effect. Volman and colleagues proposed other TLRs such as TLR2 and TLR6 for recognition of $\beta$-glucan [33], while others suggested the involvement of $\mathrm{CR}_{3}$ in arabinoxylan-mediated immune responses [34] or identified dectin-1 to be involved in recognition of arabinoxylan [35]. Alternatively, our arabinoxylan preparation has been demonstrated to contain $\beta$-glucans and mannose (Chapter 3), potentially for stability, and these structures might also provide signalling towards the macrophages [36].

Naxus significantly decreased phagocytosis and antigen processing capacity for both $\mathrm{M}_{1}$ and $\mathrm{M}_{2}$ polarised macrophages. This is in contrast to arabinoxylan from rice and finger millet that both increased phagocytosis of yeast by macrophages [37, 38]. These contradicting results might stem from non-detected LPS contaminations or might be due to the use of arabinoxylans derived from various sources with different molecular weights and degree of branching [36, 39].

Our results imply that Naxus might be a potential candidate for modulating intestinal macrophages and immunomodulatory activity as also pointed out in several studies and reviews $[36,40]$. In particular the capability to reduce inflammatory macrophages can be an interesting direction for future research as several intestinal diseases have shown to involve inflammation as a common factor like crohn's disease, ulcerative colitis and irritable bowel syndrome (IBS). Interestingly, research with polysaccharides, including lentinan and arabinoxylan arrived at similar conclusions as oral administration of lentinan significantly ameliorated DSS-induced colitis [41] and arabinoxylan has been reported to significantly decrease diarrhoea, constipation and CRP values in IBS patients [42].

Taken together the plasticity of macrophages is demonstrated by showing that the NDP Naxus can skew both inflammatory and tolerant macrophages to an alternative subset

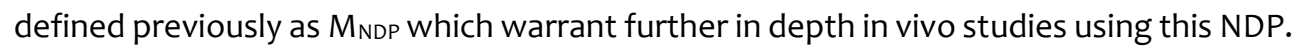




\section{Chapter 5}

Y.T., C.G., and J.J.M. conceived and designed the experiments. Y.T. performed the experiments. Y.T., C.G., and J.J.M. analysed the data. E. H. S., contributed Multiplex cytokine analysis. Y.T., C.G., J.J.M., and H.J.W. wrote the manuscript.

The authors have declared no conflicts of interest. 


\section{References}

1. Lee, S.H., P.M. Starkey, and S. Gordon, Quantitative analysis of total macrophage content in adult mouse tissues. Immunochemical studies with monoclonal antibody F4/80. Journal of Experimental Medicine, 1985.161(3): p. 475-489.

2. Bain, C.C., A. Bravo-Blas, C.L. Scott, E. Gomez Perdiguero, F. Geissmann, S. Henri, B. Malissen, L.C. Osborne, D. Artis, and A.M. Mowat, Constant replenishment from circulating monocytes maintains the macrophage pool in the intestine of adult mice. Nature Immunology, 2014. 15(10): p. 929-937.

3. Rani, R., A.G. Smulian, D.R. Greaves, S.P. Hogan, and D.R. Herbert, TGF-beta limits IL-33 production and promotes the resolution of colitis through regulation of macrophage function. European Journal of Immunology, 2011. 41(7): p. 2000-2009.

4. Cummings, R.J., G. Barbet, G. Bongers, B.M. Hartmann, K. Gettler, L. Muniz, G.C. Furtado, J. Cho, S.A. Lira, and J.M. Blander, Different tissue phagocytes sample apoptotic cells to direct distinct homeostasis programs. Nature, 2016. 539(7630): p. 565-569.

5. Grainger, J.R., J.E. Konkel, T. Zangerle-Murray, and T.N. Shaw, Macrophages in gastrointestinal homeostasis and inflammation. Pflügers Archiv. European Journal of Physiology, 2017. 469(3-4): p. 527-539.

6. Mosser, D.M. and J.P. Edwards, Exploring the full spectrum of macrophage activation. Nature Reviews: Immunology, 2008. 8(12): p. 958-969.

7. Biswas, S.K. and A. Mantovani, Macrophage plasticity and interaction with lymphocyte subsets: cancer as a paradigm. Nature Immunology, 2010. 11(10): p. 889-896.

8. Krausgruber, T., K. Blazek, T. Smallie, S. Alzabin, H. Lockstone, N. Sahgal, T. Hussell, M. Feldmann, and I.A. Udalova, IRF5 promotes inflammatory macrophage polarization and $\mathrm{TH}_{1}$ TH17 responses. Nature Immunology, 2011. 12(3): p. 231-238.

9. Ip, W.K.E., N. Hoshi, D.S. Shouval, S. Snapper, and R. Medzhitov, Anti-inflammatory effect of IL-10 mediated by metabolic reprogramming of macrophages. Science, 2017. 356(6337): p. 513-519.

10. Gabanyi, I., P.A. Muller, L. Feighery, T.Y. Oliveira, F.A. Costa-Pinto, and D. Mucida, Neuroimmune Interactions Drive Tissue Programming in Intestinal Macrophages. Cell, 2016. 164(3): p. 378-391.

11. Veldhoen, M. and V. Brucklacher-Waldert, Dietary influences on intestinal immunity. Nature Reviews: Immunology, 2012. 12(10): p. 696-708.

12. Oh, D.Y., S. Talukdar, E.J. Bae, T. Imamura, H. Morinaga, W.Q. Fan, P.P. Li, W.J. Lu, S.M. Watkins, and J.M. Olefsky, GPR120 Is an Omega-3 Fatty Acid Receptor Mediating Potent Antiinflammatory and Insulin-Sensitizing Effects. Cell, 2010. 142(5): p. 687-698.

13. Liu, M., F.L. Luo, C.L. Ding, S. Albeituni, X.L. Hu, Y.F. Ma, Y.H. Cai, L. McNally, M.A. Sanders, D. Jain, G. Kloecker, M. Bousamra, H.G. Zhang, R.M. Higashi, A.N. Lane, T.W.M. Fan, and J. Yan, Dectin-1 Activation by a Natural Product beta-Glucan Converts Immunosuppressive Macrophages into an M1-like Phenotype. Journal of Immunology, 2015. 195(10): p. 5055-5065.

14. Goodridge, H.S., R.M. Simmons, and D.M. Underhill, Dectin-1 stimulation by Candida albicans yeast or zymosan triggers NFAT activation in macrophages and dendritic cells. Journal of Immunology, 2007. 178(5): p. 3107-3115.

15. Goodridge, H.S., C.N. Reyes, C.A. Becker, T.R. Katsumoto, J. Ma, A.J. Wolf, N. Bose, A.S.H. Chan, A.S. Magee, M.E. Danielson, A. Weiss, J.P. Vasilakos, and D.M. Underhill, Activation of the innate immune receptor Dectin-1 upon formation of a 'phagocytic synapse'. Nature, 2011. 472(7344): p. 471-U541.

16. Hong, F., J. Yan, J.T. Baran, D.J. Allendorf, R.D. Hansen, G.R. Ostroff, P.X. Xing, N.K. Cheung, and G.D. Ross, Mechanism by which orally administered beta-1,3-glucans enhance the 


\section{Chapter 5}

tumoricidal activity of antitumor monoclonal antibodies in murine tumor models. Journal of Immunology, 2004.173(2): p. 797-806.

17. Ahn, H., E. Jeon, J.C. Kim, S.G. Kang, S.I. Yoon, H.J. Ko, P.H. Kim, and G.S. Lee, Lentinan from shiitake selectively attenuates AIM2 and non-canonical inflammasome activation while inducing pro-inflammatory cytokine production. Scientific Reports, 2017. 7(1): p. 1314.

18. Dai, X., J.M. Stanilka, C.A. Rowe, E.A. Esteves, C. Nieves, Jr., S.J. Spaiser, M.C. Christman, B. Langkamp-Henken, and S.S. Percival, Consuming Lentinula edodes (Shiitake) Mushrooms Daily Improves Human Immunity: A Randomized Dietary Intervention in Healthy Young Adults. Journal of the American College of Nutrition, 2015. 34(6): p. 478-487.

19. Volman, J.J., R.P. Mensink, J.D. Ramakers, M.P. de Winther, H. Carlsen, R. Blomhoff, W.A. Buurman, and J. Plat, Dietary (1-->3), (1-->4)-beta-D-glucans from oat activate nuclear factorkappaB in intestinal leukocytes and enterocytes from mice. Nutrition Research, 2010. 30(1): p. 40-48.

20. Tada, R., F. Ikeda, K. Aoki, M. Yoshikawa, Y. Kato, Y. Adachi, A. Tanioka, K. Ishibashi, K. Tsubaki, and N. Ohno, Barley-derived beta-D-glucan induces immunostimulation via a dectin-1mediated pathway. Immunology Letters, 2009. 123(2): p. 144-148.

21. Tang, Y., C. Govers, H.J. Wichers, and J.J. Mes, Macrophages treated with non-digestible polysaccharides reveal a transcriptionally unique phenotype. Journal of Functional Foods, 2017. 36: p. 280-289.

22. Govers, C., M.M.M. Tomassen, A. Rieder, S. Ballance, S.H. Knutsen, and J.J. Mes, Lipopolysaccharide quantification and alkali-based inactivation in polysaccharide preparations to enable in vitro immune modulatory studies. Bioactive Carbohydrates and Dietary Fibre, 2016. 8(1): p. 15-25.

23. Chanput, W., M. Reitsma, L. Kleinjans, J.J. Mes, H.F. Savelkoul, and H.J. Wichers, beta-Glucans are involved in immune-modulation of THP-1 macrophages. Molecular Nutrition \& Food Research, 2012. 56(5): p. 822-833.

24. Vreeburg, R.A., S. Bastiaan-Net, and J.J. Mes, Normalization genes for quantitative RT-PCR in differentiated Caco-2 cells used for food exposure studies. Food \& Function, 2011. 2(2): p. 124129.

25. de Wit, N.J., M. Hulst, C. Govers, J. van der Meulen, A. van Hoef, G. Stoopen, A. Hamers, A. Hoekman, R. de Vos, T.F. Bovee, M. Smits, J.J. Mes, and P.J. Hendriksen, Effects of Digested Onion Extracts on Intestinal Gene Expression: An Interspecies Comparison Using Different Intestine Models. PloS One, 2016. 11(9): p. e0160719.

26. Piccolo, S.R., M.R. Withers, O.E. Francis, A.H. Bild, and W.E. Johnson, Multiplatform singlesample estimates of transcriptional activation. Proceedings of the National Academy of Sciences of the United States of America, 2013. 110(44): p. 17778-17783.

27. Adams, G.G., S. Imran, S. Wang, A. Mohammad, M.S. Kok, D.A. Gray, G.A. Channell, and S.E. Harding, The Hypoglycemic Effect of Pumpkin Seeds, Trigonelline (TRG), Nicotinic Acid (NA), and D-Chiro-inositol (DCl) in Controlling Glycemic Levels in Diabetes Mellitus. Critical Reviews in Food Science and Nutrition, 2014. 54(10): p. 1322-1329.

28. Bermudez-Brito, M., N.M. Sahasrabudhe, C. Rosch, H.A. Schols, M.M. Faas, and P. de Vos, The impact of dietary fibers on dendritic cell responses in vitro is dependent on the differential effects of the fibers on intestinal epithelial cells. Molecular Nutrition \& Food Research, 2015. 59(4): p. 698-710.

29. Martin-Latil, S., N.F. Gnadig, A. Mallet, M. Desdouits, F. Guivel-Benhassine, P. Jeannin, M.C. Prevost, O. Schwartz, A. Gessain, S. Ozden, and P.E. Ceccaldi, Transcytosis of HTLV-1 across a tight human epithelial barrier and infection of subepithelial dendritic cells. Blood, 2012.120(3): p. 572-580. 
30. Mendis, M., E. Leclerc, and S. Simsek, Arabinoxylan hydrolyzates as immunomodulators in lipopolysaccharide-induced RAW264.7 macrophages. Food \& Function, 2016. 7(7): p. 30393045.

31. Tomassen et al., T., M. M. M., Hendrix, E. A. H. J., Sonnenberg, A. S. M., Wichers, H. J., Mes, J.J., Variation of bioactive lentinan-containing preparations in Lentinula edodes strains and stored products. 7th International Conference of the World Society for Mushroom Biology and Mushroom Products, Arcachon, France, 2011: p. 254-262.

32. Li, W.L., S.Y. Zhang, and C. Smith, The molecular structure features-immune stimulatory activity of arabinoxylans derived from the pentosan faction of wheat flour. Journal of Cereal Science, 2015. 62: p. 81-86.

33. Volman, J.J., J.D. Ramakers, and J. Plat, Dietary modulation of immune function by betaglucans. Physiology and Behavior, 2008. 94(2): p. 276-284.

34. Yamagishi, T., T. Tsuboi, and K. Kikuchi, Potent Natural Immunomodulator, Rice WaterSoluble Polysaccharide Fractions with Anticomplementary Activity. Cereal Chemistry Journal, 2003. 80(1): p. 5-8.

35. Sahasrabudhe, N.M., H.A. Schols, M.M. Faas, and P. de Vos, Arabinoxylan activates Dectin-1 and modulates particulate beta-glucan-induced Dectin-1 activation. Molecular Nutrition \& Food Research, 2016. 60(2): p. 458-467.

36. Zhang, S., W. Li, C.J. Smith, and H. Musa, Cereal-derived arabinoxylans as biological response modifiers: extraction, molecular features, and immune-stimulating properties. Critical Reviews in Food Science and Nutrition, 2015. 55(8): p. 1035-1052.

37. Ghoneum, M. and M. Matsuura, Augmentation of macrophage phagocytosis by modified arabinoxylan rice bran (MGN-3/biobran). International Journal of Immunopathology and Pharmacology, 2004. 17(3): p. 283-292.

38. Savitha Prashanth, M.R., R.R. Shruthi, and G. Muralikrishna, Immunomodulatory activity of purified arabinoxylans from finger millet (Eleusine coracana, v. Indaf 15) bran. Journal of Food Science and Technology, 2015. 52(9): p. 6049-6054.

39. Saulnier, L., P.-E. Sado, G. Branlard, G. Charmet, and F. Guillon, Wheat arabinoxylans: Exploiting variation in amount and composition to develop enhanced varieties. Journal of Cereal Science, 2007. 46(3): p. 261-281.

40. Mendis, M., E. Leclerc, and S. Simsek, Arabinoxylans, gut microbiota and immunity. Carbohydrate Polymers, 2016. 139: p. 159-166.

41. Nishitani, Y., L. Zhang, M. Yoshida, T. Azuma, K. Kanazawa, T. Hashimoto, and M. Mizuno, Intestinal anti-inflammatory activity of lentinan: influence on IL-8 and TNFR1 expression in intestinal epithelial cells. PloS One, 2013. 8(4): p. e62441.

42. Kamiya, T., M. Shikano, M. Tanaka, K. Ozeki, M. Ebi, T. Katano, S. Hamano, H. Nishiwaki, H. Tsukamoto, T. Mizoshita, Y. Mori, E. Kubota, S. Tanida, H. Kataoka, N. Okuda, and T. Joh, Therapeutic effects of biobran, modified arabinoxylan rice bran, in improving symptoms of diarrhea predominant or mixed type irritable bowel syndrome: a pilot, randomized controlled study. Evidence-Based Complementary and Alternative Medicine, 2014. 2014: p. 828137. 


\section{Chapter 5}

Supplementary Table 1. Gene expression profile on Mo determined by microarray.

\begin{tabular}{|c|c|c|c|c|c|c|}
\hline Genes & M1 & M2 & Wellmune & RG-I & LCES & Naxus \\
\hline IL1B & -1.4 & -3.7 & 8.8 & $19.4^{* * *}$ & $10.7^{* *}$ & $32.8 * * *$ \\
\hline IL8 & 1.3 & -3.6 & $13 \cdot 3$ & $33.9 * * *$ & $17.2^{* *}$ & $51.2 * * *$ \\
\hline TNF & $11.4 * * *$ & -1.2 & 1.5 & 1.0 & 2.3 & $5.7^{* *}$ \\
\hline CD80 & $11.7 * * *$ & 1.7 & 2.4 & $4.7 * * *$ & 2.2 & $4.9 * * *$ \\
\hline Dectin-2 & $24.5 * * *$ & 1.0 & $4 \cdot 3$ & $8.6 *$ & $5.7^{*}$ & $5 \cdot 3^{*}$ \\
\hline Mincle & $12.5^{* * *}$ & -3.0 & 3.8 & $9.0 * *$ & 3.9 & $6.4 * *$ \\
\hline LOX1 & $-4.6 *$ & -1.6 & 1.9 & 3.1 & $7.0 * *$ & $9 \cdot 9^{* * *}$ \\
\hline MGL & 1.0 & $19.8 * * *$ & 2.0 & -1.1 & -1.4 & -1.9 \\
\hline TLR7 & -1.0 & -3.4 & -4.2 & $-8.2^{* *}$ & $-7.9 * *$ & $-11.2 * * *$ \\
\hline CCL2O & $6.2^{*}$ & -1.5 & 2.6 & 7.3 & 4.3 & $69.9 * * *$ \\
\hline CXCL11 & $304.0 * * *$ & 1.1 & 1.9 & 1.7 & 1.3 & -1.1 \\
\hline CCL13 & 3.4 & $94.1 * * *$ & 10.3 & $10.8 *$ & 2.9 & 1.5 \\
\hline IDO1 & $799.7^{* * *}$ & 1.2 & 2.7 & $15.8 * * *$ & $4.1^{*}$ & $54.0 * * *$ \\
\hline $\mathrm{LAMP}_{3}$ & $83.0 * * *$ & $2.2^{*}$ & 1.4 & $12.1 * * *$ & $2.8 * *$ & $16.0 * * *$ \\
\hline IRF1 & $22.0 * * *$ & -1.3 & 1.2 & 1.5 & 1.5 & $3.1 * * *$ \\
\hline
\end{tabular}

Values represent fold changes of gene expression, $n=3$ donors. Statistically significant differences were calculated with IBMT regularised paired t-test: * FDR $\mathrm{p}<0.05$, ** FDR $p<0.01 ; * * *$ FDR $p<0.001$. 
Supplementary Table 2. Primer details

\begin{tabular}{lll}
\hline Genes & Forward (5'-3') & Reverse (5'-3') \\
\hline PUM1 & TGAGGTGTGCACCATGAAC & CAGAATGTGCTTGCCATAGG \\
RPLP0 & GCAATGTTGCCAGTGTCTG & GCCTTGACCTTTTCAGCAA \\
IL8 & CTGATTTCTGCAGCTCTGTG & GGGTGGAAAGGTTTGGAGTATG \\
CD80 & ACCATCCAAGTGCCATACC & CACGTGGATAACACCTGAAC \\
STAT1 & CTGGCACCAGAACGAATG & GCTGACGTTGGAGATCAC \\
TNF & GGCGTGGAGCTGAGAGATAA & GATGGCAGAGAGGAGGTTGA \\
CD209 & AGGAGCAGAACTTCCTAC & GCTCTCCTCTGTTCCAATAC \\
MRC1 & CAGCGCTTGTGATCTTCATT & TACCCCTGCTCCTGGTTTTT \\
MRC2 & GGAAACTCCCACGGAAAG & GTCTCGCAGTCGTTACTC \\
PPARG & TCTAAAGAGCCTGCGAAAGC & GCGGTCTCCACTGAGAATAATG \\
CD36 & GCCAAGGAAAATGTAACCCAGG & GCCTCTGTTCCAACTGATAGTGA \\
IDO1 & GCCAGCTTCGAGAAAGAGTTG & ATCCCAGAACTAGACGTGCAA \\
GBP5 & ACATTAGTTCTGCTTGACACCG & GCTGCTCAGTAAGAGTGCCAG \\
GCH1 & ACGAGCTGAACCTCCCTAAC & GAACCAAGTGATGCTCACACA \\
LAMP3 & ACTACCCCAGCGACTACAAAA & CTAGGGCCGACTGTAACTTCA \\
CXCL11 & GACGCTGTCTTTGCATAGGC & GGATTTAGGCATCGTTGTCCTTT \\
IRF1 & GCAGCTACACAGTTCCAGG & GTCCTCAGGTAATTTCCCTTCCT \\
Mincle & CTGAAACACAATGCACAGAGAGA & AAAGATGCGAAATGTCACAACAC \\
DeCtin-1 & AACCACAGCTACCCAAGAAAAC & GGGCACACTACACAGTTGGTC \\
DeCtin-2 & GCTTTCAGACCCACAAGGTAAT & GCAGAATGATTGGGCTCACCTA \\
MGL & AGCAACTTCACCTCAAACACTG & AGATGCTATCGTTTCTTCCAAGC \\
\hline & &
\end{tabular}





\section{Chapter 6}

General discussion 


\section{Chapter 6}

Non-digestible polysaccharides (NDPs), gain attention for their immunomodulatory activity. The mechanism of the immunomodulatory effects of NDPs on the intestinal immunity remained largely unknown. Some research resulted in the hypothesis that the health effects would result from fermentation products of NDPs, such as short chain fatty acids which are subsequently recognized by immune cells, leading to regulation of intestinal immunity [1]. Others studies demonstrated a direct interaction of NDPs with immune cells aligning the intestine. It is clear that the intestinal immune system involves an abundant set of immune cells both in types (include dendritic cells, macrophages, $T$ cells, B cell as well as innate lymphoid cells (ILCS)) and in number, as it contains approximately $70 \%$ of all immune cells [2]. This high abundance and complexity of the intestinal immune system on the one hand and the presence of many different NDPs that are or could be part of our diet raised the interest to gain more knowledge on which NDPs interact with these intestinal immune cells and how, and to what immune effects that leads. As the variation of NDPs in our diet is almost endless it is hard to image that all these different structures can be recognized by immune cells or lead to similar effects. Our research presented in this thesis focused on this direct interaction between NDPs and intestinal immune cells and has formed a basis to start in differentiating these NDPs based on immunomodulating effects. Our research included the interaction between NDPs and intestinal epithelial cells (IECS), macrophages, and macrophage subsets like the inflammatory macrophages and tolerant macrophages. NDPs could reduce FD4 translocation across the epithelial cells through physical interaction. Microarray analysis revealed characteristics of NDPs activation on gene expression of surface markers, NFKB family members, and cytokines. Based on transcriptome and functional analysis of macrophages, we revealed that NDPs can direct macrophages towards a specific subset for which we used the term $M_{N D P}$, a separate group compared to inflammatory macrophages or tolerant macrophages. Comparing the effects provoked by the different NDPs that we had to our disposal, we have to conclude that the wheat-derived arabinoxylan-rich preparation Naxus revealed the strongest activation of this $M_{N D P}$ subset and related responses. Therefore, we advocate that this product should be further studied in vivo for its immunomodulatory effect in order to link the observed in vitro activity to biological relevance for the in vivo situation. The models developed and used in this thesis and the studied components like Naxus could lead to their development in a functional supplement that supports a healthy human gut and immune status. 


\section{Intestinal immune barrier}

Studying the function of human small intestinal tissue and the responses to luminal factors is not easy. Small intestinal biopsy material is difficult to sample and ex vivo stimulations in Ussing chambers have shown that incubation time should be short (preferable $<1 \mathrm{~h}$ ), that RNA after such incubation is hard to obtain and cytokine expression often too low to detect due to large buffer volumes required (John-Peter Ganda Mall, personal communication). An alternative research tool to study the responses of small intestinal tissue that is currently developed is based on organoids, either derived from human inducible pluripotent stem cell lines [3, 4] or from intestinal crypt cells derived from biopsies or surgery [5]. Both strategies have high potency for future research, each having its advantages and disadvantages. However, a robust protocol for generating 2D multicellular human tissue with a reproducible make up of cell types from these 3D spheres still needs further optimisation before it can be applied on a routine base. Especially, as foods are likely to generate only mild changes, methods applied should be highly reproducible.

In literature several intestinal epithelial in vitro cell models were described which included various cell lines as HT29, T84, and Caco-2. These cell lines have shown such a reliable performance, although also for these cell systems lab-to-lab and experiment-toexperiment variation is not uncommon. Since many labs are using Caco-2 as a model, data can be integrated and used for more systematic comparison and effects evaluation like we did in our lab [6]. Therefore we chose Caco-2 as IECs model for NDP evaluation. Twenty-one-days differentiated Caco-2 cells, grown in transwells, have shown to resemble small intestinal cells. These epithelial layers can build up a transepithelial electrical resistance (TEER) between 800 and $1200\left(\Omega * \mathrm{~cm}^{2}\right)$ per transwell in 24 well plates. TEER values are both used to check for the quality of the insert tissue but also can be used to analyse the effect of a treatment on intestinal integrity. Our data are based on single measurements on specific time points. However, continuous measurements of TEER by e.g. cellZscope or similar methods can even be used for a more detailed timedose response on TEER [7]. But only when grown on membranes like in the transwell system TEER measurements can be combined with other measurements to study integrity e.g. by analysing translocation of markers like FD4. Low layer integrity is correlated with high translocation of FD4, but due to a fine regulation of cell-cell junctions a high layer integrity does not always correlate with low FD4 translocation.

In Chapter 2, we found that NDPs do not affect TEER, and physically block FD4 transport. This physical blocking could potentially also occur by other molecules in the lumen and therefore it can be hypothesised that NDPs could inhibit uptake of nutrients but also of 


\section{Chapter 6}

risk factors resulting in positive health effects. A protected barrier function can therefore be defined in different ways; an inhibition of translocation by maintaining cell integrity or support in blocking translocation of undesired components which both can have a physiological background (active response of cells) and a physical background (direct binding). In fact, a dietary fibre like $\beta 2 / 1 \rightarrow$ fructan was found to exert a polysaccharide length-dependent protection of barrier function on T84 IECs [8]. This protection involved TLR-2 activation as the effects were inhibited by a TLR-2 blocking antibody [8]. In practise also other mechanisms can have an effect on barrier function, e.g. mucus (not produced in Caco-2 in biologically relevant amounts [9]) have the capability of trapping luminal factors and food based treatments that can stimulate this mucus production [10]. Besides that, many cellular factors will be involved in maintenance of tissue integrity including the energy supply and mitochondrial function, as it was reported that an increased permeability linked to mitochondrial inhibition [11].

Intestinal integrity is very relevant for gut health and is correlated with tight junction (TJ) proteins. These TJ proteins are composed of transmembrane proteins (occludins and claudins) and intracellular scaffold proteins (ZO-1, ZO-2, and ZO-3). Some reports claim that tight junction proteins are upregulated by polysaccharides [12]. However, we found no change in TJ-gene expression after NDP treatment in Caco-2. We did find that our 21day differentiated Caco-2 exhibited high TEER values and low permeability. This suggests that TJ proteins are abundantly expressed but not changed by NDPs. We, however, did not study intracellular protein translocation and protein folding of TJ proteins which could also be effected by exposures without changes in de novo synthesis. The Caco-2 layer could also block LPS and NDP translocation, prohibiting to detect changes in gene expression by macrophages (Chapter $\mathbf{5}$ ).

\section{Caco-2 challenge model could support research}

As discussed above, 21-days differentiated Caco-2 form an intact epithelial layer for which we could not detect FD4 passage and for which we found that it blocked the potency of NDPs to signal towards macrophages in the basolateral department (chapter 5). Similar results were observed for LPS transport over Caco-2 which was fully blocked as studied with basolateral THP-1 macrophages which are able to respond to LPS even at very low concentrations of LPS [13].

$M$ cells and goblet cells function as transporters of luminal antigens or food components to underneath located immune cells such as macrophages and DCs [14]. Twenty-onedays differentiated Caco-2 might lack $M$ cells and goblet cells or do not have the full 
functional capacity to transport NDPs or LPS. In vitro models of IECs therefore should make more use of methods to introduce these transporter cells, e.g. by inducing $M$ cells via co-culturing with Raij B cells [15]. Also other immune cells are likely to signal to IECs to steer differentiation and activation towards these transport cells and structures [16].

A

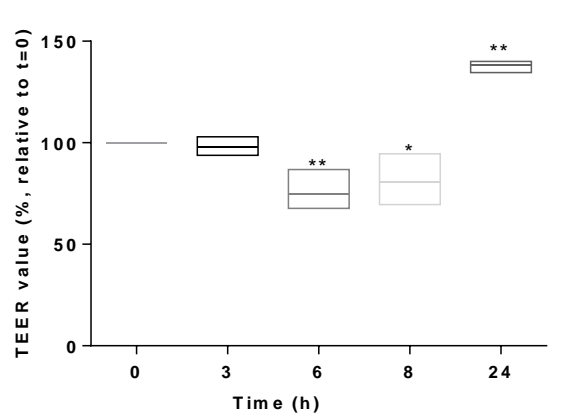

B

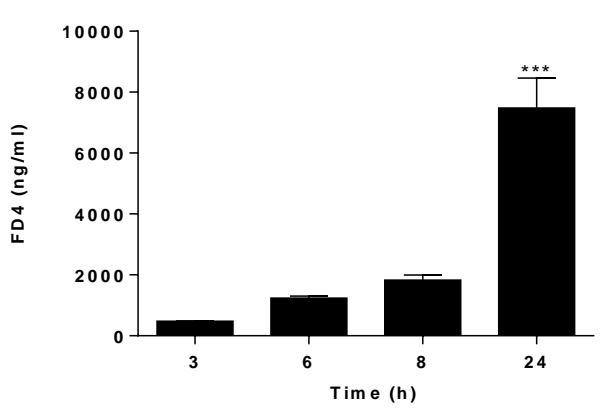

Figure 1. TEER and barrier integrity of Caco-2 with ethanol challenge. Twenty-one-day differentiated Caco- 2 cells were stimulated with $15 \%$ ethanol for 3, 6, 8, and 24 h. Cells were monitored by TEER (A) and FD4 translocation (B). $N=3$ different experiments. Statistically significant differences were analysed compared to medium $(A)$ or baseline $(B)$ by one-way ANOVA: * $\mathrm{p}<0.05, * * \mathrm{p}<0.01, * * * \mathrm{p}<0.001$.

Another approach we and others followed to study effects of treatments towards IECs was based on challenge models. The general idea is that the intestinal system has to counteract challenges and that the time needed to restore the intestinal barrier and homeostasis is an indication for health. Also for IECs several of these challenge models have been developed including bacterial derived toxins (e.g. C. difficile Tox A and B), DON (mycotoxin), melittin (bee venom), lectins like WGA, glycoalkaloids (e.g. from the Solanum family), and mixtures of inflammatory cytokines (such as TNFa and INFY) [17]. We also challenged Caco-2 with ethanol as model for the effect of alcohol consumption and found that the TEER decreased within the first $6 \mathrm{~h}$ and then starts to recover. TEER reached even higher values than control levels after $24 \mathrm{~h}$ (Figure $1 \mathrm{~A}$ ) indicating that cell morphology or connections between cells (over)compensate for the loss of integrity. This whole process was also monitored with FD4 translocation and basolateral accumulation, indicating that even after 8 hours, when the TEER started to restore, translocation was still proceeding (Figure 1B). The ethanol-induced decrease in TEER is 


\section{Chapter 6}

also dose-dependent. Changes in TJ protein (ZO-1 and claudin-1) [18] and activation of the mitogen activated protein kinase pathway might be involved [19]. Therefore, this ethanol method, or any other model mentioned earlier, could be used to further test the ability of NDPs to support recovery of intestinal homeostasis.

\section{Immunomodulating signals of IECs}

Besides forming a physical barrier, IECs also signal towards neighbouring cells and associated immune cells to warn, recruit, and instruct other immune cells [20]. IECs produce TSLP, TGF $\beta$, IL25, and APRIL that activate intestinal immune cells to limit inflammation and direct appropriate immune responses [21]. For instance, after helminth infection, IECs produce TSLP and IL25 to drive Th2 cells to promote the development of type 2 cytokine [22, 23]. To give an example for in vitro results, 21-days differentiated Caco-2 respond to LPS when applied apically at high concentration. LPS is also abundantly present in the intestine. However, as these IECs should not continuously be triggered by luminal factors like LPS, they have a higher threshold/tolerance level than immune cells. For Caco-2 this tolerance of direct apical LPS stimulation was determined to be $1 \mu \mathrm{g} / \mathrm{ml}$ E.coli LPS, at which level no significant difference in gene expression of inflammatory markers was detected (Chapter 2). This threshold level of LPS is around $10^{6}$ higher than for THP-1 macrophages [13] and $10^{3}$ higher than or primary macrophages [24]. The relatively high tolerance of Caco-2 to LPS compared to macrophages might be due to less TLR4 expression on the apical side of Caco-2 [25]. Twenty-one-days Caco-2 exposed to NDPs showed a mild but significant increase in gene expression and protein secretion of CXCL10 and CCL20 (Chapter 2). Similar results were previously reported for IEC18 cells secreting CCL2, CXCL1, and CXCL2 when incubated with oligosaccharides as FOS, GOS, GMOS, and inulin [26]. HT-29, another IEC cell line used in vitro, was reported to respond to zymosan and curdlan by secretion of IL8 in a dose-dependent manner, but not other cytokines (CCL2, IL1 $\beta$, TNFa, IL6, IL10, or IL12p70) [27]. In addition, cereal $\beta$ glucan was reported to be unable to directly activate IL 8 secretion in both Caco-2 and HT-29 [28]. In fact, an animal study showed that cytokine secretion from enterocytes might be due to cellular interaction with intestinal leukocytes that are activated by dietary $\beta$-glucan [29]. These immune responses could be activated by TLR4 and are dependent on activation of NF-KB and Myd88 signalling [26], or activated by dectin-1 and dependent on activation of SyK signalling [27]. Our data revealed that the expression of cytokines induced by NDP exposure was routed via the NF-KB pathway and likely via the TLR2 receptors (Chapter $\mathbf{2}$ ). 


\section{Sampling in intestinal immunity}

The classical view to study risk related factors in relation to intestinal immunity is based on a passive response to invading pathogens when they have entered the tissue [30, 31]. However, recent studies based on high resolution imaging revealed that dendrites of APC like macrophages can cross the intestinal barrier to sample pathogens [32]. The macrophages that reside in the intestine are the largest population of macrophages in the body [33]. They are continuously replenished by recruiting Ly6Chi monocytes [34]. A subset of mononuclear cells, including macrophages, extended dendrites across the intestinal barrier into the intestinal lumen in a $C_{3} X_{3} R_{1}$ dependent manner, as demonstrated based on transgenic mice [35]. CX3CR1 is a GPCR transmembrane protein expressed by monocytes, macrophages, dendritic cells and T-cells. The $C_{3}{ }_{3} C R 1$ positive cells showed a response to Salmonella enterica in vivo, which was absent in transepithelial dendrite-deficient ( $\left.\mathrm{CX}_{3} \mathrm{CR}_{1}{ }^{\mathrm{GFP} / \mathrm{GFP}}\right)$ mice [35]. In fact, $\mathrm{CX}_{3} \mathrm{CR}_{1}{ }^{+}$cells are nonmigratory intestine-resident cells with slow turnover rates and characterized by a poor response to FLT-3L and MCSF [36]. Within $\mathrm{CX}_{3} \mathrm{CR}^{+}$cells, $70 \%$ of these cells were macrophages expressing the CD64 marker [37]. In contrast to $C X_{3} C R 1^{+}$cells, $C D 103^{+} D C s$ migrate into the intestine draining mesenteric lymph nodes at both steady state and in inflammatory conditions with high T cell stimulatory capacity [36]. Interaction between $\mathrm{CX}_{3} \mathrm{CR}_{1} 1^{+}$macrophages and $\mathrm{CD} 103^{+} \mathrm{DCs}$ further revealed the role of $\mathrm{CX} 3 \mathrm{CR}_{1}{ }^{+}$macrophages in taking up soluble antigens and quickly transferring them to $C D 103^{+} D C s$ in a Connexin 43-dependent manner and requiring membrane transfer [38]. The starting point for our research was therefore that the cells in the intestine that interact with NDPs should be resident macrophages. Intestinal resident macrophages are highly phagocytic and in the steady-state show no enhanced production of inflammatory cytokines as IL1, IL6, and TNF $\alpha$ in response to ligation of TLR [39], but they do produce substantial amounts of IL10 [34]. By exposing the macrophages to NDPs, we could use the data to better predict and explain how NDPs impact human health.

\section{Macrophage based research}

To investigate effects of food components on intestinal immunity in vitro, models preferably should mimic both the intestinal epithelial layers and should contain the sampling immune cells as explained above. In literature, several models are described such as Caco-2 and HT-29 as IECs in coculture and with THP-1 macrophages or RAW 264.7 macrophages as immune cells. However, the IEC-barrier could also abolish the response by macrophages as we found, since the dendrites of immune cells do not cross the IEC barrier in the in vitro co-culture model. We chose to evaluate the direct interaction of 


\section{Chapter 6}

NDPs and macrophages, which is still valuable to evaluate NDPs immunomodulatory activity.

In general, there are two ways to obtain macrophages. The first is based on a human cell line like THP-1 monocytes which can be differentiated into macrophages by PMA. THP-1 cells are a human leukemia cell line broadly used for in vitro assays to evaluate immunomodulatory effects of food components [40], since it is sensitive and robust. THP-1 macrophages have been used to study immunomodulating effects of quercetin, citrus pectin, and barley glucan [41]. This macrophage model was further used to compare the immunomodulating properties of three $\beta$-glucans derived from oat, barley, and shiitake [42]. THP-1 macrophages respond to LPS as low as $1 \mathrm{pg} / \mathrm{ml}$ [13], while the primary Mo macrophages threshold is higher than THP-1 macrophages ( $1 \mathrm{ng} / \mathrm{ml}$; data not shown). THP-1 macrophages can be further polarized to M1 or M2 subsets that express specific marker genes and show specific functionality [43]. This model also has shown to be capable of identifying food components with macrophage-polarizing potential.

The second strategy for obtaining human macrophages, which was used in this thesis, is based on primary human monocytes isolated from blood buffy coat from which macrophages can be differentiated by stimulation with MCSF in vitro. Human macrophages obtained from healthy donors have the advantage that they reflect the human steady status. However, the disadvantage is that this also influences the responses to stimuli and therefore research should always be based on at least two or three donors. Again, these macrophages can be further polarized to inflammatory or tolerant macrophages with specific stimulations. We used TNF $\alpha$ together with INF $\gamma$ instead of LPS (in order to discriminate between effects of NDPs and those that might be generated by LPS contaminations in the NDP samples) to polarize to inflammatory macrophages. At the start of our research no fixed set of gene expression markers was available to characterize these subsets of macrophages. Therefore, we invested in selecting and validating a marker gene set (chapter 3 ). These sets of gene markers we setup were well established and could be useful for food components evaluation. We also studied the macrophage functionality by several assays such as phagocytic assay, antigen processing assay, and immune cell recruitment assay (chapter 4). Next, we used such human macrophages, both the non-differentiated Mo and the M1 and M2 subsets, to study the effect of NDPs on their differentiation. Furthermore, we studied the effects that macrophage-NDP interactions could have on their functionality and on immunological processes in the intestine. This revealed that NDPs can direct macrophages towards an alternative subset which was termed $M_{N D P}$ (chapter 3 ) and that this effect is strong enough to redirect macrophages that already were differentiated in a specific $M_{1}$ or $M_{2}$ subset (chapter 4 ). Characterization of this $M_{N D P}$ subset showed a 
specific secretion profile of cytokines, reduced phagocytosis and antigen processing capacity, and increased recruiting ability towards at least monocytes. The composition of the produced chemokines, which we showed in Chapter 4, suggested that more cell types could be interesting to be tested in future such as eosinophils, neutrophils, basophils, and resting and activated T cells. Our current results could be interpreted as that intestinal macrophages (those sampling from the lumen or situated in Peyer's patches in which NDPs were transported across the intestinal epithelium), whatever their differentiation stage or subsets, are (re-)directed towards a somewhat tolerant subset that is more active than intestinal residing tolerant macrophages in attracting other immune cells to the relevant location. This could result in a higher degree of infiltration of intestinal tissue with immune cells and therefore in a high immune capacity to respond in case of emergency (like wound/damage or infection).

\section{Continuum, flexibility and plasticity of macrophages}

As explained above, macrophage phenotypes appear not to be restricted to only a few sharply defined subsets. Instead, there appears to be a continuum of phenotype and function. The MNDP also do not have sharply defined characteristics and, more importantly, also not all NDPs appear to have the same capacity in directing this differentiation. Based on the diversity of health effect described for NDPs (e.g. some have shown cholesterol lowering effects while others have not [44]), variety in capacity of NDPs could also be expected. As described in chapter 3 and 4 it is very likely that specific (C-type lectin) receptors expressed on the surface of macrophages are involved and therefore the NDP should be able to correctly bind to the receptors and induce receptor clustering, crosslinking or (hetero)dimerization and subsequently activation, polarization, internalization as part of this differentiation activity [45, 46]. Not knowing the exact activity, it will be difficult to study this activation by specific receptor based assays, which as a consequence can be better performed by cells that express the full receptor panel.

The differences in potency of NDPs to direct macrophage subset differentiation should be further studied in vivo to develop this model to a more validated prediction strategy. This implies that in vivo research should be performed also with potentially less potent NDPs to be able to rank the full palette of bioactive NDPs. In our set of NDPs, Wellmune Soluble showed the least activity towards macrophage differentiation which might be in agreement with a previous report that Wellmune Soluble has reduced receptor crosslinking for dectin-1 activation [46]. We did not directly compare with the nonsolubilized Wellmune, the particulate WGP, for which a strong bioactivity has been 


\section{Chapter 6}

reported previously, both based on in vitro and in vivo studies [46, 47]. When completing a validation of the macrophage polarization approach and aligning it with in vivo effects the method could pave the way for more fundamental studies towards efficient NDP structure-function relations, effects of processing and preparations, matrix effect in food formulation and many more.

\section{Macrophages respond stronger to nutrients than IEC}

As discussed above, Caco-2 resembling IECs could produce cytokines and chemokines in response to food exposure. However those responses were weak compared to the reactions we observed for macrophages. This may relate to the fact that exposure to luminal compounds is continuously changing with our diet and IECs major function is maintaining barrier integrity, while at the same time absorbing nutrients. Next comes support to immune cells by signalling molecules, in particular when the intestine is challenged. Although responses of IEC towards the NDPs were mild, these NDPs showed a strong immune regulating effect, with Naxus inducing the strongest responses in both Caco-2 (Chapter 2) and macrophages (Chapter 4 and 5). Unfortunately, results from the human trials with these same fibres have not been published yet. However, from results that have been communicated, among the tested NDPs Naxus also showed the strongest support of the immune system based on a flu vaccination model including elderly subjects. In this model, a 2 week NDP intervention was given prior to the seasonal flu vaccination and during the following 3 weeks. After this exposure, antibody titres against all three flu strains present in the vaccine were tested. Naxus showed a trend (though not significant) towards an increased antibody titre and increased serum protection levels for all three strains, which was higher than for any other NDP included in the study (J. Schrezenmeir, personal communication). This indicates that Naxus indeed can be the most potent NDP in our set of NDPs tested and therefore correlates surprisingly well with the immune responses found, both on Caco-2 and macrophages.

\section{Trained immunity vs Tolerance}

Immune cells are often divided as being either innate immune cells or adaptive immune cells. The innate immune system, also known as non-specific or in-born immune system, provides an immediate defence against pathogens based on general recognition and defence responses. The adaptive, or acquired, immune system, is based on specialised cells and processes to eliminate pathogens which is based on immunological memory. Upon an initial response by a pathogen the memory enables an enhanced response in 
case of re-exposure. Recently it was shown that innate immune cells also possess memory. This memory by innate immune cells has been named trained immunity which is characterized as an intensified response to a secondary infection of the same pathogen but also to a different one [48]. Trained immunity has been shown for instance for monocytes primed by $\beta$-glucans [49]. This trained immunity strongly responded to TLR2 agonists like Pam3Cys resulting in an enhanced TNF $\alpha$ and IL6 secretion which supports long term immune activation [49]. Trained immunity likely is mediated via an epigenetic reprogramming as demonstrated by the changes in expression of three histone markers (H3K4me1, $\mathrm{H}_{3} \mathrm{~K}_{4} \mathrm{mme}_{3}$, and $\mathrm{H}_{3} \mathrm{~K}_{2} 7 \mathrm{ac}$ ) [49]. We found that NDPs (RG-I, LCES, and Naxus) uniquely downregulated the expression of HIST1 family genes [24] which suggested that these NDPs might also function as stimulators of the trained immunity with epigenetic regulation. Actually, NDP treated macrophages showed an increased secretion of IL1 $\beta$, TNF $\alpha$, and IL8, and also a group of chemokines (Chapter 4). Besides, trained monocytes have been characterised for their high glucose consumption, high lactate production and activation of mTOR through a dectin-1-AKT-HIF-1a pathway [50]. Our preliminary data on macrophages exposed to Naxus also identified a high lactate production (data not shown). Although we detected NDP responses by macrophages after 18 hours and training of monocytes was performed over 6 days, the responses are in line which leads us to hypothesize that NDPs like Naxus could train macrophages resulting in a broad improved innate defence against pathogens.

In contrast to $\beta$-glucan-trained monocytes, LPS-primed monocytes are characterized by a long-term tolerance with low levels of secreted proinflammation cytokines (TNFa and IL6) [49]. Endotoxin-induced tolerance is a phenomenon in which cells arrive in a transient unresponsive state and are resistant to further challenges with endotoxin [51]. An example is presented where dendritic cells, after a long term LPS stimulation, attained a self-tolerant status, which revealed IDO to be involved in intracellular signalling and maintenance of a stable regulatory phenotype [52].

Trained immunity and tolerance can therefore be seen as opposing functional programs which greatly depend on the type and concentration of pathogen-associated molecular patterns (PAMPs) [53]. A strong infection could lead to fast resolution and to a tolerant activation state. However, a low grade of infection/food based stimulation can support trained immunity, leading to a broad enhanced defence and support of the development of memory of the immune system. 


\section{Chapter 6}

\section{Food and trained immunity}

Based on the previous discussion, the question raises whether dietary compounds can train this innate immunity and whether 'functional' foods, containing these bioactive compounds, can be used as an effective strategy to treat immune deficiency status or modulating exaggerated inflammation $[54,55]$. Several NDPs were reported to have immunomodulatory effects, including yeast/fungal and cereal $\beta$-glucans which share common structural features with $\beta$-glucans as present in pathogens. It is therefore not unlikely that food, containing these $\beta$-glucans, can train our immune system, especially when intestinal cells can recognize these $\beta$-glucans and pass this 'training' signal systemically. The macrophages that cross the intestinal barrier for sampling could also initiate the interaction of immune cells and $\beta$-glucans [32]. The results on vaccination efficacy increase by Naxus, as explained earlier, also resulting in a reduced incidence of common cold and respiratory tract infection (unpublished data), are therefore in line. These NDPs, as a food product or supplement, are therefore worth to study for this trained immune effects. Optimal dosing and duration of intervention need to be finetuned. Also, duration of maintained trained status and the cross protection against a large array of pathogens need to be established.

\section{Techniques to prove immunomodulatory function of food components}

To study the immunomodulatory or training activity of NDPs and other food compounds we need efficient methods to study the status and function of immune cells. In the early stage of our research, at the time we developed the methods to polarise macrophages to $M_{1}$ and $M_{2}$, we applied common methods like flow cytometry based on established surface markers (like HLA2, CD80, and CD83 as M1 markers and CD209, CD163 as M2 markers). This resulted in only slight differences between these subsets. The reason for this could be that macrophages, differentiated by MCSF for 6-days, push macrophages to express a high background level of those markers. We next applied qPCR to check gene expression of IL8, IL1 $\beta$, IL12p40, TNF $\alpha$ as M1 markers, and dectin-1, CD209, MRC1, $M R C_{2}$, PPAR $\gamma$, and CD36 as M2 markers. These showed to provide more information on differential status of the subsets and the marker list could be easily expanded based on microarray analysis. Gene expression markers are therefore preferred over surface markers for this type of in vitro analysis although some of the newly identified markers like the C-type lectins could be valuable surface markers, especially as it is likely that they are capable of identifying a highly variable set of carbohydrate structures. However, in vitro, changes in gene expression can be followed but not necessarily describe the true physiological status of the immune cell. So the challenge will be how to apply gene 
expression markers more self-explanatorily in in vivo situations. Also here the best strategy might be to apply a challenge (like PAMPs) on whole blood, PBMCs or separately on isolated monocytes or macrophages and to analyse the responses by gene expression and cytokine analysis.

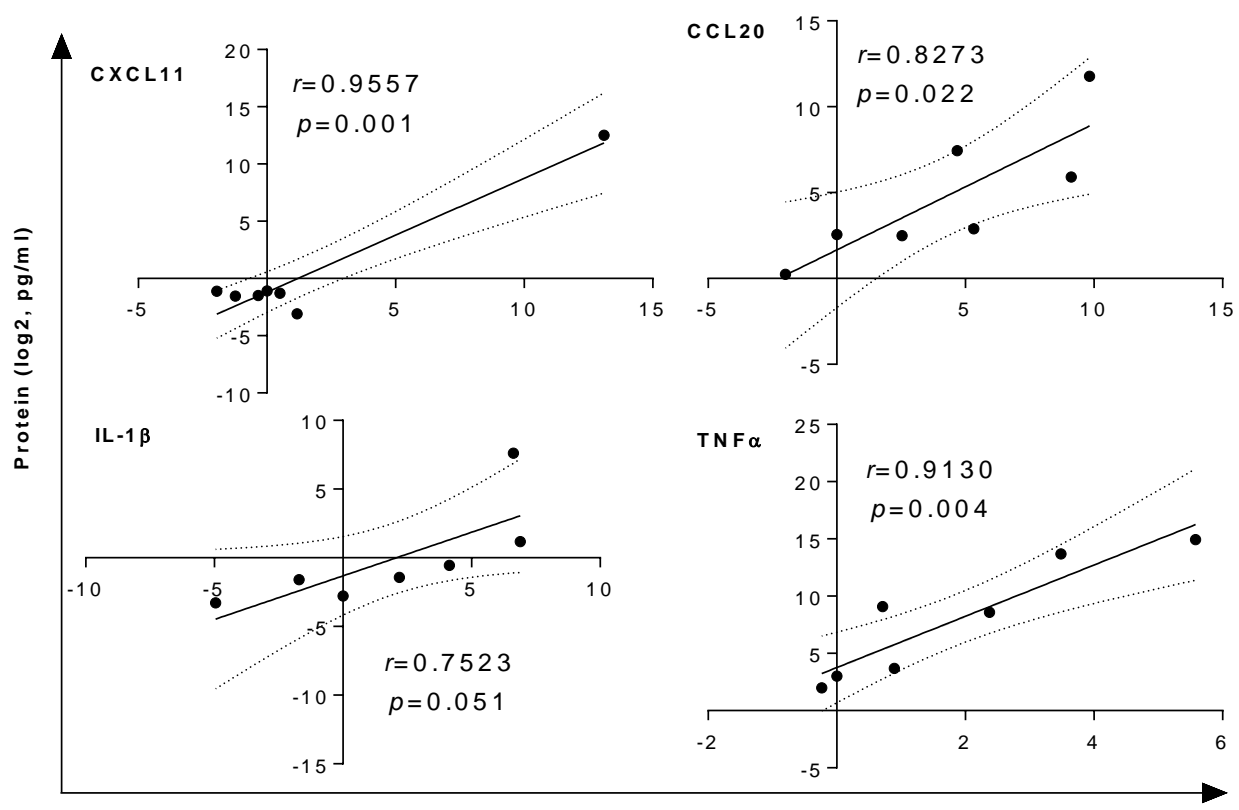

m RNA (relativ expression, log2)

Figure 2. Correlation between gene expression and excreted protein for macrophages stimulated with NDPs. Gene expression data and cytokines protein production were analysed for the linear regression analysis by GraphPad Prism 6 (GraphPad Software, Inc., La Jolla, CA).

\section{Gene expression predicts protein level}

The gene expression markers set that we developed to distinguish $M_{1}$ and $M_{2}$ and to characterise the newly identified $M_{N D P}$ subset can have interesting applications in future research. However, as current research makes us of cytokines instead of gene expression markers, we studied the correlation between expression of cytokine genes and excreted proteins in our macrophage model. Here we include some additional data, analysed by linear regression analysis, to the data presented in the separate chapters 


\section{Chapter 6}

(Figure 2). These data indicate that mRNA expression is significantly correlated with protein production for $C X C L 11(p=0.001), C C L 20(p=0.022)$, and TNF $\alpha(p=0.004)$. Only IL1 $\beta$ did not reach significance ( $p=0.051)$, which might be due to the low expression of both gene and protein or the sampling time point used for the gene expression analysis was not optimal. Overall, from our experience we believe that gene expression analysis in cell models is a rapid and sensitive tool.

\section{Future perspectives}

A macrophage polarisation model has been developed and is descried in this thesis, together with the effects of NDPs studied based on this macrophage model. The study revealed that $M_{N D P}$ could be characterized by gene expression of a panel of markers, by secretion of cytokines and chemokines, and that $M_{N D P}$ induce functional changes in phagocytosis, antigen processing, and recruiting ability. Furthermore the gene expression of a group of C-type lectin receptors were changed by NDPs [24]. To be more specific, we found that dectin-2 and Mincle are both increased in expression when macrophages are incubated with NDPs. Those two receptors also have been shown to be involved in $\alpha$-mannose recognition, both independently. These two receptors also can form a heterodimer with different sensitivity and diversity for recognizing microbiota [45]. It would be interesting to study these receptors in more detail, specifically in relation to NDP recognition. In addition, it would be worthwhile to study the intercellular signalling in macrophages and to analyse whether receptor activation leads to similar or divergent signals that eventually regulate immune functionality. It would be also interesting to use this in vitro model as selection tool for other NDPs and to correlate to in vivo data. By using these analyses, possibly we can select and target the NDPs as functional food ingredients to support maintenance of the intestinal immune barrier, support the immune system, or support both. 


\section{References}

1. Correa-Oliveira, R., J.L. Fachi, A. Vieira, F.T. Sato, and M.A. Vinolo, Regulation of immune cell function by short-chain fatty acids. Clin Transl Immunology, 2016. 5(4): p. e73.

2. Mowat, A.M. and W.W. Agace, Regional specialization within the intestinal immune system. Nature Reviews: Immunology, 2014. 14(10): p. 667-685.

3. Yin, X., B.E. Mead, H. Safaee, R. Langer, J.M. Karp, and O. Levy, Engineering Stem Cell Organoids. Cell Stem Cell, 2016. 18(1): p. 25-38.

4. Fatehullah, A., S.H. Tan, and N. Barker, Organoids as an in vitro model of human development and disease. Nature Cell Biology, 2016. 18(3): p. 246-254.

5. Mahe, M.M., N. Sundaram, C.L. Watson, N.F. Shroyer, and M.A. Helmrath, Establishment of human epithelial enteroids and colonoids from whole tissue and biopsy. J Vis Exp, 2015(97).

6. Venkatasubramanian, P.B., G. Toydemir, N. de Wit, E. Saccenti, V.A.P. Martins Dos Santos, P. van Baarlen, J.M. Wells, M. Suarez-Diez, and J.J. Mes, Use of Microarray Datasets to generate Caco-2-dedicated Networks and to identify Reporter Genes of Specific Pathway Activity. Scientific Reports, 2017. 7(1): p. 6778.

7. Srinivasan, B., A.R. Kolli, M.B. Esch, H.E. Abaci, M.L. Shuler, and J.J. Hickman, TEER measurement techniques for in vitro barrier model systems. J Lab Autom, 2015. 20(2): p. 107126.

8. Vogt, L.M., D. Meyer, G. Pullens, M.M. Faas, K. Venema, U. Ramasamy, H.A. Schols, and P. de Vos, Toll-Like Receptor 2 Activation by beta 2 -> 1-Fructans Protects Barrier Function of T84 Human Intestinal Epithelial Cells in a Chain Length-Dependent Manner. Journal of Nutrition, 2014. 144(7): p. 1002-1008.

9. Gagnon, M., A. Zihler Berner, N. Chervet, C. Chassard, and C. Lacroix, Comparison of the Caco2, HT-29 and the mucus-secreting HT29-MTX intestinal cell models to investigate Salmonella adhesion and invasion. Journal of Microbiological Methods, 2013. 94(3): p. 274-279.

10. Barcelo, A., J. Claustre, F. Moro, J.A. Chayvialle, J.C. Cuber, and P. Plaisancie, Mucin secretion is modulated by luminal factors in the isolated vascularly perfused rat colon. Gut, 2000. 46(2): p. 218-224.

11. JanssenDuijghuijsen, L.M., Good, Bad, or Risky? 2017, Wageningen University: Wageningen.

12. Iraha, A., H. Chinen, A. Hokama, T. Yonashiro, T. Kinjo, K. Kishimoto, M. Nakamoto, T. Hirata, N. Kinjo, F. Higa, M. Tateyama, F. Kinjo, and J. Fujita, Fucoidan enhances intestinal barrier function by upregulating the expression of claudin-1. World Journal of Gastroenterology, 2013. 19(33): p. 5500-5507.

13. Teodorowicz, M., O. Perdijk, I. Verhoek, C. Govers, H.F. Savelkoul, Y. Tang, H. Wichers, and K. Broersen, Optimized Triton X-114 assisted lipopolysaccharide (LPS) removal method reveals the immunomodulatory effect of food proteins. PloS One, 2017. 12(3): p. e0173778.

14. Johansson, M.E. and G.C. Hansson, Immunological aspects of intestinal mucus and mucins. Nature Reviews: Immunology, 2016. 16(10): p. 639-649.

15. Gullberg, E., M. Leonard, J. Karlsson, A.M. Hopkins, D. Brayden, A.W. Baird, and P. Artursson, Expression of specific markers and particle transport in a new human intestinal M-cell model. Biochemical and Biophysical Research Communications, 2000. 279(3): p. 808-813.

16. Sonnenberg, G.F. and D. Artis, Innate lymphoid cells in the initiation, regulation and resolution of inflammation. Nature Medicine, 2015. 21(7): p. 698-708.

17. Dewi, B.E., T. Takasaki, and I. Kurane, In vitro assessment of human endothelial cell permeability: effects of inflammatory cytokines and dengue virus infection. Journal of Virological Methods, 2004.121(2): p. 171-180.

18. Wang, Y., J. Tong, B. Chang, B. Wang, D. Zhang, and B. Wang, Effects of alcohol on intestinal epithelial barrier permeability and expression of tight junction-associated proteins. Mol Med Rep, 2014. 9(6): p. 2352-2356. 


\section{Chapter 6}

19. Elamin, E., A. Masclee, F. Troost, H.J. Pieters, D. Keszthelyi, K. Aleksa, J. Dekker, and D. Jonkers, Ethanol impairs intestinal barrier function in humans through mitogen activated protein kinase signaling: a combined in vivo and in vitro approach. PloS One, 2014. 9(9): p. e107421.

20. Peterson, L.W. and D. Artis, Intestinal epithelial cells: regulators of barrier function and immune homeostasis. Nature Reviews: Immunology, 2014. 14(3): p. 141-153.

21. Artis, D., Epithelial-cell recognition of commensal bacteria and maintenance of immune homeostasis in the gut. Nature Reviews: Immunology, 2008. 8(6): p. 411-420.

22. Saenz, S.A., M.C. Siracusa, J.G. Perrigoue, S.P. Spencer, J.F. Urban, Jr., J.E. Tocker, A.L. Budelsky, M.A. Kleinschek, R.A. Kastelein, T. Kambayashi, A. Bhandoola, and D. Artis, IL25 elicits a multipotent progenitor cell population that promotes $T(H) 2$ cytokine responses. Nature, 2010. 464(7293): p. 1362-1366.

23. Siracusa, M.C., S.A. Saenz, E.D. Wojno, B.S. Kim, L.C. Osborne, C.G. Ziegler, A.J. Benitez, K.R. Ruymann, D.L. Farber, P.M. Sleiman, H. Hakonarson, A. Cianferoni, M.L. Wang, J.M. Spergel, M.R. Comeau, and D. Artis, Thymic stromal lymphopoietin-mediated extramedullary hematopoiesis promotes allergic inflammation. Immunity, 2013. 39(6): p. 1158-1170.

24. Tang, Y., C. Govers, H.J. Wichers, and J.J. Mes, Macrophages treated with non-digestible polysaccharides reveal a transcriptionally unique phenotype. Journal of Functional Foods, 2017. 36: p. 280-289.

25. Cario, E. and D.K. Podolsky, Differential alteration in intestinal epithelial cell expression of toll-like receptor 3 (TLR3) and TLR4 in inflammatory bowel disease. Infection and Immunity, 2000. 68(12): p. 7010-7017.

26. Ortega-Gonzalez, M., B. Ocon, I. Romero-Calvo, A. Anzola, E. Guadix, A. Zarzuelo, M.D. Suarez, F. Sanchez de Medina, and O. Martinez-Augustin, Nondigestible oligosaccharides exert nonprebiotic effects on intestinal epithelial cells enhancing the immune response via activation of TLR4-NFkappaB. Molecular Nutrition \& Food Research, 2014. 58(2): p. 384-393.

27. Cohen-Kedar, S., L. Baram, H. Elad, E. Brazowski, H. Guzner-Gur, and I. Dotan, Human intestinal epithelial cells respond to beta-glucans via Dectin-1 and Syk. European Journal of Immunology, 2014. 44(12): p. 3729-3740.

28. Samuelsen, A.B., A. Rieder, S. Grimmer, T.E. Michaelsen, and S.H. Knutsen, Immunomodulatory activity of dietary fiber: arabinoxylan and mixed-linked beta-glucan isolated from barley show modest activities in vitro. International Journal of Molecular Sciences, 2011. 12(1): p. 570-587.

29. Volman, J.J., R.P. Mensink, J.D. Ramakers, M.P. de Winther, H. Carlsen, R. Blomhoff, W.A. Buurman, and J. Plat, Dietary (1-->3), (1-->4)-beta-D-glucans from oat activate nuclear factorkappaB in intestinal leukocytes and enterocytes from mice. Nutrition Research, 2010. 30(1): p. 40-48.

30. Flannigan, K.L., D. Geem, A. Harusato, and T.L. Denning, Intestinal Antigen-Presenting Cells: Key Regulators of Immune Homeostasis and Inflammation. American Journal of Pathology, 2015. 185(7): p. 1809-1819.

31. Heath, W.R. and F.R. Carbone, Cross-presentation, dendritic cells, tolerance and immunity. Annual Review of Immunology, 2001. 19: p. 47-64.

32. Allen, F., A.A. Tong, and A.Y. Huang, Unique Transcompartmental Bridge: Antigen-Presenting Cells Sampling across Endothelial and Mucosal Barriers. Frontiers in Immunology, 2016. 7: p. 231.

33. Lee, S.H., P.M. Starkey, and S. Gordon, Quantitative analysis of total macrophage content in adult mouse tissues. Immunochemical studies with monoclonal antibody F4/80. Journal of Experimental Medicine, 1985.161(3): p. 475-489.

34. Bain, C.C., C.L. Scott, H. Uronen-Hansson, S. Gudjonsson, O. Jansson, O. Grip, M. Guilliams, B. Malissen, W.W. Agace, and A.M. Mowat, Resident and pro-inflammatory macrophages in the 
colon represent alternative context-dependent fates of the same Ly6Chi monocyte precursors. Mucosal Immunology, 2013. 6(3): p. 498-510.

35. Niess, J.H., S. Brand, X. Gu, L. Landsman, S. Jung, B.A. McCormick, J.M. Vyas, M. Boes, H.L. Ploegh, J.G. Fox, D.R. Littman, and H.C. Reinecker, CX3CR1-mediated dendritic cell access to the intestinal lumen and bacterial clearance. Science, 2005. 307(5707): p. 254-258.

36. Schulz, O., E. Jaensson, E.K. Persson, X. Liu, T. Worbs, W.W. Agace, and O. Pabst, Intestinal CD103+, but not $\mathrm{CX}_{3} \mathrm{CR}_{1+}$, antigen sampling cells migrate in lymph and serve classical dendritic cell functions. Journal of Experimental Medicine, 2009. 206(13): p. 3101-3114.

37. Marelli, G., C. Belgiovine, A. Mantovani, M. Erreni, and P. Allavena, Non-redundant role of the chemokine receptor $\mathrm{CX}_{3} \mathrm{CR}_{1}$ in the anti-inflammatory function of gut macrophages. Immunobiology, 2017. 222(2): p. 463-472.

38. Mazzini, E., L. Massimiliano, G. Penna, and M. Rescigno, Oral Tolerance Can Be Established via Gap Junction Transfer of Fed Antigens from CX3 $\mathrm{CR}_{1}(+)$ Macrophages to CD103(+) Dendritic Cells. Immunity, 2014. 40(2): p. 248-261.

39. Smythies, L.E., M. Sellers, R.H. Clements, M. Mosteller-Barnum, G. Meng, W.H. Benjamin, J.M. Orenstein, and P.D. Smith, Human intestinal macrophages display profound inflammatory anergy despite avid phagocytic and bacteriocidal activity. Journal of Clinical Investigation, 2005. 115(1): p. 66-75.

40. Chanput, W., J.J. Mes, and H.J. Wichers, THP-1 cell line: an in vitro cell model for immune modulation approach. International Immunopharmacology, 2014. 23(1): p. 37-45.

41. Chanput, W., J. Mes, R.A. Vreeburg, H.F. Savelkoul, and H.J. Wichers, Transcription profiles of LPS-stimulated THP-1 monocytes and macrophages: a tool to study inflammation modulating effects of food-derived compounds. Food \& Function, 2010. 1(3): p. 254-261.

42. Chanput, W., M. Reitsma, L. Kleinjans, J.J. Mes, H.F. Savelkoul, and H.J. Wichers, beta-Glucans are involved in immune-modulation of THP-1 macrophages. Molecular Nutrition \& Food Research, 2012. 56(5): p. 822-833.

43. Chanput, W., J.J. Mes, H.F. Savelkoul, and H.J. Wichers, Characterization of polarized THP-1 macrophages and polarizing ability of LPS and food compounds. Food \& Function, 2013. 4(2): p. 266-276.

44. Othman, R.A., M.H. Moghadasian, and P.J. Jones, Cholesterol-lowering effects of oat betaglucan. Nutrition Reviews, 2011. 69(6): p. 299-309.

45. Zhu, L.L., X.Q. Zhao, C.Y. Jiang, Y. You, X.P. Chen, Y.Y. Jiang, X.M. Jia, and X. Lin, C-Type Lectin Receptors Dectin-3 and Dectin-2 Form a Heterodimeric Pattern-Recognition Receptor for Host Defense against Fungal Infection. Immunity, 2013. 39(2): p. 324-334.

46. Goodridge, H.S., C.N. Reyes, C.A. Becker, T.R. Katsumoto, J. Ma, A.J. Wolf, N. Bose, A.S.H. Chan, A.S. Magee, M.E. Danielson, A. Weiss, J.P. Vasilakos, and D.M. Underhill, Activation of the innate immune receptor Dectin-1 upon formation of a 'phagocytic synapse'. Nature, 2011. 472(7344): p. 471-U541.

47. Fuller, R., M.V. Moore, G. Lewith, B.L. Stuart, R.V. Ormiston, H.L. Fisk, P.S. Noakes, and P.C. Calder, Yeast-derived beta-1,3/1,6 glucan, upper respiratory tract infection and innate immunity in older adults. Nutrition, 2017. 39-40: p. 30-35.

48. Netea, M.G., J. Quintin, and J.W. van der Meer, Trained immunity: a memory for innate host defense. Cell Host Microbe, 2011. 9(5): p. 355-361.

49. Saeed, S., J. Quintin, H.H. Kerstens, N.A. Rao, A. Aghajanirefah, F. Matarese, S.C. Cheng, J. Ratter, K. Berentsen, M.A. van der Ent, N. Sharifi, E.M. Janssen-Megens, M. Ter Huurne, A. Mandoli, T. van Schaik, A. Ng, F. Burden, K. Downes, M. Frontini, V. Kumar, E.J. GiamarellosBourboulis, W.H. Ouwehand, J.W. van der Meer, L.A. Joosten, C. Wijmenga, J.H. Martens, R.J. Xavier, C. Logie, M.G. Netea, and H.G. Stunnenberg, Epigenetic programming of monocyteto-macrophage differentiation and trained innate immunity. Science, 2014. 345(6204): p. 1251086. 


\section{Chapter 6}

50. Cheng, S.C., J. Quintin, R.A. Cramer, K.M. Shepardson, S. Saeed, V. Kumar, E.J. GiamarellosBourboulis, J.H. Martens, N.A. Rao, A. Aghajanirefah, G.R. Manjeri, Y. Li, D.C. Ifrim, R.J. Arts, B.M. van der Veer, P.M. Deen, C. Logie, L.A. O'Neill, P. Willems, F.L. van de Veerdonk, J.W. van der Meer, A. Ng, L.A. Joosten, C. Wijmenga, H.G. Stunnenberg, R.J. Xavier, and M.G. Netea, mTOR- and HIF-1alpha-mediated aerobic glycolysis as metabolic basis for trained immunity. Science, 2014. 345(6204): p. 1250684.

51. Biswas, S.K. and E. Lopez-Collazo, Endotoxin tolerance: new mechanisms, molecules and clinical significance. Trends in Immunology, 2009. 30(10): p. 475-487.

52. Pallotta, M.T., C. Orabona, C. Volpi, C. Vacca, M.L. Belladonna, R. Bianchi, G. Servillo, C. Brunacci, M. Calvitti, S. Bicciato, E.M. Mazza, L. Boon, F. Grassi, M.C. Fioretti, F. Fallarino, P. Puccetti, and U. Grohmann, Indoleamine 2,3-dioxygenase is a signaling protein in long-term tolerance by dendritic cells. Nature Immunology, 2011. 12(9): p. 870-878.

53. Ifrim, D.C., J. Quintin, L.A. Joosten, C. Jacobs, T. Jansen, L. Jacobs, N.A. Gow, D.L. Williams, J.W. van der Meer, and M.G. Netea, Trained immunity or tolerance: opposing functional programs induced in human monocytes after engagement of various pattern recognition receptors. Clinical and Vaccine Immunology, 2014. 21(4): p. 534-545.

54. Netea, M.G., L.A. Joosten, E. Latz, K.H. Mills, G. Natoli, H.G. Stunnenberg, L.A. O'Neill, and R.J. Xavier, Trained immunity: A program of innate immune memory in health and disease. Science, 2016.352(6284): p. aaf1098.

55. van der Meer, J.W., L.A. Joosten, N. Riksen, and M.G. Netea, Trained immunity: A smart way to enhance innate immune defence. Molecular Immunology, 2015. 68(1): p. 40-44. 
Summary 


\section{Summary}

Non-digestible polysaccharides (NDPs) are considered as important ingredients to support health. Among these health effects, immunomodulatory effects raised interests in the past decade. The intestine is the primary organ that interact with NDPs. The intestinal epithelial cells (IECS) form a dynamic physical barrier and together with associated immune cells determine for a large part our immune homeostasis. Studying the direct interaction between NDPs and intestinal and immune cells could help us to uncover the mechanism by which NDPs exert immunomodulatory effects and how NDPs can differ in this activity. In this thesis, we investigated the immunomodulatory effects of NDPs through interaction with intestinal immune cells using in vitro methods in order to characterise the NDPs and preselect NDPs with differential activity for further in vivo evaluations.

The intestinal immune barrier is formed by various IECs and immune cells, which are introduced and their specific functions discussed in Chapter 1. NDPs could interact directly with both IECs and immune cells that sample in or from the lumen. The majority of IECs are enterocytes and most relevant immune cells responsible for sampling in the lumen have been characterised as macrophages, which leads us to focus on these cell types by in vitro approaches. In addition, basic information on NDPs and current status on health effects of NDPs both in vitro and in vivo are discussed.

In Chapter 2, the direct response of IEC to NDPs stimulation was investigated. IECs form the largest surface of the body that, with a crucial role as barrier also, perform a role in signalling towards immune cells. We used 21-day transwell cultured Caco-2 to resemble the small intestinal enterocytes that form largest part of this intestinal layer. We first characterized the chemical composition of five NDPs which revealed different mono sugar composition, linkages of backbone and side chains and a wide range of $\mathrm{MW}$ (from $17 \mathrm{KDa}$ to $2100 \mathrm{KDa}$ ). The NDPs could reduce translocation of FITC-Dextran of $4 \mathrm{kDa}$ across the epithelial layer, potentially through physical interference. Gene expression analysis indicated the induction of unique gene expression characteristics in Caco-2 cells upon exposure to different NDPs. An arabinoxylan preparation from wheat and a lentinan-containing extract from shiitake mushrooms showed upregulation of gene expression of the NF-KB family and chemokines CCL20 and CXCL10. Besides these immune related changes by some NDPs, we also observed changes in receptor expression (like TLR2, CD14 and GPCRs) and other pathways, amongst which the cholesterol biosynthesis pathway.

Macrophages, as the resident population of immune cells penetrating between or associating with close contact with the IECs, are generally classified as inflammatory (M1) or as tolerant (M2) macrophages. In Chapter 3, we set up a macrophage differentiation 
method based on primary blood cells and selected and validated $M_{1}$ and $M_{2}$ specific gene expression markers. Next, we analysed the effect when macrophages are exposed to NDPs and compared the resulting macrophages with $M_{1}$ and $M_{2}$ macrophages. Based on $M_{1}$ and $M_{2}$ markers we identified an alternative subset that we named $M_{N D P}$. This $M_{\text {NDP }}$ was further studied by microarray analysis and revealed a commonly modulated set of genes, involved in migration, metabolic processes, cell cycle, and inflammatory immune function.

In Chapter 4, we further functionally characterize these $M_{N D P}$ in comparison to $M_{1}$ and M2 macrophages based on a set of functional assays. NDP-treated macrophages showed no IDO activity and showed an inhibited antigen uptake and processing capacity compared to $\mathrm{M}_{1}$ and $\mathrm{M}_{2}$ macrophages. Also their phagocytic capacity was reduced compared to both $\mathrm{M}_{1}$ and $\mathrm{M}_{2}$ macrophages. Furthermore, the alternative expression pattern for NDP-treated macrophages, as demonstrated by gene expression, was confirmed by protein measurements. The signature mix of the chemokines $C_{C L} 1, C C L 5$, CCL20, CCL24, CXCL8, and IL1 $\beta$ secreted by MNDP, and in particular when macrophages were treated with Naxus, was shown to induce a recruitment of monocytes.

As macrophage plasticity could be essential for intestinal immune homeostasis, resolving activity of inflammatory responses upon a challenge is important. Besides, redirecting differentiation and function of tolerant macrophages can also be beneficial to the intestinal immune status. In Chapter 5, we analysed plasticity of $M_{1}$ and $M_{2}$ macrophages to NDPs exposure. Macrophage plasticity was demonstrated as M1 and M2 could be skewed to an alternative subset indicated by a dedicated set of gene expression markers, selected to characterize $M_{1}, M_{2}$ and $M_{N D P}$ macrophages. In addition, phagocytosis and antigen processing capacity of both $M_{1}$ and $M_{2}$ were decreased by the NDP Naxus. Besides, Naxus could change the secretion of cytokines by macrophages that previously were differentiated towards $M_{1}$ and $M_{2}$. For $M_{2}$, this resulted in an increase of recruitment of monocytes by $\mathrm{M} 2$ macrophages.

In Chapter 6, we discussed the important findings in each chapter of this thesis together with current literature, and gave a general perspective on this research line focussing on the immunomodulating activity of NDPs and the direction for future research. We suggested NDPs in terms of Naxus as candidate for guiding investigations in ex vivo and in vivo studies for immunomodulation of intestinal disease. 

Acknowledgement 
It was a great dream for me to be a PhD candidate in science, to work independently, to build a research hypothesis, to think critically, and to discuss different opinions. It seems that my PhD study is going to be completed at this moment. However, this is not an ending but extending my research journey with more exciting, challenging and pressure to come. Compared to five years ago, trained with knowledge and expression, I am prepared for the future at this stage. Thank you to all the dedicated, kind, and intelligent people who were with me on this journey and inspired me to be assertive and confident. Thank you to my promotor, co-promotor, colleagues, collaborators, friends, family, and support staff in FBR, VLAG, and library in Wageningen University and Research. The atmosphere where I worked, the smiles you had, the professional knowledge and attitude you showed are all valuable memories that I will carry with me through the future.

I gratefully acknowledge my promoter Prof. Dr. Harry Wichers, co-promotor Dr. Jurriaan Mes and Dr. Coen Govers. You supported me from the very beginning of research to the end of my thesis. However, your support continues since we still have papers to publish. I am hopeful for collaborations in future since we are all interested in "Health Effects". Working together, I learnt so much from you. Our Monday morning meetings were stressful and challenging, but also interesting and fruitful. To be honest, I had to take a break after every meeting because of the battle I "fought" with three "big guys" consumed my energy, pushed me to re-organize the plan. The more "battles" I attended, the more pleasure I gained. Somewhere, I started to enjoy the "battle", expect the "battle", and miss the "battle". Because, I realized that what I received was not only questioning but also critical thinking, not only arguing but also suggesting. Prof. Dr. Harry Wichers, thank you for giving me the chance to study in Wageningen and experience the difference of the expected and unexpected. I remember how anxious I was when I was awaiting your response during the Christmas holiday before I came. I am sorry that I missed our first appointment since I was sleeping in my room and you could not wake me by cell phone on my first day. Harry, you are also a professor of birds and joy, since you know every bird, always have jokes at breaks in the meeting. Dr. Jurriaan Mes, you have a difficult first name and easy last name. I could not pronounce your name for two months. Your hair puzzled me for a long time since it is long and curly which I have never seen so close before. Thank you for being polite, smiling, being patient from the very beginning to the end. Thank you for your inspiring ideas that presented during our discussion, the way to interpret data, the idea to link 
from one part of data to other related data. Dr. Coen Govers, I have worked with you for more than four years. Thank you for supporting me and helping me get used to the new lab and new environment. You provided much support, and I enjoyed our discussions on planning experiments, interpreting data and life outside of science. I am expecting more of these kinds of meetings.

Many thanks to all members in Food Quality and Health Effect. Thank you to Shanna, Nicole, Dianne, Renata, Monic, Els, Addie, Judith, Marloes, Marion, and Isabelle. You are friendly, open-minded, warm, and enthusiastic. So much support, help, and suggestions from all. I will definitely miss you all in future, please let me know if we can meet at any chance, any place, and any time in future.

Thank you PhD roommates in Room 2004. Thank you Marit, Lonneke, Balaji, Alexia, Ying, Liyou, Priscilla, and Francisca. We had so many interesting discussion on research, life, and jobs. You were always there when I asked for help in the lab with reagents, operating equipment, or data interpretation. You are friendly and helpful. You are my friends forever.

To House 84 at Van Uvenweg. This is a wonderful place for me and my family. It is the home for all of the friends that have lived there and friends we have met there. So many happy memories in this place, which will stay with me my whole life. We used to clean rooms together, cook together, and eat together for dinner. The topics of our talks were shopping, planning for travel, campus, new PhDs, and definitely the research and future planning. Wenbiao, you made everything happen. You were the director who made those beautiful memories happen. You were enthusiastic to go to so many places to buy everything we needed to settle "our home". Yu Zhu, you were supposed to stay a month, however, you stayed more than a year. You were our chef since you can make any dish no matter Chinese food, curried potatoes, or Burrito. However, I must complain about your playing so late and puzzled about the interest in playing games even though I have tried to learn by observing. Jing and Rong, you are amazing friends. I miss the time we were traveling together. Let us talk about those memories together by reading the photos one day. Wenbo Jiang, you made me realize that a man who loves research can have a peaceful heart. Roy Zhang, you used your actions to change my notion and be open to accept differences. Best wishes for you and Timen. Thank you Huajie, Menyuan, Yutian, Yang Zhang, Rui, and Michele, I am very happy to have met you in House 84 . 
To my friends in Wageningen. The life in Wageningen was not only my research, but also you. Many thanks to Fahui, Wen and Duobao, Lingmin and Laowei, Lina and Wei, Liya and Haofeng, Ya and Jiao, Jinfen and Gongbao, Kun, Min, Fangjie, Xiongling, Chunyue, Jue and Fefei, Yuxi, Jun, Zhaojun, Zouyuan, Zhili, Yingxue, Ningjing, Yin, Juncai, Guozhi, Yiqian, Luyue, Yuanyuan, Xu Chen, Tao Zhao, and Tian Zeng. From eating lunch outside, to celebrating Chinese New Year, travelling, and playing games will remain fresh in my mind. You are amazing friends, I miss you forever!

Thanks to my lovely family, uncles and aunts, and cousins! My father and mother, you could not read what I wrote, could not understand what I was saying or doing, but I know you love me. Jiacui, your love could not be weighed, you support could not be counted, however, they are all touched and felt by my heart. I know it would be totally different and a loss of a lot of joy and happiness from my life without of you. Xinzhi, yes, you have three names, thank you playing with me, climbing on my body, and painting for me. Thank you for your coming! I know I am very lucky to have you! My father-in-law and mother-in-law, thank you for supporting and caring for us, every chat we had was reassuring and relaxing. Thank you all for supporting me! 
About the Author 


\section{Curriculum vitae}

Yongfu Tang was born on January 13, 1982, in Shandong, China. In 2001, he started his Bachelor's degree in Shandong Agricultural University (Shandong, China). After receiving a bachelor degree in Food Science and Technology, he continued with the Master degree in Nutrition and Food Hygiene in Nanchang University (Jiangxi, China) in 2005. He specialized in Nutrition and Health with a project of immunomodulatory effects of polysaccharides isolated from Plantago asiatica $L$ on dendritic cells under the supervision of Prof. Mingyong Xie in State Key Laboratory of Food Science and Technology (Nanchang University). In 2008, he worked as a research assistant on health effects of tropical agricultural products in Chinese Academy of Tropical Agricultural Sciences (Guangdong, China). In 2012, he started his PhD project to investigate how nondigestible polysaccharides support intestinal immune barrier with in vitro macrophage and epithelial cell models under the supervision of Prof. Harry Wichers, Dr. Jurriaan Mes, and Dr. Coen Govers in Wageningen University and Research. The results of his PhD research are presented in this thesis. He will continue his research in Nutrition and Health to prevent brain disease and help brain disease recovery by nutrient intake. 


\section{List of selected publications}

Yongfu Tang, Coen Govers, Luc Saulnier, Svein H. Knutsen, Harry J. Wichers, Jurriaan J. Mes. Macrophages treated with non-digestible polysaccharides reveal a transcriptionally unique phenotype. Journal of functional foods, 2017 (36): 280-289.

Yongfu Tang, Coen Govers, Sophie Le Gall, Luc Saulnier, Anna Rieder, Svein H. Knutsen, Monic M.M. Tomassen, Nicole de Wit, Harry J. Wichers, Jurriaan J. Mes. Gene expression analysis characterizes Caco-2 responses to non-digestible polysaccharides: a first step to a systematic comparison of dietary fibres. Submitted.

Yongfu Tang, Coen Govers, Ellen Kranenbarg-Stolte, Harry J. Wichers, Jurriaan J. Mes. Human macrophages stimulated with non-digestible polysaccharides are in function and chemokine production different from inflammatory and tolerant macrophages. In preparation.

Yongfu Tang, Coen Govers, Ellen Kranenbarg-Stolte, Harry J. Wichers, Jurriaan J. Mes. Non-digestible polysaccharides mediate macrophage plasticity by function change on macrophage subsets. In preparation.

Malgorzata Teodorowicz, Olaf Perdijk, Iris Verhoek, Coen Govers, Huub F. J. Savelkoul, Yongfu Tang, Harry Wichers, Kerensa Broersen. Optimized Triton X-114 assisted lipopolysaccharide (LPS) removal method reveals the immunomodulatory effect of food proteins. PLOS one, 2017 12(3): e0173778.

Danfei Huang, Yongfu Tang, Shaoping Nie, Yin Wan, Mingyong Xie, Xiaomei Xie. Effect of phenylethanoid glycosides and polysaccharides from the seed of Plantago asiatica L. on the maturation of murine bone marrow-drived dendritic cells. European Journal of Pharmacology, 2009, 620 (1-3): 105-111.

Danfei Huang, Mingyong Xie, Junyi Yin, Shaoping Nie, Yongfu Tang, Xiaomei Xie, Chao Zhou. Immunomodulatory activity of the seeds of Plantago asiatica L. Journal of Ethnopharmacology, 2009, 124 (3): 493-498. 


\section{Overview of completed training activities}

Discipline specific activities (courses, workshops, symposia, summer schools, conferences etc.)

2nd progress meeting of FibeBiotics. Kiel, Germany, 2013

3rd progress meeting of FibeBiotics and 2nd InP meeting. Bologna, Italy, 2014

7th International Immunonutrition Workshop, “Eating for Preventing”. Bari, Italy, 2014

4th progress meeting of FibeBiotics. Oslo, Norway, 2014

12th China Nutrition Science congress. Beijing, China, 2015

6th progress meeting of FibeBiotics and 4th InP meeting. Paris, France, 2015

17th Gut day symposium. Rotterdam, NL, 2015

Carbohydrate Competence Center symposium. Zwolle, NL, 2015

3rd Wageningen PhD Symposium "Diversity in Science", Wageningen, NL, 2016

7th progress meeting of FibeBiotics. Ede, NL, 2016

19th International Society for Mushroom Science (ISMS). Amsterdam, NL, 2016

The 5th Beneficial Microbes Conference. Amsterdam, NL, 2016

Microglia phenotype and function analysis in stroke. Houston, USA , 2017

\section{General courses}

VLAG PhD week VLAG. Baarlo, NL 4, 2013

Philosophy and Ethics of Food Science \& Technology. VLAG/WGS, Wageningen, NL, 2015

WGS PhD Workshop Carousel. WGS, Wageningen, NL, 2015

Techniques for writing and presenting a scientific paper. WGS, Wageningen, 2016

Reviewing a Scientific Paper. WGS, Wageningen, NL, 2016

Scientific Publishing. WGS, Wageningen, NL, 2016

Career Perspectives. WGS, Wageningen, NL, 2016

\section{Optional courses and activities}

Preparation of research proposal. 2012

Science meeting of FQHE, weekly

Journal club of FQHE, weekly

Abbreviations:

FQHE: Food Qulity and Health Effect, Food and Biobased Research; VLAG: Graduate School for nutrition, Food Technology, Agrobiotechnology and Health Science; WGS: Wageningen Graduate School. 
This research is part of the FibeBiotics EU project supported by the European Community's Seventh Framework Programme [FP7/2007-2013] under Grant Agreement $\mathrm{n}^{\circ}$ 289517. Yongfu Tang is funded by the China Scholarship Council.

Financial support from Wageningen University and Research for printing this thesis was gratefully acknowledged. 
Cover design by Yongfu Tang Layout by Yongfu Tang

Printed by Digiforce, Vianen (NL) (www.dfprint.nl) 